

Aus dem Max-Planck-Institut für Biophysika lisc he Chemie in Göttingen

Abteilung Zelluläre Biochemie

Direktor. Prof. Dr. Reinhard Lühmann

\title{
Isolation and Characterization of Human Precatalytic Spliceosomal B Complexes
}

\author{
Dissertation \\ zur Erlangung des Doktorgrades \\ der Mathematisch-Naturwissensc haftlic hen Fa kultäten \\ der Georg-August-Universität zu Göttingen
}

vorgelegt von

J ochen Deckert

a us Neumarkt i.d.OPf.

Göttingen 2006 
D 7

Referent: Prof. Dr. H.-J . Fritz Korreferent: Prof. Dr. T. Pieler Tag der mündlichen Prüfung: 
Figure list

vii

Table list

ix

Abstract

$\mathrm{xi}$

1. Introduction

1

$\begin{array}{lll}1.1 & \text { Gene structure: exons and introns } & 1\end{array}$

$\begin{array}{lll}1.2 & \text { Pre-mRNA splicing } & 1\end{array}$

1.3 Altemative splicing 3

1.4 Splic eosome assembly 4

1.5 Dynamic rea rangements occur within the splic eosome 6

1.6 Studies in yeast and human revealed a very complex protein composition of the spliceosome $\quad 7$

1.7 Methods to purify splic eosomal subcomplexes from distinct steps in the splic eosomal cycle

1.8 Previous studies on purified splic eosomal partic les confirmed the complex nature of the splic eosome

1.9 Factors of the hPrp19/CDC5 complex and associated proteins potentially play a key role in catalytic activation of the human spliceosome

1.10 Struc tural dyna mic s of the splic eosome as revealed by Electron Mic rosc opy studies $\quad 12$

1.11 Mass spectrometry as a means to identify proteins 12

$\begin{array}{lll}1.12 \text { Aim of this study } & 15\end{array}$

2. Materials and Methods 17

2.1 Materials 17

$\begin{array}{ll}\text { 2.1.1 Chemicalsand Media } & 17\end{array}$

2.1.2 Antisera and poly-/monoclonal antibodies 18

$\begin{array}{lll}2.1 .3 & \text { Enzymesand Enzyme inhibitors } & 18\end{array}$

$\begin{array}{lll}2.1 .4 & \text { Nucleotides } & 19\end{array}$

$\begin{array}{lll}2.1 .5 & \text { DNA-Oligonucleotides } & 19\end{array}$

$\begin{array}{lll}2.1 .6 & \text { Plasmids } & 20\end{array}$

$\begin{array}{lll}2.1 .7 & \text { Cell lines } & 20\end{array}$

$\begin{array}{lll}2.1 .8 & \text { Bacteria strains } & 20\end{array}$

$\begin{array}{ll}2.1 .9 \text { Common buffers } & 20\end{array}$ 
2.1.10 Commercial reaction sets (kits) 22

2.1.11 Working equipment $\quad 22$

2.1.12 Machines 23

2.2 Methods 24

2.2.1 Molec ular biology standard methods 24

2.2.1.1 Generation of RNA a ptamer-tagged pre-mRNA and RNA synthesis 24

2.2.1.2 Concentration determination of nucleic acids 24

2.2.1.3 TNT in vitro translation 25

2.2.1.4 Polymerase Chain Reaction 25

2.2.1.5 Agarose gel electrophoresis of DNA 25

2.2.1.6 DNA isolation from agarose gels 26

2.2.1.7 Preparation of electrocompetent cells 26

2.2.1.8 Proteinase $K$ digestion 26

2.2.1.9 Denaturing polyacrylamide gelelectrophoresis 27

2.2.2 Protein biochemical standard methods 27

$\begin{array}{lll}\text { 2.2.2.1 Protein quantification } & 27\end{array}$

2.2.2.2 Denaturing SDS polyacrylamide gel electrophoresis 27

\subsubsection{Immunological Methods 28}

2.2.3.1 Affinity purific ation of peptide-antibodies 28

2.2.3.2 Immunoblot (Westem Blot) 29

\subsubsection{Special Methods 29}

2.2.4.1 Immunoaffinity purific ation of snRNP complexes 29

$\begin{array}{lll}2.2 .4 .2 & \text { Cell culture } & 30\end{array}$

2.2.4.3 Preparation of splicing active HeLa cell nuclear extract 30

2.2.4.4 In vitro splicing reactions 31

2.2.4.5 Micrococcal Nuclease treatment of HeLa nuclear extract

2.2.4.6 Depletion of U2 snRNPs or U4/U6 di-snRNPs from HeLa nuclear extract 32

2.2.4.7 Analysis of splic ing complexes by native agarose gel electrophoresis 32

2.2.4.8 Coupling of tobramycin to NHS-activated Sepharose 4 Fast Flow 32

2.2.4.9 Solid phase splicing reaction 33

2.2.4.10 Tobramyc in a ffinity selection of splic eosomal B complexes 33 
2.2.4.11 MS2 affinity selection of splic eosomal B complexes

2.2.4.12 In vitro splic ing assays with MS2 affinity-selec ted B complexes isolated at $150 \mathrm{mM}$ salt conditions

2.2.4.13 Electron mic roscopy

2.2.4.14 Mass spectrometry

\subsection{Punification of B complexes by glycerol gradient}

centrifugation followed by MS2-based affinity selection

3.1.1 Experimental strategy to isolate human splic eosomal B complexes via the MS2 affinity purification strategy

3.1.2 Purific ation of the MS2-MBP fusion protein

3.1.3 Adding MS2 RNA a pta mer binding sites to the 3' end of MINX exon 2 does not alter splic ing kinetic s or the overall yield of splicing

3.1.4 The MS2-MBP protein specific ally binds to MS2-tagged MINX pre-mRNA in a dose dependent manner

3.1.5 Kinetic s of in vitro splicing reactions in solution using MS2-tagged MINX pre-mRNA as a substrate

3.1.6 MS2 affinity selection of splic eosomal B complex

3.1.7 MS2 affinity-selected B complexes are functionally committed for subsequent activation and splicing catalysis

3.1.8 MS2 affinity-selected B complexes do not catalyze splic ing when incubated under splicing conditions in the absence of HeLa cell nuclear extract

3.1.9 MS of the MS2 selected B complex isolated under $150 \mathrm{mM}$ salt conditions

3.1.10 MS a ffinity-selection of spliceosomal B complex under low salt conditions

3.1.11 MS of the MS2 selected B complex isolated under low salt conditions

3.2 Punific ation of B complexes by tobramycin affinity selection coupled with immunoaffinity purification

3.2.1 Tobramyc in affinity selection of splic eosomal B complexes

3.2.2 Kinetic s of solid phase in vitro splicing reactions using Tobramyc intagged MINX pre-mRNA as a substrate

3.2.3 Immunoa ffinity purified a nti-61kDa (hPrp31) antibodies specific ally detect 61kDa (hPrp31) protein in Westem Blots 
3.2.4 In vitro translated 61kDa (hPrp31) protein is specific ally recognized by cognate a ffinity-purified a ntibodies

3.2.5 Affinity purified anti-61kDa (hPrp31) antibodies effic iently precipita te U4/U6.U5 tri-snRNP from HeLa nuclear extract

3.2.6 Tobra myc in affinity selection of splic eosomal B complex

3.2.7 Mass spec trometry of splic eosomal B complexes purified by tobramycin affinity selection followed by immunoprecipitation

3.3 Punification of spliceosomes in the presence of NIPP1

3.3.1 Punific ation of splic eosomal intermedia te complexes by dominant negative protein variants 77

3.3.2 MS2 affinity selection of NIPP1 sta lled splic eosomal B complex

3.3.3 MS of MS2 affinity purified splic eosomal complexes stalled with NIPP1 (1 - 311)

3.4 Eectron mic rosc opy of spliceosomal complexes

3.4.1 Struc ture a na lysis of splic eosomal complexes by elec tron mic rosc opy

3.4.2 Electron mic rosc opy of purified native B complex

\section{Disc ussion}

4.1 Purific ation of precatalytic B complexes using two independent approaches

4.2 Determining the stoic hio metry of certa in proteins within different splic eosomal complexes is a major task in the future

4.3 A number of proteins were detected only once in our purifications 90

4.4 MS2 and tobramyc in affinity-purified B complexes are highly pure $\quad 91$

4.5 Members of the exon junction complex are rec ruited a fter B complex formation

4.6 A large number of B complex proteins a re lost upon treatment with heparin

4.7 The vast majority of A complex proteins a re also present in the B complex

4.8 A large number of proteins, including the hPrp19/CDC5 complex, are recruited during $B$ complex formation

4.9 Analysis of the factor requirements for catalytic activation and step I of splic ing using MS2 affinity-selected B complexes 
4.10 Splic eosome assembly can be stalled with dominant negative $\begin{array}{ll}\text { protein variants } & 98\end{array}$

4.11 Electron mic rosc opy of MS2 affinity-purified B complexes 99

5. References

101

6. Appendix 111

$\begin{array}{lll}6.1 & \text { Abbreviations } & 111\end{array}$

$\begin{array}{lll}6.2 & \text { Acknowledgements } & 115\end{array}$

$\begin{array}{lll}6.3 & \text { Publications } & 117\end{array}$

$\begin{array}{lll}6.4 & \text { Erklärung/Affidavit } & 119\end{array}$

$\begin{array}{lll}6.5 & \text { Cumiculum Vitae } & 121\end{array}$ 



\section{Figure list}

Figure 1 The chemistry of the splic ing reaction

Figure 2 Schematic illustration of the composition of major splic eosomal U snRNPs

Figure 3 The spliceosomal cycle

Figure 4 Dynamic s of RNA-RNA interactions in the splic eosome

Figure 5 Schematic diagram of the MS2 affinity purification strategy used to isolate human splic eosomal B complexes

Figure 6 Purific ation of the MS2-MBP fusion protein

Figure 7 In vitro splic ing kinetic s of ${ }^{32} \mathrm{P}$-la beled MS2-tagged or untagged MINX pre-mRNA

Figure 8 Test whether the MS2-MBP fusion protein binds specific a lly and quantitatively to MINX pre-mRNA tagged with MS2 RNA aptamer haimins

Figure 9 In vitro splicing kinetic s of ${ }^{32 P}$-la beled MS2-tagged MINX pre-mRNA

Figure 10 Glyc erol gradient analysis of splic eosomal complexes

Figure 11 MS2 affinity selection of human precatalytic spliceosomal B Complexes

Figure 12 RNA composition of untreated, depleted or mock-depleted nuclear extracts

Figure 13 MS2 affinity-selected splic eosomal B complexes catalyze splic ing in nuclear extracts depleted of snRNPs

Figure 14 Protein content of MS2 selected precatalytic splic eosomal B complexes isolated under $150 \mathrm{mM}$ salt conditions

Figure 15 Characterization of MS2 affinity-selected B complexes isolated under low salt conditions

Figure 16 MS2 affinity-selected splic eosomal B complexes purified under low salt conditions cata lyze splic ing in nuclear extracts depleted of snRNPs

Figure 17 MS2 affinity-selected splic eosomal B complexes are func tionally committed for the subsequent steps of splic ing but do not catalyze any splicing step when incubated under splic ing conditions in the absence of extract

Figure 18 Protein content of MS2 selected precatalytic spliceosomal B complexes isolated under low salt conditions

Figure 19 Schematic diagram of the two-step purific ation strategy of B complexes using tobramyc in affinity selection coupled with 
anti-61K immunoaffinity purific ation

Figure 20 In vitro solid phase splic ing kinetic s of 32P-la beled Tobramycintagged MINX pre-mRNA 67

Figure $21 \quad$ Immunodetection of 61kDa (hPrp31) protein 69

Figure 22 Characterization of anti-61kDa (hPrp31) sera 70

Figure 23 Characterization of immunoaffinity purified human U4/U6.U5 tri-snRNP partic les followed by glycerol gradient centrifugation

Figure 24 Tobramyc in a ffinity selection of B complexes followed by immunoaffinity selection

Figure 25 Protein content of precatalytic spliceosomal B complexes purified via a combination of the Tobramyc in affinity selection procedure coupled with an immunoaffinity step using anti-61kDa (hPrp31) a ntibodies 74

Figure 26 Schematic representation of the domains of NIPP1

Figure 27 In vitro splic ing kinetic s of ${ }^{32} \mathrm{P}$-la beled MS2-tagged MINX pre-mRNA in the presence of increasing concentrations of NIPP1 [1 - 311] protein

Figure 28 In vitro splic eosomal complex assembly on 32P-labeled MS2-tagged MINX pre-mRNA in the presence and absence of NIPP1 (1 - 311) dominant negative mutant protein

Figure 29 Purific ation of MS2 a ffinity-selected NIPP1 (1 - 311) sta lled B complexes at $150 \mathrm{mM}$ salt

Figure 30 Protein content of MS2 selected, NIPP1 [1 - 311] trapped splic eosomal complexes isolated under $150 \mathrm{mM}$ salt conditions $E M$ of the native splic eosomal B complex

Figure $32 \quad E M$ of native splic eosomal complexes a fter 8 minutes of incubation in HeLa nuc lear extract in the presence of $10 \mu \mathrm{M}$ of NIPP1 ( 1 - 311) 
Table list

Table 1 Stable components of the 14S hPrp19/CDC5 complex and yeast NTC

Table 2 DNA-Oligonucleotides

Table 3 Plasmids

20

Table 4 Protein composition of the human splic eosomal B complex isolated under physiologic al conditions

Table 5 Proteins detected by MS in only one preparation, and proteins not considered asbona fide B complex proteins but rather contaminants 



\section{Abstract}

The nuclear process of cutting the pre-mRNA to remove the introns and joining together of the exons is called splicing. It is catalyzed by a large, dynamic machinery termed the spliceosome, which consists of five urid ine rich small nuclear ribonucleoprotein (UsnRNP) particles, containing a particular U snRNA molecule complexed with Sm or Sm-like proteins and several particle specific proteins, and numerous non-snRNP proteins. To form the splic eosome's catalytic center, the complex splic eosomal machinery is created a new on each intron during the highly dynamic process of splic eosome assembly. The latter is an ordered process during which several assembly intermediates, the $E, A, B, B^{*}$ and $C$ complexes, can be detected in vitro.

Spliceosome assembly culminates with the formation of the spliceosomal B complex, which contains a full set of $U$ snRNAs in a precatalytic state. It subsequently undergoes major rea rrangements, including destabilization or loss of the U1 and U4 snRNPs, leading to catalytic activation. These events are understood to some detail on the RNA level, but less so on a protein level. They are not at all understood on a three-dimensional structural level.

Previous characterization of a B-like complex was performed in the presence of heparin, which dissociates less stably-associated components. To obtain a more comprehensive inventory of the B complex proteome and perform functional and structural studies on this particle, I therefore isolated and characterized the precatalytic spliceosomal B complex under low stringency conditions using two independent methods. For both procedures, RNA aptamers, namely the MS2 coat protein RNA binding sequence or the tobramycin RNA aptamer sequence, were inserted into the pre-mRNA to provide a tag on the RNA for affinity selections. The first procedure then combines density gradient centrifugation followed by maltose binding protein (fused to MS2 coat protein) affinity selection whereas the second procedure makes use of the tobramyc in affinity selection procedure followed by immunoa ffinity selection.

In both cases, isolated complexes contained stoichiometric amounts of unspliced premRNA and the U1, U2, U4, U5 and U6 snRNAs. MS2 affinity-selected B complexes supported splicing when incubated in nuclear extract depleted of U2 SnRNP, U4 and U6 SnRNPs or of all endogenous snRNPs, thus they do not require complementation with any of the spliceosomal snRNPs for their activity. The data clearly demonstrate that MS2 affinity-selected B complexes were functionally committed for subsequent catalytic activation and splic ing catalysis as opposed to being "dead-end" complexes.

Mass spectrometry was then employed to determine the protein content of complexes isolated by both purification strategies. Over 110 proteins were identified in both independently purified B complex preparations, including $\sim 50$ non-snRNP proteins not 
previously found in the spliceosomal A complex. As expected, all the U1, U2, U5, U4/U6 and U4/U6.U5 snRNP specific proteins were detected. Interestingly, I also detected all members of the previously described heteromeric $14 \mathrm{ShPrp} 19 / \mathrm{CDC} 5$ core complex and 10 additional hPrp19/CDC5-related proteins, indicating they are recruited prior to splic eosome activation.

Furthemore, numerous SR and hnRNP proteins, the cap binding proteins CBP80 and CBP20 as well as Sm and LSm proteins a re present. Surprisingly, a lso human homologues of the yeast proteins Snu23, Prp38 and Spp382 were detected. These factors are present in yeast tri-snRNPs $(49,139)$ but they are absent in purified human U4/U6.U5 tri-snRNP particles. In addition, some of these proteins were associated with splicing by an approach combining experimental data and in silico structure predictions (57).

In addition, I a lso found three proteins, namely Snip1, MGC13125 and CGI-79, whose yeast counterparts (PML1, BUD13 and IST3/SNU17) were recently detected in a trimeric complex termed RES (for retention and splicing) $(43,121)$ which is involved in the retention of unspliced pre-mRNAs in the nucleus. My data also indic ate that another set of 25 proteins, among others RNA helicases, peptidyl-prolyl isomerases, RNA binding proteins, phosphatases, regulators of phosphatases and DEAD-box containing proteins are also associated with the spliceosome at the stage of B complex. Attesting to the purity of the complexes, I did not detect most of the first and second step splic ing factors and almost no known components of the exon junction complex.

I also obta ined stalled spliceosomes at a stage after B complex formation by a complete different approach. This approach makes use of a so-called dominant negative phenotype observed for the spliceosomal protein NIPP1 (negative inhibitor of protein phosphatase 1 ). This means that a protein variant of NIPP1 lacking parts of its C-terminal domain inhibits spliceosome assembly in a dominant manner. Large scale experiments revealed that U1 snRNP specific and associated proteins are missing in this complex. I a Iso identified signific antly less hPrp19/CDC5 related proteins, no RES complex components and only a minor fraction of non-snRNP proteins usually specifically associated with $B$ complexes.

Purified precatalytic B complexes were also used for structural analysis by cryo-electron mic rosc opy. Images of MS2 a ffinity-purified B complexes are at an unprecedented quality level. Inspection of negatively stained EM raw images demonstrated a high level of structural preservation and homogeneity since neither aggregates nore dissociation products were visible but only monodispers particles of similar sizes. Further EM studies revealed that MS2 affinity-selected B complexes exhib it a rhombic shape with a maximum dimension of $420 \AA$ and are structurally more homogeneous than B complexes treated with heparin. B complexes consist of two major structural domains, namely a triangular body (most likely resembling the tri-snRNP) and a so-called head domain. 
All these data provide novel insights into the composition and structure of the spliceosome just prior to its catalytic activation and suggest a potential role in activation for proteins rec ruited at this stage. Furthermore, the spliceosomal complexes isolated here are well-suited for complementation studies with purified proteins or fractionated HeLa cell nuclear extract to dissect factor requirements for sp lic eosome ac tivation and splic ing catalysis. In addition, images of purified B complex particles should be well suited for three-dimensional structure analysis. Furthemore, this work paves the way for further studies to investigate the structure of the spliceosomal B complex by labeling with specific antibodies. One major challenge in the compositional characterization of molecular complexes at present is to determine the absolute stoichiometry of all proteins within a purified particle or the relative stoichiometry within different complexes. Based on this study, quantitative Westem Blotting, two-dimensional (2D) fluorescence difference gel electrophoresis, or stable isotope labeling by amino acids in cell culture (SILAC) might help to gain knowledge of this important aspect of the protein composition of spliceosomal complexes.
\end{abstract}





\section{Introduction}

\subsection{Gene structure: exons and introns}

The fundamental process of gene expression is the sum of all steps involved in converting genetic information from DNA sequences into a primary amino acid sequence via transc ription, RNA processing and translation.

In higher eukaryotes, the coding sequences of genes, the exons, are intemupted by noncoding sequences, the introns. After transcription, introns are removed from the so-called precursor-messenger RNA (pre-mRNA) by a process called splicing and the flanking sequences, the exons, are thus joined to form the mature mRNA. Lower eukaryotes have only few and usually small introns. In contrast, in higher eukaryotes the exons are rather short (50 - 300nt), while the introns can be as long as hundreds of thousands of nucleotides. In addition, the coding potential of a gene is distributed over multiple exons. The regions of an mRNA molecule which are finally translated into protein in the cytoplasm are referred to as the open reading frame (ORF). The very $5^{\prime}$ and $3^{\prime}$ ends of mature mRNA are regions that are not translated into an amino acid sequence and therefore these segments are referred to as untranslated regions (UTRs). They usually conta in regula tory sequences controlling sta bility and transla tional a c tivity.

Pre-mRNA molecules are not only modified by splicing, but the very $5^{\prime}$ and $3^{\prime}$ ends are also modified. 7-methylguanylate is cotranscriptionally attached by a triphosphate linkage to the ribose at the $5^{\prime}$ end of pre-mRNA, whereas at the $3^{\prime}$ end, transcripts are first cleaved before an enzyme termed poly $(A)$ polymerase adds a poly $(A)$ tail. Both of these posttranscriptional modific ations are involved in va rious aspects of mRNA function such as translation, mRNA stability and export from the nucleus.

\subsection{Pre-mRNA splicing}

Splic ing itself requires a set of specific sequences conta ined within the intron. The 5 '-end of almost all introns contains the sequence $5^{\prime}-\mathrm{GU}-3^{\prime}$ and the $3^{\prime}$-end nomally is 5'-AG-3'. This AG dinucleotide is preceded by a pyrimidine-rich sequence called the polypyrimidine tract $\left(Y_{n}\right)$ (see Figure 1). The branchpoint sequence containing a conserved adenosine is located upstream of the polypyrimidine tract and nomally located 18 - 40 nt upstream of the 3 ' splice site (112).

Pre-mRNA splicing is catalyzed by a two-step mechanism (reviewed by 100). As shown in Figure 1, in the first step, the 2' OH group of the conserved branchpoint adenosine attacks the phosphate at the $5^{\prime}$ exon/intron junction (the $5^{\prime}$ splice site) resulting in a free $5^{\prime}$ exon containing a $3^{\prime}$ terminal $\mathrm{OH}$ group and a branched lariat intermediate which contains the 
intron and 3' exon. In the second step, the 3' $\mathrm{OH}$ of the 5' exon attacks the phosphate at the intron/3' exon boundary (the 3' splice site), thereby ligating the $5^{\prime}$ and 3 ' exons and releasing the intron in a la riat conformation (117).
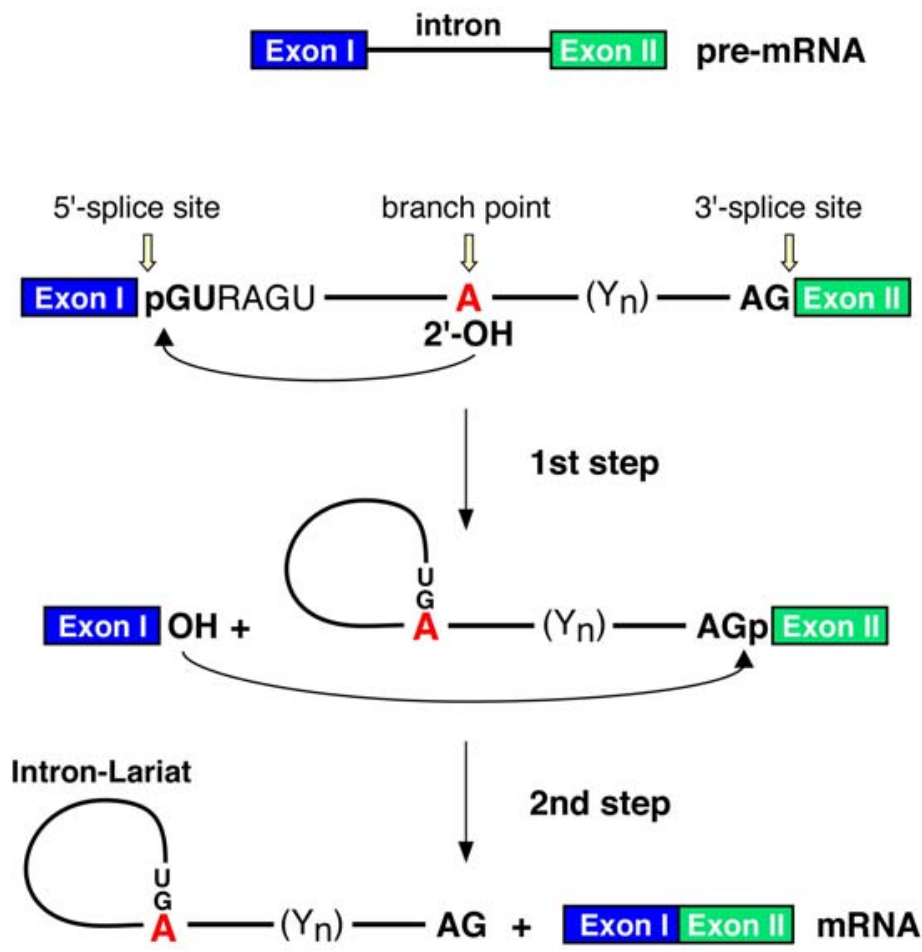

Fig. 1. The chemistry of the splicing reaction. Two successive phosphoester transfer reactions lead to the excised intron and the joined exons. In the first step, the 2' OH group of the conserved branchpoint adenosine attacks on the phosphate at the $5^{\prime}$ exon/intron junction (the 5' splice site) resulting in a free $5^{\prime}$ exon containing a $3^{\prime}$ terminal $\mathrm{OH}$ group and a branched lariat intermediate which contains the intron and $3^{\prime}$ exon. The adenosine at the branchpoint is located 18 to 40 nt upstream of the $3^{\prime}$ splice site (112). In the second step, the $3^{\prime} \mathrm{OH}$ of the $5^{\prime}$ exon attacks the phosphate at the intron/3' exon boundary (the 3 ' splice site), thereby ligating the 5' and $3^{\prime}$ exons and removing the intron lariat (117). The scheme was kindly provided by Dr. Eva Kühn-Hölsken.

The splicing reaction is catalyzed by a large, dynamic molecular machine, temed the splice osome, which consists of the U1, U2, U4/U6 and U5 small nuclear nibonuc leoprotein (snRNP) and an undefined number of non-snRNP proteins (reviewed by 163). Each snRNP particle is formed from one (or two in the case of U4/U6) U snRNA molecule complexed with a set of seven Sm or Sm-like proteins and several partic le specific proteins. Figure 2 illustrates schematically the composition of the major U snRNPs. 12S U1 snRNP conta ins three specific proteins, U1 $70 \mathrm{kDa}, \mathrm{U1} \mathrm{A}$ and $\mathrm{U1} \mathrm{C}$ ( $\mathrm{kDa}$ and $\mathrm{K}$ are interchangeable throughout the text). The composition of 17S U2 snRNP is more complex. It comprises the particle specific proteins U2 $\mathrm{A}^{\prime}$ and U2 $\mathrm{B}^{\prime \prime}$ and the heteromeric protein complexes SF3a and SF3b, which conta in subunits of 120, 66 and $60 \mathrm{kDa}$, and 155, 145, 130, 49, 14 and 10 $\mathrm{kDa}$, respectively. The 13S U4/U6 di-snRNP contains proteins of molec ular weights of 15.5, $61,20,60$ and $90 \mathrm{kDa}$. The $20 \mathrm{~S}$ U5 snRNP is composed of proteins of $220,200,116,102,52$, 
40 and $15 \mathrm{kDa}$. The U4/U6 and U5 snRNP associate to form the 25S U4/U6.U5 tri-snRNP complex, which conta ins three additional proteins of 110, 65 and $27 \mathrm{kDa}$, but which lacks the U5 $52 \mathrm{kDa}$ protein (82).

In the case of the 17S U2 SnRNP particle, further proteins in addition to the core proteins listed above were recently found (164). Among these, the proteins SPF30, SPF31, SPF45,

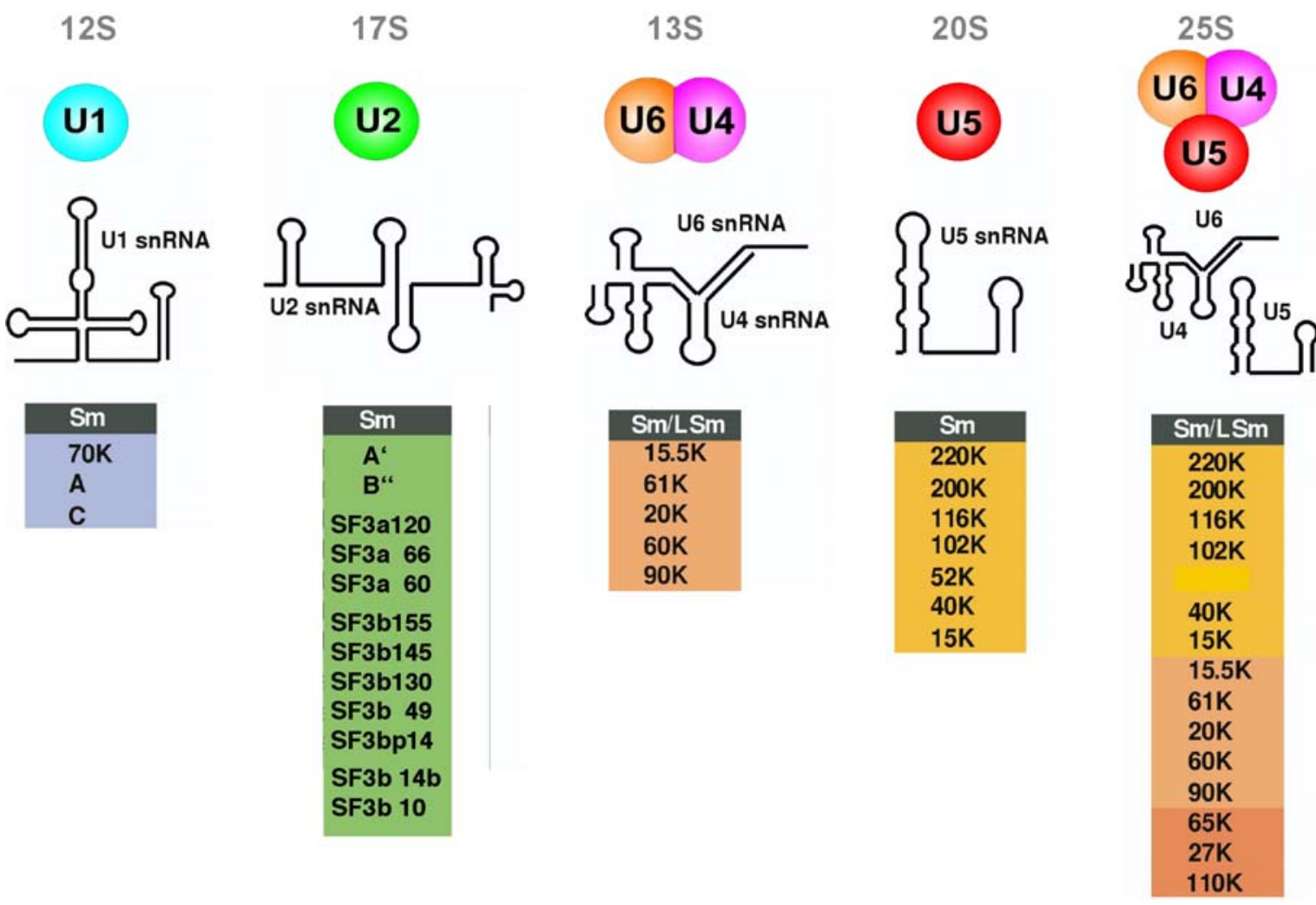

Fig. 2. Schematic illustration of the composition of major spliceosomal $\mathbf{U} \mathbf{s n R N P s}$. Each snRNP particle is formed from a U snRNA molecule complexed with a set of seven Sm or Sm-like proteins and several particle specific proteins. The Svedberg (S) value of each snRNP is shown on the top, followed by a schematic representation of the respective RNA secondary structure and the protein composition. Sm proteins comprise Sm B, Sm D1, Sm D2, Sm D3, Sm E, Sm F and Sm G, whereas Sm-like (LSm) proteins include LSm 2 - LSm 8, respectively. The illustration was kindly provided by Dr. Berthold Kastner.

hPrp43, SR140, CHERP, hPrp5, Hsp 75, PUF60, Hsp60 and BRAF35 were detected in immunoaffinity purified particles, however only in substo ic hiometric amounts (164).

\subsection{Altemative splicing}

With the exception of some genes coding for example for proteins of the histone or interferon class, most other protein coding genes contain introns which show dramatic variation with respect to intron number and length. When the human genome was sequenced it came as a surprise that the number of protein-coding genes does not correlate with the complexity of the proteome within a cell. Sequencing of the human genome revealed $\sim 30000$ genes (155), whereas the complete human proteome is 
estimated to consist of more than 300000 distinct proteins ( $\mathrm{NCBl}$ website: http://www.ncbi.nlm.nih.gov/). How is this complexity on a protein level achieved with only the limited number of protein coding genes?

A process temed altemative splicing is responsible for the generation of protein isoforms by inclusion and/or exclusion of partic ular portions of coding sequences in the pre-mRNA (reviewed in 96). Hence, protein isoforms generated by altemative splicing differ in their primary amino acid sequence by inclusion or exclusion of a particular exon sequence and thus in their chemical and biological activity or their structure $(12,14,51)$. The diversity of proteins within individual cells, tissues, organelles or whole organisms is dramatically increased by this process. It has been estimated that 40 - $60 \%$ of all human genes (99) and more than $70 \%$ of multiexon human genes are altematively splic ed (69) in response to homonal and developmental signals or in a tissue-specific manner. In general, the rate of altemative splicing increases with organismal complexity. In theory more transcripts can be generated from a single gene than the number of all genes in an entire genome $(51,133)$.

An extra ordinary example for the potential of altemative splicing to generate a variety of transcripts is the Drosophila melanogaster gene Dscam (Down syndrome cell adhesion molecule) which encodes for axon guidance receptors with an extracellular domain containing immunoglobin (lg) repeats. The Dscam pre-mRNA can be altematively spliced into over 38000 different mRNA isoforms $(51,52,132)$.

An important role in regulating spliceosome formation and thus altemative splicing is played by $c$ is regulatory elements. Exonic splicing enhancers (ESEs) and exonic splicing silencers (ESSs) either promote or inhibit exon inclusion through the activity of associated regulatory proteins such as members of the SR protein family. Interestingly, SR proteins bound to exonic enhancers also act as bamiers to prevent exon skipping thereby ensuring exon joining in a strict 5' to $3^{\prime}$ linear order in constitutively splic ed pre-mRNAs (61). Exon exclusion via ESS elements functions by inhibiting U1 and/or U2 snRNP from binding to cognate splice sites. In general, splicing regulation is controlled by a combinatorial communic ation of multiple proteins and cis-acting RNA sequence elements.

\subsection{Spliceosome assembly}

The active site(s) responsible for the catalysis of pre-mRNA splicing by the splic eosome is (are) not pre-formed, but rather created anew during the highly dynamic process of spliceosome assembly. The latter is an ordered process during which several intermediates, the E, A, B, B* and C, can be detected in vitro (reviewed by 163). Figure 3 shows a schematic representation of the spliceosomal assembly pathway. 
In the early phase of spliceosome formation, assembly is initiated by the ATP-independent interaction of the U1 SnRNP with the conserved 5 ' splice site of the pre-mRNA by a short stretch of RNA-RNA base paining interaction, forming the Ecomplex. At this stage, the U2 SnRNP is loosely associated with the pre-mRNA (32). In a subsequent step requining ATP, the U2 snRNP stably interacts with the pre-mRNA's branch site, leading to formation of the A complex (also called the pre-spliceosome). Next, the

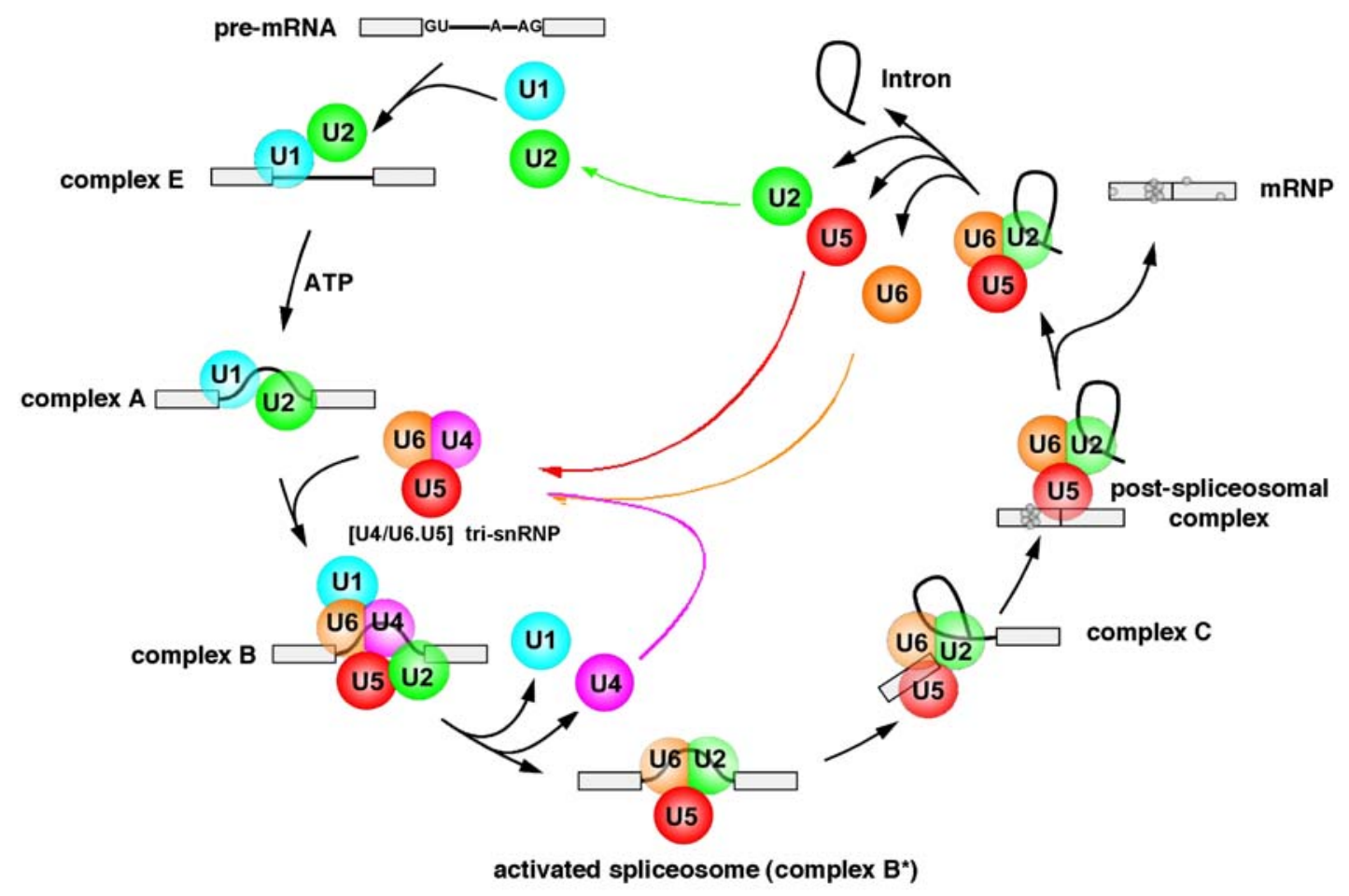

Fig. 3. The spliceosomal cycle. Pre-mRNA splicing is catalyzed by five $U$ snRNPs and a multitude of non-snRNP proteins. Splic eosome assembly is initiated by the interaction of the U1 snRNP with the $5^{\prime}$ 'ss, forming the E complex, followed by stable interaction of U2 snRNP with the branch site, generating the A complex. In the next step, the tri-snRNP is integrated, resulting in the formation of the pre-catalytic B complex. The B complex then undergoes major rea rrangements - including destabilization of U1 (leading to formation of the BAU1 complex) and U4 snRNPs - that leads to the formation of the catalytically activated spliceosome $B^{*}$. The first catalytic step is accompanied by formation of the spliceosomal C complex and after the second step of splicing, the spliceosome dissociates. The scheme was kindly provided by Dr. Berthold Kastner.

pre-formed U4/U6.U5 tri-snRNP particle interacts with the A complex and spliceosome assembly culminates with the formation of the spliceosomal B complex. The B complex thus contains a full set of $U$ snRNAs in a pre-catalytic state. It subsequently undergoes major rea rrangements, including destabilization or loss of the U1 and U4 snRNPs, leading to catalytic activation and the formation of the so-called activated spliceosome (B* complex). The first catalytic step of splicing is then accompanied by formation of the spliceosomal C complex and after the second step of splicing, the spliceosome dissociates. Upon dissociation of the spliceosome, both pre-mRNA splicing products are 
ultima tely released and the individual subunits of the splic eosome take part in subsequent rounds of splic ing.

\subsection{Dynamic rearangements occ ur within the spliceosome}

During the course of spliceosome assembly, a highly dynamic RNA-RNA network is formed (reviewed in references 105 and 163). Already at the stage of complex E formation, the three most important cis elements, namely the $5^{\prime}$ splice site, the branch point region including the branch point adenosine and the 3 ' splice site, are organized in close proximity $(76,77)$. During the catalytic activation of the spliceosome, an ordered sequence of rearrangements in this RNA-RNA network position the reactive groups of the pre-mRNA (i.e. the $5^{\prime}$ splice site and branch site) in a favourable spatial position for the first step of splicing to occur. The RNAs forming the network (primarily U2 and U6) are thought to form the core of the active center that catalyzes the first step of splicing. Figure 4 illustrates sc hematic ally the formation of the U2/U6/pre-mRNA network.

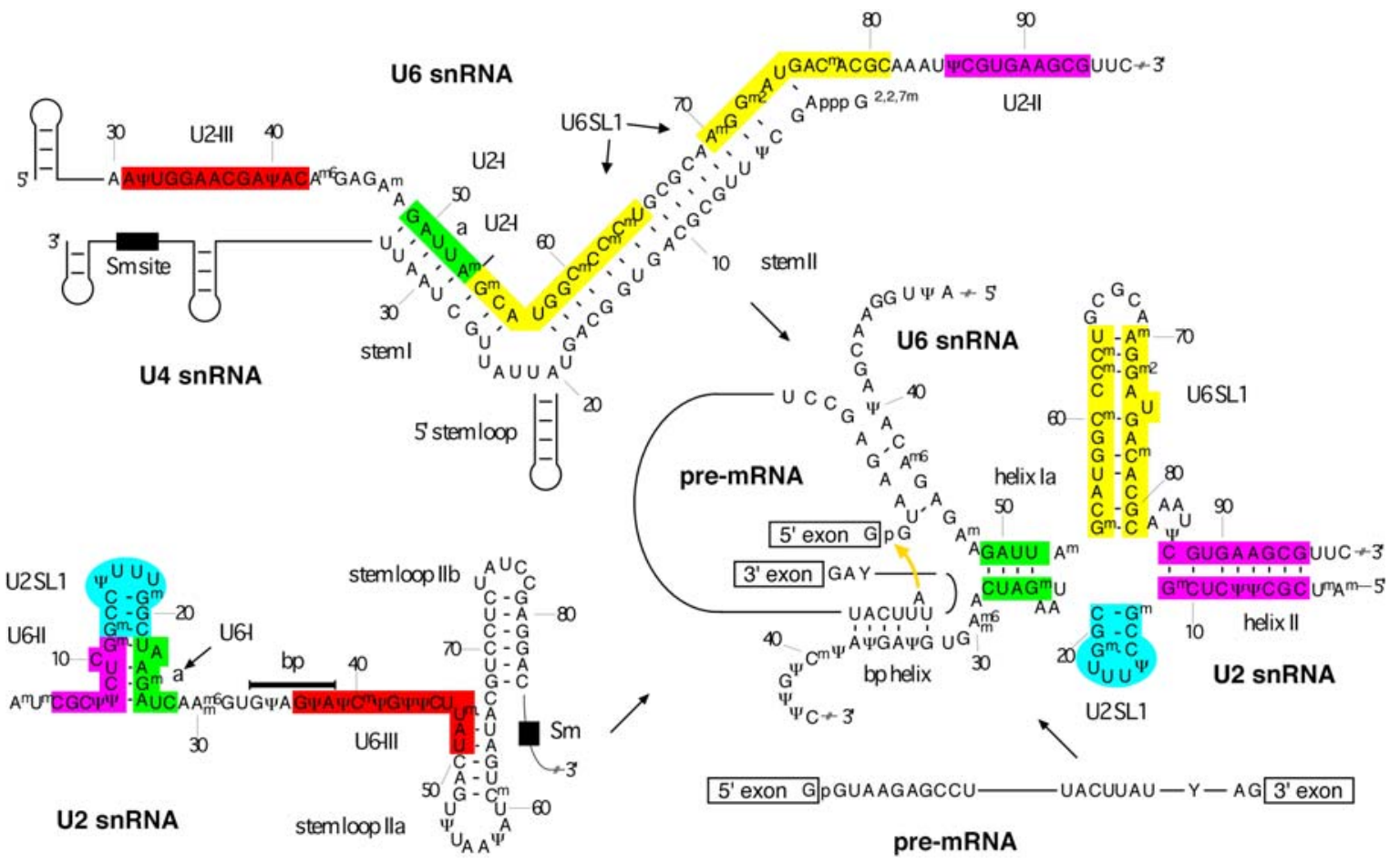

Fig. 4. Dynamics of RNA-RNA interactions in the spliceosome. U6 snRNA is released from the U4/U6 snRNA duplex and the structure of the 5' part of U2 SnRNA is opened to facilitate the formation of the U2/U6 helices la and II. The sequences U6-I, and U6-II, and U6-III of U2 snRNA interact with the sequences U2-I, U2-II, and U2-III of U6 snRNA, to form helic es la, II, and III, respectively. The branch point sequence (bp) of the pre-mRNA binds to the branch point binding region on U2 snRNA. Sections of the molecules not involved in the interactions a re shown only schematic ally, with the terminal 3' stem-loops of U2 snRNA being omitted. The RNA-RNA interactions are shown for the human sequences and are based on the human model (141). Known intemal modifications of U2 or U6 snRNA are indic ated as follows: $m$ : 2' O-methylation (G, A, and C); m6: N6-methylation (A); m2: $\mathrm{N}^{2}$ methylation (G); $\Psi$ : pseudouridine. The scheme was kindly provided by Dr. Klaus Hartmuth. 
As in the U4/U6 di-snRNP, the U4 and U6 snRNAs are base-paired within the tri-snRNP complex (23), and form the Y-shaped U4/U6 interaction domain, consisting of stems I and II separated by the 5 ' stem-loop of U4 snRNA. After association of the tri-snRNP with the presplic eosome, activation of the spliceosome involves dissociation of the U4/U6 RNA duplices. While the region of U6 snRNA constituting U4/U6 stem II forms a new intramolecular stem-loop (U6 Sப), the region of U6 comprising stem I base-pairs with U2 RNA forming U2/U6 helix la (141). An additional base paining interaction occurs between the 5' end of U2 and the 3' end of U6 RNA (U2/U6 helix II) (33). Moreover, the conserved ACAGAG sequence of U6 SnRNA base-pairs with the $5^{\prime}$ splice site of the pre-mRNA as a prerequisite for U4/U6 RNA duplex unwinding (80). Prior to, or concomitant with this event, U1 snRNA must be released from the 5 ' splice site. In yeast, the DEXD/H box family member Prp28p (U5 $100 \mathrm{kDa}$ in humans) unwinds the U1 snRNA - 5' splice site duplex in an ATP-dependent manner (136). Thus, formation of this RNA network at the active center of the spliceosome, requires several mutually exclusive rearangements in the structures of both the U2 and U6 snRNAs. Furthemore, U5 snRNA also interacts with the pre-mRNA, sequentially paining with the $5^{\prime}$ and 3 ' exon boundaries during splicing, a process which is required for the alignment of the exons $(62,104,149)$.

\subsection{Studies in yeast and human revealed a very complex protein composition of the splic eosome}

In addition to the snRNAs, proteins play an essential role in splicing (reviewed in reference 163). The aforementioned relatively short RNA-RNA interactions cannot form on their own and it is not known whether they are stable in the absence of protein. Thus, protein components most likely contribute to the stability and specific ity of these interactions. As mentioned, each snRNP particle consists of a set of particle-specific proteins, plus seven Sm or LSm proteins found in all of the spliceosomal snRNPs. Thus, over 50 unique proteins are recruited to the splic eosome as stable components of the snRNPs. In addition, a large number of non-snRNP proteins are also associated with the spliceosome as initially revealed by genetic studies in yeast, and later confimed and extended by biochemical analyses in the human system.

Members of certa in protein families are highly abundant within known splicing factors. For example, SR proteins, heterogeneous nuclear ribonucleoproteins (hnRNPs) and ATPdependent RNA helicases are some of them. SR proteins contain carboxy-terminal domains rich in serine-arginine dipeptides and one or more amino-terminal RNA recognition motifs (RRMs). SR proteins are both positive and negative regulators of premRNA splicing $(15,60,128)$. In contrast, RNA binding hnRNP proteins act mostly as splic ing silencers $(54,114)$, whereas ATP-dependent RNA helicases are involved in the 
rearrangement of both RNA-RNA as well as RNA-protein interactions including unwinding of RNA duplexes $(66,168)$, displacing proteins (67) or RNA annealing (168). Interestingly, many of these proteins as well as the $U$ snRNAs are highly conserved from yeast to humans, indic ating that the basal splic eosomal machinery is conserved.

In an attempt to identify the full complement of proteins required for pre-mRNA splicing, recent studies were performed in which spliceosomes were affinity-selected and their protein composition determined by mass spectrometry (MS). MS studies of a mixture of splic eosomal complexes (including the mRNP) that were isolated under mild conditions (60-100 mM salt) indicated that the number of proteins that associate with spliceosomes assembled in HeLa nuclear extract under splicing conditions lies between 170 (170) and -300 (109). While these studies underlined the very complex nature of the spliceosomes' protein composition, the apparent large discrepancy in the total number of spliceosomeassociated proteins was unexpected. It may reflect the fact that in these studies: (i) different isolation protocols were used, and (ii) different criteria were used to decide whether a given protein is a bona fide spliceosomal protein. For example, in the first study, spliceosomes were isolated using two different substrates and only those proteins common to both were designated as bona fide spliceosomal proteins (170). However, the identification of numerous ribosomal proteins and many factors known to function in splicing-unrelated processes revealed a copurification of contaminants in the course of the purific ation procedures. Furthemore, since mixtures of splic eosomal complexes were analyzed, this renders it impossible to draw meaning ful conclusions about the presence of certa in splic eosomal proteins within distinct subcomplexes during splic eosome assembly.

\subsection{Methods to purify spliceosomal subcomplexes from distinct steps in the splic eosomal cycle}

As we were interested in the protein composition of splic eosomes at distinct stages along the assembly pathway, we had to develop more sophisticated methods to purify selected splic eosomal complexes. A prerequisite for proteomic, structural and functional analysis of spliceosomal complexes is the purification of these complexes under native/non-denaturing conditions to a high degree of homogeneity. Up to date, several methods were used to achieve this goal. One approach includes the use of HeLa cells stably expressing a tagged spliceosomal protein. Nuclear extract prepared from these cells can subsequently be used to isolate target complexes via the tag (Dr. I. Lemm, personal communication). An altemative to the purification of tagged, exogenously expressed proteins is targeting endogenous factors with antibodies allowing the recovery of proteins associated with endogenous levels of the targeted proteins, thereby avoiding overexpression artifacts $(88,164)$. Other groups made use of either biotinylated antisense 
oligonucleotides (118) or altematively, pre-mRNAs cotranscriptionally labeled with biotinylated nucleotides $(103,109,116)$. Another possibility to purify spliceosomal complexes includes specific binding of RNA aptamer-tagged substrate pre-mRNA by either viral MS2 coat protein fused to maltose binding protein $(71,171)$, or tobramycin $(8$, 56). Such affinity-selection methods can then be combined with standard chromatography techniques like size exclusion chromatography or density gradient centrifugation $(8,36,56,109,170,171)$.

A number of methods have been developed to obtain spliceosomes at a defined assembly state. These include kinetic control of splicing reactions in solution (36) and in solid phase (56). Another one comprises the depletion of splicing factors required at a particular stage from nuclear extract by specific antibodies (89) thereby enriching spliceosomes at a stage when this protein becomes essential. Furthemore, modifications to the pre-mRNA substrate such as a GG mutation at the 3 ' splice site $(28,50)$ or inclusion of inhibitory molecules (98) during purific ation yielded in splic eosomes at partic ular stages during assembly. Still another approach includes dominant negative protein variants (150), RNa se H-mediated digestion of snRNA/pre-mRNA, depletion of individual snRNPs by streptavidin agarose affinity selection using biotinylated 2'-O-methyl RNA oligonucleotides $(16,125)$ or finally depletion of nuclear extract from ATP in order to accumulate spliceosomal E complex. It could also be demonstrated that adding an excess of binding partner for a spliceosomal protein can result in accumulation of spliceosomes at a distinct stage (106). However, not all of these a pproaches have been tested for the purific ation of spliceosomes in larger scale, which is required for proteomic, structural and functional studies.

\subsection{Previous studies on purified spliceosomal particles confimed the complex nature of the spliceosome}

Individual splicing complexes a nalyzed to date by mass spectrometry (MS) are the A, a B-like complex lacking the $\mathrm{U} 1$, the $\mathrm{B} \Delta \mathrm{U} 1, \mathrm{~B}^{*}$ and $\mathrm{C}$ complexes $(56,71,88,91)$. However, the latter three complexes were isolated under stringent conditions (i.e. in the presence of heparin) and thus only those proteins that are stably associated at these stages could be determined. This approach tumed out to be very effic ient with respect to the reduction of copurification of unspecifc contaminants. In addition, the similar isolation conditions used for these purifications allowed meaningful comparisons to be made between the proteomes of the $\mathrm{B} \Delta \mathrm{U} 1, \mathrm{~B}^{*}$ and $\mathrm{C}$ complexes. This comparison demonstrated the dynamic nature of the spliceosome's protein composition. It further revealed stabilization/destabilization events involving spliceosomal proteins during catalytic 
activation and provided information a bout a given protein's potential window of function during splic ing.

However, due to the highly stringent conditions employed to isolate the $\mathrm{B} \Delta \mathrm{U} 1, \mathrm{~B}^{*}$ and $\mathrm{C}$ complexes, information about the recruitment of proteins that were not stably incorporated into the spliceosome at these stages of assembly/function - but nonetheless functionally important - could not be obtained. That is, an unknown number of proteins were likely stripped away in the presence of heparin. Indeed, the previously analyzed $\mathrm{B} \Delta \mathrm{U} 1$ complex lacked the U1 snRNP and other proteins were presumably likewise lost apparently because of the heparin treatment (91). The stringent nature of the isolation protocol previously used to isolate $\mathrm{B}$ complexes, further made it impossible to make a meaningful comparison of the proteome of the $\mathrm{B} \Delta \mathrm{U} 1$ complex with that of the A complex, which was isolated in the absence of heparin (56). Thus, the isolation of spliceosomes at defined stages under native conditions should provide important information about the complete set of proteins associated with a particular spliceosome assembly/functional intermediate. An indication may thus be obtained where in the spliceosome assembly pathway a particular spliceosomal protein acts and at what stage they are initially recruited or released. Of particular interest in this respect is the precatalytic splic eosomal B complex because proteins present in this complex potentially take part in the functiona lly decisive catalytic activation step.

\subsection{Factors of the hPrp19/CDC5 complex and associated proteins potentially play a key role in catalytic activation of the human splic eosome}

A number of recent studies have greatly expanded our understanding of the role of proteins at the point of catalytic activation. Prp19 and a number of proteins that associate with it play a key role at this critical step of spliceosome maturation $(91,144$, 145). In humans, Prp19 is stably associated with seven proteins, including CDC5 (see table 1) (2, 91). This hPrp19/CDC5 complex appears to be involved in the catalytic activation of the splic eosome, as its depletion from HeLa cell nuclear extract blocks premRNA splic ing prior to the first catalytic step, but at a stage a pparently after U4/U6.U5 trisnRNP association $(26,91)$. In yeast, Prp19 is present in the heteromeric NTC protein

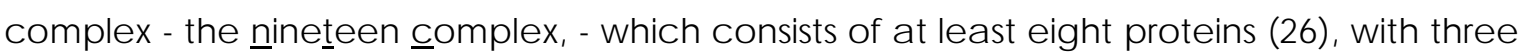
having homologues in the human hPrp19/CDC5 complex (see table 1). Recent studies in yeast have revealed that the NTC is required subsequent to U4 dissociation, apparently by stabilizing the association of U5 and U6 with the activated spliceosome (25). 
The human hPrp19/CDC5 complex and its associated proteins appear to be stably integrated in a hepanin-resistant fashion into the spliceosome (i.e., they rema in bound in the presence of heparin) only at the time of its activation (91), but whether it is recruited

14S hPrp19/CDC5

\section{complex}

Makarova et al., 2004

Ajuh et al., 2000

hPrp19

CDC5

PRL1

AD002

HSP73

SPF27

-catenin like*

\section{Prp19 complex}

Chen et al., 2002

Prp19

Ntc $85 /$ Cef1/Cdc 5

Ntc 25/Snt309

Ntc 77/C If1/Syf3
Ntc 90/Syf1
Ntc 30/Isy1
Ntc 31/Syf2
Ntc 20

Table 1. Stable components of the 14S hPrp19/CDC5 complex and the yeast NTC. The table is a dapted from Maka rova et al., 2004 (91). *: only found by Maka rova et al., 2004.

at an earlier stage is not clear. In yeast, immunoprec ipitation studies suggested that Prp19 first stably associates after B complex formation (144). Table 1 summanizes stable components of immunoaffinity purified 14S hPp19/CDC5 complexes (91), and immunoprecipitated Prp19 complex (Prp nineteen complex, NTC) isolated from S. cerevisiae (26).

Taken together, these data reveal a different composition of subcomplexes containing Prp19/CDC5 in humans compared to yeast. In addition, the hPrp19/CDC5 complex seems to function in catalytic activation of the spliceosome, whereas in yeast Prp19p as a component of the NTC protein complex acts after catalytic activation.

The previously purified B-like complex was isolated under harsh conditions including treatment with heparin (91). The complex lacked U1 snRNP and therefore was termed $\mathrm{B} \Delta \mathrm{U} 1$. It a lso did not conta in most of the hPrp19/CDC5 complex proteins in contrast to the activated spliceosome $B^{*}$ (88). In addition, B complex was efficiently formed in hPrp19/CDC5-depleted HeLa nuclear extract suggesting that hPrp19/CDC5 complex is not necessary for B complex formation. In addition to the question of when the hPrp19/CDC5 complex is initially recruited, it remains to be determined whether these subcomplexes a re recruited to the spliceosome as a particle as such or whether individual factors associate with it and assist in bind ing subsequent proteins. 


\subsection{Structural dynamics of the spliceosome as revealed by Electron Mic rosc opy studies}

The ability to affinity purify spliceosomal complexes has not only allowed the analysis of their protein composition using MS, but has also enabled the first views of the threedimensional structure of the spliceosome to be generated by electron microscopy studies. The complexity and dynamic nature of spliceosomes are both challenges and obstacles for the determination of a spliceosomal 3D structure. Nevertheless, using singlepartic le electron cryo mic roscopy, higher order structures at a resolution of 30 - $40 \AA$ were obtained for the human splic eosomal B $\Delta \mathrm{U1}$ (19) and C complexes (72). These complexes were isolated after performing in vitro splicing in HeLa cell nuclear extract followed by affinity selection. Though the complex isolation procedures differed for the two preparations, they both made use of heparin during the isolation. Thus several less-tightly associated proteins may have been lost during purification. The BAU1 splic eosome, which has not yet undergone catalytic activation and contains the U2, U4/U6 and U5 snRNPs, has a triangular body and an additional upperglobular domain, and is $370 \AA$ long with a maximum width of $260 \AA$ (19). The C complex, on the other hand, which has undergone step I of splicing and contains the U2, U5 and U6 snRNPs, exhibits an asymmetric shape with three major domains and overall dimensions of $270 \times 220 \times 240 \AA$ (72). Thus, it appears to be considerably smaller than the B complex. More recently, the 3D structure of a single subunit of large, tetrameric 2005 spliceosomal complexes (referred to as supraspliceosomes) was determined by cryo-EM (5). This complex, which is thought to be a single spliceosome, was isolated by biochemical means from HeLa cell nuclear extract, but its precise assembly stage(s) and protein composition are presently not known. In contrast to the structures described above, it exhibits a globular shape with a maximum height of $280 \AA$ and consists of two distinct subunits. Thus, the 3D structures currently available from three different splic eosomal preparations differ considerably in their sizes and shapes. Some of these apparent discrepancies are likely due to the fact that (i) different assembly/functional stages of the spliceosome were analyzed and (ii) that different purification methods were employed. Therefore, additional EM analyses are clearly needed to resolve current questions that remain regarding the structure of the human splic eosome.

\subsection{Mass spectrometry as a means to identify proteins}

Mass spectrometry (MS) is one of the key analytic al tec hnologies for the identific ation of proteins in biological samples. Large biomolecules can be analyzed after ionization by either matrix-a ssisted la ser desorption ionization (MALDI MS) (73) or electrospray ionization (ESI MS) (45) (reviewed in 94). 
With MALDI, the analytes (peptides, proteins or biomolec ules) are mixed with an excess of matrix and subsequently crystallized on the MALDI sample plate (target). Subsequently, a short laser pulse of 3 - 4 nanoseconds desorbs matrix and peptides from the target (usually small organic molecules with absorbance at the wavelength of the laser are employed) into the gasphase. By this process, a singly positive charge $\left(\mathrm{H}^{+}\right)$is transfered from the matrix to the analyte. By applying an electric field the charged molecules are accelerated and fly through a high vacuum tube towards a detector. The time the molecules need to reach this detector is directly proportional to the molecular weight of the molecules. Small ions have a highervelocity and reach the detector before the larger ones. Therefore, from measuring the "time of flight" (ToF), the mass of a particular molecule can be determined in a highly accurate manner.

With electrospray MS, a continuous ionization takes place whereby multiply charged molecules are produced in solution from a capillary electrode placed at high voltage with respect to a grounded counter electrode, thereby a so-called electrospray is generated. The ions then travel into the mass spectrometer and can be analyzed by a quadrupole mass a nalyzer according to their $\mathrm{m} / \mathrm{z}$ value. The great advantage of ES-MS is that single peptidescan be selected from the mixture by the quadrupole mass analyzer and subsequently sequenced in a second MS experiment. Such an experiment is called ES-MS/MS.

To analyze the protein composition of large biomolecules such as spliceosomal complexes, protein bands within gels are excised. The proteins within the gel are hydrolyzed by endoproteinases (e.g. Trypsin) and thus generated peptides are extracted. The extracted peptides are separated on a C18 reversed phase (RP) high performance liquid chromatography (HPLC) system that is directly coupled to a ESI-MS. In this configuration, the peptides which elute from the RP-column by applying a gradient of increasing organic solvent, are immediately ionized at the tip of the needle and sprayed into the mass spectrometer where they are sequenced (94). This configuration is called LC-ES-MS/MS. It has the advantage that the complexity of the sample is drastically reduced and even low abundant peptidescan be identified.

The advantage of ESI MS over MALDI MS is that multiple charged ions are generated, i.e. peptides are doubly or triply charged. They produce more fragment ions and thus the sequence information of a single peptide is more reliable and often suffic ient to identify a protein. 



\subsection{Aim of this study}

The a im of this study was manyfold. These a re: first, a method was to be established that would allow for large-scale, reproducible preparation of precatalytic spliceosomal B complexes. On a biochemical level, purification conditions and isolated spliceosomes should fulfill three stringent criteria. (1) Homogeneity. Precatalytic spliceosomal B complexes should only conta in uncleaved pre-mRNA and all five snRNAs in an equimolar ratio. No spliceosomal intermediates or products and no contaminating other RNA should be present in these purified particles. (2) Mild purification conditions. Precatalytic B complexes should be isolated in a native state using as mild conditions as possible in order to get a comprehensive protein inventory of spliceosomes at this stage by MS analysis. In contrast to previous studies, heparin treatment, by which less stably associated factors are stripped off, should not be used. (3) Functionality. Isolated complexes should be able to catalyze both steps of pre-mRNA splicing in vitro so that they could form the basis for further biochemical in vitro investigations of functionally dissecting the spliceosome's catalytic activation step and thereby elucidate the protein factor requirements.

Second, the macromolecular structure of B complexes should be investigated at low resolution by electron microscopy. These studies should also allow an evaluation of the homogeneity of B complex purifications with respect to structural homogeneity. The long term a im is to obta in a three-dimensional (3D) image reconstruction of the B complex, so that structural changes can be deduced through a comparison with other complexes from the splic eosomal assembly pathway.

Third, the potential use of dominant negative mutants of splicing factors in the isolation of intermediate spliceosomes stalled at a particular stage was to be investigated. For this purpose, spliceosomes were to be trapped in a „BAU1 state“ by titrating dominant negative mutants of NIPP1 (nuclear inhibitor of protein phosphatase $\underline{1}$ ) into nuclear extract. Resulting complexes should be purified and analyzed on a proteomic, structural and func tional level.

This study describes my efforts to leam more about the catalytic activation of the spliceosome, as well as the dynamic s of splic eosomal protein recruitment. I have isolated the human, spliceosomal B complex which is the spliceosome assembly intermediate that is structurally remodelled during catalytic activation. B complexes were assembled in HeLa cell nuclear extract and purified under native, low stringency conditions using two independent purification methods: (i) glycerol gradient centrifugation followed by MS2-based affinity selection, and (ii) tobramyc in affinity selection coupled with anti$61 \mathrm{~K} / \mathrm{hPrp31}$ immunoaffinity purification.

In both cases purified complexes contained stoichiometric amounts of unspliced premRNA and the U1, U2, U4, U5, and U6 snRNAs. MS2 affinity-selected B complexes were 
functionally committed for subsequent catalytic activation and splicing catalysis as evidenced by in vitro splicing assays with nuclear extract depleted of snRNPs. Isolating the complex with two different approaches made it possible to statistically analyze the MS data and thereby identify bona fide B complex proteins. The analysis revealed more than 110 proteins common to both affinity-purified human B complexes. In the course of this study we generated an extensive data base of factors associated with pre-catalytic spliceosomal B complex. Data indicated that, in addition to tri-snRNP proteins, a large number of non-snRNP proteins, including the hPrp19/CDC5 complex and related proteins, are rec ruited to the pre-mRNA prior to catalytic activation.

Finally, negative staining electron microscopy was performed to elucidate the 2D (3D) struc ture of the human B complex isolated under physiological conditions.

These data provide important information about proteins associated with the precatalytic spliceosome, as well as its structure, just prior to the functionally decisive, spliceosome activation step. The ability to purify native, pre-catalytic spliceosomal complexes paves the way for complementation studies with purified proteins to dissect factor requirements for the subsequent activation and catalytic steps of splic ing. 


\section{Materials and Methods}

\subsection{Materials}

\subsubsection{Chemic als and Media}

Acryla mide solution (ready to use)

Roth, Ka rlsruhe

Rotiphorese Gel 30 (30 \% Acrylamide, 0.8 \% Bis-Acryla mide) for protein gels

Rotiphorese Gel 40 (38 \% Acrylamide, 2 \% Bis-Acrylamide) for RNA gels

Agarose (low melting point)

Agarose (NuSieve GTG)

Ammoniumperoxodisulfate (APS)

Ampic illin

Bovine Serum Albumin (BSA), a cetylated

Bradford-dye

Bromphenol blue

Creatine phosphate

DMSO (Dimethylsulfoxide)

DNA-Molecular Weight marker

DTT (Dithiothreitol)

DTT (Dithiothreitol, 100mM)

EDTA (Disodium salt Dihydrate)

Fish sperm DNA (10mg/ml)

Gluc ose

Glycogen

Glycine

Heparin (sodium salt)

HEPES (N-2-Hyd roxyethylp ipera zin-N-2-etha nsulfonic a cid)

Imidazole

LB-Agar

LB-liquid media

2-Mercaptoethanol

Milk powder, dry, instant

NHS-a ctivated Sepha rose 4 Fast Flow

Paraformaldehyde

PMSF (Phenylmethylsulfonylfluoride)

Ponceau S

Protein-A-Sepha rose CL-4B
Invitrogen, Netherlands

BioWhitta ker, USA

Merck, Da msta dt

Sigma, Ta ufkirchen

Sigma, Ta ufkirc hen

Bio-Rad, Munich

Merck, Da mstadt

Sigma, Ta ufkirc hen

Roth, Ka rlsruhe

GIBCO, New Zealand

Roth, Ka rlsruhe

Promega, USA

Roth, Ka rlsruhe

Roche, Mannheim

Sigma, Ta ufkirchen

Roche, Mannheim

Merck, Da msta dt

Roth, Ka rlsruhe

Calb ioc hem, USA

Merck, Da msta dt

BIO 101, USA

BIO 101, USA

Roth, Ka rlsruhe

Heirler, Radolfzell

GE Healthcare, UK

Merck, Da rmsta dt

Roche, Mannheim

Serva, Heidelberg

GE Healthca re, UK 
Roti-Phenol-Chloroform

Salmon sperm DNA (10mg/ml), sonified

SDS (Sodiumd odec ylsulfa te)

Standard proteins for electrophoresis

Sulfo Link coupling gel

TEMED (N, N, N', N'-Tetra methylenethylend ia mine)

Tris-(hyd roxymethyl)a minometha ne (Tris)

Triton X-100

tRNA E. coli

Tween 20

Urea

Xylene cyanol
Roth, Karlsruhe

Stratagene, USA

Serva, Heidelberg

Bio-Rad, Munich

Pierce, USA

Sigma, Taufkirc hen

Roth, Karlsruhe

Sigma, Taufkirchen

Boehringer, Mannheim

Sigma, Taufkirchen

Merck, Da mstadt

Fluka, Schweiz

All other chemicals, organic substances and solvents were supplied by Merck (Da mstadt), Roth (Karlsruhe), Sigma (Taufkirchen), Serva (Heidelberg) or Fluka (Sc hweiz).

\subsubsection{Antisera and poly-/monoclonal antibodies}

Anti-hPrp31 rabbit peptide a ntisera („4825“)

C-terminal peptide incl. residues 484-497

Goat anti rabbit antibodies,

Peroxidase coupled

\subsubsection{Enzymes and Enzyme inhibitors}

Proteina se K (10 mg/ml)

Restriction endonucleases

RNase A (1 mg/ml)

$\mathrm{RNa} \sin (40 \mathrm{U} / \mu \mathrm{l})$

Protease inhibitor cocktail ta blets

RQ 1 DNase (1 U/ $\mu$ l)

SP6 RNA polymerase $(20 \mathrm{U} / \mu \mathrm{l})$

Taq DNA polymerase $(5 \mathrm{U} / \mu \mathrm{l})$

T4 DNA Ligase

77 RNA polymerase $(50000 \mathrm{U} / \mathrm{ml})$
AG Lühmann (Makarova et al., 2002)

J a ckson Immunoresearch, USA
Sigma, Ta ufkirc hen

New England Biolabs, Frankfurt

Ambion, USA

Promega, USA

Roche, USA

Promega, USA

Promega, USA

Promega, USA

New England Biolabs, Frankfurt

New England Biolabs, Frankfurt 


\subsubsection{Nucleotides}

Nuc leoside-5'-Triphosp hate $\quad$ (ATP, CTP, GTP, UTP; 100 mM each)

$m^{7} G\left(5^{\prime}\right) p p p\left(5^{\prime}\right) G$ cap

(7-Monomethyl-digua nosine Triphosphate)

Radionucleotides (each with $10 \mathrm{mCi} / \mathrm{ml}$ )
[ - $32 \mathrm{P}]$ UTP
$3000 \mathrm{Ci} / \mathrm{mmol}$
$[-32 P] d A T P$
$3000 \mathrm{Ci} / \mathrm{mmol}$
$[-32 P] d C T P$
$3000 \mathrm{Ci} / \mathrm{mmol}$

Enlisted nucleotides were provided from Promega (USA), radionucleotides from Amersham Phamacia Biosciences (Freiburg, Germany). $m^{7} G\left(5^{\prime}\right) p p p\left(5^{\prime}\right) G$ cap was supplied by Kedar (Poland).

\subsubsection{DNA-Oligonuc leotides}

Table 2. DNA-Oligonucleotides

Synthetic oligonucleotides for polymerase chain reactions were purchased from MWG Biotech (Martinsried, Germany).

\begin{tabular}{|c|c|c|}
\hline oligo & description & Sequence \\
\hline K57 & $\begin{array}{lrr}5^{\prime} \quad \text { PCR } & \text { primer } & \text { to } \\
\text { amplify MINX } & \text { and } \\
\text { introduce } & \text { a } & \text { T7 } \\
\text { promoter } & \end{array}$ & $\begin{array}{c}\text { 5'-G GG TAC CTA ATA CGA CTC ACTATA GGG } \\
\text { AGA CG AATTCG AGC TCG CCC-3' }\end{array}$ \\
\hline K58* & $\begin{array}{l}\text { 3' PCR primer to } \\
\text { amplify MINX }\end{array}$ & 5'-GGA TCC CCA CTG GAA AGA CC-3' \\
\hline MS2 FOR & $\begin{array}{l}5^{\prime} \text { PCR primer } \\
\text { complementary to } \\
\text { the } 3^{\prime} \text { end MINX to } \\
\text { attach MS2 sites }\end{array}$ & 5'-AAA CTC TTC GCG G TC TाTCC-3' \\
\hline MS2 REV & $\begin{array}{l}3^{\prime} \text { PCR primer } \\
\text { complementary to } \\
\text { the } 3^{\prime} \text { end of MS2 to } \\
\text { attach restriction site }\end{array}$ & 5'-CTA TAG AAC TCG ACTCTA GAG-3' \\
\hline K106 & $\begin{array}{l}3^{\prime} \text { PCR primer to } \\
\text { amplify MINX and } \\
\text { attach Tobramycin } \\
\text { RNA a ptamer }\end{array}$ & $\begin{array}{c}\text { 5'-CGG ATC CGG CTC AGC ACG AGTGTA GCT } \\
\text { AAA CCTCGC TATACTAAG CCG GATCCC } \\
\text { CAC TGG AAA GAC C-3' }\end{array}$ \\
\hline
\end{tabular}




\subsubsection{Plasmids}

Table 3. Plasmids

\begin{tabular}{|l|l|l|}
\hline Plasmid & origin & description \\
\hline pMINX & Zllman et al., 1988 & $\begin{array}{l}\text { U2-dependent pre-mRNA construct (MINX) in } \\
\text { pSP65-vector under control of SP6 promoter; } \\
\text { linearized with BamHI; Amp }\end{array}$ \\
\hline pAdML-M3 & $\begin{array}{l}\text { Zhou et al., 1998 } \\
\text { and Das et al., } \\
2000\end{array}$ & $\begin{array}{l}\text { A plasmid encoding wild-type AdML and three } \\
\text { phage R17 MS2 binding sites at the 3'end; } \\
\text { linearized with Xbal; T7 RNA polymerase promoter }\end{array}$ \\
\hline
\end{tabular}

\subsubsection{Cell lines}

HeLa S3 c ells

Shooter und Grey, 1952

(human cervical cancer cells)

\subsubsection{Bacteria strains}

Escheric hia coli stra in XL-1 blue; Tet ${ }^{R}$

Stratagene, USA

\subsubsection{Common buffers}

Commonly used media, buffers and solutions were prepared according to Sambrook et al., 1989 (119). Deionized water was from a Millipore apparatus. Solutions were autoclaved if necessary $\left(121^{\circ} \mathrm{C}, 20 \mathrm{~min}, 1 \mathrm{bar}\right)$. Thermolabile components were filtersterilized $(0.22 \mu \mathrm{m})$. The $\mathrm{pH}$ was adjusted using $\mathrm{HCl}$ or $\mathrm{NaOH}$ if not stated otherwise.

10X TBE:

RNA extraction buffer.

10x D buffer.

10x Roeder A buffer.

\section{$0.89 \mathrm{M}$ Tris \\ $0.89 \mathrm{M}$ Boric Acid \\ 25 mM EDTA pH 8.0 \\ $20 \mathrm{mM}$ Tris-Hcl pH 7.5 \\ $150 \mathrm{mM} \mathrm{NaCl}$ \\ 0.2 mM EDTA pH 8.0 \\ $0.5 \%(w / v)$ SDS}

20 mM HEPES-KOH pH 7.9

$1.5 \mathrm{mM} \mathrm{MgCl}_{2}$

$0.2 \mathrm{mM}$ EDTA pH 8.0

adjust to $\mathrm{pH} 7.9$

100 mM HEPES-KOH pH 7.9

$15 \mathrm{mM} \mathrm{MgCl} 2$

$100 \mathrm{mM} \mathrm{KCl}$ 
1x Roeder C buffer.

10x MC buffer.

10x Roeder $D$ buffer.

2x PK buffer.

Saturation buffer.

10x Semi-dry blotting buffer.

6x SDS loading dye:

10x TBE buffer.

RNA loading dye:

Stripping buffer.
$25 \%(v / v)$ glycerol

$20 \mathrm{mM}$ HEPES-KOH pH 7.9

$420 \mathrm{mM} \mathrm{NaCl}$

$1.5 \mathrm{mM} \mathrm{MgCl} 2$

$0.2 \mathrm{mM}$ EDTA pH 8.0

100 mM HEPES-KOH pH 7.6

$100 \mathrm{mM} \mathrm{KOAC}$

$5 \mathrm{mM} \mathrm{MgOAC}$

(add 5 mM DTTto 1x, add one Complete

EDTA-free protease inhibitor cocktail tablet to

$0.5 \mathrm{ml}$ of $1 \times \mathrm{MC}$ buffer)

200 mM HEPES-KOH pH 7.9

$1 \mathrm{M} \mathrm{KCl}$

$2 \mathrm{mM}$ EDTA

$15 \mathrm{mM} \mathrm{MgCl} 2$

200 mM Tris-Hcl pH 7.5

25 mM EDTA pH 8.0

$2 \%(w / v)$ SDS

$0.2 \mathrm{M} \mathrm{NaHCO}_{3}$

$0.1 \mathrm{M} \mathrm{NaCl}$

$1 \mathrm{M}$ Ethanolamine

$480 \mathrm{mM}$ Tris

$390 \mathrm{mM}$ Glycine

$1 \%(w / v)$ SDS

$244 \mathrm{mM}$ Tris- $\mathrm{HCl} \mathrm{pH} 6,8$

$2.4 \%(w / v)$ SDS

$244 \mathrm{mM}$ DTT

$21.2 \%(w / v)$ Glycerol

$0.12 \%(w / v)$ Bromphenol blue

$1 \mathrm{M}$ Tris

$1 \mathrm{M}$ Boric Acid

20 mM EDTA pH 8.0

adjust to $\mathrm{pH} 8.3$

$80 \%$ Formamide

1 mM EDTA pH 8.0

$0.05 \%(w / v)$ Bromphenolblue

$0.05 \%(w / v)$ Xylene cyanol

$25 \mathrm{mM} \mathrm{Na}_{2} \mathrm{HPO}_{4}$

$25 \mathrm{mM} \mathrm{NaH}_{2} \mathrm{PO}_{4}$

$2 \%$ (w/v) SDS

add $175 \mu \mathrm{l} 14.3 \mathrm{M}$-Mercaptoethanol

per $25 \mathrm{ml}$ solution 
10x TRO buffer.

10x TBS buffer.

Coomassie staining sol. for SDS-PAGE:

1x PBS buffer.
400 mM Tris-HCl pH 8.1 @ $37^{\circ} \mathrm{C}$

$60 \mathrm{mM} \mathrm{MgCl} 2$

$50 \mathrm{mM}$ DTT

$10 \mathrm{mM}$ Spermid ine

$0.1 \%(v / v)$ Triton X-100
$200 \mathrm{mM}$ Tris

$1.5 \mathrm{M} \mathrm{NaCl}$

adjust to $\mathrm{pH} 7.6$

$0.25 \%(w / v)$ Cooma ssie (R250)

$40 \%(v / v) \mathrm{MeOH}$

$10 \%(v / v)$ Acetic Acid

$130 \mathrm{mM} \mathrm{NaCl}$

$20 \mathrm{mM}$ potassium phosphate

adjust to $\mathrm{pH} 8.0$

\subsubsection{Commercial reaction sets (kits)}

BCA protein assay kit

Bradford assay

ECL Westem Blot Detection Kit

Prime It II Rand om Primer La beling Kit

QIAgen Plasmid Mini/Maxi Preparation Kit

QIAquick Gel Extraction Kit

QIAquick PCR Purific ation Kit

\subsubsection{Working equipment}

Dialyses membranes MWCO 6000-8000 Da

Electroporation cuvettes

Nylonmembrane Hybond XL

Nesc 0-/Para film

Nitroc ellulose

ProbeQuant ${ }^{T M}$ G-25/G 50 columns

Protran Nitrocellulose Membrane

Slide-A-Lyzer Mini-dia lysis units

(MWCO $7000 \mathrm{Da}$; Volume $0.5 \mathrm{ml}-3.0 \mathrm{ml}$ )

Sterile filters $0.2 \mu \mathrm{m}$ or $0.45 \mu \mathrm{m}$

Surgical blades

X-ray films Bio Max MR

Whatman 3MM Paper
PIERCE, USA

Bio-Rad, Munich

Amersham Phamacia, Freiburg

Stratagene, USA

Qiagen, Hilden

Qiagen, Hilden

Qiagen, Hilden

Spektra Por, USA

Bio-Rad, Munich

Amersham Phamacia, Freiburg

Roth, Ka rlsruhe

Sc hleic her \& Schuell, Dassel

Amersham Phamacia, Freiburg

Schleic her \& Schüll, Dassel

Pierce, USA

Millipore, France

Martin, Tuttlingen

Kodak, USA

Whatman Paper, UK 


\subsubsection{Machines}

Biofuge fresc 0

Biofuge pico

DNA Thermal Cycler

Elec troporation system Mic roPulser

Gel documentation unit

Gelelec tro phoresis a p pa ratus

Geldryer Model 583

Gradient Master Modell 106

„head-over-ta il“ Rotor

Heating blocks

Hybrid iza tion oven

Megafuge 1.0R

Milli-Q-water supply a pparatus

$\mathrm{pH}-$ Meter

Phosphorimager Typhoon 8600

Power supply EPS2A 2000

Power supply EPS 3501/XL

Sc intilla tion c ounter LS 1701

Sorva II HB-6 Rotor

Sorva ll SLA-1500

Sorvall SS-34 Rotor

Speed Vac Konzentrator 5301

Spec tro photometer Ultrospec 3000 pro

Tabletop centrifuges

TRANS-BLOTC ell

TST 41.14 Rotor

Ultrac entrifuge

UV-la mps $254 \mathrm{~nm}$

UV-Stra ta linker 2400

Vortex

X-ray film developer X-O mat 2000
Kendro, USA

Kendro, USA

Hybaid Omni Gene, UK

Bio-Rad, Munich

Bio-Rad, Munich

in-house

Bio-Rad, Munich

BioComp Instruments, Kana da

Cole-Pa mer, USA

Eppendorf, Hamburg

Hybaid Biometra, UK

Kendro, USA

Millipore, USA

Mettler Toledo, Sc hweiz

Amersham Phamacia, Freiburg

Hoefer Pharma cia Biotech, USA

Amersham Phamacia, Freiburg

Beckman/Packard, USA

Kendro, USA

Kendro, USA

Kendro, USA

Eppendorf, Hamburg

Amersham Phamacia, Freiburg

Heraeus, Hanau

Bio-Rad, Munich

Centrikon; Kendro, USA

Sorvall; Kendro, USA

Bachofer, Reutlingen

Stratagene, USA

J anke \& Kunkel, Sta ufen i.Br.

Kodak, USA 


\subsection{Methods}

Unless otherwise stated, all molecular-biological procedures were performed according to Sambrook et al. 1989 (119) or, when a commercial kit was used, according to the manufacturers' instructions.

\subsubsection{Molec ular biology standard methods}

\subsubsection{Generation of RNA aptamer-tagged pre-mRNA and RNA synthesis}

A transcription template for the MINX pre-mRNA was generated from pMINX plasmid (172) by PCR. The MINX plasmid ( $p M I N X$ ) contains a duplic ation of leader 2 of the major late transcription unit of a denovirus separated by one intron (172).

A PCR product containing three MS2 coat protein RNA binding sites was generated using pAdML-M3 (170), which was a kind gift from R. Reed. A transcription template for MINX pre-mRNA tagged with three MS2 RNA aptamers (MS2-tagged MINX) was generated by overlapping PCR of the MINX and MS2 PCR products.

MINX pre-mRNA tagged with the $J 6 f 1$ tobramycin RNA aptamer (161) was generated essentially as described previously (9). A transcription template containing one Tobramycin RNA aptamer at the $3^{\prime}$ end was generated by PCR using PMINX plasmid and oligos K57 and K106.

Uniformly [32P]-labeled, $\mathrm{m}^{7} \mathrm{G}\left(5^{\prime}\right) \mathrm{ppp}\left(5^{\prime}\right) \mathrm{G}$-capped pre-mRNA was synthesized in vitro by $\mathrm{T}$ runoff transcription. A typical $65 \mu$ transcription reaction was camied out at $37^{\circ} \mathrm{C}$ for at least 2:30 hours. The DNA template was removed by a ddition of $3.6 \mu$ of $1 \mathrm{U} / \mu \mathrm{RQ} 1$ DNa se to the reaction mix and further incubation at $37^{\circ} \mathrm{C}$ for 20 minutes. The RNA was precipitated with Lithium Chloride ( $\mathrm{LCl}$ ) according to the MEGAsc ript ${ }^{\mathrm{TM}}$ protocol from Ambion and dissolved in $75 \mu \mathrm{l}$ of CE buffer (10 mM cacodylic acid-KOH pH 7.0, $0.2 \mathrm{mM}$ EDTA $\mathrm{pH}$ 8.0). To further remove unincomorated nucleotides, S300 HR spin columns (Amersham Pharmacia) were used according to the manufacturer's instructions.

\subsubsection{Concentration determination of nucleic acids}

To determine the concentration of nucleic acids, the extinction in an aqueous solution was measured at a wavelength of $260 \mathrm{~nm}$ in comparison to the corresponding buffer without nucleic acids. The following equations were used to detemine concentrations (119):

$1 \mathrm{OD}_{260}=50 \mu \mathrm{g} / \mathrm{ml}$ double stranded DNA $=0.15 \mathrm{mM}$ (in nucleotides)

$1 \mathrm{OD}_{260}=33 \mu \mathrm{g} / \mathrm{ml}$ single stranded DNA $=0.10 \mathrm{mM}$ (in nucleotides)

$1 \mathrm{OD}_{260}=40 \mu \mathrm{g} / \mathrm{ml}$ single stranded RNA $=0.11 \mathrm{mM}$ (in nucleotides) 
Altematively, the concentration of pre-mRNA cotranscriptionally labeled with ${ }^{32 P-\alpha U T P}$ was detemined according to the ratio of hot and cold UTP, the reference date of provided ${ }^{32} \mathrm{P}-\alpha \mathrm{UTP}$ and the absolute number of uridines in the transc ript.

\subsubsection{TNT in vitro translation}

PROMEGA's TNT Quick Coupled Transcription/Translation System allows coupled transcription/translation reactions in a single tube yielding eukaryotic in vitro translated proteins. $61 \mathrm{kDa}$ in vitro translation reaction was performed in a $25 \mu$ reaction according to the manufacturer's instructions. In control reactions, no exogenous template DNA was added.

Proteins were separated by denaturing SDS-PAGE. The gel was fixed for 1 hour in $40 \%$ $\mathrm{MeOH} / 10 \%$ acetic acid followed by a 30 minute incubation in Amersham Phamacia's Amplify solution and exposure to an autoradiogra phy sensitive phosphoimager screen.

\subsubsection{Polymerase Chain Reaction}

PCR was used for a mplific a tion of DNA with simultaneous a ddition of promoter sequences and restriction sites. A typical polymerase chain reaction for DNA amplification of transc ription templates:

$\begin{array}{llll}\text { 1x } & 95^{\circ} \mathrm{C} & 2 \mathrm{~min} & \text { initial denaturation } \\ 35 \times & 95^{\circ} \mathrm{C} & 30 \mathrm{sec} & \text { denaturation } \\ & 49^{\circ} \mathrm{C} & 1 \mathrm{~min} & \text { a nnealing } \\ & 72^{\circ} \mathrm{C} & 1 \mathrm{~min} & \text { elongation } \\ 1 \mathrm{x} & 72^{\circ} \mathrm{C} & 5 \mathrm{~min} & \text { final elongation }\end{array}$

Reaction mixtures contained 1x Taq DNA polymerase buffer (Promega), $0.4 \mathrm{mM}$ dNTPs, 1 $\mu \mathrm{M}$ forward primer, $1 \mu \mathrm{M}$ reverse primer, $100 \mathrm{ng}$ DNA template and $200 \mathrm{U} / \mathrm{ml}$ Taq DNA polymerase (Promega).

\subsubsection{Agarose gel electrophoresis of DNA}

Agarose gel electrophoresis was used both for analytic al pumposes (20 $\mu \mathrm{l} \mathrm{PCR} \mathrm{reactions)}$ and to purify preparative amounts of DNA, particularly to separate DNA fragments after 0.1 - $1.0 \mathrm{ml}$ PCRs or restriction enzyme digestions. Depending on the length of PCR products, gels contained $1.5-2 \%$ agarose in $1 x$ TBE buffer containing $0.4 \mu \mathrm{g} / \mathrm{ml}$ ethidiumbromide. Samples were supplemented with DNA loading dye (5x DNA loading dye: $30 \%(\mathrm{v} / \mathrm{v})$ glycerol, $0.25 \%(\mathrm{w} / \mathrm{v})$ bromphenol blue, $0.25 \%(\mathrm{w} / \mathrm{v})$ xylene cyanol). Gels were run in self made $7 \mathrm{~cm} \times 10 \mathrm{~cm}$ gel chambers at 100 Volts for a pproximately 1 hour in 
1x TBE buffer. The 100 or 1000 bp DNA ladder (DNA marker III) from Roche was used as a size standard.

\subsubsection{DNA isolation from agarose gels}

In order to isolate DNA from agarose gels, DNA bands illuminated with UV-light at a wavelength of $365 \mathrm{~nm}$ were cut out of the gel using a sterile razor blade. DNA was extracted using Qiagen's Q IAquick gel extraction kit.

\subsubsection{Preparation of elec troc ompetent cells}

$5 \mathrm{ml}$ of LB medium containing $10 \mu \mathrm{g} / \mathrm{ml}$ Tetracyclin were inoculated with $100 \mu \mathrm{l}$ of a glycerol stock containing XL-1 Blue DE3 cells and incubated ovemight at $37^{\circ} \mathrm{C}$ while rapidly shaking at $250 \mathrm{pm}$. Subsequently, 1/100 volume of the ovemight culture was used to inoculate $500 \mathrm{ml}$ of $L B$ medium containing $10 \mu \mathrm{g} / \mathrm{ml}$ Tetrac yc lin and inc ubated at $37^{\circ} \mathrm{C}$ while rapidly shaking at $250 \mathrm{~mm}$ until $\mathrm{OD}_{600}$ reached $0.5-1.0$. Cells were harvested by centrifugation at $4^{\circ} \mathrm{C}$ for $10 \mathrm{~min}$ at $5000 \mathrm{rm}$ in a Sorvall SLA-1500 rotor using a Sorvall evolution RC centrifuge. Pelleted cells were resuspended in $400 \mathrm{ml}$ of a cold $10 \%$ glycerol solution and centrifuged under the same conditions. Pelleted cells were resuspended in $200 \mathrm{ml}$ of cold $10 \%$ glycerol solution and subjected to centrifugation using the same parameters as above followed by resuspending in $25 \mathrm{ml}$ of cold $10 \%$ glycerol solution and harvesting by centrifugation at $4^{\circ} \mathrm{C}$ for $20 \mathrm{~min}$ at $4000 \mathrm{pm}$ in a Megafuge $1.0 \mathrm{R}$ centrifuge. Finally, cells were resuspended in $2.5 \mathrm{ml}$ of cold $10 \%$ glycerol solution, aliquoted, frozen in liquid nitrogen and stored at $-80^{\circ} \mathrm{C}$.

\subsubsection{Proteinase K digestion}

In a standard proteinase $\mathrm{K}$ digestion reaction, $5 \mu$ of splicing reaction aliquot was supplemented with $125 \mu$ proteina se K mix consisting of $62.5 \mu \mathrm{l} 2 \times$ PK buffer, $1 \mu \mathrm{l} 10 \mathrm{mg} / \mathrm{ml}$ glycogen, $57.5 \mu \mathrm{l} \mathrm{H} \mathrm{O}_{2}$ and $4 \mu \mathrm{l} 10 \mathrm{mg} / \mathrm{ml}$ proteinase $\mathrm{K}$, and incubated for $60 \mathrm{~min}$ at $37^{\circ} \mathrm{C}$. After a ddition of $70 \mu \mathrm{l}$ 1x D-buffer (10x D- buffer. $20 \mathrm{mM}$ HEPES-KOH pH 7.9, $1.5 \mathrm{mM} \mathrm{MgCl}$, $0.2 \mathrm{mM}$ EDTA pH 8.0) and $20 \mu \mathrm{l} 10 \%$ (v/v) SDS, the mix was vortexed extensively at RT. The RNA was recovered by $\mathrm{PCl}$ and Chloroform extraction followed by two precipitations in the presence of $0.3 \mathrm{M} \mathrm{NaOAc}$ pH 5.3 and drying in a speedvac. The RNA was subsequently resuspended in RNA loading dye and analyzed on a $0.5 \mathrm{~mm} 9.6 \%$ PAA-urea gel as detailed below. 


\subsubsection{Denaturing polyacrylamide gel electrophoresis}

Denaturing polyacrylamide gel electrophoresis in the presence of urea is used to separate RNA and DNA fragments up to 2000 nucleotides. According to the length of nucleic acids, the polyacrylamide content varied between 5 and $14 \%$ (119). A typical 40 $\mathrm{ml} 9.6 \%(\mathrm{v} / \mathrm{v})$ denaturing polya cryla mide gel solution conta ined: $8 \mathrm{M}$ urea and $9.6 \%(\mathrm{v} / \mathrm{v})$ Rotiphorese Gel 40 (ROTH, Karlsruhe) in 1x TBE buffer. We accomplished polymerization by addition of $40 \mu \mathrm{l}$ TEMED and $400 \mu \mathrm{l} 10 \%$ (w/v) APS. Denaturing polyacrylamide gel electrophoresis was done in 1x TBE buffer. The RNA samples were dissolved in RNA loading buffer, denatured for $3 \mathrm{~min}$ at $96^{\circ} \mathrm{C}$ and immediately chilled on ice before loading. RNA was visua lized by silver staining (17) or a utora diog ra phy.

\subsubsection{Protein biochemical standard methods}

\subsubsection{Protein quantific ation}

To quantitatively determine the concentration of proteins, the BCA Protein Assay Kit from PIERCE was used according to the manufacturer's instructions. This assay is a detergentcompatible formulation based on bicinchoninic acid (BCA) for the colorimetric detection and quantification of total protein. $\mathrm{Cu}^{2+}$ is reduced to $\mathrm{Cu}^{1+}$ by protein in an alkaline medium (Biuret Reaction). The $\mathrm{BCA}$ chelates $\mathrm{Cu}^{1+}$ ions forming purple-colored complexes with an absorbance maximum at $562 \mathrm{~nm}$ (134).

\subsubsection{Denaturing SDS polyacrylamide gel electrophoresis}

Proteins were resolved by denaturing SDS-PAGE according to Laemmli (81). Protein samples were dissolved in 6x SDS loading dye, or altematively, 1/10 vol. $10 \%$ (w/v) SDS, $1 / 10$ vol. $100 \%$ glycerol and $1 / 10$ vol. 1 M DTT containing bromphenolblue was added to the samples. Proteins were denatured for $3 \mathrm{~min}$ at $96^{\circ} \mathrm{C}$ and loaded onto a $10 \%$ or $10 \%$ to $13 \%$ step polyacrylamide gel (stacking gel: $5 \%$ polyacrylamide). Protein rich gels were stained with Coomassie Brilliant Blue $(0.25 \%$ (w/v) Coomassie Brilliant Blue, $40 \%$ (v/v) $\mathrm{MeOH}$ and $10 \%$ (v/v) acetic acid) for approximately 1 hour, and subsequently destained in $40 \%(\mathrm{v} / \mathrm{v}) \mathrm{MeOH}$ and $10 \%(\mathrm{v} / \mathrm{v})$ acetic acid at room temperature. Protein gels containing low amounts of protein were stained in silver (17). In particular, protein gels were fixed in $500 \mathrm{ml}$ of $40 \%(\mathrm{v} / \mathrm{v}) \mathrm{MeOH} / 10 \%(\mathrm{v} / \mathrm{v})$ acetic acid for 30 minutes at room temperature while gently shaking. Gels were incubated twice in $500 \mathrm{ml}$ each of $10 \%(\mathrm{v} / \mathrm{v})$ $\mathrm{EtOH} / 5 \%(\mathrm{v} / \mathrm{v})$ ac etic acid for 15 minutes at RT followed by a brief wash in Millipore water.

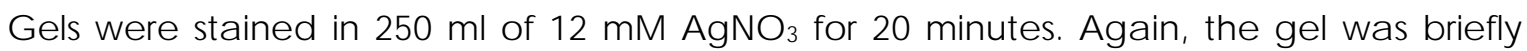
washed in Millipore water followed by the development step in $0.28 \mathrm{M} \mathrm{Na}_{2} \mathrm{CO}_{3}$ and 0.0185 
$\%(v / v)$ Formaldehyde until the desired visualization of RNA bands was achieved. The development step was finally stopped by addition of $250 \mathrm{ml}$ of $5 \%(\mathrm{v} / \mathrm{v})$ acetic acid. Gels were dried undervacuum for 1 hour at $80^{\circ} \mathrm{C}$.

In order to standardize the protein recovery for MS and separation of proteins by gel electrophoresis, INVITROGEN's NuPAGE® System was used. It is based upon a Bis-Tris-HCI buffered ( $\mathrm{pH}$ 6.4) polyacrylamide gel, with a separating gel that operates at $\mathrm{pH}$ 7.0. Despite the fact that these gels do not contain SDS, they are fomulated for denaturing gel electrophoresis applications only. The system was operated according to the manufac turer's instruc tions.

\subsubsection{Immunological Methods}

\subsubsection{Affinity purification of peptide-antibodies}

Antibodies were affinity purified using a SulfoLink column (PIERCE) conta ining immobilized peptide. For this purpose, the peptide was first coupled to the column resin followed by affinity purification of the antibody.

First, $2 \mathrm{ml}$ of SulfoLink coupling gel were equilibrated with $2 \times 12 \mathrm{ml}$ of SulfoLink coupling buffer (50 mM Tris, $5 \mathrm{mM}$ EDTA-Na pH 8.5) at RT. After dissolving $2 \mathrm{mg}$ of sulfhydryl containing peptide in $2 \mathrm{ml}$ of Sulfo Link coupling buffer, the solution was filtered $(0.2 \mu \mathrm{m})$ and added to the column. After incubating at RT for 15 min while rotating head over tail $(\mathrm{HOT})$, the column was incubated for another $30 \mathrm{~min}$ without mixing. Subsequently, the column was drained off the buffer and washed with $6 \mathrm{ml}$ of SulfoLink coupling buffer. In order to block non-specific binding sites on the SulfoLink coupling gel, $2 \mathrm{ml}$ of $0.05 \mathrm{M}$ L-cysteine/ $\mathrm{HCl}$ in SulfoLink coupling buffer was added, followed by an incubation step for $15 \mathrm{~min}$ at RT while rotating HOT and another 30 min incubation without mixing. After draining off the buffer, the column was washed with $4 \times 4 \mathrm{ml}$ of SulfoLink wash buffer (1 M $\mathrm{NaCl})$ and $3 \times 4 \mathrm{ml}$ of $0.05 \%(\mathrm{v} / \mathrm{v})$ sodium azide ( $\left.\mathrm{NaN}_{3}\right)$.

Second, affinity purification of the antibody was performed as follows. The column conta ining the coupled peptide was equilibrated by washing with at least $6 \mathrm{ml}$ of $1 \times$ PBS $\mathrm{pH}$ 8.0. Washing steps were monitored by Bradford assay (Bio-Rad) according to the manufacturer's instructions. $2-8 \mathrm{ml}$ of filtered $(0.45 \mu \mathrm{m})$ serum (containing $1 \times \mathrm{PBS}$ pH 8.0) were added per $1 \mathrm{ml}$ of SulfoLink coupling gel resin with peptide. After incubation for 60 min at RT while rotating $\mathrm{HOT}$, the flowthrough was collected and tested for complete antibody removal by Westem Blot. Subsequently, the column was washed with $16 \mathrm{ml}$ of sample buffer 1 x PBS pH 8.0 (washing steps were again monitored by Bradford assay). Finally, antibodies were eluted by applying stepwise $8 \times 1 \mathrm{ml}$ of $100 \mathrm{mM}$ glycine buffer $\mathrm{pH}$ 2.75. Fractions of $1 \mathrm{ml}$ were collected and immediately neutralized with $50 \mu \mathrm{l}$ of $1 \mathrm{M}$ Tris $\mathrm{pH}$ 9.5. Antibody distribution in the fractions was monitored with the Bradford assay. Peak 
fractions containing the affinity purified antibody were pooled and dialyzed ovemight $(\mathrm{O} / \mathrm{N})$ aga inst $1 \times \mathrm{PBS} \mathrm{pH} 8.0$ at $4^{\circ} \mathrm{C}$.

\subsubsection{Immunoblot (Westem Blot)}

Total protein from HeLa nuclear extract was run on a $10 \%$ SDS-PAGE gel ( $25 \mu \mathrm{g}$ soluble protein per $\mathrm{cm}$ gel slab). The gel was transferred to a nitrocellulose membrane for 1 hour using the semi-dry blotting method. The apparatus for semi-dry blotting consists of two electrode plates (Kathode on bottom, Anode on top) separated by a vertical sandwich of five sheets of Whatman paper, gel, nitrocellulose membrane and again five sheets of Whatman paper. Whatman paper and nitrocellulose membrane are soaked in $1 x$ semi-dry blotting buffer. Air bubbles trapped within layers of the sandwich are removed by rolling a glass pipette on the very top of the sandwich from the center towards the outer regions. Blotting was performed by applying a constant electricity ( $1 \mathrm{~mA}$ per $\left.\mathrm{cm}^{2}\right)$ for 60 minutes at RT.

Subsequently, membranes were blocked ovemight in $1 x \mathrm{TBS} / 0.1 \%(\mathrm{v} / \mathrm{v})$ Tween-20/5 \% $(w / v)$ dry milk powder at $4^{\circ} \mathrm{C}$. Immunoblotting was performed with a ntibodies specified in the figure legends according to standard protocols. Horseradish peroxidase-conjugated anti-rabbit or anti-mouse antibodies were used as the secondary antibody and proteins were detected by enhanced chemiluminescence (Amersham Phamacia) using an ECL kit according to the manufacturer's instructions.

\subsubsection{Special Methods}

\subsubsection{Immunoaffinity punific ation of snRNP complexes}

Immunoaffinity precipitation of snRNP complexes, in partic ular U4/U6.U5 tri-snRNPs, from HeLa nuclear extract is a multistep procedure involving princ ipally six steps: (1) coupling of rabbit polyclonal anti-61kDa (hPrp31) peptide antibodies to Protein A Sepharose (PAS) beads followed by extensive washing to remove excess unbound antibody, (2) equilibration of PAS matrix with immunoprecipitation buffer, (3) binding of 61kDa (hPrp31) containing snRNP complexes to antibody coupled PAS beads by loading total snRNP fraction of $\mathrm{H} 20$ eluate (18), (4) extensive washing followed by equilibration of PAS matrix with elution buffer, (5) specific elution under native conditions with elution buffer containing an excess of cognate peptide, and (6) size fractionation of snRNP complexes by glyc erol gradient centrifugation.

To immunoprecipitate U4/U6.U5 tri-snRNP from a mixture of snRNPs (total snRNPs containing fraction of H20 eluate) (18), $300 \mu$ of PAS beads (bed volume) were inc ubated with anti-61kDa (hPrp31) affinity-purified antibodies in a total volume of $1500 \mu \mathrm{l}$ of 
phosphate-buffered saline (PBS) $\mathrm{pH} 8.0$, supplemented with $0.5 \mathrm{mg} / \mathrm{ml}$ of bovine serum albumin (BSA) and $50 \mu \mathrm{g} / \mathrm{ml}$ total yeast tRNA. The 61kDa (hPrp31) protein was shown to be a U4/U6 specific protein which is important for tri-snRNP formation and pre-mRNA splicing (89). The mix was incubated for $90 \mathrm{~min}$ at $4^{\circ} \mathrm{C}$ while rotating head over tail (HOT). Subsequently, PAS beads were washed twice with $1 \mathrm{ml}$ of 1 x PBS pH 8.0 followed by two washes with IPP 250 buffer (20 mM HEPES-KOH pH 7.9, $1.5 \mathrm{mM} \mathrm{MgCl}, 250 \mathrm{mM} \mathrm{NaCl}, 0.5 \mathrm{mM}$ DTT and $0.05 \%$ (v/v) NP-40) for equilibration. For immunoprecipitation, PAS beads coupled with anti-61kDa (hPrp31) antibodies were incubated with $1.5 \mathrm{mg}$ of total snRNPs in a volume of $2000 \mu \mathrm{l}$ at $4^{\circ} \mathrm{C}$ while rotating HOT for 2 hours. Subsequently, the beads were washed four times with $1 \mathrm{ml}$ of IPP 250 buffer and twic e with IPP 150 buffer (20 mM HEPES-KOH $\mathrm{pH}$ 7.9, $1.5 \mathrm{mM} \mathrm{MgCl} 2,150 \mathrm{mM} \mathrm{NaCl}, 0.5 \mathrm{mM}$ DTT and $0.05 \%$ (v/v) NP-40) containing $5 \%$ ( $v / v)$ glyc erol for equilibration. SnRNP complexes were eluted under native conditions with $\mathrm{IPP}_{150}$ buffer containing $5 \%(\mathrm{v} / \mathrm{v})$ glycerol and $0.6 \mathrm{mg} / \mathrm{ml}$ cognate peptide while rotating HOT at $4^{\circ} \mathrm{C}$ for one hour. The supematant was subsequently loaded onto a $3.8 \mathrm{ml}$ linear (10 to $30 \%$, v/v) glycerol gradient containing G150 buffer (20 mM HEPES-KOH pH 7.9, 1.5 $\mathrm{mM} \mathrm{MgCl} 2,150 \mathrm{mM} \mathrm{NaCl}$ ). Gradients were centrifuged for $180 \mathrm{~min}$ at $374000 \times \mathrm{g}$ in a Sorva II TH660 rotor, and $175 \mu$ fractions were harvested from the top of the gradient.

Protein and RNA were recovered and analyzed by sodium dodecyl sulfatepolyacrylamide gel electrophoresis (SDS-PAGE) on a $10 \%$ polya cryla mide gel followed by staining with Coomassie Brilliant Blue or by denaturing PAGE on an 8.3 M urea-9.6\% polyac ryla mide gel, respectively, and visualized by sta ining with silver (17).

\subsubsection{Cell culture}

HeLa S3 cells (Computer Cell Culture Center, Belgium) were cultivated in suspension (2.5 $5 \times 10^{6} \mathrm{cells} / \mathrm{ml}$ medium) at a logarithmic growth rate using a bioreactor. We used S-MEM medium (Gibco BRL), supplemented with $5 \%(v / v)$ new bom calf senum (Gibco BRL), 50 $\mu \mathrm{g} / \mathrm{ml}$ Penicillin and $100 \mu \mathrm{g} / \mathrm{ml}$ Streptomycin. Cultivation (74) and harvesting of the cells was done essentially according to Dignam et al. (39).

\subsubsection{Preparation of splicing active Hela cell nuclear extract}

Nuclear extracts were prepared from HeLa cells essentially as described by Dignam et al. (39). In partic ular, six to eight liters of HeLa cells were grown in suspension culture in S-MEM media supplemented with $5 \%(\mathrm{v} / \mathrm{v})$ newbom calf serum, $50 \mu \mathrm{g} / \mathrm{ml}$ penic illin, and 100 $\mu \mathrm{g} / \mathrm{ml}$ streptomycin to a density of $2.5-5 \times 10^{5} \mathrm{cells} / \mathrm{ml}$ (74). Cells were harvested by centrifugation for $10 \mathrm{~min}$ at $2000 \mathrm{~mm}$ in a Cryofuge 6000i centrifuge (HERAEUS) and washed $3 \times$ with ice-cold $1 \times$ PBS for 10min each. Subsequently, cells were resuspended in 
1.25 volumes of MC buffer (10 mM HEPES-KOH pH 7.6, $10 \mathrm{mM} \mathrm{KOAc,} 0.5 \mathrm{mM} \mathrm{MgOAc}, 5$ mM DTT, $125 \mu \mathrm{M}$ DTE) supplemented with 2 protease inhibitor cocktail ta blets a nd allowed to swell for 5 minutes on ice, and lysed with 18 strokes of a Dounce homogenizer at $4^{\circ} \mathrm{C}$. Nuclei were pelleted in Corex tubes at 13000 RCF in a Sorvall SS35 rotor for 5 minutes. After removing the supematant, the pellet was dounced with 20 strokes in 1.3 volumes of Roeder C buffer (25\% [vol/vol] glycerol, $20 \mathrm{mM}$ HEPES-KOH pH 7.6, $0.2 \mathrm{mM}$ EDTA pH 8.0, $420 \mathrm{mM} \mathrm{NaCl}$ ) supplemented with $125 \mu \mathrm{M}$ DTE and $20 \mu \mathrm{M}$ PMSF. The mix was stired for 40 minutes at $4^{\circ} \mathrm{C}$, followed by transfer to $70 T$ tubes. $\mathrm{N}$-heptan was added on top followed by centrifugation at $40000 \mathrm{pm}$ for 30 minutes using a Beckman 45T rotor. The clear supematant was recovered and dialyzed twice for 2.5 hours aga inst 50 - 100 volumes of Roeder D buffer (20 mM HEPES-KOH pH 7.6, 0.2 mM EDTA pH 8.0, 1.5 mM MgCl 2,100 mM $\mathrm{KCl}, 10 \%$ [vol/vol] glycerol, $0.5 \mathrm{mM}$ DTE and $0.5 \mathrm{mM}$ PMSF). The dialysate was recovered and centrifuged at $10000 \mathrm{~mm}$ at $4^{\circ} \mathrm{C}$ in an HB6 rotor. The precipitate was discarded and the HeLa nuclear extract was frozen in aliquots in liquid nitrogen, stored at $-80^{\circ} \mathrm{C}$ and tested for splicing a ctivity.

\subsubsection{In vitro splic ing reactions}

Standard splicing reactions were either performed in solution or in solid phase. Typical splicing assays contained $15 \mathrm{nM}$ pre-mRNA substrate, $40 \%$ (v/v) HeLa nuclear extract (39) in buffer D supplemented with $25 \mathrm{mM} \mathrm{KCl}, 3 \mathrm{mM} \mathrm{MgCl}$, $2 \mathrm{mM} \mathrm{ATP}$ and $20 \mathrm{mM}$ creatine phosphate. Spliceosomal complexes were allowed to form at $30^{\circ} \mathrm{C}$ for the times indic ated. Inc ubation was performed either in a standard heating block or by rotating the mixture HOT. After splicing, reactions were chilled on ice.

\subsubsection{Micrococcal Nuclease treatment of Hela nuclear extract}

To deplete splicing active HeLa nuclear extract of all endogenous snRNPs, $\mathrm{CaCl}_{2}$ was added to HeLa nuclear extract in Roeder D buffer to a final concentration of $1.5 \mathrm{mM}$ followed by addition of Micrococcal Nuclease ( $10 \mathrm{U} / \mu$, Amersham Pharmacia) to a final concentration of $0.5 \mathrm{U} / \mu \mathrm{l}$. The mixture was incubated for $10 \mathrm{~min}$ at $30^{\circ} \mathrm{C}$ and immediately transfered on ice. To quench the nuclease activity, EG TA-KOH pH 8.0 was added to a final concentration of $4.5 \mathrm{mM}$ followed by incubation for $1 \mathrm{~min}$ at $30^{\circ} \mathrm{C}$. 


\subsubsection{Depletion of U2 snRNPs or U4/U6 di-snRNPs from Hela nuclear extract}

HeLa nuclear extract was depleted of U2 or U4/U6 snRNPs by strepta vid in a ga rose a ffinity selection using a biotinylated 2'-OMe RNA oligonucleotide complementary to the U2 snRNA or the $3^{\prime}$ end of the U6 snRNA, respectively, as previously described $(16,125)$.

\subsubsection{Analysis of splicing complexes by native agarose gel electrophoresis}

The process of splic eosomal assembly in vitro can be analyzed by a mobility retardation assay $(79,83)$. In principle, spliceosomal complexes A, B and C form in a subsequent mannerand show decreased mobility on a native agarose gel.

To resolve spliceosomal complexes by native agarose gel electrophoresis, $20 \mu \mathrm{l}$ of standard splicing reactions were incubated at $30^{\circ} \mathrm{C}$ for the times indic ated. Heparin was added to a final concentration of $0.125 \mathrm{mg} / \mathrm{ml}$ and the mixtures were incubated for a nother $1 \mathrm{~min}$ at $30^{\circ} \mathrm{C}$ before addition of $4 \mu \mathrm{l}$ of sample loading dye $(50 \%(\mathrm{v} / \mathrm{v}) \mathrm{glyc}$ erol in $0.5 \times$ TBE buffer supplemented with Bromphenol blue). The samples were mixed and immediately loaded onto a native gel $(26 \mathrm{~cm} \times 15 \mathrm{~cm})$ containing $1.5-2 \%(\mathrm{w} / \mathrm{v})$ of low melting point agarose (Invitrogen) in $0.5 \times$ TBE buffer. Electrophoresis was performed by applying 120 Voltage (constant) for 5.5 hours. Gels were fixed for $30 \mathrm{~min}$ at room temperature in $10 \%(\mathrm{v} / \mathrm{v}) \mathrm{MeOH}$ and $10 \%(\mathrm{v} / \mathrm{v})$ acetic acid and then dried at $60^{\circ} \mathrm{C}$ for a minimum of 4.5 hours and exposed to a phosphoimage plate.

\subsubsection{Coupling of tobramycin to NHS-activated Sepharose 4 Fast Fow}

N-hydroxysuc cinimide (NHS)-activated Sepharose 4 Fast Flow was derivatized with $5 \mathrm{mM}$ tobramyc in as follows. $2 \mathrm{ml}$ of matrix was washed four times with $9 \mathrm{ml}$ of $1 \mathrm{mM} \mathrm{HCl}$. The resin wascentrifuged at $2000 \mathrm{pm}$ for $1 \mathrm{~min}$ at $4^{\circ} \mathrm{C}$ in a tabletop megafuge. After the final wash and draining the resin, $950 \mu \mathrm{l}$ of coupling buffer $\left(0.2 \mathrm{M} \mathrm{NaHCO}_{3}, 0.5 \mathrm{M} \mathrm{NaCl}, \mathrm{pH} 8.3\right.$ ) and $50 \mu$ of $0.1 \mathrm{M}$ tobramyc in in coupling buffer were added. The beads were inc ubated ovemight at $4^{\circ} \mathrm{C}$ while rotating head over tail. Beads were then pelleted by centrifugation at $2000 \mathrm{~mm}$ for $5 \mathrm{~min}$ at $4^{\circ} \mathrm{C}$ in a mic rocentrifuge. $8 \mathrm{ml}$ of freshly prepared blocking buffer $\left(0.2 \mathrm{M} \mathrm{NaHCO}_{3}, 0.1 \mathrm{M} \mathrm{NaCl}, 1 \mathrm{M}\right.$ ethanolamine, $\mathrm{pH}$ 8.0) were added to Sepharose beads and incubated for another 2 hours at RT while rotating head over tail. Subsequently, beads were pelleted as described above and washed three times with $9 \mathrm{ml}$ of $1 x$ PBS $\mathrm{pH}$ 8.0. Finally, Sepharose beads were washed two times with $9 \mathrm{ml}$ of $1 \times \mathrm{PBS} / \mathrm{Azide}(0.02 \%$ Azide in 1x PBS pH 8.0) and pelleted again. NHS-activated Sepharose 4 Fast Flow beads were then stored in $2 \mathrm{ml}$ of $1 \times \mathrm{PBS} / \mathrm{Azide}$ at $4^{\circ} \mathrm{C}$. 


\subsubsection{Solid phase splicing reaction}

Solid phase splicing was performed by immobilizing tobramyc in RNA aptamer-tagged adenovinus-derived MINX pre-mRNA on the tobramycin matrix and then incubating with nuc lear extract under splic ing conditions essentially as desc ribed (56).

Briefly, 4x binding buffer (4x BP: $80 \mathrm{mM}$ Tris-HCl pH 8.1 at RT, $4 \mathrm{mM} \mathrm{CaCl} 2,4 \mathrm{mM} \mathrm{MgCl} 2$ and $2 \mathrm{mM}$ DTT) was prepared freshly. $15 \mu \mathrm{l}$ of tobramyc in matrix were blocked over night at $4^{\circ} \mathrm{C}$ while rotating head over tail in $500 \mu \mathrm{l}$ of blocking buffer (1x BP without DTT, $300 \mathrm{mM}$ $\mathrm{KCl}, 0.1 \mathrm{mg} / \mathrm{ml}$ E.coli tRNA, $0.5 \mathrm{mg} / \mathrm{ml}$ BSA and $0.01 \%(\mathrm{v} / \mathrm{v}) \mathrm{NP}-40)$. After collecting the matrix, $250 \mu$ l of RNA mix containing 90 - 100 pmol of tobramyc in-tagged MINX pre-mRNA in $1 \times$ BP without DTT, $145 \mathrm{mM} \mathrm{KCl}$ and $0.01 \mu \mathrm{g} / \mu \mathrm{l}$ tRNA was added and incubated for one hour at $4^{\circ} \mathrm{C}$ while rotating head over tail. The matrix was then washed three times $(1 \mathrm{ml}$ each) with buffer W145 (1x BP, $145 \mathrm{mM} \mathrm{KCl,} 0.01 \%(v / v)$ Nonidet P-40). $750 \mu$ l of splic ing mix conta ining $40 \%(v / v)$ HeLa cell nuclear extract in dialysis buffer D (supplemented with $10 \%$ (v/v) glycerol, $0.5 \mathrm{mM}$ DTT and $0.5 \mathrm{mM}$ PMSF) supplemented with $25 \mathrm{mM} \mathrm{KCl,} 20 \mathrm{mM}$ creatine phosphate, $2 \mathrm{mM} \mathrm{ATP}$ and $3 \mathrm{mM} \mathrm{MgCl} 2$ was added to the matrix and inc ubated at $30^{\circ} \mathrm{C}$ for the indicated times while rotating head over tail. Subsequently, reactions were chilled on ice and the matrix was collected by centrifugation in a tabletop microfuge. Matrix aliquots were pooled during the washes and washed three times (750 - $800 \mu \mathrm{l}$ each) with buffer W75 (1x BP, $75 \mathrm{mM} \mathrm{KCl} 0.1 \%$ (v/v) NP-40). Spliceosomal complexes were eluted by incubating with elution buffer (1x BP, $145 \mathrm{mM} \mathrm{KCl}, 2 \mathrm{mM} \mathrm{MgCl}, 5 \mathrm{mM}$ tobramycin) while rotating head over tail at $4^{\circ} \mathrm{C}$ for $15 \mathrm{~min}$. RNA was recovered by PCI extraction and Ethanol precipitation and analyzed on $8.3 \mathrm{M}$ urea/9.6 \% (v/v) polyacrylamide gels.

\subsubsection{Tobramycin affinity selec tion of splic eosomal B complexes}

Precatalytic spliceosomal B complexes were isolated combining a tobramyc in affinity selection a pproach with immunoprecipitation (IP) using an anti-61kDa (hPrp31) antibody. After a solid phase splicing reaction for $60 \mathrm{~min}$, the crude tobramyc in eluate still conta ins a mixture of $A$ and $B$ complexes. We therefore specifically selected for complexes containing the 61kDa (hPrp31) protein by IP. As the U4/U6.U5 tri-snRNP is first incorporated during $B$ complex formation, the tobramyc in eluate should be free of $\mathrm{H} / \mathrm{A}$ complexes, which do not contain the U4/U6 snRNP specific 61kDa (hPrp31) protein.

A mixture of $A$ and $B$ complexes was purified by affinity selection with a tobramycin aptamer-tagged MINX pre-mRNA essentially as described previously (56), see also above. $B$ complex was subsequently immunoaffinity purified from this mixture with anti-peptide antibodies directed against amino acids 484 to 497 of the U4/U6-61K (hPrp31) protein essentially as previously described for the $\mathrm{B} \Delta \mathrm{U} 1$ complex, except that heparin was omitted 
(91). Altogether $2415-\mu l$ a liquots of tobramyc in matrix bound with a tobramyc in a ptamertagged MINX pre-mRNA were prepared, and $750 \mu$ of a standard splicing reaction was added per $15 \mu$ of matrix and incubated for $60 \mathrm{~min}$. After bound complexes were washed and eluted with an excess of tobramycin, glycerol was added to the eluate to a final concentration of $3 \%(\mathrm{vol} / \mathrm{vol})$. The eluate was diluted fivefold with immunoprecipitation (IP) buffer (20 mM HEPES-KOH, pH 7.9, $150 \mathrm{mM} \mathrm{NaCl}, 1.5 \mathrm{mM} \mathrm{MgCl}$, $0.5 \mathrm{mM}$ dithiothreitol) containing $0.05 \% \mathrm{NP}-40$ and incubated for $3 \mathrm{~h}$ at $4^{\circ} \mathrm{C}$ with $250 \mu \mathrm{l}$ of protein A Sepharose bound with affinity-purified anti-61K/hPrp31 antibodies (approximately $350 \mu \mathrm{g}$ ) that had been preblocked with $0.5 \mathrm{mg} / \mathrm{ml}$ bovine serum albumin and $0.05 \mathrm{mg} / \mathrm{ml}$ yeast tRNA. Beads were washed four times with IP buffer lacking NP-40, and bound material was eluted by incubating $1 \mathrm{~h}$ with IP buffer containing $3 \%$ glycerol (vol/vol) and $0.6 \mathrm{mg} / \mathrm{ml}$ cognate peptide. Protein and RNA were recovered at several purification steps and analyzed as described for the MS2 affinity selection of the B complex.

\subsubsection{MS2 affinity selec tion of splic eosomal B complexes}

The second approach to isolate precatalytic spliceosomal B complexes included (i) the co-transc riptional addition of three MS2 coat protein RNA binding aptamers at the 3 ' end of the pre-mRNA molecule, (ii) preincubation of substrate with excess of the MS2 coat protein and maltose binding protein (MBP), (iii) assembly of spliceosomal complexes in solution on MS2-tagged pre-mRNA, (iv) fractionation of complexes by size on a linear glycerol gradient, $(v)$ affinity selection of splic eosomal B complexes from the 405 peak fractions using amylose beads and (vi) elution under native conditions using an exc ess of maltose.

In particular, we incubated MS2-tagged MINX pre-mRNA with a 20-fold molar excess of purified MS2-MBP fusion protein (21) at $4^{\circ} \mathrm{C}$ for 30 min prior to splic ing in $20 \mathrm{mM}$ HEPES-KOH $\mathrm{pH} 7.9,60 \mathrm{mM} \mathrm{KCl}$. To affinity purify preparative amounts of the B complex, a reaction was camied out with a $12 \mathrm{ml}$ standard splic ing mixture containing $15 \mathrm{nM}$ of [32P]-labeled MS2tagged MINX pre-mRNA (specific activity $8000 \mathrm{cpm} / \mathrm{pmol}$ ). B complexes were assembled by inc ubating at $30^{\circ} \mathrm{C}$ for $8 \mathrm{~min}$. Two milliliter aliquots of the splic ing reaction were loaded onto six $14 \mathrm{ml}$ linear 10-30\% [vol/vol] glycerol gradients containing G buffer (20 mM HEPES$\mathrm{KOH} \mathrm{pH} \mathrm{7.9,} 1.5 \mathrm{mM} \mathrm{MgCl} 2,150 \mathrm{mM} \mathrm{NaCl}$ ). Gradients were centrifuged for $16 \mathrm{~h}$ at $80000 \times \mathrm{g}$ in a Sorvall TST 41.14 rotor and harvested manually in $500 \mu \mathrm{l}$ fractions from the top. Peak fractions conta ining the B complex were pooled, divided into two fractions and loaded onto two separate columns containing $250 \mu$ of amylose beads (New England Biolabs) equilibrated with $\mathrm{G}$ buffer. The matrix was washed $6 \times$ with $1 \mathrm{ml} \mathrm{G}$ buffer each. Spliceosomal complexes were eluted dropwise with $900 \mu$ of elution buffer (G buffer containing $12 \mathrm{mM}$ maltose). Protein and RNA were recovered and analyzed by sodium 
dodecyl sulfate-polyacrylamide gel electrophoresis (SDS-PAGE) on a 10/13\% polyacrylamide gel or by denaturing PAGE on an $8.3 \mathrm{M}$ urea/9.6\% polyacrylamide gel, respec tively, and visualized by sta ining with silver and/or by a utora diogra phy.

For functional and EM studies, $600 \mu \mathrm{l}$ of the eluate were loaded onto a $3.8 \mathrm{ml}$ linear $10-30 \%$ [vol/vol] glycerol gradient containing $\mathrm{G}$ buffer (EM studies) or $\mathrm{G}$ buffer with only $75 \mathrm{mM}$ $\mathrm{KCl}$ (functional assays). Gradients were centrifuged for $107 \mathrm{~min}$ at $374000 \times \mathrm{g}$ in a Sorvall TH660 rotor. For functional studies, fractions of $175 \mu \mathrm{l}$ were harvested from the top, whereasfor EM studies, fractions were taken starting from the bottom of the gradient.

\subsubsection{In vitro splicing assays with MS2 affinity-selected B complexes isolated at $150 \mathrm{mM}$ salt conditions}

To demonstrate that MS2 affinity-selected B complexes are functionally committed for subsequent activation and splic ing catalysis, purified B complex was incubated in HeLa nuclear extract devoid of either U2, U4/U6 or all five snRNPs. Splic ing activity was assayed be denaturing PAGE in comparison to reactions where only naked MINX pre-mRNA was incubated under the same conditions.

For this reason, HeLa nuclear extract was treated with mic roc occal nuclease as essentia lly described previously (88) (see a lso above). In vitro splicing (15 $\mu$ l reaction) was performed essentially as described above for the indicated times with 30\% U2-depleted, 30\% U4/U6depleted, 30\% mock-depleted or 35\% mic rococcal nuclease (MN)-treated HeLa nuclear extract and $5 \mu \mathrm{l}$ of the peak gradient fraction containing MS2 affinity-selected B complexes ( 13 fmoles). In parallel, an equimolar amount of [32P]-labeled MS2-tagged MINX was incubated under the same conditions. To assay whether the B complex is formed de novo during splicing complementation, in vitro splicing was performed with [32P]-labeled MS2-tagged MINX pre-mRNA or equimolar amounts of affinity-selected splic eosomal B complexes ( $5 \mu$ l of peak gradient fraction) (specific activity of tagged premRNA $250,000 \mathrm{cpm} / \mathrm{pmol}$ ) in the presence of an equimolar amount of radioactive, untagged MINX pre-mRNA (specific activity 500,000 cpm/pmol) for 0-90 min. In each case, RNA was isolated, fractionated on an $8.3 \mathrm{M}$ urea/9.6\% polyacrylamide gel and visua lized by autora diogra phy.

\subsubsection{Electron microscopy}

The structure of pre-catalytic splic eosomal B complexes was a nalyzed on a low resolution level by electron microscopy (EM). All these experiments were performed by Dr. D. Boehringer, a member of the 3D Electron Cryomic rosc opy Group at our institute headed by Dr. H. Stark, respectively. Negative staining was camied out by the double carbon film method (75) a fter fixing RNP complexes with gluta ra ld ehyde. Briefly, complexes in solution 
were allowed to adsorb to a thin carbon film. The immobilized complexes were then transferred to a copper grid covered with a perforated carbon support film and sta ined for $2 \mathrm{~min}$ in a $2 \%(\mathrm{w} / \mathrm{v})$ uranyl formate solution. Subsequently, they were overlaid with a second carbon film. Images of the sandwiched B complex were recorded with a Philips CM 200 FEG electron mic roscope (Philips, Eindhoven, Netherlands) at a magnification of $122,000 \times$ with a TVIPS 4k $\times 4 k$ CCD camera (TemCam-F415, TVIPS, Gauting, Gemany) using a Philips holder. For comparison, the BAU1 complex was isolated as previously described (19) and imaged with a TVIPS $1 k \times 1 k$ camera at a magnification of $27,000 \times$. For the $B$ complex, the camera was used with $2 \times$ coarsening of the pixels. Images were taken under low dose conditions at $1.5-3 \mu \mathrm{m}$ defocus and were computationally coarsened to a final pixel size corresponding to $9.8 \AA$ on the specimen scale. Imagic-5 (Image Science, Berlin, Gemany) was used for image processing of 7,500 individual molecular images (154). Briefly, after a 'reference-free' alignment procedure (alignment by classification) (42), images were subjected to multivariate statistical analysis (MSA) (153) and classification (152). Based on the classification, 15-20 individual molecular images were averaged. The resulting class averages were used as reference images in subsequent round s of a lignment until the computed class averages were stable.

\subsubsection{Mass spectrometry}

In order to get a comprehensive inventory of the protein composition of isolated $B$ complexes, purified particles were subjected to mass spectrometry (MS) analysis in the Bioa na lytic al Mass Spectrometry G roup headed by Dr. H. Urla ub.

MS analyses were performed on several individual preparations of both the MS2 and tobramycin affinity-selected complexes. Proteins recovered from MS2 or tobramycin affinity-selected B complexes were separated by 10/13\% SDS-PAGE and stained with Coomassie blue. Altematively, Invitrogen's NuPAGE system including precasted $1.5 \mathrm{~mm}$ Bis-Tris-HCl buffered ( $\mathrm{pH}$ 6.4) 4-12\% polyacrylamide gels and MOPS running buffer were used to separate the protein mixture. An entire lane of the Coomassie blue-stained gel was cut into 25 - 60 slices, and proteins were digested in gel with trypsin and extracted according to Shevchenko et al. (126). The extracted peptides from the tobramyc in and MS2 samples were either analyzed in a liquid chromatography-coupled electrospray ionization quadrupole time of flight (Q-ToF Ultima; Waters) mass spectrometer, or were analyzed in a linear ion trap (4000 QTrap; Applied Biosystems) mass spectrometer, both under standard conditions. Proteins were identified by searching fragment spectra of sequenced peptides against the NCBI nonredundant database using Mascot as search engine. 


\section{Results}

The following sections describe experiments to establish purification conditions that would allow for the isolation of precatalytic spliceosomal B complexes under mild conditions with the aim, to study the protein inventory, the functionality and structure of these particles. We succeeded in purifying B complexes using two principally different techniques. Full functionality of the isolated $B$ complexes could be demonstrated in a series of biochemical chase experiments. In collaboration with the group of Dr. Henning Urlaub (Bioanalytical Mass Spectrometry Group) a comprehensive inventory of the protein composition of purified B complexes was determined. In collaboration with Dr. Holger Stark (3D Electron Cryomic rosc opy Group), we started to detemine the structure of the $B$ complexes at low resolution.

Splic eosomal B complexes were then isolated under low salt conditions in order to identify all proteins which are possibly associated with spliceosomes at the B complex stage beyond a transient interaction.

In addition, we set out to leam more about the feasibility of studying spliceosomal assembly intemediates by titrating dominant negative protein variants into HeLa cell nuclear extract and subsequently purify "stalled“ complexes. These trapped complexes were also a nalyzed with respect to protein composition and structure.

\subsection{Punification of B complexes by glycerol gradient centrifugation followed by MS2-based affinity selection}

\subsubsection{Expenimental strategy to isolate human spliceosomal B complexes via the MS2 affinity purific ation strategy}

Maltose-binding protein affinity chromatography was used before by other laboratories to isolate spliceosomes in highly purified and functional form $(170,171)$. In these studies however, a mixture of spliceosomes at different assembly stages was isolated and analyzed. To gain knowledge of the protein composition, structure and function of the precatalytic spliceosomal B complex only, we extensively modified the original purification conditions and developed the following experimental strategy to isolate human splic eosomal B complexes via the MS2 affinity purification strategy (Figure 5):

We first added three MS2 coat protein RNA binding aptamers cotransc riptionally at the 3' end of the MINX pre-mRNA molecule. This pre-mRNA substrate was subsequently preincubated with an excess of a fusion protein consisting of MS2 coat protein and maltose binding protein. Subsequently, splic eosomal complexes were allowed to form in solution on MS2-tagged pre-mRNA, kinetically controlled in such a way to minimize the formation of contaminating later spliceosomal complexes. Assembled complexes were 
then fractionated by size on a linear glycerol gradient, on which early spliceosomes can be separated from precatalytic B complexes. We then affinity selected spliceosomal B complexes from the $40 S$ peak fractions using a mylose beads and finally eluted complexes under native conditions using an excess of maltose. The whole experimental strategy is shown schematically in figure 5 . The stepwise development of individual steps within the overall purification strategy is desc ribed in the following chapters.

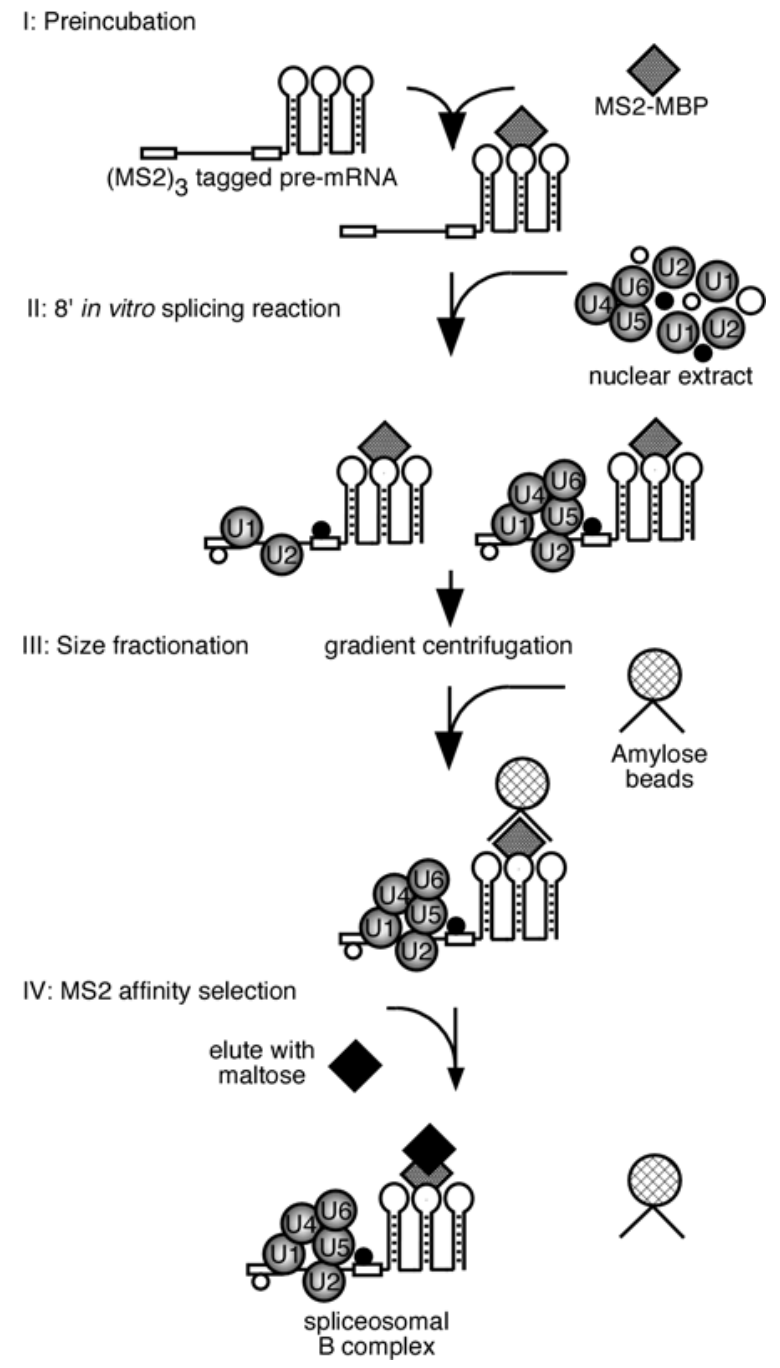

Fig. 5. Schematic diagram of the MS2 affinity purification strategy used to isolate human splic eosomal B complexes. MINX pre-mRNA tagged at its 3' end with three RNA binding sites of the MS2 coat protein was preincubated with a MS2-MBP fusion protein (step I). Subsequently, nuclear extract was added and spliceosomes were allowed to form for 8 min (step II). Complexes were then fractionated by size on a linear 10 to $30 \%$ glycerol gradient (step III). Splic eosomal B complexes from the $40 \mathrm{~S}$ peak fractions were affinity selected using amylose beads and subsequently eluted with maltose (step IV). The sc heme is published in Deckert et al., 2006 (36). 


\subsubsection{Punific ation of the MS2-MBP fusion protein}

A prerequisite for the purification of precatalytic splic eosomal B complexes by MS2-based affinity selection is the availability of highly pure and soluble MS2 coat protein fused to maltose binding protein.

For the affinity selection step we used a fusion protein of MS2 coat protein (MS2) and maltose binding protein (MBP) recombinantly expressed in E. coli. This MS2-MBP fusion protein conta ins a mutation in the MS2 coat protein, namely V75Q and A81G, which was shown to prevent MS2 coat protein oligomerization (85), only MS2-MBP dimers might form. MS2-MBP was first purified over an a mylose matrix and subsequently eluted with an exc ess of maltose. To prevent copunification of nucleic acids while purifying the fusion protein, a chromatography step with heparin was included as desc ribed previously (71).

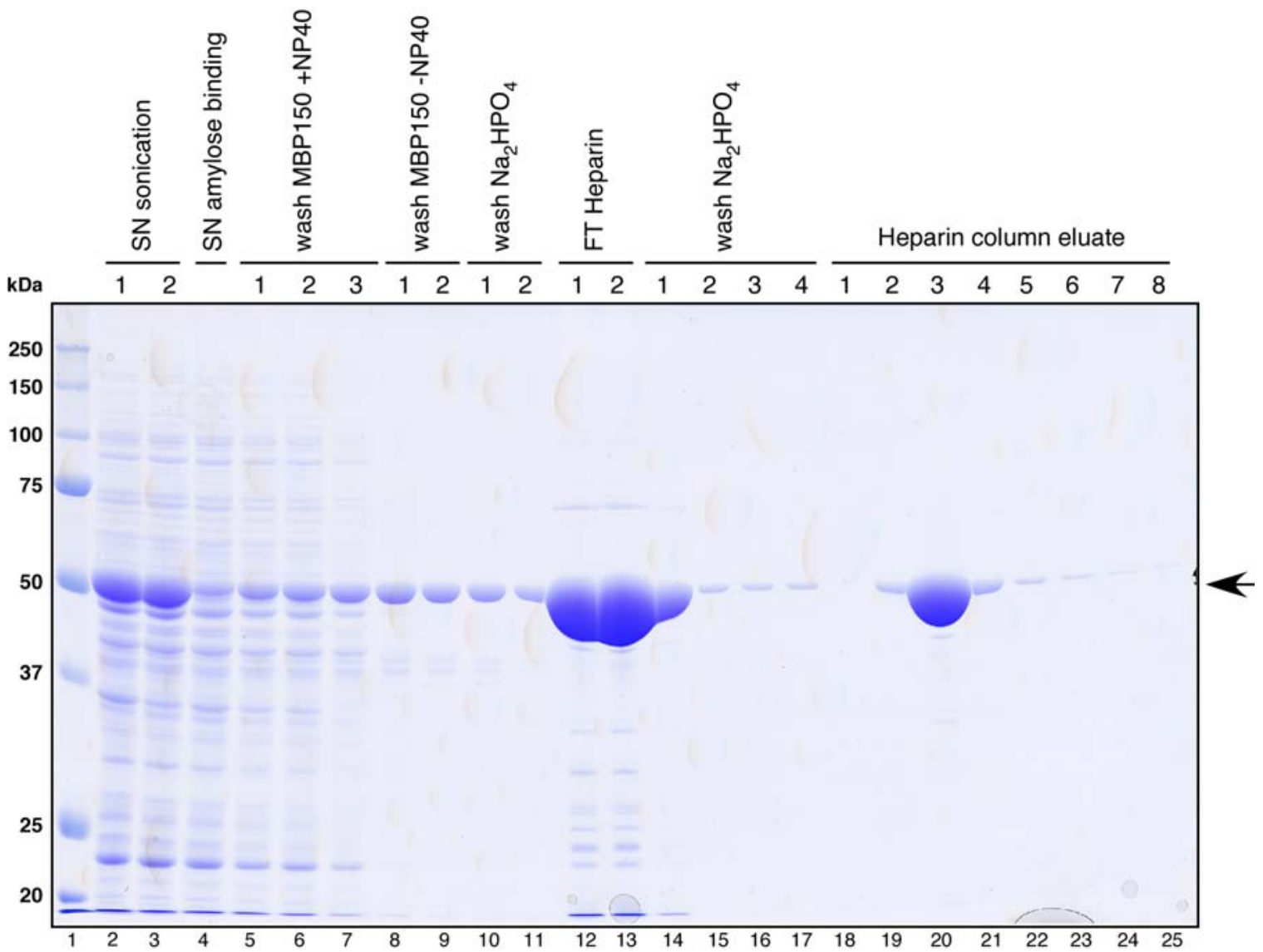

Fig. 6. Punification of the MS2-MBP fusion protein. The MS2-MBP fusion protein was expressed in E. coli and purified first over an a mylose column followed by purific ation over a heparin column. Lane 2: 1/2000 vol. supematant after sonic ation; Lane 3: 1/2000 vol. pre-clearing supematant after sonic ation; lane 4: 1/2000 vol. supematant after binding to amylose beads; lanes 5 - 7: 1/125 vol. of washes with MBP150 buffer; lanes 8 - 9: 1/125 vol. of washes with MBP150 buffer lacking NP-40; lanes 10 - 11: 1/125 vol. of washes with $\mathrm{Na}_{2} \mathrm{HPO}_{4}$ buffer, lanes 12 - 13: 1/125 vol. of flowthrough after binding of Amylose eluate onto Heparin column; lanes 14 - 17: 1/125 vol. of washes with $\mathrm{Na}_{2} \mathrm{HPO}_{4}$ buffer, lanes 18 25: $1 / 125$ vol. of eluate from Heparin column.

Proteins were separated by $10 \%$ SDS-PAGE and sta ined with Coomassie blue. The position of the $50 \mathrm{kDa}$ MS2-MBP fusion protein is indicated on the right by an arrowhead. The molec ular weights of protein standards from BioRad (lane 1) are indicated on the left. 
The purification of the MS2-MBP fusion protein was monitored by analyzing a liquots from each purification step (Figure 6) by SDS-PAGE and subsequent Coomassie blue staining. Figure 6 shows a typical purification procedure profile. The eluate peak fraction (lane 20) contained $13.7 \mathrm{mg} / \mathrm{ml}$ soluble protein of high purity. For subsequent purifications of splic eosomes using the MS2 affinity selection technology, the MS2-MBP fusion protein from the peak eluate fraction wasused.

\subsubsection{Adding MS2 RNA aptamer binding sites to the 3' end of MINX exon 2 does not alter splicing kinetics or the overall yield of splic ing}

Next, we investigated whether MS2 RNA aptamer binding sites (the "tag") had any influence on splicing of the pre-mRNA. Thus, we incubated MS2-tagged MINX or untagged MINX pre-mRNA in HeLa cell nuclear extract under splicing conditions and recovered RNA a liquots at indic ated time points (see Figure 7).

A

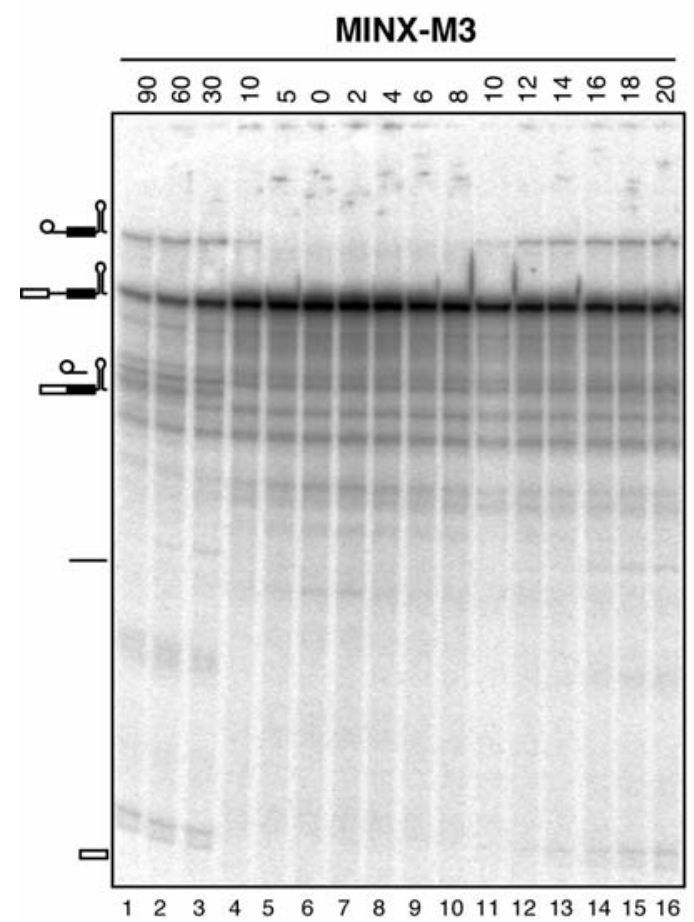

B

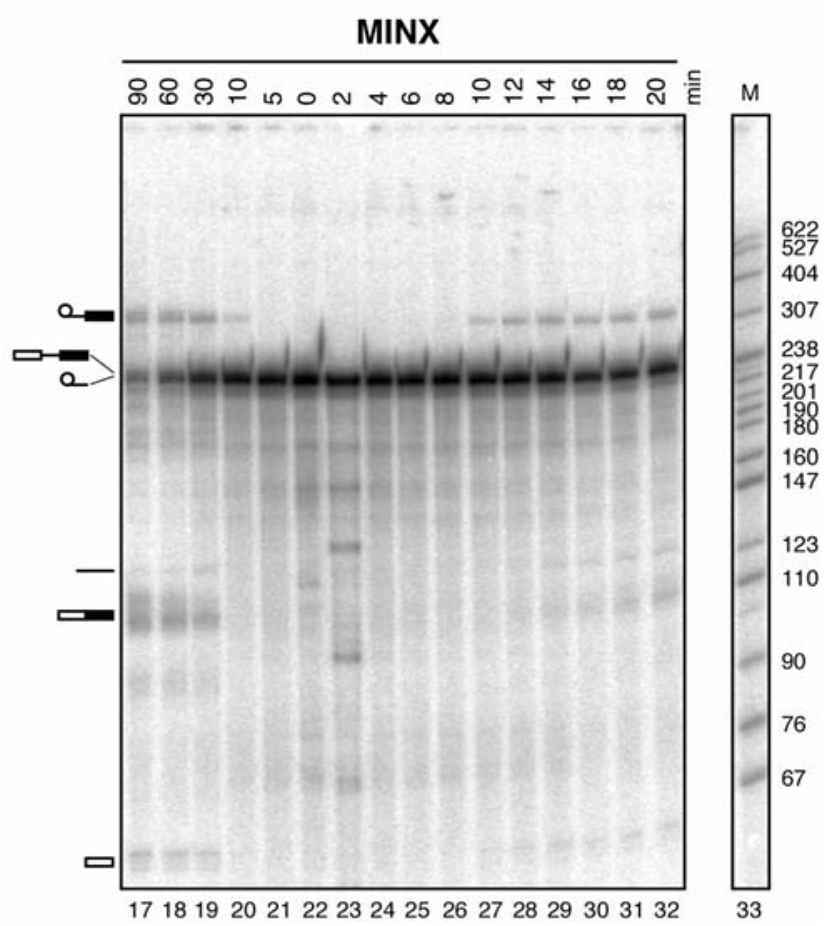

Fig. 7. In vitro splicing kinetics of 32P-labeled MS2-tagged or untagged MINX pre-mRNA. Splic ing was performed in HeLa cell nuclear extract for 0 to 90 minutes (lanes $1-6$ and 17 - 22) or 0 to 20 minutes in two minute intervals (lanes $6-16$ and $22-32$ ) as indicated above each lane using MS2-tagged MINX pre-mRNA (MINX-M3) (panel A) or untagged MINX pre-mRNA (MINX) (panel B). At the indicated time points, aliquots of the reaction mix were removed and the RNA was recovered and separated on an $8.3 \mathrm{M}$ urea-9.6\% polyac rylamide gel. The ${ }^{32} \mathrm{P}-\mathrm{lab}$ beled pre-mRNAs and splicing intermediates and products were detected by autoradiography, and their positions are indicated on the left. The lengths (in base pairs) of a size marker ( $3^{\prime}$ end-labeled Mspl cleaved pBR322) (NEB) (M, lane 33) are indicated on the right. The single hairpin in the drawing in panel $A$ sc hematic ally represents three MS2 coat protein RNA binding sites. 
Both for the MS2-tagged and the untagged MINX pre-mRNA, the first intermediates could be detected after 10 minutes of incubation and reaction products were readily visible after 14 to 16 minutes of incubation. The overall yield of the splicing reactions was the same for both MS2-tagged as well as untagged MINX pre-mRNA.

We therefore conclude that addition of three MS2 RNA aptamer binding sequences to the 3' end of MINX pre-mRNA's exon 2 has neither an effect on kinetic s of splice reactions in solution nore on the absolute yield of splicing intermediates and/or products. Thus, the MS2-tagged MINX pre-mRNA can be used as an efficient substrate in in vitro splicing reactions to isolate precatalytic splic eosomal $B$ complexes.

The next set of experiments were designed to ensure that the recombinant MS2-MBP fusion protein specifically interacts with pre-mRNA tagged with binding sites of the MS2 coat protein.

\subsubsection{The MS2-MBP protein specifically binds to MS2-tagged MINX pre- mRNA in a dose dependent manner}

To test whether MS2-MBP fusion protein bind ing to MS2-tagged MINX pre-mRNA is spec ific, we incubated increasing amounts of MS2-MBP fusion protein with either MS2-tagged (MINX-M3) or untagged MINX (MINX) pre-mRNA and analyzed binding and complex formation by using a gel shift assay. As shown in Figure 8, no complexes formed on MINX pre-mRNA lacking the MS2 RNA a ptamer hairpins at the 3' end of exon 2 (lanes 10 - 18).

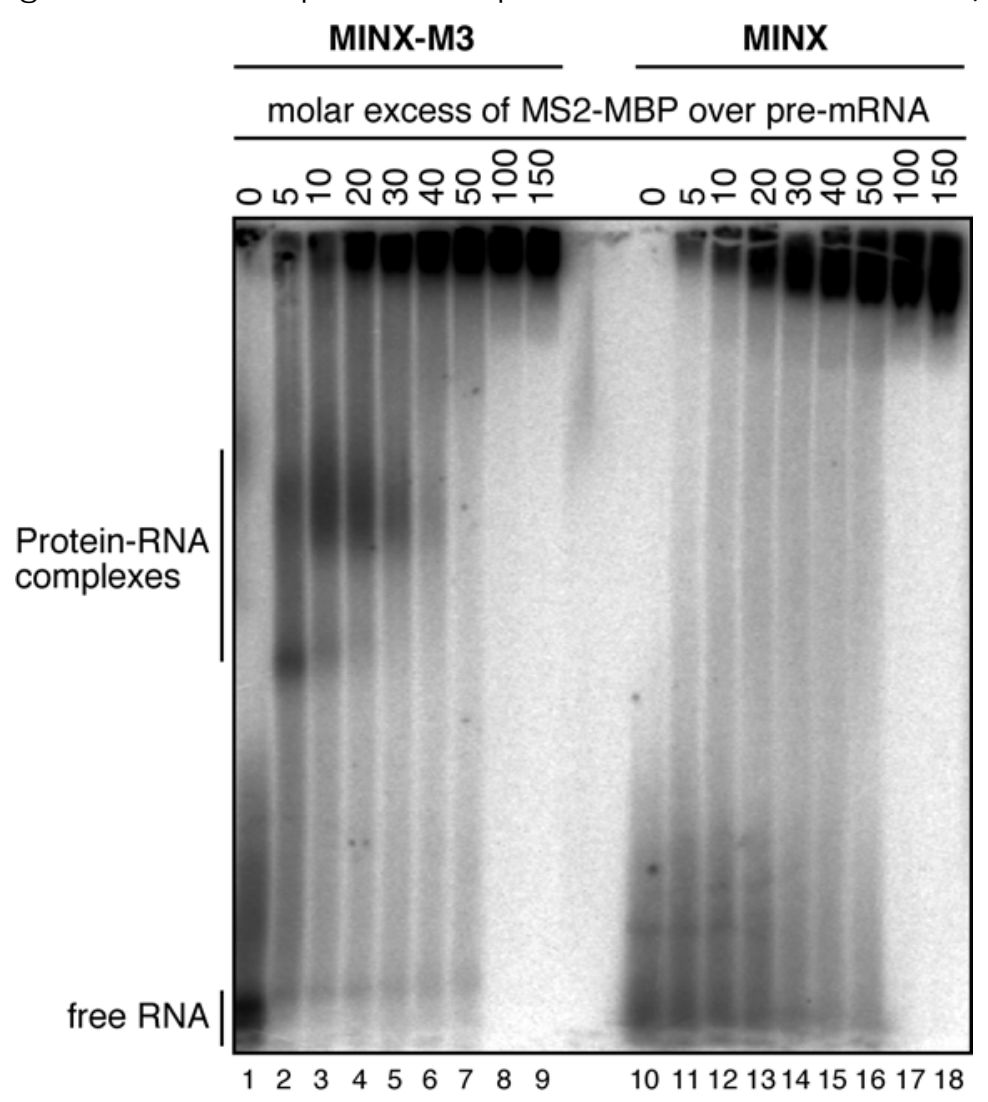


Fig. 8. Test whether the MS2-MBP fusion protein binds specifically and quantitatively to MINX pre-mRNA tagged with MS2 RNA aptamer haipins. MINX pre-mRNA tagged with MS2 RNA aptamer haipins was incubated with 0 to 150 fold molar excess of MS2-MBP fusion protein for $30 \mathrm{~min}$ at $4^{\circ} \mathrm{C}$ (lanes 1 - 9). Binding and complex formation was analyzed on a native $1.5 \%$ agarose gel. As a negative control, MINX pre-mRNA lacking the MS2 RNA aptamer haipin was also incubated with increasing amounts of MS2-MBP fusion protein under exactly the same conditions (lanes 10 - 18).

However, MS2-MBP fusion protein formed efficiently protein-RNA complexes on MINX premRNA tagged with MS2 RNA a ptamers in a dose dependent manner (lanes 1 - 9, ProteinRNA complexes). The distinct subcomplexes observed probably are due to binding of a different number of MS2-MBP fusion proteins per RNA molecule or MS2-MBP dimerization. Quantitative binding was observed at a protein to RNA ratio of 10:1 - 30:1. Higher MS2MBP concentrations resulted in complexes that no longer entered the gel.

Taken together, this demonstrates that the MS2-MBP fusion protein is specific for the MS2 coat protein binding sites containing RNA. MS2-MBP and MS2-tagged MINX pre-mRNA formed complexes in a dose-dependent manner. For all subsequent experiments we used a 20 fold molar excess of MS2-MBP fusion protein over MS2-tagged MINX pre-mRNA.

\subsubsection{Kinetics of in vitro splicing reactions in solution using MS2-tagged MINX pre-mRNA as a substrate}

In previous studies by other laboratories, splic eosomal complexes were allowed to form on MS2-tagged substrates for 30 or 60 minutes and subsequently separated by loading them onto a sizing column followed by MS2 affinity-selection $(71,170,171)$ or altematively, biotin-labeled substrates were incubated under splic ing conditions for 60 minutes, loaded onto a gel filtration column and finally affinity-selected on streptavidin beads (109). We previously purified human spliceosomal A complexes assembled on substrates tagged with a Tobramyc in RNA a ptamer which was immobilized on a tobramyc in matrix. After 60 minutes, spliceosomes were released by competition with Tobramycin and further fractionated by glycerol gradient centrifugation (56).

In the first two studies no particularcaution was taken with respect to kinetic control of the formation of a specific spliceosomal subcomplex. Thus, spliceosomal mixtures of complexes were purified rather than a homogeneous population of a distinct subcomplex. In the latter study, however, the slowed splicing kinetic s on the immobilized pre-mRNA was used to control the formation of spliceosomal complexes. In this way, copurification of contaminating complexes could be reduced to a minimum. Thus, we decided to kinetic ally control also our splic ing reactions in solution to optimize isolation of precatalytic B complexes.

For that purpose we first tested the HeLa cell nuclear extract to be used in the purification procedure for splicing activity and complex formation over time. A typical experiment for 
splic ing activity over time is shown in Figure 9. As shown in panel A, splic ing intermediates were first observed after 10 min of incubation with MS2-tagged MINX pre-mRNA, whereas the first splicing products could be detected after 12 to 14 minutes. We also analyzed complex formation under these conditions by native gel electrophoresis (panel B). It was demonstrated before that resolution of splicing reactions by non-denaturing gel electrophoresis results in a well-defined pattem of shifts corresponding to sequential

A

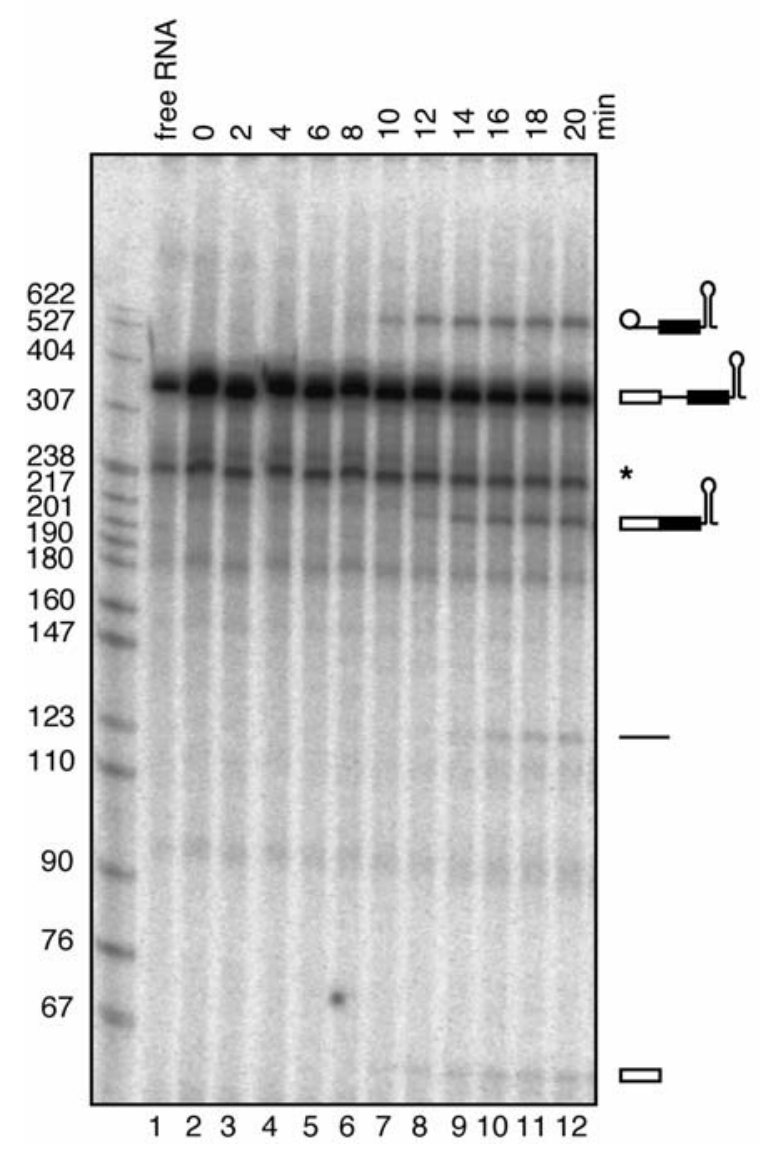

B

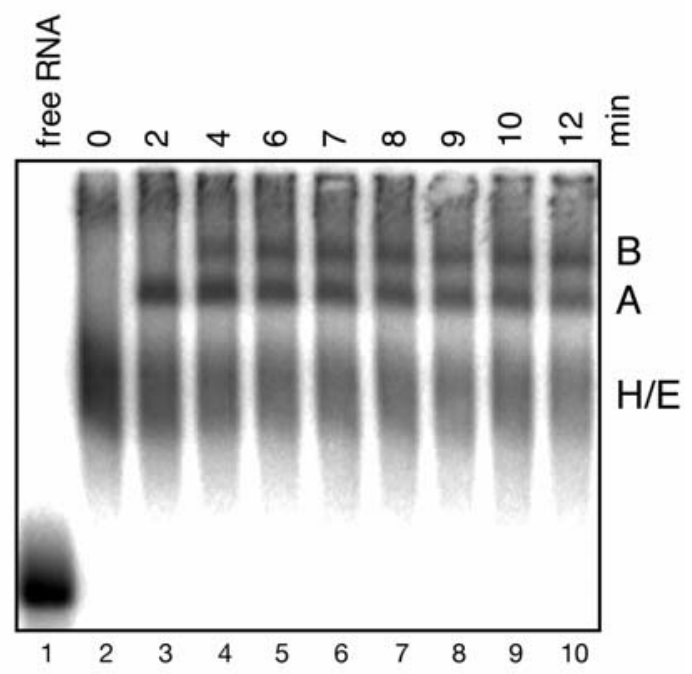

Fig. 9. In vitro splicing kinetics of 32P-labeled MS2-tagged MINX pre-mRNA. (A) Splicing was performed in HeLa cell nuc lear extract for 0 to 20 min as indic ated above each lane. RNA was recovered and separated on an $8.3 \mathrm{M}$ urea-9.6 \% polyacrylamide gel. The ${ }^{32} \mathrm{P}-$ labeled pre-mRNA and splicing intemediates or products were detected by autoradiography, and their positions are indicated on the right; note that the straight line represents debranched, exc ised intron. The lengths (in base pairs) of a size marker ( $3^{\prime}$ endlabeled Mspl cleaved pBR322) (NEB) are indicated on the left. The band indicated by an asterisk is a pre-mRNA degradation product. (B) Analysis of spliceosome assembly over time by native gel electrophoresis. Splic ing was performed in HeLa nuclear extract for 0 to $12 \mathrm{~min}$ as indicated above each lane. Complexes were separated on a native agarose gel. The bands corresponding to the $\mathrm{H} / \mathrm{E}, \mathrm{A}$ and $\mathrm{B}$ complexes are indicated on the right. The figure in panel A is published in Deckert et al., 2006 (36).

complexes along the assembly pathway (79). The electrophoretic positions of free MS2tagged MINX pre-mRNA and of complexes $\mathrm{H} / \mathrm{E}, \mathrm{A}$ and $\mathrm{B}$ are indicated. B complex first appeared after 4 min of splicing and reached its maximal level by $8 \mathrm{~min}$. Identic al results 
were observed with MS2-tagged MINX pre-mRNA preincubated with the MS2-MBP fusion protein (not shown). Every fresh nuclear extract was characterized in such a way. Thus, to isolate complexes that are in a precatalytic state, splicing was camied out with the MS2tagged MINX pre-mRNA for exactly 8 min under splicing conditions in HeLa cell nuclear extract to prevent the formation of later spliceosomal complexes. Thus, we prevent copurification of contaminating spliceosomal complexes by "kinetic control" of the splicing reaction.

\subsubsection{MS2 affinity selection of splic eosomal B complex}

A schematic diagram of the MS2 affinity purification strategy used to isolate human splic eosomal B complexes was shown in Figure 5.

As outlined, after preincubation of MS2 tagged MINX pre-mRNA with a 20 fold excess of recombinant MS2-MBP fusion protein, spliceosomes were allowed to form for $8 \mathrm{~min}$ in HeLa cell nuclear extract under splicing conditions. The splic ing reaction was then subjected to glycerol gradient centrifugation in order to separate the B complex from other RNP complexes such as the splic eosomal A complex.

Figure 10 shows the analysis of the distribution of radioactivity. In parallel gradients, prokaryotic ribosomal subunits (a generous gift from Dr. M.V. Rodnina) were used as sedimentation markers.

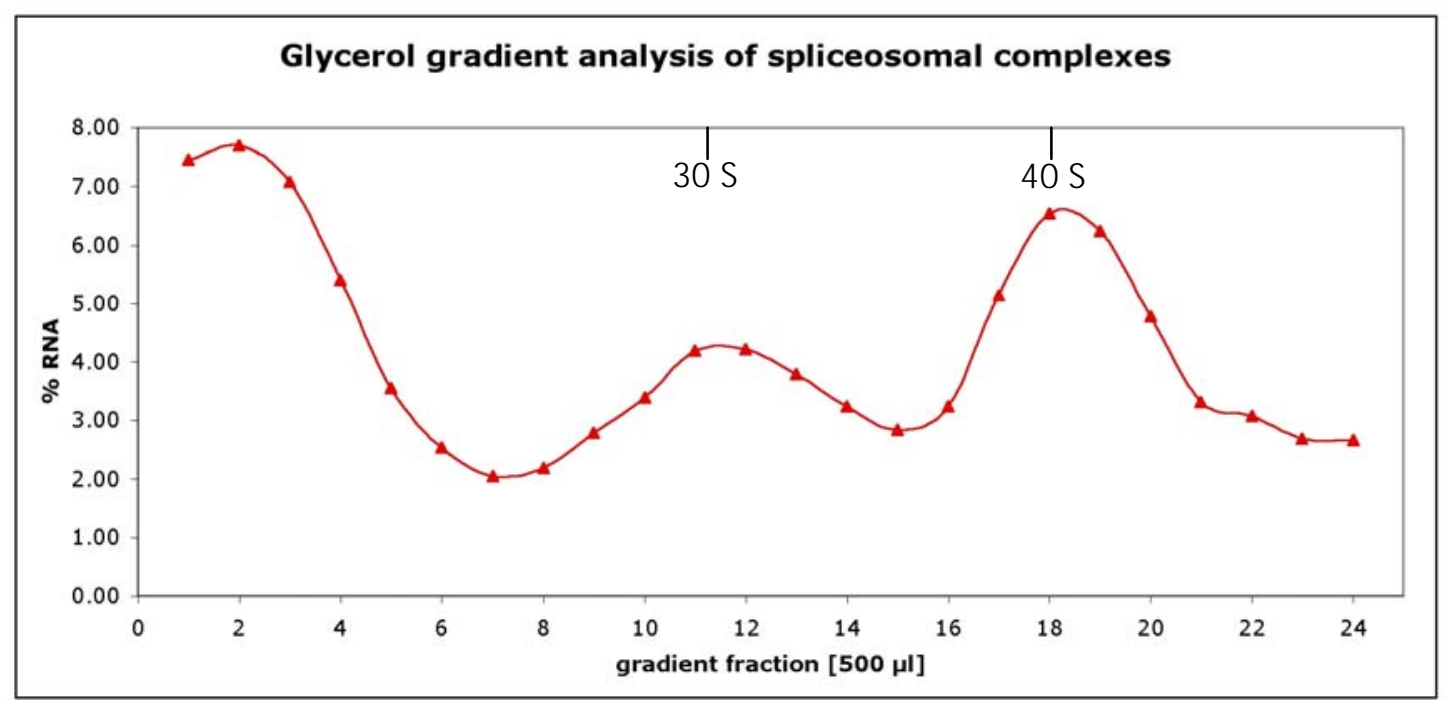

Fig. 10. Glycerol gradient analysis of splic eosomal complexes. Spliceosomal complexes were allowed to form on MS2-tagged MINX pre-mRNA incubated for 8 min at $30^{\circ} \mathrm{C}$ under splic ing conditions. Aliquots of the splic ing reaction were loaded onto $14 \mathrm{ml}$ linear 10 to 30 $\%(\mathrm{v} / \mathrm{v})$ glycerol gradients containing G buffer. Gradients were centrifuged for $16 \mathrm{~h}$ at $80000 \times \mathrm{g}$ in a Sorvall TST 41.14 rotor and harvested manually in $500 \mu \mathrm{l}$ fractions from the top. The percent of $32 \mathrm{P}$-labeled pre-mRNA in each fraction was determined by Cherenkov counting. $\mathrm{S}$ values correspond to the migration of prokaryotic ribosomal subunits. Their sedimentation was monitored by analyzing the UV absorbance of each gradient fraction. 
The vast majority of complexes migrated in two peaks, mainly in fractions 10 - 13 and 17 19. For analyzing the RNA content of the various fractions, the RNA was recovered and analyzed by denaturing PAGE. Figure 11 reveals the snRNA (panel A) and premRNA/intermediates/products (panel B) content of these fractions (lanes 3 to 14). After 8 minutes of splicing, no splic eosomal intermediates or products are present (lane 2), only unspliced pre-mRNA can be detected. Fractions 10 - 13 contained mostly U1 and U2 snRNAs indic ating the presence of $E$ and A complexes, whereas fractions 17 - 19 contain signific ant a mounts of $\mathrm{U} 4, \mathrm{U} 5$ and $\mathrm{U} 6$ snRNAs suggesting the presence of B complexes. Material from the $40 \mathrm{~S}$ region, comprising fractions 17 - 19, respectively, was now used for the MS2 affinity selection. For comparison, splic eosomal E and A complexes were recovered from material from the 305 region in an identical manner (fractions 10 - 13). After affinity selection of spliceosomal complexes from the two peaks with amylose beads, bound material was eluted under native conditions by incubating with an excess of maltose.

The progress of the purification was monitored by analyzing the RNA content of the various fractions, the RNA was recovered and analyzed by denaturing PAGE. A typical purific ation profile is shown in Figure 11 (lanes 15 -20) which reveals the snRNA and/orpremRNA/intermediates/products content of individual steps of the purification.

Spliceosomal complexes bound efficiently to amylose beads via the MS2-MBP fusion protein associated with MS2 RNA aptamer tagged MINX pre-mRNA. Under the conditions used, quantification revealed that around $60-70 \%$ of pre-mRNA within spliceosomal complexes could be recovered after elution by competition with maltose.

The eluate from gradient fractions 10 - 13 contained mostly uncleaved pre-mRNA as well as U2 and U1 snRNAs (lane 17). Since slightly more U1 than U2 snRNA is present in this region of the gradient, this indicates that spliceosomal E complex is present with splic eosomal A complexes. The B complex eluate conta ined nearly equimolar a mounts of uncleaved pre-mRNA, U1, U2, U4, U5 and U6 snRNA, confiming that the vast majority of complexes present are precatalytic $B$ complexes and have not undergone catalytic activation (lane 20). Only minute a mounts of high-molecular-weight RNA were a lso visible on the gel. Aside from unspliced pre-mRNA, only faint amounts of the intron-lariat intermediate, but no splicing products were detected in the eluate, as evidenced by autoradiography (panel B, lane 20). Contaminating snRNPs and most of high molecular weight complexes present in HeLa nuclear extracts were removed by the MS2 affinity selection step.

The profile of the radioactivity distribution over the gradient already indic ated a clean separation of the splic eosomal E/A and B complexes. As shown in Fig. 11, the 30S peak contains a mixture of H/E and A complexes (here denoted "A“), whereas the 40S peak contains the precatalytic B complex (, $\left.\mathrm{B}^{\prime \prime}\right)$. 
From these experiments we conclude that we isolated essentially pure precatalytic spliceosomal B complexes as evidenced by the presence of stoichiometric amounts of all five snRNAs and only uncleaved pre-mRNA in our partic les.

A

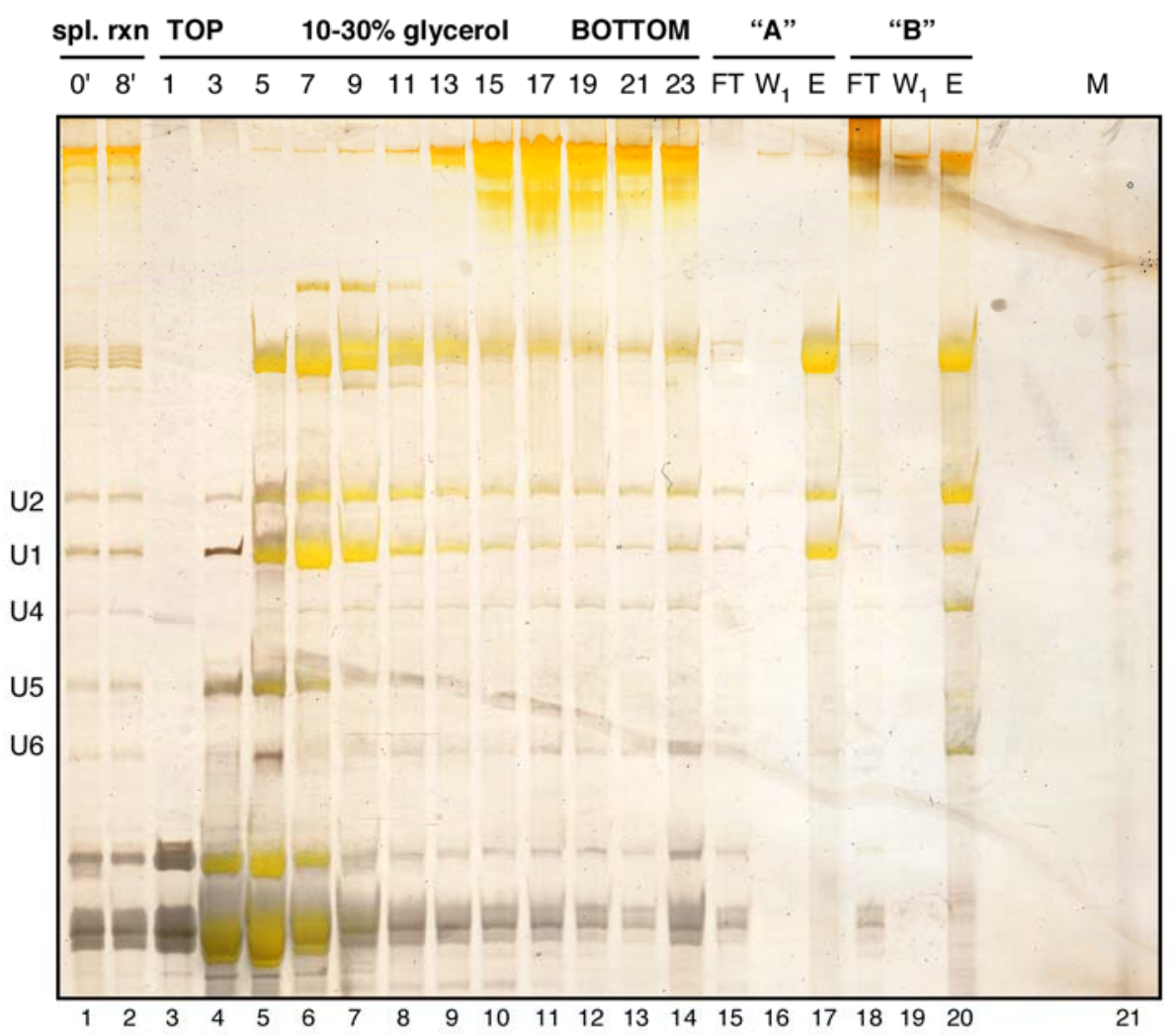

\section{B}

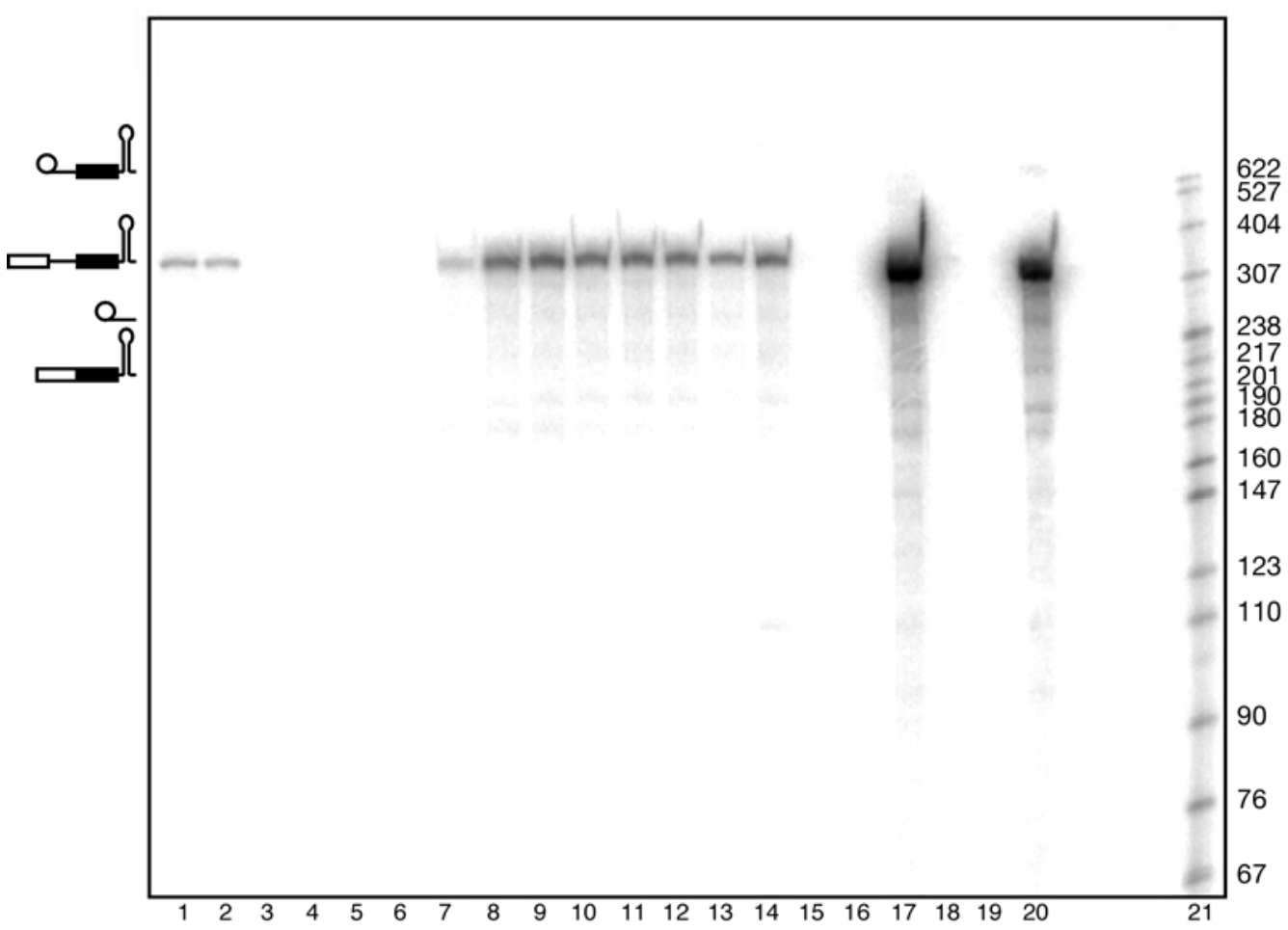


Fig. 11. MS2 affinity selection of human precatalytic spliceosomal B complexes. (A) RNA was recovered from distinct steps during the purification procedure, separated on an 8.3 M urea-9.6 \% polyacrylamide gel and visualized by staining with silver. Lanes 1 and 2: aliquots of the splic ing reaction mixture incubated for 0 and 8 minutes, respectively; lanes 3 - 14: a liquots of odd $10-30 \%$ linear glycerol gradient fractions after centrifugation and subsequent fractionation from the TOP to BOTTOM; lane 15: flowthrough aliquot after binding of pooled E/A complex peak gradient fractions to amylose beads; lane 16: aliquot of a washing step; lane 17: RNA recovered from the eluate. Lanes 18 - 20: same as lanes 15 - 17, but pooled B complex peak gradient fractions were used; lane 21: size marker (M) ( 3 ' end-labeled Mspl cleaved pBR322). The position of the snRNAs is indicated on the left. (B) Autoradiography of the gel in (A). The positions of pre-mRNA, splicing intermediates or products are indicated on the left. The lengths (in base pairs) of the size marker $M$ are indic ated on the right.

\subsubsection{MS2 affinity-selected B complexes are functionally committed for subsequent activation and splicing catalysis}

As demonstrated in the previous chapter, we succeeded in purifying precatalytic splic eosomal B complexes as judged by the RNA content. We next investigated whether these complexes are functionally active and able to catalyze both steps of splic ing. Thus, we assayed whether or not MS2 affinity-purified B complexes a re functionally committed to splicing.

The method of choice to test functional committment is an assay in which first, all endogenous snRNPs in HeLa cell nuclear extract are inactivated with micrococcal nuclease (MN), and second, purified complexes are incubated under splicing conditions in this MN-treated extract in the presence of naked, competitor pre-mRNA. If the purified complex is functionally committed to splicing, only the pre-mRNA substrate within this complex should get spliced, whereas the naked, competitor pre-mRNA should not catalyze splicing. Altematively to this assay, you can also block splicing activity of HeLa nuclear extract by adding large amounts of cold (non-radioactively labeled) pre-mRNA substrate and subsequently spike in purified complexes. Again, after incubation under splicing conditions, these complexes should catalyze both steps of splicing when func tionally committed to splic ing.

We first tested whether our purified B complexes catalyze splicing in HeLa cell nuclear extract depleted of individual snRNPs before we tested functional committment by the assa y described above.

For that we first depleted HeLa cell nuclear extract either specifically of U2 snRNPs or U4/U6 snRNPs using biotinylated 2'-OMe oligonucleotides complementary to U2 or U6 SnRNA $(16,125)$, respectively, followed by streptavidin-agarose affinity selection, or of all end ogenous snRNPs by treating with mic rococcal nuclea se (MN) (88). Analysis of the RNA content of these extracts revealed that, in each case, quantitative digestion or depletion of the targeted snRNPs was achieved (see Figure 12). In the presence of U2- or U4/U6depleted nuclear extract, purified B complexescatalyzed both steps of splicing (Figure 13, 
panels A and B, lanes 1 - 6), whereas no splic ing was observed even after 90 min when an equimolar a mount of naked, [32P]-labeled MS2-tagged MINX pre-mRNA was added (data not shown). Likewise, purified B complexes, but not naked MINX pre-mRNA, underwent splicing in MN-digested extract (MN-NX), which is devoid of all snRNPs (Figure 13, panel C, lanes 1 -12).

To exclude the possibility that the observed splicing activity (Figure 13, panel C, lanes 7 12 ) is due to a disassembly with following reassembly of splic eosomes, we performed the splic ing assay of MS2 affinity purified B complex in MN-treated HeLa cell nuclear extract

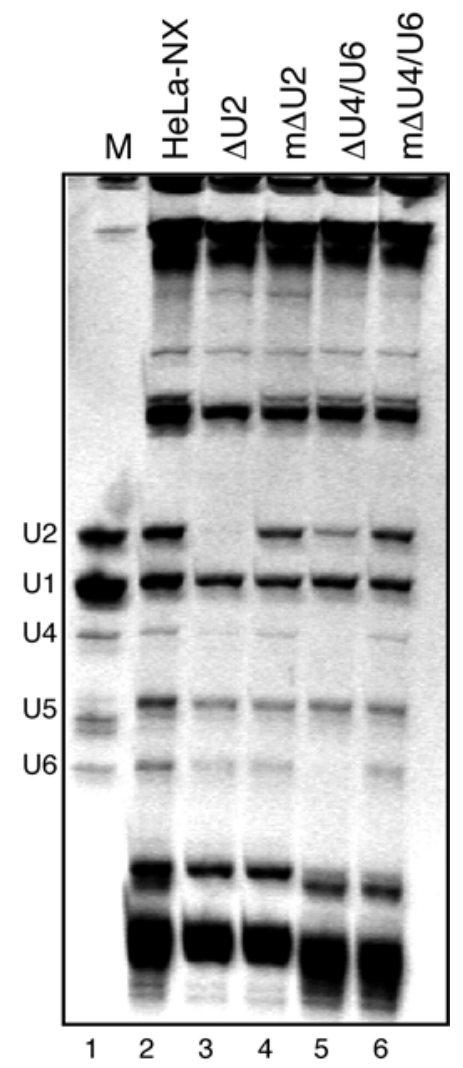

Fig. 12. RNA composition of untreated, depleted or mock-depleted nuclear extracts. RNA composition of untreated (lane 2) HeLa nuclear extract (HeLa-NX), U2 snRNP-depleted (lane 3, U2), U4/U6 snRNP-depleted (lane 5) and mock-depleted (lanes 4, $\mathrm{m} \mathrm{U2,} \mathrm{and} \mathrm{6,}$ $m$ U4/U6) extracts. RNA was separated by denaturing PAGE and detected by staining with ethidium bromide. Lane 1: snRNA marker. The identity of the various RNAs is indicated on the left. The figure is published in Behzadnia et al., 2006 (8).

in the presence of an equimolar amount of [32P]-labeled MINX pre-mRNA lacking a tag and MS2 affinity-purified B complexes. As a control, splic ing was also performed with an equimolar amount of MS2-tagged and untagged MINX pre-mRNA. Neither naked MS2tagged pre-mRNA, nor untagged pre-mRNA were spliced in the MN-treated extract (Figure 13, panel D, lanes 1 - 6). Significantly, the preassembled tagged substrate added as purified B complexes underwent splicing, but no splicing of the untagged pre-mRNA was detected (Figure 13, panel D, lanes 7 - 12). Thus, splic ing active B complexes are not formed de novo by a disassembly/reassembly sequence under these conditions; identical 
results were also obtained with the MS2 eluate that was not subjected to a second gradient centrifugation step.

Taken together, these experiments demonstrate that the MS2 affinity-selected B complexes do not require complementation with any of the splic eosomal snRNPs for their activity and that they are fully functional for the subsequent steps of splic ing (as opposed to being "dead-end" complexes).

A

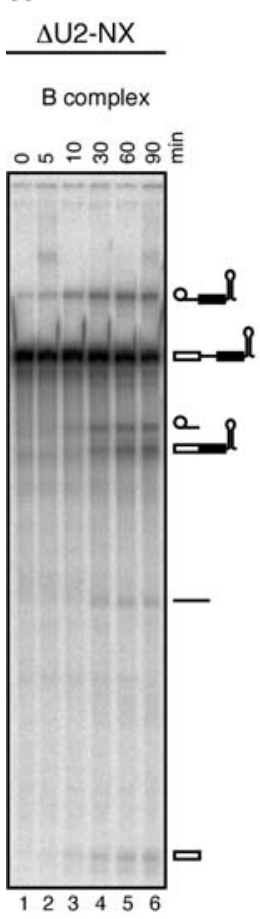

B

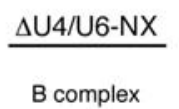

ㄴㅇ욜요

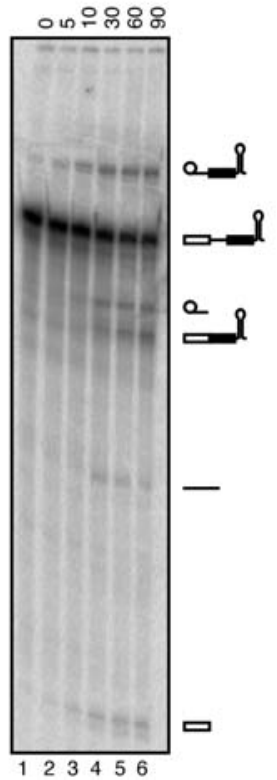

C
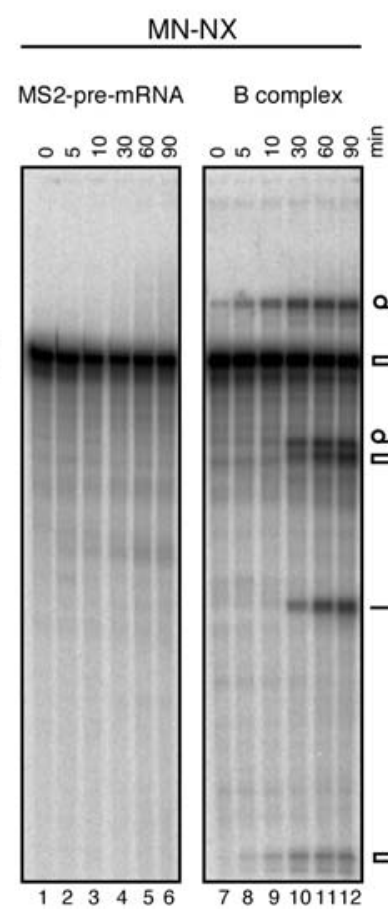

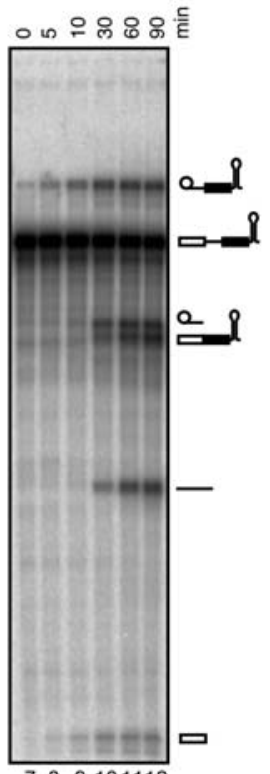

D

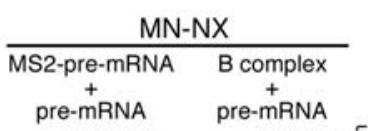

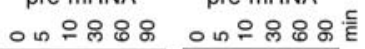
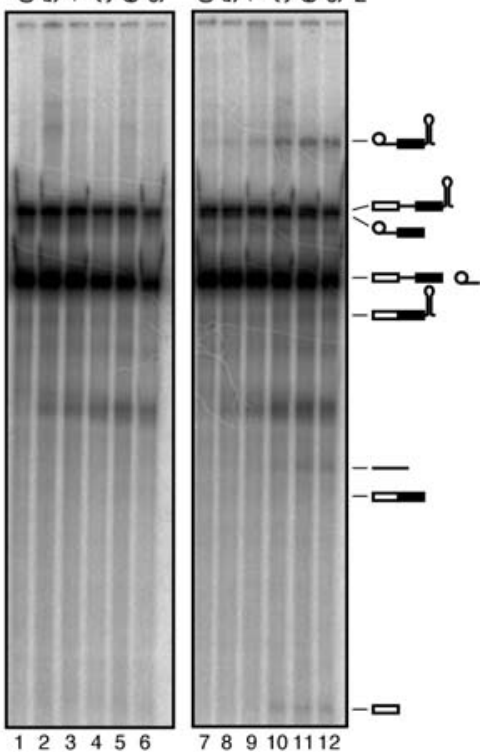

Fig. 13. MS2 affinity-selected spliceosomal B complexes catalyze splicing in nuclear extracts depleted of snRNPs. MS2 a ffinity-selected splic eosomal B complex was incubated for the indic ated times (0 to $90 \mathrm{~min}$ ) in HeLa nuclear extract from which U2 snRNPs (A) or U4/U6 snRNPs (B) were depleted using biotinylated 2'-OMe oligonucleotides complementary to the U2 or U6 snRNA. (C) Naked [32P]-labeled MS2-tagged MINX premRNA (MS2-pre-mRNA) (lanes 1-6) or MS2 affinity-selected splic eosomal B complex (B complex) (lanes 7-12) were incubated from 0 to 90 min under splicing conditions in the presence of micrococcal nuclease treated HeLa nuclear extract (MN-NX). (D) Naked [32P]-labeled MS2-tagged MINX pre-mRNA (MS2-pre-mRNA) (lanes 1-6) or MS2 affinityselected splic eosomal B complex (B complex) (lanes 7-12) were inc ubated for 0 to 90 min (as indic ated above each lane) under splicing conditions together with an equimolar amount of untagged, naked [32P]-labeled MINX pre-mRNA in the presence of MN-NX (pre-mRNA). In each case, RNA was rec overed and a nalyzed as in Fig. 2A. The positions of the intron-3' exon intermediate, pre-mRNA, spliced out intron, spliced mRNA, and 5' exon intermediate are indic ated on the right. The figure is published in Deckert et al., 2006 (36). 


\subsubsection{MS2 affinity-selected B complexes do not catalyze splicing when incubated under splicing conditions in the absence of Hela cell nuclear extract}

The find ings that MS2 affinity-selected B complexes are functionally committed to splic ing raised the interesting possibility that they even might catalyze activation and maybe the first step of splicing in the absence of any additional factor. Since both catalytic activation and the splicing steps themselves include structural rearrangements on the RNA and protein levels, we decided to add ATP and GTP, which might be needed by RNA helic a ses and other enzymes nec essary for these steps.

In our case, however, incubation of purified B complexes (subjected to either one or two rounds of glycerol gradient centrifugation) under splicing conditions in the presence of ATP and GTP, but in the absence of extract, did not result in splicing (data not shown). Thus, these purified complexes appear to lack one or more factors required for subsequent splic eosome activation and/or catalysis, or potentially conta in a full protein complement but lack func tionally important posttranslational protein modific ations.

Subsequent studies on pre-catalytic spliceosomal B complexes isolated under low salt conditions should reveal whether factors necessary for activation were stripped off the splic eosome under $150 \mathrm{mM}$ salt conditions.

\subsubsection{MS of the MS2 selected B complex isolated under $150 \mathrm{mM}$ salt conditions}

As demonstrated in the previous chapters, we succeeded in purifying functionally active, precatalytic B complexes to apparently great homogeneity with respect to the RNA composition. All five snRNAs are present in nearly stoichiometric amounts and only uncleaved pre-mRNA and no splicing intemediates or products were detected, respec tively.

Thus, we now determined the protein composition of B complexes isolated under $150 \mathrm{mM}$ salt conditions in three individual, independent experiments. This allowed us to statistically evaluate the presence of protein factors in purified B complexes. The repeated identification of specific proteins in independent preparations would argue for bona fide B complex factors.

For that we subjected the complex to denaturing PAGE. Figure 14 shows the proteins as visualized by Coomassie staining of a typical B complex preparation. For MS analysis, entire lanes of Coomassie stained gels were cut either into 25 - 60 (depending on the size of the gel) equidistant slices irrespective of the presence or absence of a protein band or altematively, the visible protein bands were cut out of the gel. Please note that also in this case, remaining gel pieces containing no Coomassie stained protein band were 
analyzed by MS. It is known that proteins are differentially stained with Coomassie and furthemore, this staining procedure is not qua ntitative.

Proteins were identified by liquid chromatography-tandem mass spectrometry (LCMS/MS) in the Bioanalytic al Mass Spectrometry Group at our institute, and their presence in each preparation (indicated by the absolute number of peptides sequenced in each preparation) is summarized in Tables 4 and 5 (MS2 \#1 to MS2 \#3). The tables conta in several columns containing from left to right the human protein names, the calculated molecular weight of the respective protein in $\mathrm{kDa}$, two columns of $\mathrm{B}$ complex preparations using the Tobramycin affinity approach followed by anti-61kDa immunoaffinity selection (see later chapters) (TOB/61 \#1 and TOB/61 \#2), three columns of B complex preparations using glycerol gradient centrifugation followed by MS2 affinity

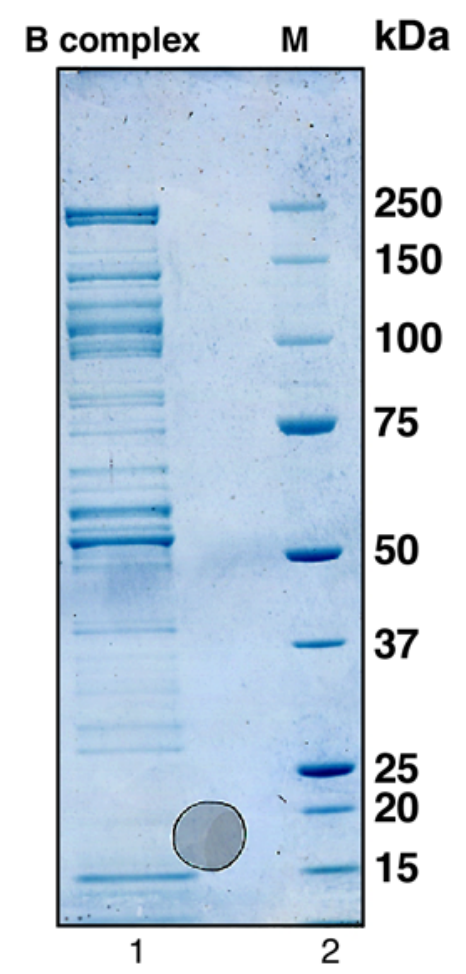

Fig. 14. Protein content of MS2 selected precatalytic spliceosomal B complexes isolated under $150 \mathrm{mM}$ salt conditions. $4.0 \mathrm{pmol}$ (as judged by the activity of nucleic acid in the sample) of MS2 affinity purified B complexes (lane 1) were loaded onto a $1.5 \mathrm{~mm}$ thick precasted $4-12 \%$ NuPAGE Bis-Tris gel (INVITROGEN) and subsequently stained with Coomassie. The molecular weights of protein standards from BIORAD (lane 2) are indic ated on the right in $\mathrm{kDa}$.

selection (MS2 \#1 to MS2 \#4), one B complex preparation isolated under low salt conditions (see later chapter) (MS2 low salt) and another purification in the presence of NIPP1 ( 1 -311) (see later chapter) (8' NIPP1) followed by two columns containing the cognate S. cerevisiae or S. pombe gene names. The proteins themselves are organized in subgroups highlighted in different colours according to their occurence in different subcomplexes of the splic eosome or according to functional groups. 
Most proteins identified were consistently detected in all B complex preparations, and thus they clearly represent B complex components (Table 4). Factors which were found repeatedly, but not in all preparations, most likely are less stably associated B complex components that are more readily lost during purification. Proteins which were detected only once likely represent non-B complex components that are associated with other spliceosomal complexes (i.e., A, B*, and C complexes) that may be present in low amounts in our B complex preparations. Indeed, based on the absolute number of peptides identified for these proteins, most of them appear to be present in very low amounts. They are listed in Table 5.

A total of $\sim 140$ proteins were identified repeatedly in our B complex purifications. Almost all of these proteins have been shown previously (i) to participate in pre-mRNA splicing and/or (ii) to be associated with spliceosomal complexes, argueing that most are bona fide splic eosomal proteins.

As in the human A complex (56), all U1 snRNP-specific (i.e., C, A, and 70kDa) (light blue) and 17S U2 snRNP-specific proteins (i.e., U2 A'/ $\mathrm{B}^{\prime \prime}$ and all SF3a and SF3b subunits) (green) were detected. Several U2-associated proteins (e.g., SPF45, SPF30, and hPrp43p) were also found (green). In contrast, six proteins, Hsp 75, Hsp60, BRAF35, hPrp5, SR140 and SF3b $125 \mathrm{kDa}$, respectively, described as $17 \mathrm{~S}$ U2 snRNP related proteins (164) were not detected. In addition to numerous SR and hnRNP proteins (40) (light turquoise), the cap binding proteins CBP20 and CBP80 (lavender), and the early factors U2AF65 and U2AF35, many of the other non-snRNP proteins previously detec ted in tobramycin affinity-purified $A$ complexes (i.e., FL 10839, RBM5/ LUCA15, E1B- APS, SMC1/2, and FL 21007), some of which have no known function in splicing, were not detected in our B complexes, suggesting that they are lost during the transition from the A to B complex. Thus, they may associate solely with early spliceosomal complexes, and if they indeed contribute to the splicing reaction, they likely act prior to $B$ complex formation.

The presence of U2AF65 and U2AF35 in native splic eosomal B complexes contradicts previous data indicating that these two U2AF subunits are specifically present in early splic eosomal c omplexes and not found within splicing intermediates or products $(28,30)$.

A comparison of the proteomes of the $A$ and $B$ complexes further revealed that a large number of proteins is recruited to the pre-mRNA during B complex formation. As expected for the B complex, nearly all U5- $(4,6,113)$ (yellow), U4/U6- $(7,58,84,89)$ (light yellow), and U4/U6.U5 tri-snRNP-specific $(46,90)$ (tan) proteins were detected.

The detection of U4/U6 and U4/U6.U5 specific proteins demonstrates that we isolated a precatalytic splic eosomal B complex rather than an activated complex where U1 and/or U4 snRNPs a re alrea dy released. 


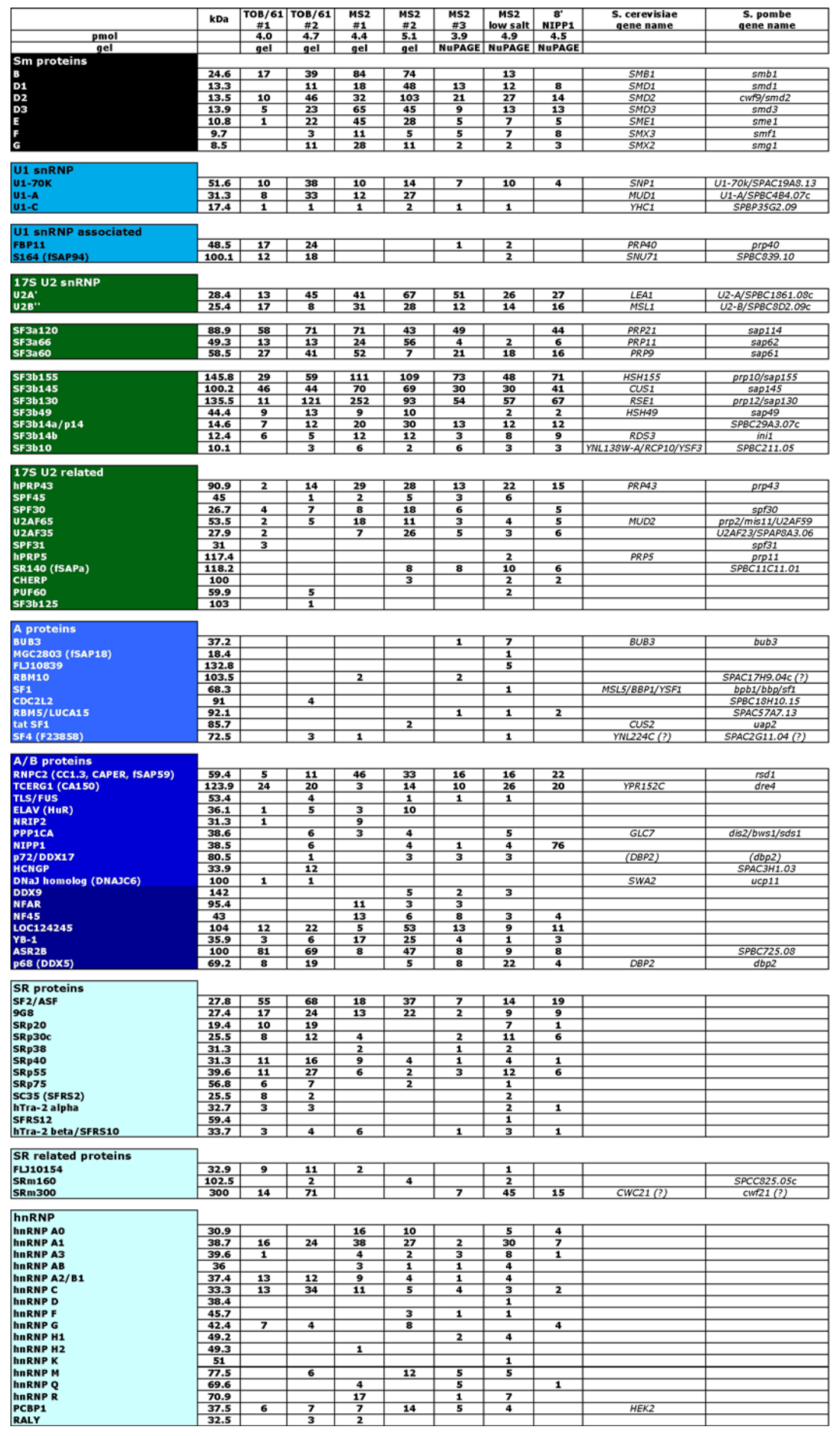




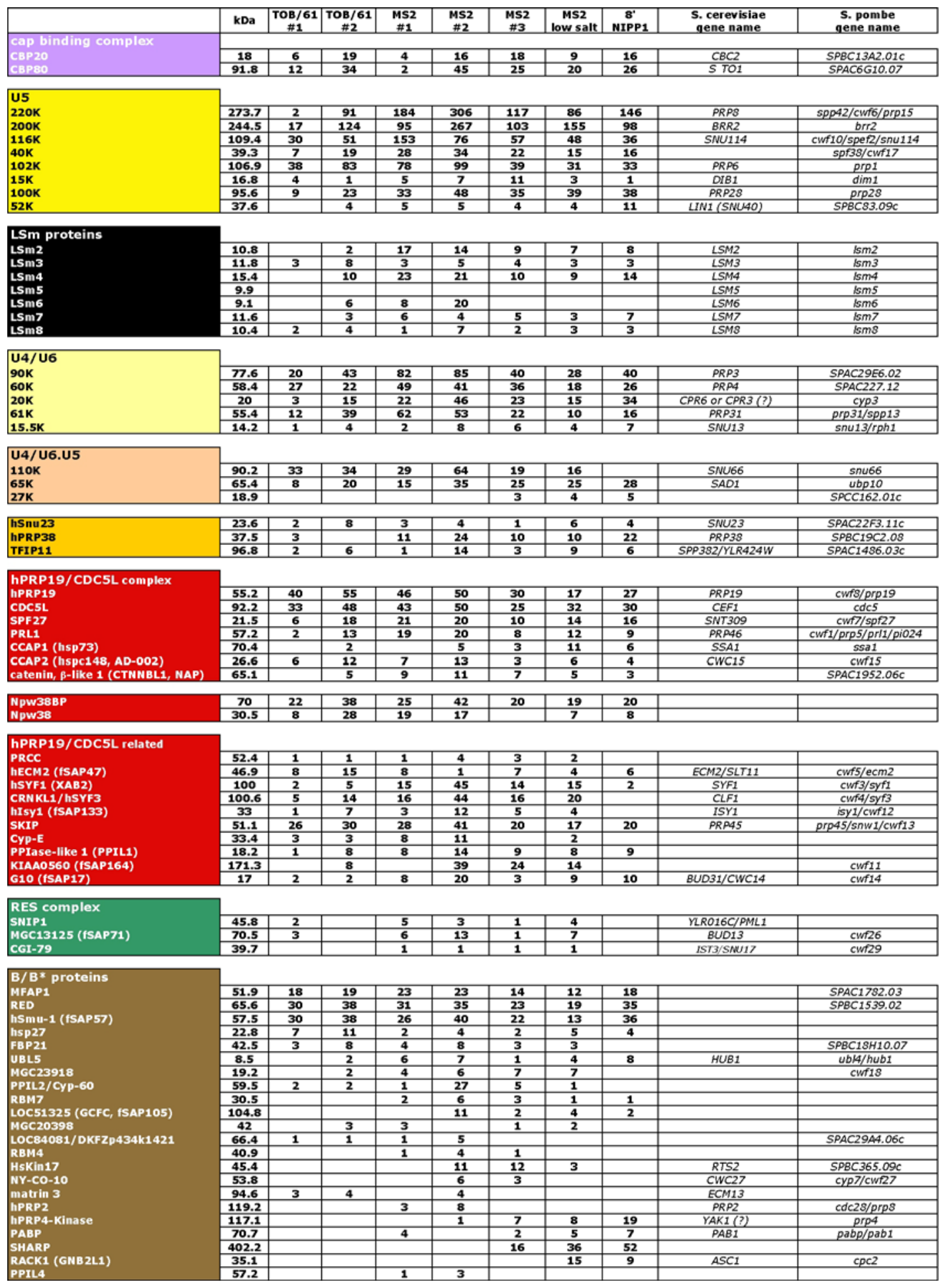

Table 4 continued. Protein composition of the human spliceosomal B complex isolated under physiological conditions. 


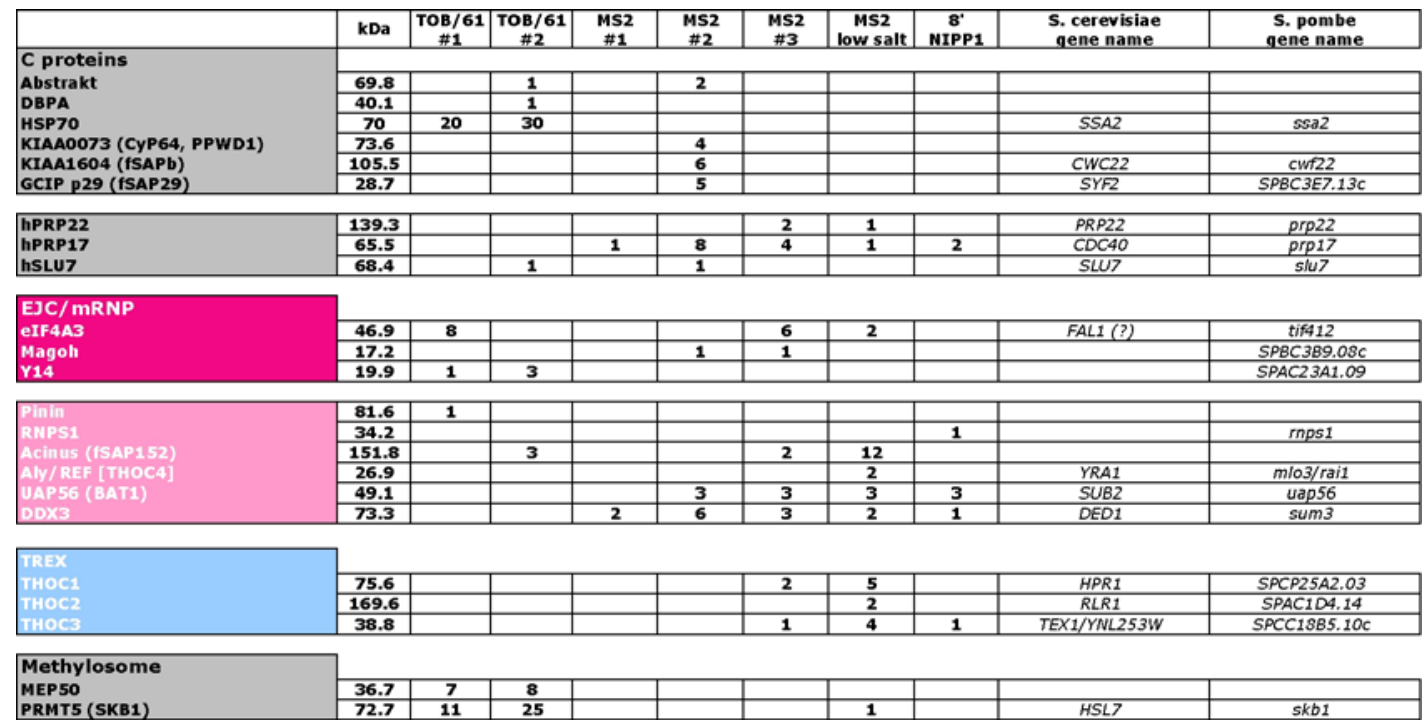

Table 4 continued. Protein composition of the human spliceosomal B complex isolated under physiological conditions. Proteins were identified by liquid chromatographytandem mass spectrometry after separation by SDS-PAGE. The presence of a protein (indicated on the left) in tobramyc in and MS2 B complex preparations is indicated by a number which represents the absolute number of peptides sequenced for that protein. Note that a number of proteins were detected in multiple bands; also because the tandem MS analysis of MS2 \#2 was performed in a linear ion trap, the overall number of sequenced peptides per protein is higher (on average), compared to the other $\mathrm{B}$ complex preparations (which were analyzed in a quadrupole-time of flight MS instrument). TOB/61 \#1 and \#2: B complexes purified by tobramycin affinity selection followed by immunoaffinity purification with antibodies against the U4/U6-61kDa (hPrp31) protein; MS2 \#1 to \#4: B complexes purified by glycerol gradient centrifugation followed by MS2 affinity selection. Proteins were resolved either on a standard Laemmli gel (gel) or using precasted gradient gels from Invitrogen (NuPAGE); MS2 low salt: B complexes purified by glycerol gradient centrifugation followed by MS2 affinity selection under low salt conditions (67 mM instead of $150 \mathrm{mM} \mathrm{NaCl);} \mathrm{8'} \mathrm{NIPP1:} \mathrm{spliceosomal} \mathrm{complexes}$ purified by glycerol gradient centrifugation followed by MS2 affinity selection after 8' incubation at $30^{\circ} \mathrm{C}$ in the presence of $10 \mu \mathrm{M}$ of NIPP1 [1 - 311]. The amount of $\mathrm{B}$ complexes loaded onto the preparative gel, determined from the specific activity of the pre-mRNA, is indicated on the top in pmol. Several ribosomal proteins and translation elongation factors (not shown) were also detected but, based on the low number of peptides identified, appear to be present in substoichiometric amounts and represent contaminants. The gene names of the $S$. cerevisiae and $S$. pombe homologues of the indic ated human protein a re given. A question mark indic ates that it is c urrently not clear whether the indicated yeast protein is a true functional homolog. BLAST alignments of both p68 (DDX5) and p72 (DDX17) revealed significant homology to S. cerevisiae DBP2 and S. pombe dbp2 (between 56 and 59\% sequence identity, respectively). Since true homology rema ins to be verified, DBP2 and dbp2 are both enclosed in parentheses. 


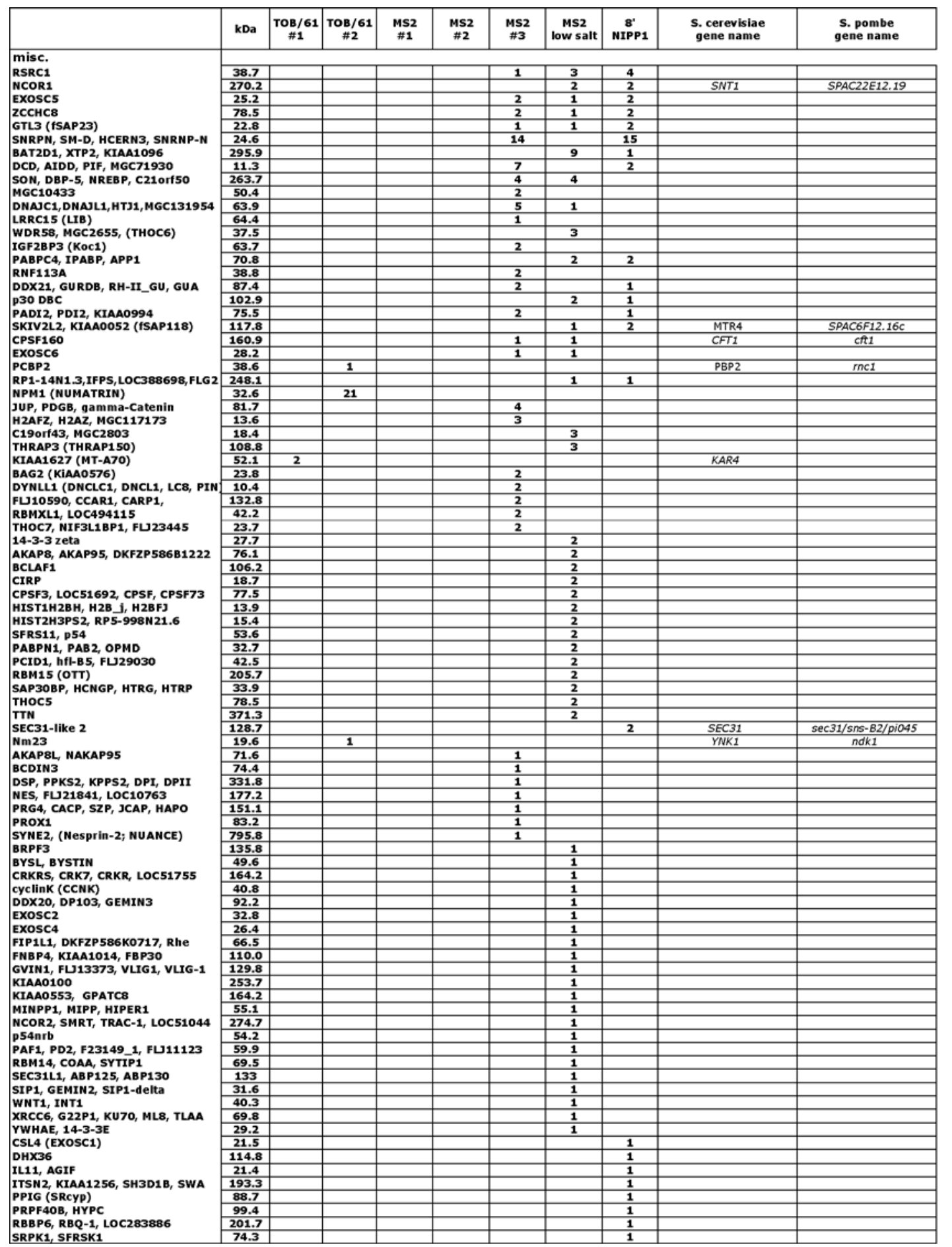

Table 5. Proteins detected by MS in only one preparation, and proteins not considered as bona fide B complex proteins but rather contaminants. Column designations and abbreviations a re as described in the notes to Table 4.

Strikingly, over 50 non-snRNP proteins not previously detected in the A complex were also found, suggesting that they are first recruited at the time of B complex formation. These include, among others, two proteins, namely hSnu23 and hPp 38, whose yeast homologues a re known as stable components of the U4/U6.U5 tri-snRNP in yeast $(139,166)$ (gold). Surprisingly, there are no apparent Snu23 and Prp38 homologues in the human 
tri-snRNP. Prp38 has been first identified in yeast as an essential splic ing factor necessary for the maintenance of stable U6 snRNA levels (13). Later, its requirement as an integral yeast tri-snRNP specific protein for conformational changes leading to catalytic activation of the spliceosome (namely U4/U6 snRNA intermolecular helix unwinding and U4 snRNA release) was shown (166). In addition, we also detected the human homologue of yeast Spp382p, namely TFIP11, whose yeast counterpart was shown to be associated with spliceosomes by a number of independent methods, as there are (i) a ffinity purifications followed by MS, (ii) yeast two hybrid analysis, (iii) fluorescence microscopy and (iv) in silico structure prediction (57). It was also demonstrated that Spp382p, like Spp381p (87), is a suppressor of Prp38-1. Human TFIP11 was first identified as a potential splicing factor by proteomic studies (170) before in vivo data from the Paine laboratory showed for the first time that TFIP11 is a novel splicing factor (162).

We also detected subunits of the newly identified RES (retention and splic ing) complex $(43,121)$ (sea green). This trimeric complex consisting of Bud13p, Pml1p and Snu17p, was shown to be required for efficient splicing and the retention of pre-mRNA in the yeast nucleus. Surprisingly, the RES complex is not associated with any snRNP, but rather associates with the spliceosome before step 1. In our complexes we detected the human homologues, namely MGC13125, Snip 1 and CGI-79. These findings provide the first indic ation that, like components of the yeast RES complex, they are involved in splicing and might act prior to the first catalytic step of splic ing.

Similarly, all components of the $14 \mathrm{~S}$ hPp19/CDC5 complex and a group of 10 hPrp19/CDC5 related proteins were detected in our complexes (red). The heteromeric 14ShPrp19/CDC5 complex, together with the loosely bound proteins Npw38BP and Npw38, is required just prior to the first step of splicing but dispensable for stable integration of U4/U6.U5 tri-snRNP into the spliceosome (91). Members of the 10 hPrp19/CDC5 related proteins were shown to physically or genetic ally associate with the hPrp19/CDC 5 core complex or the respective yeast counterparts $(2,26,107)$.

In addition to all these proteins, we also found a number of non-snRNP factors designated here $B / B^{*}$ (dark yellow). Among others we detected phosphatases, peptidyl-prolylisomerases, RNA binding proteins, ATP dependent RNA helicases, kinases and regulators of phosphatases. Most of these proteins were shown to be associated with splic ing before, either by MS analysis of other spliceosomal complexes, yeast two hybrid assays or coimmunoprecipitation studies. However, further studies a re needed to determine the exact role of these proteins in pre-mRNA splic ing.

Nevertheless, all these proteins are recruited prior to spliceosome activation and thus potentially play a role in the transition from the B complex to the catalytic ally activated $\mathrm{B}^{*}$ complex. 
Equally important, several proteins known to act during the first or second step of splic ing such as Abstrakt, DBPA, hsp70, KIAA0073, PPlase-like 3b, GCIP p29, DDX35, cactin, Q9BRR8, hPrp16, hPrp18 and hPrp22 as well as most components of the exon junction complex such as MLN51, Magoh, Pinin, RNPS1, SAP18 or Aly/Bef were either not detected in our B complexes or were highly underrepresented. Thus, they are likely recruited at a later stage of assembly.

Table 5 lists proteins which are not considered as candidates for bona fide B complex components. They were either detected only once, with a very low peptide score or unrelated to pre-mRNA splicing and therefore considered as contaminants.

Taken together, our studies thus provide novel insights into the composition of the spliceosome just prior to its ca talytic activation (see discussion).

\subsubsection{MS2 affinity-selection of spliceosomal B complex under low salt conditions}

As mentioned, B complexes isolated under $150 \mathrm{mM}$ salt conditions did not catalyze splicing when incubated under splicing conditions in the absence of HeLa cell nuclear extract. Since we did not assay activation itself, either by Northem Blot analysis or gel mobility shift assays with native gels, we cannot rule out that our purified precatalytic B complexes underwent activation. However it was clear that the complexes were unable to perform the first and second step of splicing. An explanation would be that these purified complexes lack one or more factors required for spliceosome activation and/or catalysis or - altematively - contain a full protein complement but some functionally important posttranslational protein modific a tions are missing.

Thus in the next experiments we purified precatalytic splic eosomal B complex principally as before but under low salt conditions (67 mM NaCl instead of $150 \mathrm{mM}$ ) to test whether essential activation factors or 1st/2nd step proteins were possibly stripped off the spliceosome under the previous $150 \mathrm{mM}$ salt conditions.

As expected, the migration behaviour of the B complex changed. After centrifugation in SW60 gradients, the B complex particle peak was shifted two gradient fractions towards the bottom of the linear 10 - $30 \%$ glycerol gra dient. Thus, material in gradient fractions 16 and 17 was used for the MS2 affinity selection steps whereas at $150 \mathrm{mM}$ salt conditions B complexes peaked in fractions 14 and 15 under these conditions. The purification procedure was monitored as before by analyzing the RNA at each step. The eluate conta ined equimolar amounts of uncleaved pre-mRNA, U1, U2, U4, U5 and U6 snRNA (Fig. 15 , lane 19), confirming that the vast majority of complexes present are precatalytic $B$ complexes and have not undergone catalytic activation. Only minute amounts of highmolecular-weight RNA were also visible on the gel. Aside from unspliced pre-mRNA, only 
faint a mounts of the intron-lariat intermediate, but no splic ing products were detected in the eluate, as evidenced by autoradiography (lane 37). These data confim that essentially pure precatalytic spliceosomal complexes had been isolated.

A

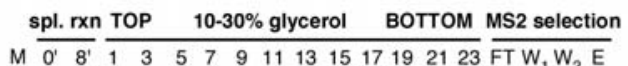

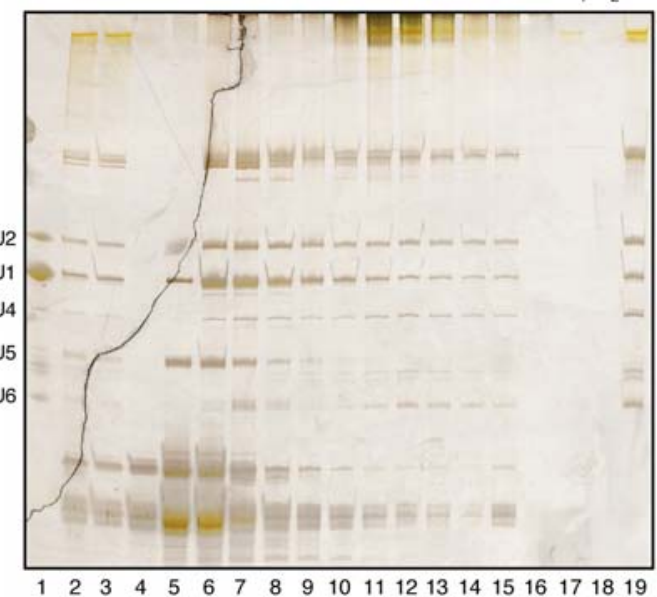

B spl. rxn TOP $\quad 10-30 \%$ glycerol BOTTOM MS2 selection

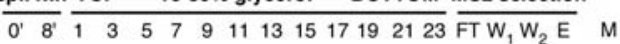

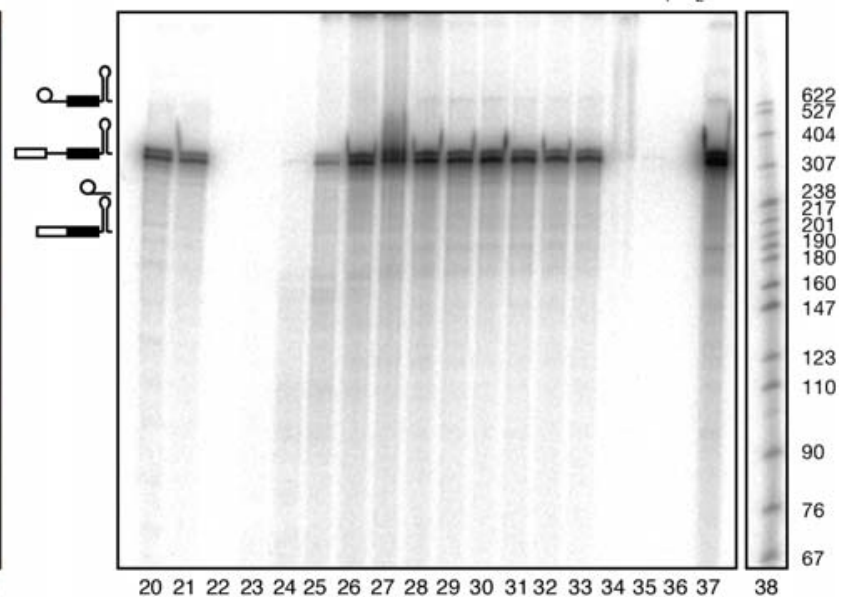

Fig. 15. Characterization of MS2 affinity-selected B complexes isolated under low salt conditions. (A) RNA was recovered from distinct steps during the purific ation procedure, separated on an $8.3 \mathrm{M}$ urea-9.6 \% polyacrylamide gel and visualized by staining with silver. Lane 1: $2 \mu$ of RNA extracted from total $\mathrm{H} 20$ antibody eluate at $250 \mathrm{mM}$ salt; lanes 2 - 3: $1 / 720$ vol. of the splicing reaction mix incubated for 0 and 8 minutes; lanes 4 - 15: 1/21 vol. of odd $10-30 \%$ linear glycerol gradient fractions after centrifugation for $107 \mathrm{~min}$ at $374000 \times \mathrm{g}$ in a Sorvall TH660 rotor and subsequent fractionation from TOP to BOTTOM; lane 16: $1 / 42$ vol. flowthrough after binding of pooled $B$ complex peak gradient fractions to a mylose beads (NEB); lanes 17 - 18: $1 / 5$ vol. washes at the beginning and at the end of 25 column volumes of washing buffer; lane 19: RNA recovered from the last elution fraction after adding maltose to the amylose beads. The position of the snRNAs is indic ated on the left. (B) The ${ }^{32} \mathrm{P}-$ labeled pre-mRNA and splicing intermediates or products were detected by autoradiography. The positions of pre-mRNA, splicing intermediates or products are indicated on the left. The lengths (in base pairs) of a size marker ( 3 'endlabeled Mspl cleaved pBR322) (NEB) (lane 38) are indic ated on the right. Please note that that the precursor mRNA a ppears in a doublet due to incomplete restriction digest of the corresponding transcription template.

Similar to the experiments performed with the B complex isolated under $150 \mathrm{mM}$ salt conditions, we tested MS2 affinity-selected B complexes isolated under $67 \mathrm{mM}$ salt conditions for functional committment for activation and splicing catalysis. We first depleted splicing active HeLa nuclear extract of all endogenous snRNPs by treatment with Micrococcal nuclease (MN) and subsequently compared the splic ing activity of nontreated vs. MN treated extract (Figure 16). Both purified B complexes (B complex) (lanes 1 - 6) and naked, 32P-labeled MS2-tagged MINX pre-mRNA (MINX-M3 pre-mRNA) (lanes 7 - 12) catalyzed both steps of splicing in a wild-type nuclear extract (NX). In contrast, only the MS2-tagged pre-mRNA from purified B complexes (lanes 13 -18), but not naked MS2-tagged MINX pre-mRNA (lanes 19 - 24) underwent splicing in MN treated extract. 
Two interesting observations could be made. (i) It seems that both prec ursors as well as all splicing intermediates/products are stabilized in Micrococcal nuclease treated HeLa nuclear extract (lanes 13 - 24) compared to non-treated extract (lanes 1 - 12). (ii) Splic ing kinetics of purified B complex differ slightly to naked MINX pre-mRNA in non-treated extract. Splicing intermediates were first observed after 5 minutes when purified $B$ complex was incubated in non-treated nuclear extract (lane 2 ) whereas naked MINX premRNA underwent the first step of splicing only after 10 minutes of incubation under splicing conditions (lane 9).
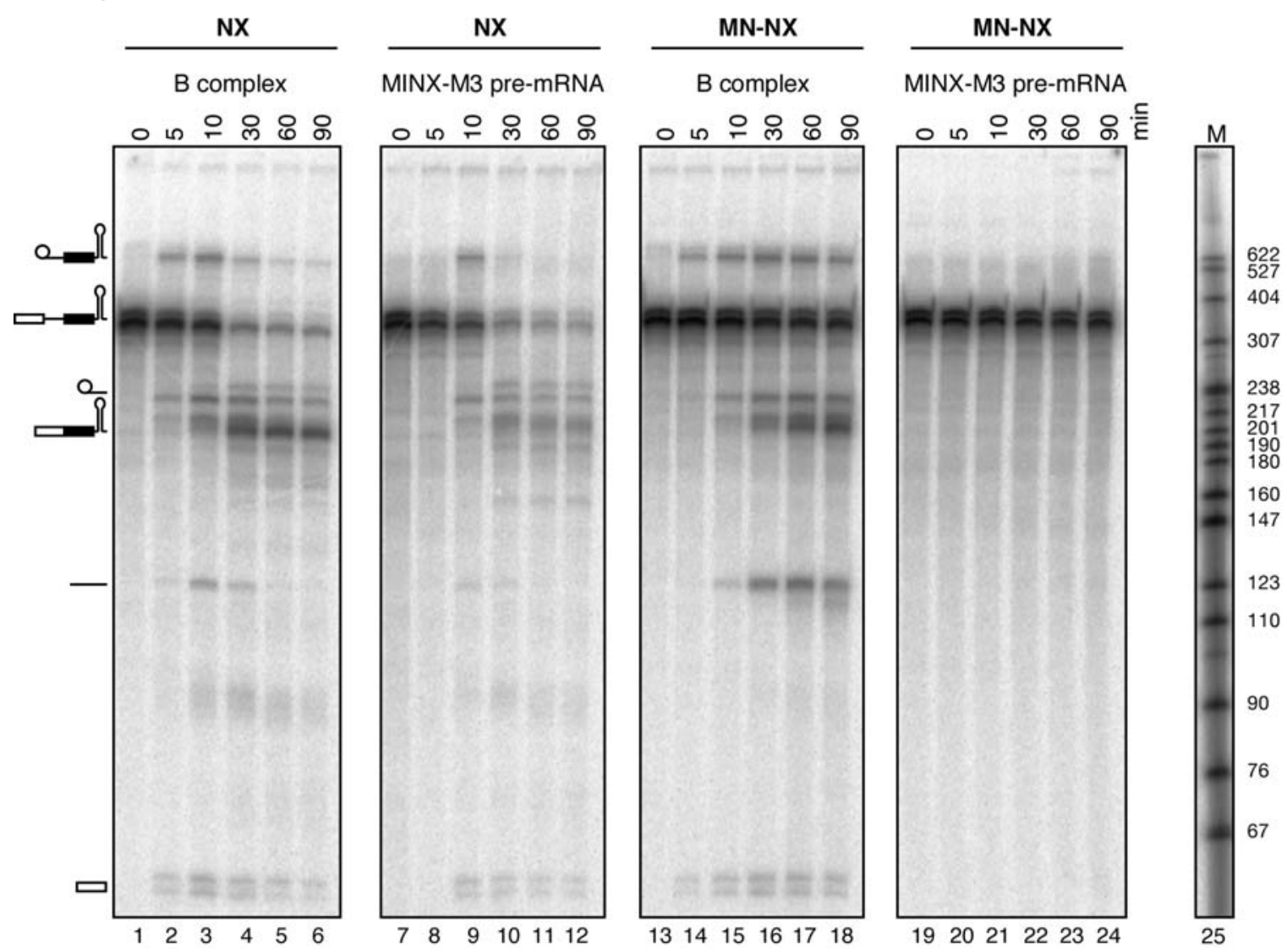

Fig. 16. MS2 affinity-selected spliceosomal B complexes punified under low salt conditions catalyze splicing in nuclear extracts depleted of snRNPs. MS2 affinity-selected splic eosomal B complex (B complex) (lanes 1 - 6) or naked 32P-labeled MS2-tagged MINX pre-mRNA (MINX-M3 pre-mRNA) (lanes 7 - 12) was inc ubated under splic ing conditions for the indicated times $(0-90 \mathrm{~min})$ in HeLa nuclear extract (NX) as a positive control. Altematively, MS2 affinity-selected spliceosomal B complex (lanes 13 - 18) or naked 32Plabeled MS2-tagged MINX pre-mRNA (lanes 19 - 24) was incubated for the indicated times $(0-90 \mathrm{~min})$ under splicing conditions in the presence of MN-treated HeLa nuclear extract (MN-NX). In each case, RNA was recovered and separated on an $8.3 \mathrm{M}$ urea-9.6\% polyacrylamide gel and visualized by autoradiography. The positions of the pre-mRNA, splicing intermediates or products are indicated on the left. The lengths (in base pairs) of a size marker ( $3^{\prime}$ end-labeled Msp I cleaved pBR322) (NEB) a re indic ated on the right.

Thus it appears that the long lag phase with the naked RNA is required for complex assembly and activation whereas in the case of the B complex the assembly already 
occured and the observed short lag phase is that required for activation and/or the first step of splicing.

To again rule out the possibility that the affinity-selected B complexes isolated under low salt conditions dissociate and new splic ing-active B complexes are formed, we performed splicing in MN-treated nuclear extract in the presence of an equimolar amount of Tobramycin RNA aptamer tagged MINX pre-mRNA (Figure 17). Affinity purified B complexes were able to catalyze both steps of splicing (lanes 1 - 6), although with reduced effic iency with respect to the sec ond step. Surprisingly, minor a mounts of naked, 32P-labeled Tobramyc in-tagged MINX pre-mRNA were also spliced. However, control

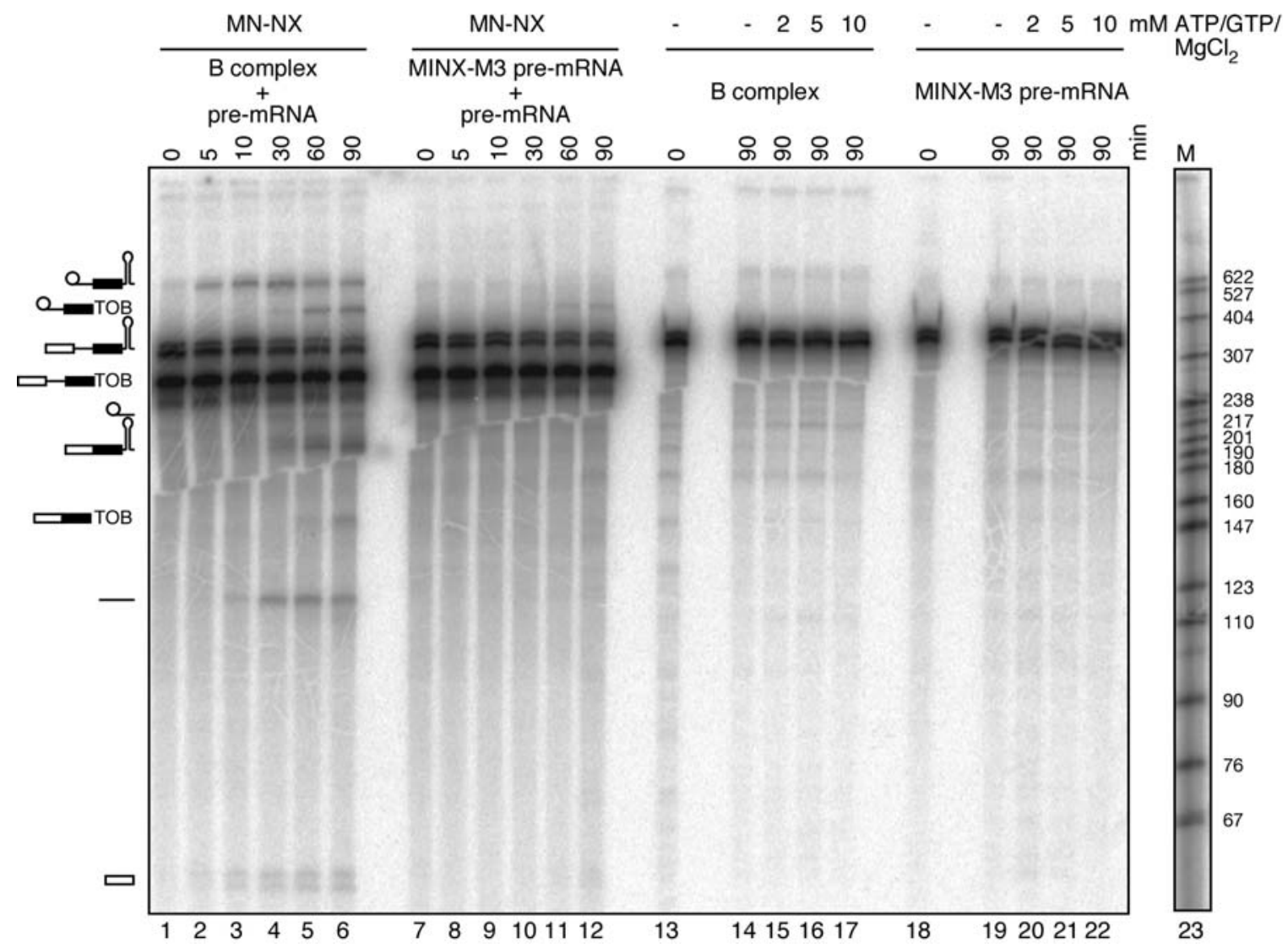

Fig. 17. MS2 affinity-selec ted spliceosomal B complexes are functionally committed for the subsequent steps of splicing but do not catalyze any splic ing step when incubated under splicing conditions in the absence of extract MS2 affinity selected spliceosomal B complex (B complex) (lanes 1- 6) or naked, 32P-labeled MS2-tagged MINX pre-mRNA (MINX-M3 pre-mRNA) (lanes 7 - 12) was incubated for 0 to 90 minutes (as indicated above each lane) under splicing conditions together with an equimolar amount of naked, 32P-labeled Tobramyc in tagged MINX pre-mRNA (pre-mRNA). Furthemore, MS2 affinity selected splic eosomal B complex (lanes 13 -17) or naked, 32P-labeled MS2-tagged MINX pre-mRNA (lanes 18 - 22) were inc ubated under splic ing conditions in the absence of HeLa nuclear extract supplemented with ATP, GTP and $\mathrm{MgCl}_{2}$ as indicated above each lane. In each case, RNA was recovered, separated on an $8.3 \mathrm{M}$ urea-9.6\% polyacrylamide gel and visualized by autoradiography. The positions of the pre-mRNAs, splicing intermediates and products are indicated on the left. The lengths (in base pairs) of a size marker ( $3^{\prime}$ end-labeled Mspl cleaved pBR322) (NEB) a re indicated on the right. 
experiments revealed residual splicing activity in the MN treated HeLa nuclear extract (lanes 7 - 12). This low background activity, however, cannot account for the observed splicing of MS2-tagged MINX pre-mRNA within purified B complexes. In these reactions, neither naked, ${ }^{32} \mathrm{P}$-labeled MS2-tagged MINX pre-mRNA (MINX-M3 pre-mRNA) nor naked, 32P-labeled Tobramycin-tagged MINX pre-mRNA (pre-mRNA) were able to catalyze both steps of splic ing efficiently (lanes 7 - 12). After one hour of incubation, only faint amounts of Tobramycin tagged intron-lanat exon 2 were observed. We speculate that there is some residual amount of splic ing step I activity in the MN treated nuclear extract. Why, however, only minute amounts of Tobramycin-tagged and not MS2-tagged MINX premRNA undergo the first step of splicing, cannot be explained and remains to be determined. Please note that the specific activity of naked Tobramyc in-tagged MINX premRNA is more than twice as high as the one of MS2-tagged MINX pre-mRNA.

Since the equimolar amount of "competitor" Tobramycin-tagged pre-mRNA was only spliced with slowed kinetic s and only to a minor extend, we conclude that splic ing-active B complexes are not formed de novo to an extend comparable to untreated nuclear extract. The fact that Tobramycin RNA aptamer tagged MINX pre-mRNA undergoes splicing more efficiently in the presence of purified $B$ complexes might indicate that factors are liberated from the complex that allow for Tobramycin tagged MINX pre-mRNA splicing. Maybe "low salt" B complexes drag more loosely associated splicing factors along, which then can enable competitor pre-mRNA to undergo splicing in MN treated nuclear extract.

Taken together, it appears that MS2 affinity-selected B complexes isolated under low salt conditions do not require complementation with any of the spliceosomal snRNPs for their activity but, rather, that they are functionally committed for the subsequent steps of splicing.

To finally test whether such B complexes are able to catalyze the first step of splicing without any further protein factor, we incubated MS2-affinity selected complexes from 0 to 90 minutes under splicing conditions, but in the absence of extract (Figure 17, lanes 13 22). We supplemented the reactions with increasing concentrations of $A T P, G \mathbb{P}$ and $\mathrm{MgCl}_{2}$. As is evident, affinity purified complexes did not undergo splic ing under any of the reaction conditions used.

We conclude that these purified particles appear to either lack one or more factors required for subsequent splic eosome activation and/or catalysis or potentially conta in a full protein complement but lack functionally important posttranslational protein modifications. Punfying precatalytic spliceosomal B complexes under low salt conditions does not allow for the isolation of a complex capable of catalyzing both steps of splicing without the necessity of factor complementation from nuclear extract. 


\subsubsection{MS of the MS2 selec ted B complex isolated under low salt conditions}

The shift of migration behaviour by two fractions towards the bottom of the linear glycerol gradient already indicates that more proteins are associated to the spliceosomal B complexpurified at $67 \mathrm{mM}$ salt conditions compared to $150 \mathrm{mM}$ salt conditions.

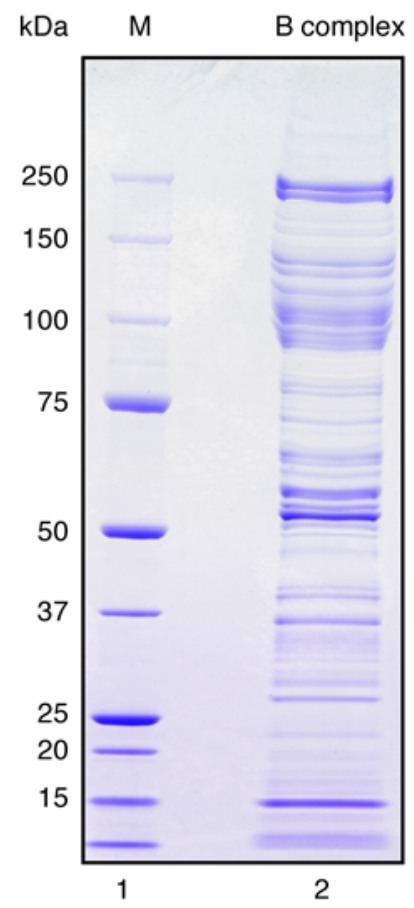

Fig. 18. Protein content of MS2 selected precatalytic spliceosomal B complexes isolated under low salt conditions. $4.9 \mathrm{pmol}$ (as judged by the activity of nucleic acid in the sample) of MS2 affinity purified B complexes (lane 2) were loaded onto a $1.5 \mathrm{~mm}$ thick precasted 4-12\% NuPAGE Bis-Tris gel (INVITROGEN) and subsequently stained with Coomassie. The molecular weights of protein standards from BIORAD (lane 1) are indic ated on the left in $\mathrm{kDa}$.

Thus, we subsequently analyzed the protein content of precatalytic spliceosomal B complexes isolated under low salt conditions, at $67 \mathrm{mM}$ salt, respectively, by denaturing PAGE using $1.5 \mathrm{~mm}$ thick precasted NuPAGE 4 - 12 \% Bis-Tris gels from INVITRO GEN. Figure 18 shows the proteins as visualized by Coomassie staining. Proteins were identified by liquid chromatography-tandem MS in the Bioanalytical Mass Spectrometry Group of Dr. Henning Urlaub. As listed in Tables 4 and 5 (MS2 low salt) we detected essentially all proteins present in B complexes isolated under $150 \mathrm{mM}$ sa lt conditions. In a ddition, we also found some members of the EJC complex, such as Acinus, Aly/Bef, UAP56 and DDX3, members of the TREX complex, namely THOC $1, T H O C 2$ and $\mathrm{THOC} 3$, and more than 35 proteins mostly undetected in standard B complex purifications with very low absolute peptide numbers indicating that they are underrepresented (Table 5, MS2 low salt). The TREX (transcription/export) complex is recruited by the splic ing machinery in ma mma ls (95, 
111) whereas in yeast it is rec ruited by the transc niption ma chinery (140). Its core consists of THOC 1, THOC2, THOC3, UAP56 and Aly/Bef.

These findings implicate that members of the EJC or TREX complex together with various other factors are specifically associated with spliceosomes under low salt conditions or, altema tively, they bind unspecific ally. It is currently not known to which extend individual factors of these groups of proteins are required for activation and/or catalysis, or whether they are nonspecific contaminants. 


\subsection{Punification of B complexes by tobramycin affinity selection coupled with immunoaffinity punification}

\subsubsection{Tobramyc in affinity selec tion of spliceosomal B complexes}

We wanted to isolate the $\mathrm{B}$ complex by an altemative but independent procedure so that we could gain confidence in its protein composition. In principle, a number of techniques exist to specifically select for snRNP or spliceosomal complexes (see introduction).

We extended our previously described Tobramycin RNA aptamer affinity selection procedure (56) to isolate bona fide precatalytic B complexes. We modified and extended the procedure in such a way that we were able to purify precatalytic $B$ complexes under mild conditions. This new procedure combines the established tobramycin affinity-selection procedure with an immunoaffinity selection step using the antibody directed against the particle specific protein, namely the 61kDa (hPp31) protein. The overall purific ation strategy is shown schematic ally in Figure 19.

Pre-mRNA tagged with the tobramyc in RNA aptamer was bound to a tobramycin matrix (step I). Spliceosomal complexes were then allowed to form for $60 \mathrm{~min}$ by incubating under splicing conditions in the presence of nuclear extract (step II). Since the kinetics of the solid phase splicing reaction are much slower than that observed in solution, only a very low level of splicing intermediates (but no products) appear first after 60 min (56). Thus, at most precatalytic spliceosomal complexes can have formed at this time point. After elution of spliceosomal complexes with an excess of tobramycin (step III), B complexes were punified from this mixture by immunoaffinity selection using an antipeptide antibody raised against the $61 \mathrm{~K}(\mathrm{hPp} 31$ ) protein (step IV). This U4/U6 specific protein is present in the $25 \mathrm{~S}$ U4/U6.U5 tri-snRNP. As such it should first be found associated with B complexes. It bridges the di-snRNP and U5 snRNP by specific interaction with the U5 snRNP specific 102K (hPrp6) protein (89) and therefore associates with the spliceosome first at the time of $B$ complex formation and should not be present in the A complex and the activated $\mathrm{B}^{*}$ complex.

In the following chapters, the individual steps leading to that overall purification strategy are described in detail. 


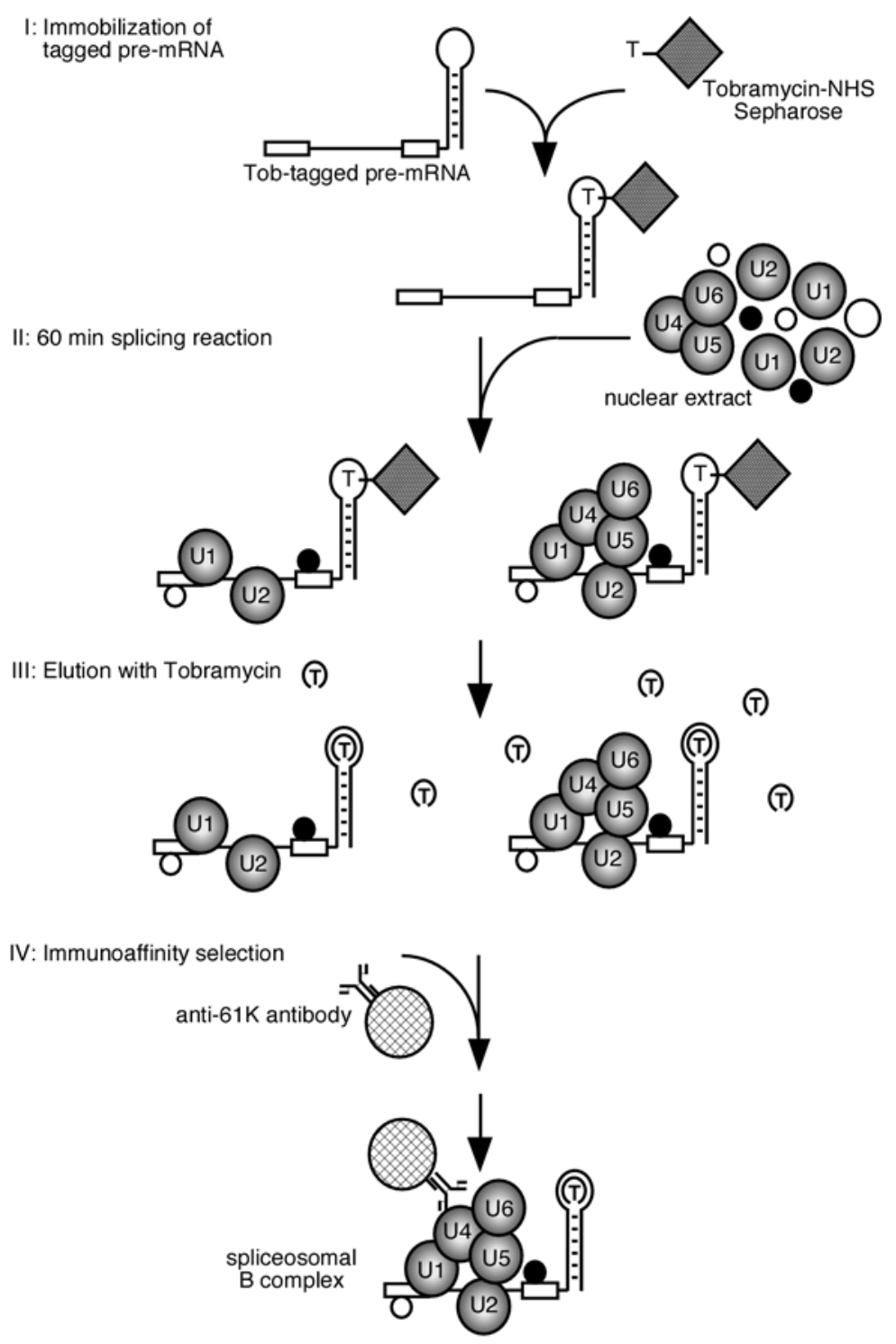

V: Elution with cognate peptide
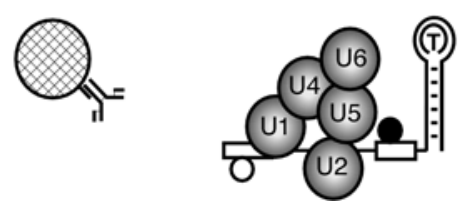

Fig. 19. Schematic diagram of the two-step purification strategy of B complexes using tobramycin affinity selection coupled with anti-61K immunoaffinity purfication. Pre-mRNA tagged at its 3' end with the tobramyc in RNA aptamer was bound to a tobramyc in matrix (step I). Spliceosomal complexes were allowed to form for 60 min by incubating under splicing conditions in the presence of nuclear extract (step II). After elution with tobramycin (step III), precatalytic spliceosomal B complexes were isolated by immunoaffinity selection using anti-peptide antibodies directed against the U4/U6-61K (hPrp31) protein (step IV). Spliceosomal B complexes were subsequently eluted with cognate peptide (step V). The scheme is published in Deckert et al., 2006 (36). 


\subsubsection{Kinetics of solid phase in vitro splicing reactions using Tobramycin- tagged MINX pre-mRNA as a substrate}

Previously, human spliceosomal A complexes were isolated after incubating matrix bound Tobramyc in tagged MINX pre-mRNA for $45 \mathrm{~min}$ in HeLa cell nuclear extract under splicing conditions. It was shown that at this time point predominantly $E$ and $A$ complexes were formed (56). Since the kinetics of solid phase splicing is significantly reduced in comparison to reactions in solution, we first determined the required incubation time to obta in B complexes in the system. To this end we incubated Tobramycin tagged MINX pre-mRNA bound to matrix from 0 to $180 \mathrm{~min}$ under splicing conditions and recovered RNA aliquots at indicated time points (see Figure 20). This allowed us to determine a suitable time of incubation to obta in precatalytic spliceosomal B complexes minimizing the amount of contaminating splic eosomal complexes such as $\mathrm{B}^{*}$ or $\mathrm{C}$.

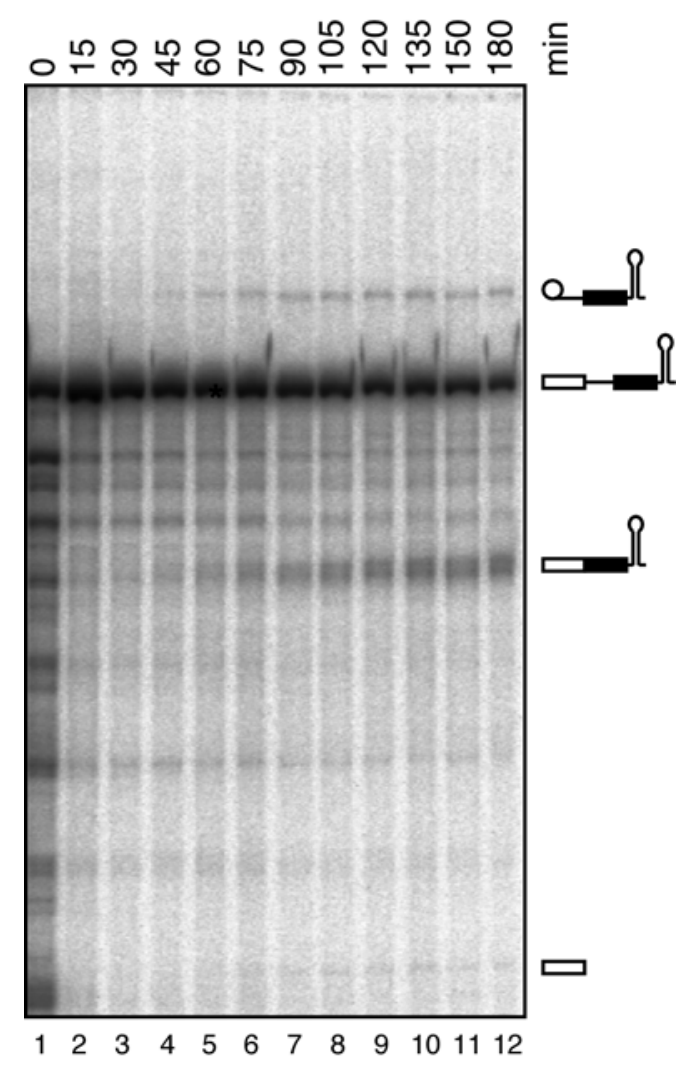

Fig. 20. In vitro solid phase splicing kinetics of 32P-labeled Tobramycin-tagged MINX premRNA. Solid phase splicing was performed in HeLa cell nuclear extract for 0 to $180 \mathrm{~min}$ (lanes 1 - 12) as indicated above each lane using Tobramycin-tagged MINX pre-mRNA. At the indic ated time points, aliquots of the reaction mix were removed and the RNA was eluted under native conditions with an excess of Tobramycin. RNA was recovered and separated on an $8.3 \mathrm{M}$ urea - $9.6 \%$ polyacryamide gel. The ${ }^{32} \mathrm{P}$-labeled pre-mRNA and splicing intermediates and products were detected by autoradiography, and their positions a re indic ated on the right. 
In agreement with previous data, matrix-bound MINX pre-mRNA is efficiently spliced. Splicing intermediates and products were observed first at $60 \mathrm{~min}$ and increased significantly till the 180 minute time point. We conclude that for the isolation of precatalytic spliceosomal B complexes, an incubation time of 60 minutes seems to be well suited. At that time a significant amount of B complexes is assembled together with presplic eosomes whereas only minor a mounts of splic ing ac tive spliceosomes a re formed, reducing the possibility of copurifying contaminating splic eosomal complexes.

To punify the precatalytic B complex from the mixture of predominantly $A$ and $B$ complexes in the eluate of the tobramycin affinity selection step we performed a second selection step. We now prepared anti-61kDa (hPrp31) peptide antibodies.

\subsubsection{Immunoaffinity purified anti-61kDa (hPrp31) antibodies specifically detect 61kDa (hPp31) protein in Westem Blots}

To verify that the peptide antibodies raised against a C-terminal peptide specifically detected the $61 \mathrm{kDa}$ (hPrp31) protein, we first ensured that affinity-purified anti-61kDa (hPrp31) antibodies detected the target protein on immunoblots without crossreactions. Subsequently we tested several batches of antisera in pulldown experiments using in vitro translated target protein. We also tested whether antibodies could be used to isolate U4/U6.U5 tri-snRNP particles out of HeLa cell nuclear extract before we finally established conditions to purify precatalytic $B$ complexes from a mix of predominantly $A$ and $B$ complexes in the eluate after a tobramycin affinity selection procedure as proposed above.

Proteins of HeLa cell nuclear extract were separated by $10 \%$ SDS-PAGE and blotted onto

a membrane. Subsequently, we monitored several fractions during the anti-61kDa (hPrp31) antibody affinity purification procedure by Westem-blotting (Figure 21). Immunosta ining results for crude 61kDa (hPrp31) rabbit antiserum (la ne 1), the flowthrough after binding of the antibodies to the antigenic peptide coupled to a matrix (lane 2), affinity-purified, dialyzed anti-61kDa (hPrp31) antibody (lane 3) and affinity-purified anti$61 \mathrm{kDa}$ (hPrp31) antibody previously used to isolate B $\Delta \mathrm{U1}$ complex (lane 4) (91) a re shown. As shown in Figure 21, affinity purified anti-61kDa (hPrp31) antibodies specifically recognized the respective target protein (lanes 3 and 4). The flowthrough after binding did not contain any anti-61kDa (hPrp31) antibodies (lane 2) indicating that all specific antibodies bound to the matrix coupled with antigenic peptide. We conclude that immunoaffinity purified anti-61kDa (hPp31) antibodies potentially can be used for immunoaffinity purifications. Since an antibody which recognizes a cognate denatured target protein on a Westem blot is not necessarily suited for immunoprecipitation studies 
where the native protein has to be recognized, we performed additional experiments to test the applicability of immunopunified antibodies to isola te spliceosomal B complexes.

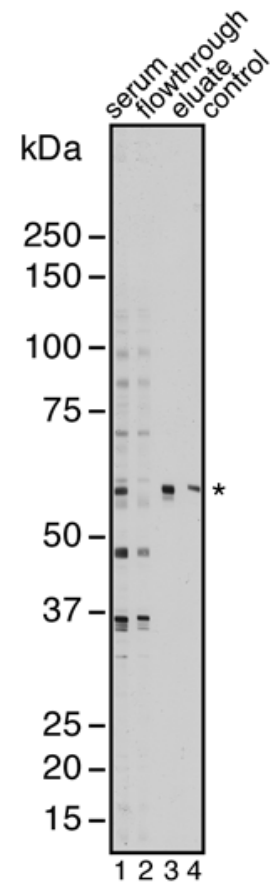

Fig. 21. Immunodetection of 61kDa (hPrp31) protein. Proteins of HeLa nuclear extract were separated by $10 \%$ SDS-PAGE, blotted onto a membrane and immunostained with crude 61kDa (hPrp31) antisenum (lane 1, 1:1000 dilution), the flowthrough after binding of the antibodies to the antigenic peptide coupled to a matrix (lane 2, 1:1000 dilution) or highly concentrated affinity-purified anti-61kDa (hPrp31) antibody (la ne 3, 1:2000 dilution). Lane 4: positive control (1:2000 dilution). The identity of proteins is indicated on the left. The $61 \mathrm{kDa}$ (hPrp31) protein is indicated by an asterisk.

\subsubsection{In vitro translated 61kDa (hPrp31) protein is specifically recognized by cognate affinity-purified antibodies}

As one means of testing the specificity of anti-61kDa (hPrp31) antibodies, we transcribed/translated the target protein's CDNA using the TNT coupled retic uloc yte lysate system from Promega. The most prominent translation product in the presence of $61 \mathrm{kDa}$ (hPrp31) cDNA had the expected size and was absent in the control reaction where addition of the respective cDNA was omitted (data not shown). We then used this native protein to assay a number of antisera containing polyclonal antibodies as well as monoc lonal a nti-61kDa (hPrp31) antibodies from rabbit Asc ites fluid for recognition of the native protein (Figure 22). For this purpose we coupled antibodies to beads and asked whether native, recombinant GST-tagged 61kDa (hPrp31) protein purified from E. coli (panel A) or in vitro translated [35S]methionine labeled 61kDa (hPp31) protein (panel B) is co-immunoprecipitated. All antibodies used were positive in Westem Blots. Bound material was either complemented with in vitro translated 61kDa (hPrp31) protein (panel B) or recombinant GST-tagged 61kDa (hPrp31) protein purified from E. coli (panel A). Bound 
material was eluted with SDS, denatured and separated by $10 \%$ SDS-PAGE followed by detec tion with silver sta ining (panel A, lanes 1 - 11) or fluorography (panel B, la nes 12 - 22). As expected, corresponding pre-immune serum (NIS) neither immunoprecipitated purified, recombinant GST-tagged 61kDa protein (panel A, lane 3) nore in vitro translated $61 \mathrm{kDa}$ protein (panel B, lane 14). In addition, Figure 22 clearly demonstrates that neither PAS nore PGS beads alone immunoprecipitate target proteins (panel A, lanes $10-11$ and panel B, lanes 21 - 22).

A

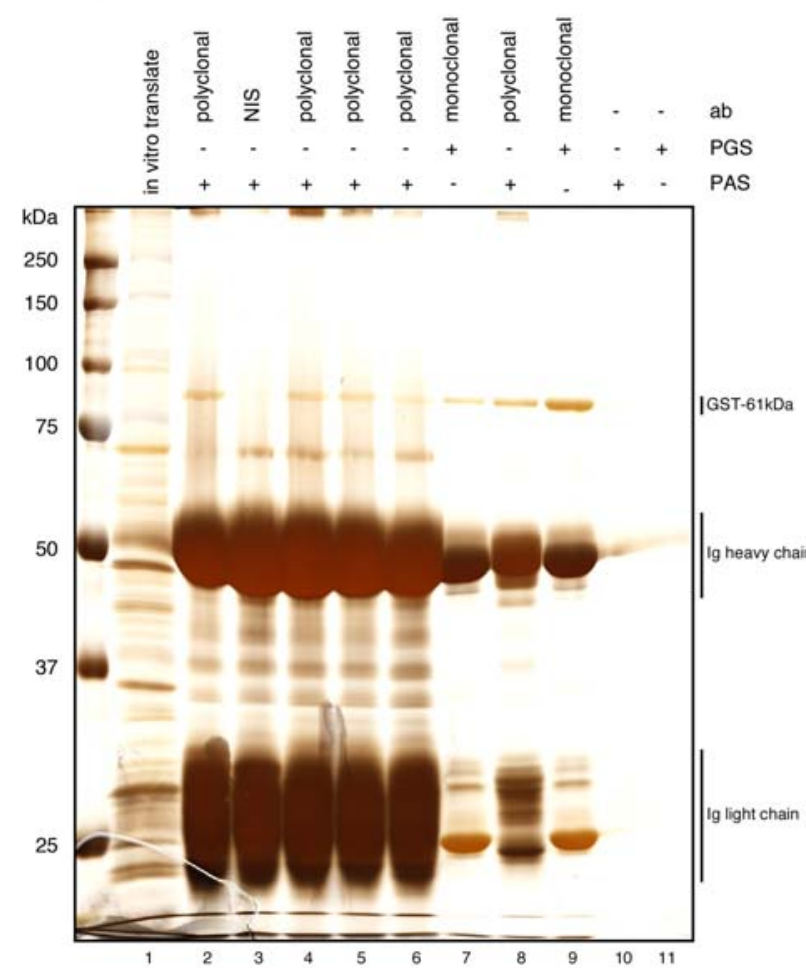

B
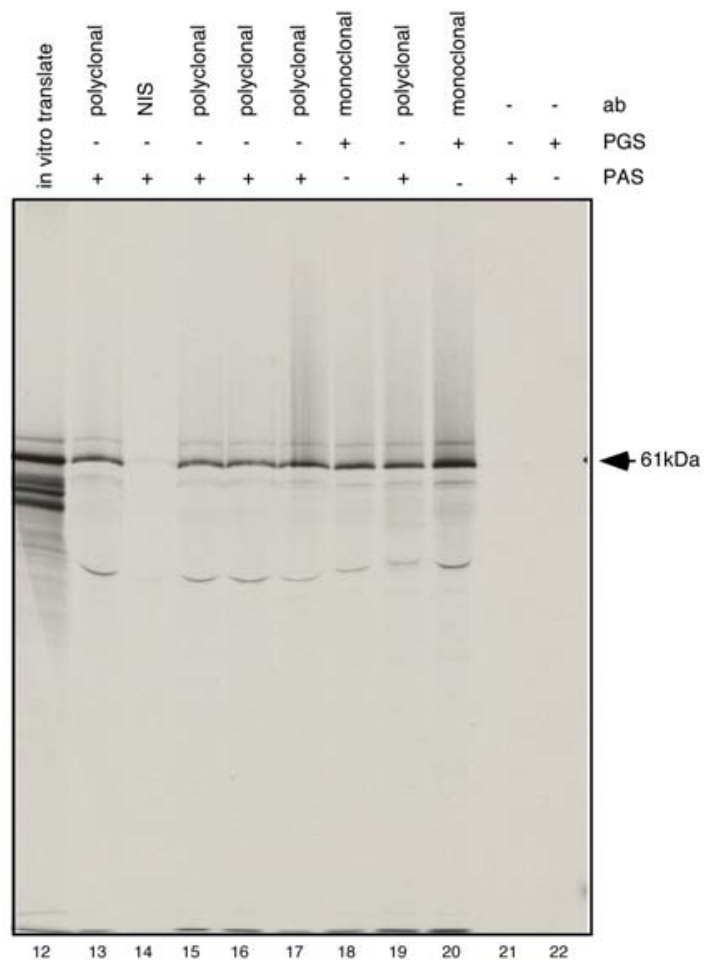

Fig. 22. Characterization of anti-61kDa (hPp31) sera. Following immunoaffinity selection, bound material was eluted with SDS, denatured and separated by $10 \%$ SDS-PAGE followed by detection with silver staining (panel A) or fluorography (panel B). Recombinant GST-tagged $61 \mathrm{kDa}$ protein was added to all reaction aliquots in panel A, whereas in vitro translated $61 \mathrm{kDa}$ protein was added to all reaction aliquots in panel $\mathrm{B}$. Lane 1 shows an aliquot of the in vitro translation reaction using the 61kDa (hPp31) protein CDNA as a template. Lane 2: IP using purified antibodies from polyclonal antiserum N11 (3rd bleeding). Lane 3: IP using non-specific pre-immune serum (NIS). Lanes 4 - 6: IP using purified antibodies from polyclonal antisera 4825 bleedings 8,7 or 12 . Lane 7: IP using Ascites fluid containing monoclonal antibodies N1 139B2F9. Lane 8: IP using purified antibodies from polyclonal antisenum N11.f 2016. Lane 9: IP using Ascites fluid containing monoclonal antibodies N1 139B2F9 in the presence of three times as much GST tagged $61 \mathrm{kDa}$ protein compared to all other lanes. Lanes 10 and 11 : mock immunoprecipitation performed in the absence of anti-61kDa (hPrp31) antibodies in the presence of PAS and PGS beads, respectively. Experiments in lanes $1-11$ were perfomed essentially as those in lanes 12 - 22, except that in vitro translated 61kDa (lanes 12 - 22) instead of recombinant GST-tagged 61kDa protein (lanes 1 - 11) was added to all reaction aliquots and analysis was by fluorography. The GST-tagged 61kDa protein was kindly provided by Dr. Stephanie Nottrott.

The positions of the recombinant GST-61kDa protein (ca. $90 \mathrm{kDa}$ ) and both the heavy and light Immunoglobulin chains are indicated with bars (panel A). The position of in vitro translated 61kDa protein is indic ated by an arrow (panel B). 
Most interestingly, all polyclonal antisera tested (panel A lanes 2, 4-6 and 8) and also rabbit Ascites fluid conta ining monoc lonal antibodies (panel A lanes 7 and 9) specifically immunoprecipitated recombinant GST-tagged $61 \mathrm{kDa}$ protein. Likewise, the same specificity was achieved with respect to recognition of in vitro translated 61kDa protein with a lmost identic al va ria tions (panel B).

Taken together, these data indic ate that based on immunoprecipitation studies of either GST-tagged recombinant $61 \mathrm{kDa}$ protein or in vitro translated $61 \mathrm{kDa}$ protein, all antisera containing polyclonal antibodies of va rious origin as well as rabbit Ascites fluid containing monoclonal anti-61kDa antibodies could be used to immunoprecipitate specifically precatalytic spliceosomal B complexes - containing the U4/U6 specific 61kDa (hPrp31) protein - of a mixture of predominantly $A$ and B complexes.

\subsubsection{Affinity punified anti-61kDa (hPrp31) antibodies efficiently precipitate U/ U6.U5 tri-snRNP from Hela nuclear extract}

To test whether the recognized epitopes are accessible in purified samples, we first assa yed for immunop recipitation of U4/U6.U5 tri-snRNP.

We immunoaffinity selected human U4/U6.U5 tri-snRNP from total snRNP fractions selected via a specific antibody from HeLa cell nuclear extract (18). To this end, H2O fractions highly enriched in total snRNPs (see Materials and Methods) were bound to anti-61kDa antibodies coupled to a matrix. After extensive washing, we specifically eluted target complexes under native conditions by adding excess of cognate peptide and subjected the eluted material to glycerol gradient centrifugation on a linear $10-30 \%(\mathrm{v} / \mathrm{v})$ glycerol density gradient. Proteins and RNA were recovered and analyzed by SDS-PAGE (Figure 23) or by denaturing PAGE on an $8.3 \mathrm{M}$ urea-9.6\% polya cryla mide gel, respectively.

The RNA composition of the gradient fractions revea led equimolar a mounts of U4/U6 and U5 snRNAs in fractions 15 to 19, nearly no U2 or U1 snRNA could be detected (data not shown). Protein analysis of the gradient fractions, shown in Figure 23, revealed that almost all 25 S tri-snRNP specific proteins comigrated in fractions 15 to 19 , in perfect agreement with the $U$ snRNA pattem. Proteins were assigned to known tri-snRNP proteins by comparison to previous experiments (7) and the molecular weight markers.

We conclude, that the $61 \mathrm{kDa}$ epitope is accessible by immunoaffinity purified antibodies in the human U4/U6.U5 tri-snRNP partic le. In addition, immunoaffinity selection followed by glycerol gradient centrifugation allowed for the effic ient purific ation of tri-snRNP partic les. We now used this procedure to specifically isolate native, precatalytic splic eosomal $B$ complexes from the mixture of E/A and B complexes obtained by tobramycin affinity selection. 


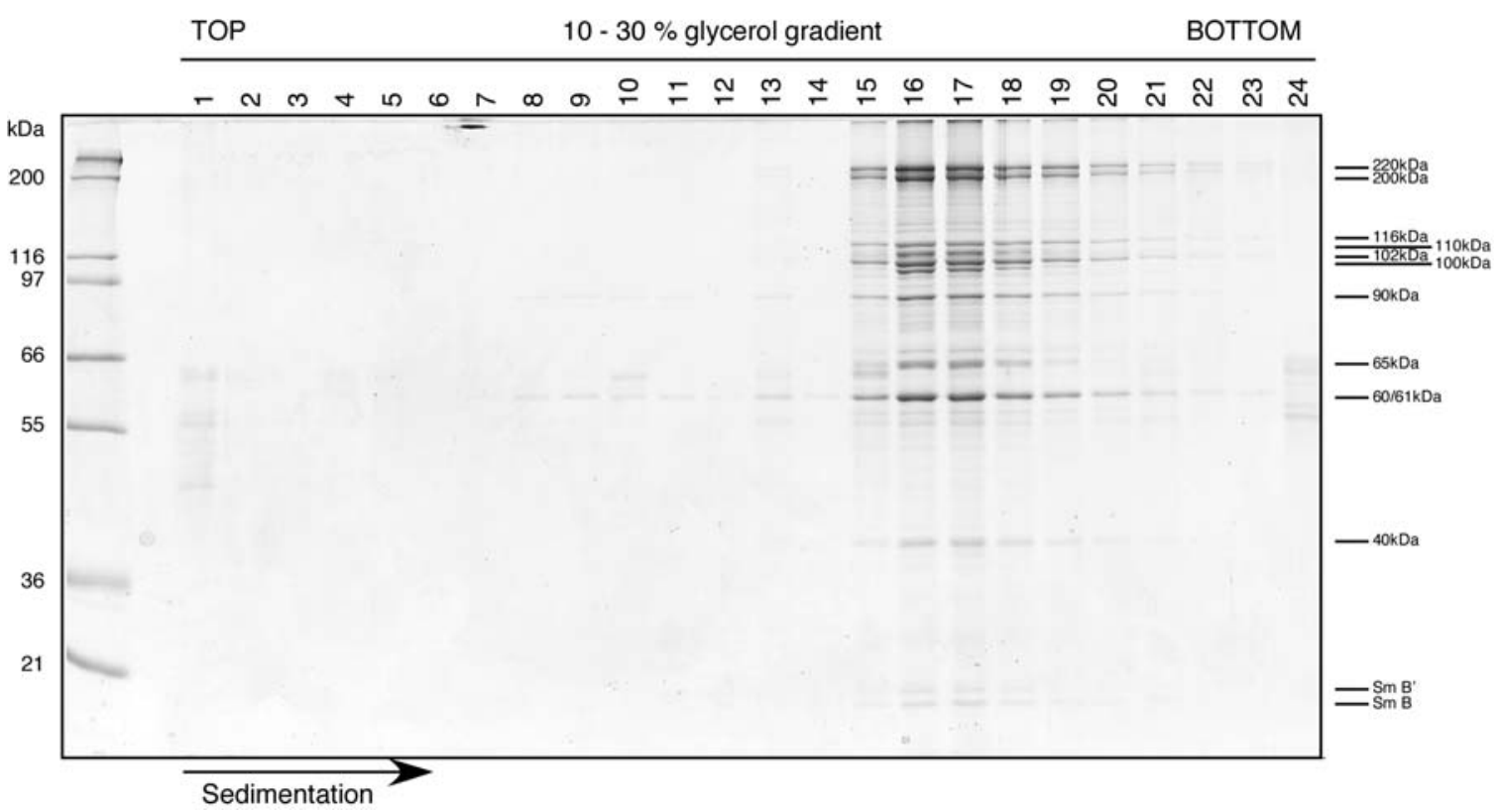

Fig. 23. Characterization of immunoaffinity punified human U//U6.U5 tri-snRNP particles followed by glycerol gradient centrifugation. The $61 \mathrm{kDa}$ immunoprecipitate from total snRNPs was subjected to glycerol gradient centrifugation. Coimmunoprecipitated proteins from each fraction were separated by $10 \%$ SDS-PAGE and visualized by Coomassie staining. The identity of the proteins is indic ated on the right. The positions of protein molecularweight standards are indic ated on the left.

\subsubsection{Tobramyc in affinity selection of splic eosomal B complex}

We finally combined the Tobramyc in affinity selection procedure with the immunoaffinity step using an anti-61kDa (hPrp31) antibody as outlined above for the 25S U4/U6.U5 trisnRNP. Purific ation was monitored by assaying of total RNA at each step by denaturing PAGE (Figure 24).

To this end, we first bound tobramyc in RNA aptamer tagged MINX pre-mRNA effic iently to tobramyc in derivatized Sepharose beads. The interaction was specific since $50-60 \%$ of aptamer-tagged pre-mRNA but less than $1.5 \%$ of untagged substrate bound to the matrix under the conditions used. As shown in Figure 19, HeLa cell nuclear extract was added and spliceosomes were allowed to form for 60 minutes. After extensive washing, complexes were eluted under native conditions with an excess of tobramyc in. Altogether, between 15 and $20 \%$ of activity with respect to the input was recovered. This material was loaded onto PAS beads bound with polyclonal anti-61kDa (hPrp31) antibodies, incubated for three hours at $4^{\circ} \mathrm{C}$, extensively washed and finally eluted under native conditions with excess of cognate peptide. Approximately $2.5 \%$ of the material added to the antibody column could be eluted.

The overall purification of precatalytic spliceosomal B complexes by tobramyc in affinityselection coupled with immunoaffinity selection was monitored by assaying the RNA content at each step by denaturing PAGE (Figure 24). 
A

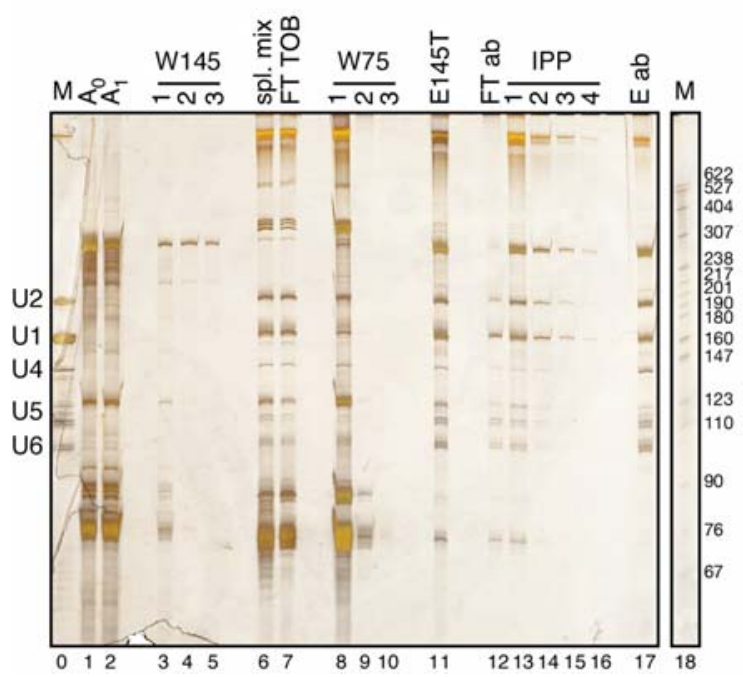

B

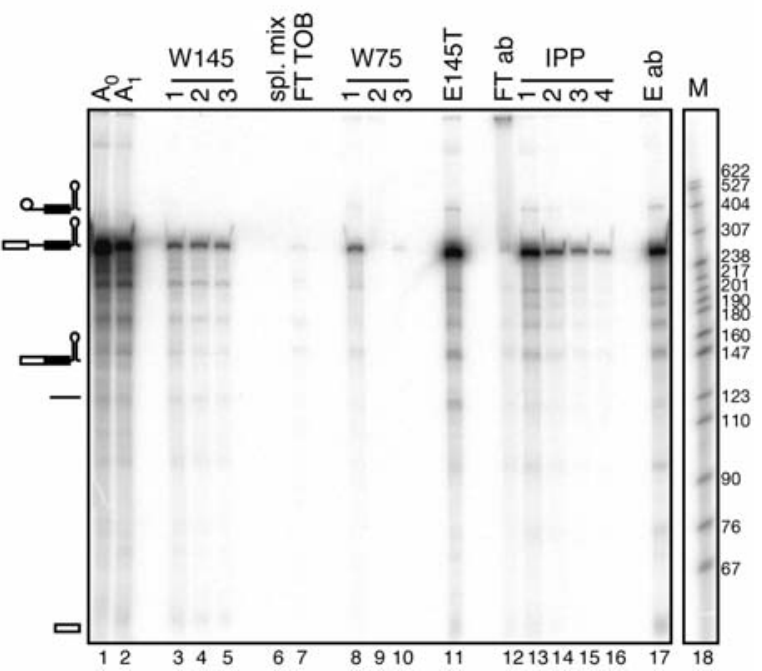

Fig. 24. Tobramyc in affinity selection of B complexes followed by immunoaffinity selection. RNA was recovered from distinct steps duning the purification procedure, separated on an $8.3 \mathrm{M}$ urea-9.6 \% polyacrylamide gel and visualized by staining with silver $(\mathrm{A})$ or by autoradiography (B). Lane 0: $2 \mu$ of RNA extracted from total $\mathrm{H} 20$ antibody eluate at 250 $\mathrm{mM}$ salt; lane 1: 1/500 vol. of RNA input mix $A_{0}$; lane $2: 1 / 500$ vol. of unbound RNA $A_{1}$; lanes $3-5$ : 1/250 vol. of W145 washes; lane6: 1/3600 vol. of splic ing mix; lane 7: 1/3600 vol. of flowthrough Tobramyc in beads; lanes 8 - 10: 1/ 250 vol. of W75 washes; lane 11: 1/250 vol. of Tobramyc in eluate (E145T); lane 12: 1/250 vol. of flowthrough -61kDa PAS beads; lanes 13 - 14: $1 / 60$ vol. of IPP washes before pooling reactions; lanes 15 - 16: $1 / 20$ vol. of IPP washes after pooling reactions; lane 17: $1 / 5$ vol. of $-61 \mathrm{kDa}$ eluate $(E \mathrm{ab})$. The position of the snRNAs is indicated on the left (A). The ${ }^{32}$ P-labeled pre-mRNA and splicing intermediates or products were detected by autoradiography (B). The positions of premRNA, splicing intermediates or products are indicated on the left. The lengths (in base pairs) of a size marker ( $3^{\prime}$ end-labeled Mspl cleaved pBR322) (NEB) (lane 18) are indicated on the right.

The eluate contained almost exclusively unspliced tobramycin-tagged pre-mRNA and only faint a mounts of lariat intermediate but no product (panel B, lane 17). As the $61 \mathrm{kDa}$ protein is first incorporated into the splic eosome as part of the U4/U6.U5 tri-snRNP into the $B$ complex, the eluate is therefore free of H/A complexes which do not conta in the U4/U661kDa (hPrp31) protein. Indeed, complexes in the eluate contained the full set of snRNAs in nearly stoic hiometric amounts, indicating that $B$ complexes had been isolated (panel A, lane 17). As with the MS2 approach, minor amounts of high-molecular-weight RNA were also visible on the gel. Thus, by all criteria, essentially only precatalytic spliceosomal $B$ complexes had been isolated.

In summary, our data demonstrate that by using a combination of tobramycin and immunoaffinity selection, highly pure human B complexes can be obtained and spec ific ally enric hed. 


\subsubsection{Mass spectromety of spliceosomal B complexes purified by tobramyc in affinity selection followed by immunoprecipitation}

Having thus a pure B complex preparation which should be independent from that obta ined by glycerol gradient centrifugation followed by MS2 affinity selection, we set out to detemine its proteome. To this end we fractionated two different B complex preparations of the Tobramyc in $/ 61 \mathrm{kDa}$ procedure by denaturing PAGE using $1.0 \mathrm{~mm}$ thick $10 \% 13 \%$ step SDS-polyacrylamide gels. The Coomassie-stained gels are shown in Figure 25.

A

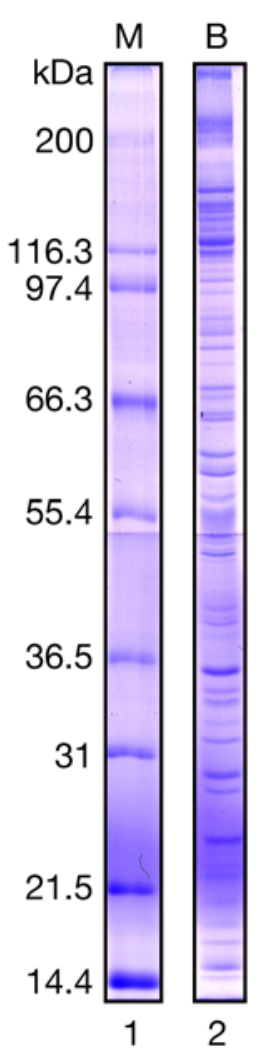

B

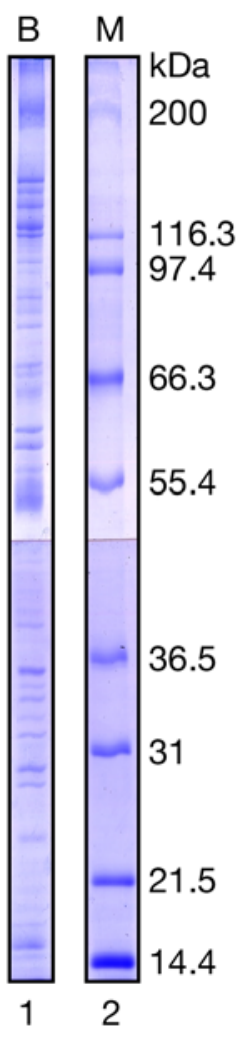

Fig. 25. Protein content of precatalytic spliceosomal B complexes purified via a combination of the Tobramycin affinity selection procedure coupled with an immunoaffinity step using anti-61kDa (hPp31) antibodies. $4.0 \mathrm{pmol}$ (panel A, lane 2) and $4.7 \mathrm{pmol}$ (panel B, lane 1) of Tobramycin affinity selected B complexes followed by immunoaffinity selection (B) were loaded onto $1.5 \mathrm{~mm}$ thick $10 \% 13 \%$ step SDSpolyac rylamide gels and subsequently stained with Coomassie. The molec ular weights of protein standards $(\mathrm{M})$ are indicated in $\mathrm{kDa}$.

Proteins were recovered from individual bands as well as from space between and the protein inventory was determined as before. Results are summarized next to all other proteomic results in Tables 4 and 5 (TOB/61 \#1 and $\mathrm{TOB} / 61$ \#2), including the number of total sets of peptides detected for each protein. Please note that in contrast to the protein analysis of B complexes purified by glycerol gradient centrifugation followed by 
maltose binding protein affinity chromatography where mostly precasted NuPAGE gel systems from Promega were used, we here applied standard Laemmli gels at least twice the size to separate proteins.

Visual comparison of the Coomassie stained protein pattems in Figure 25 shows that the isolation of B complexes by tobramycin affinity selection followed by immunoaffinity purific ation is highly reproduc ible.

Proteins detected by two or more independent peptide spectra in two or more purifications with either of the two purification approaches were considered to be associated with high specificity and affinity, they are shown in Table 4. Factors identified only once or proteins considered to be not bona fide B complex proteins are listed in Table 5. Attesting to the purity of our B complexes, most proteins however were detected in all B complex preparations and thus clearly represent B complex components. Furthemore, most of the factors identified only once appear to be present in very low amounts based on the absolute number of peptides for these proteins. Altogether we detected 140 proteins, 116 of which were found in both MS2- and tobramycin-affinityselected complexes.

We essentially identified the same proteins as with B complexes purified by glycerol gradient centrifugation followed by maltose binding protein affinity chromatography.

For example, we again detected numerous hnRNP and SR proteins (light turquoise) together with components of the cap binding complex (CBC) (lavender), which was shown to be involved in pre-mRNA splicing (63). SR proteins usually are involved in both constitutive and altemative splicing $(27,35,86,165,169)$, but also play important roles in other stages of RNA metabolism (60).

In addition to the canonical U1 snRNP specific proteins, we also detected two proteins, namely the FF and WW doma in containing FBP11 and RRM/PWI containing S164, whose yeast counterparts were shown to be associated with U1 snRNP (B. Seraphin, unpublished data) (light blue). Interestingly, these proteins a re not known to be stable components of human U1 snRNPs. However, data indic ated that interactions between SF1, FBP11 and U1 snRNP bridge the $5^{\prime}$ splice site and the branch region in the E complex $(1,110)$.

Other proteins which were identified only in $\mathrm{TOB} / 61 \mathrm{~K} \mathrm{~B} \mathrm{complexes}$ and absent in the MS2 B complexes include DNAJ C6, SRp20, SC 35, hTra-2 alpha, FL 10154, HSP70, MEP50, PRMT5 and Y14.

Vice versa, proteins CGI-79, RBM4, RBM7, NF45, hPrp2, PPIL4, hPrp17, NFAR, hnRNP A0, hnRNP $A / B$ or DDX3 were not found in TOB/61K complexes compared to particles prepared by the altemative strategy.

These differences in protein composition are likely due to differences in the two purification methods employed, which may lead to the loss of a specific set of proteins in each case. Altematively, as they were not observed in both affinity-selected B complex 
preparations, they might represent contamina nts. However, most of the proteins identified solely in the MS2 or tobramyc in affinity-selected B complexes have been shown previously (i) to participate in pre-mRNA splicing and/or (ii) to be associated with spliceosomal complexes, argueing that most a re bona fide splic eosomal proteins.

Taken together, MS a nalysis of B complexes purified either by MS2 or tobramyc in affinity selection revealed an almost identic al protein composition. This shows that any of our two approaches of purifying precatalytic B complexes yields highly purified precatalytic B complexes. 


\subsection{Punification of splic eosomes in the presence of NIPP1}

\subsubsection{Purification of spliceosomal intermediate complexes by dominant negative protein variants}

We previously purified precatalytic spliceosomal B complex after kinetic control of the splicing reactions. However, this a pproach is not fea sible for purific ation of later assembly stages due to the fast kinetics of activation and the two catalytic steps of splicing. Therefore, in a third series of experiments I tried to obta in stalled spliceosomes or stage specifically trapped spliceosomes by a complete different approach. This approach involved the exploitation of a dominant negative phenotype observed for the spliceosomal protein NIPP1 (negative inhibitor of protein phosphatase 1).

Other methods are also suited to purify a distinct population of splic eosomal complexes and to study the importants of certain factors or protein interactions necessary for premRNA splicing. For example, peptide inhibitors were used to block specific protein-protein interactions to investigate the role of this interaction during pre-mRNA splicing $(3,55)$, in addition, a nontoxic derivative of the small molecule rapamycin was used to control splicing (53). Furthemore, morpholino oligomers complementary to the branch-site recognition elements of U2 or U12 snRNA were applied to specifically suppress the respective spliceosomal machinery (97), whereas several small chemicals were successfully applied to manipulate the regulation of altemative splicing (101). Platinum analogs were shown to specifically block spliceosome assembly (122), boric acid can reversibly inhibit the second step of splicing (129) and a zinc chelating agent also stalls spliceosome assembly between catalytic step I and II (130). Another study showed that Indole derivatives can prevent the formation of splic eosomes at a very early stage (135). Also diospyrin derivatives added to HeLa cell nuclear extract prior to splic ing tumed out to be efficient means to stall splic eosome assembly and purify partic les (146).

Having established very mild conditions for the purification of large amounts of native spliceosomal complexes in a very concentrated form in solution allowed us to check the feasibility of trapping spliceosomes in an intermediate stage by adding dominant negative protein variants to nuclear extract prior to purification of complexes. The resulting complex could then be purified under the exact same mild conditions. Preliminary experiments from other labs, in particular from the Bollen lab at the University of Leuven in Belgium, indicated that a negative regulator of a phosphatase might be a potential candidate to test this possibility in vitro. The protein of interest was NIPP1, whose domain structure is sc hematic ally shown in figure 26.

Experiments in vitro suggested that NIPP1 isolated from bovine thymus gets i.e., phosphorylated by protein kinase A (PKA) both on Serines 178 and 199 as well as on Threonine residue 161 and Serine residue 204 by protein kinase CK2 (157). Data implied 
that phosphorylation decreases the inhibitory potency of free NIPP1 due to a decrease in the affinity to Protein phosphatase 1 (PPP1CA), thereby preventing reassociation of PPP1CA with NIPP1 $(11,151)$ following dissociation. PPP1CA is one of the major serine/threonine-specific protein phosphatases of eukaryotic cells.

Later it was shown that NIPP1 shows a speckled nucleopla smic distribution and colocalizes with pre-mRNA splicing factors, such as Sm proteins, U1A, U2AF65 and SR proteins (150) as well as CDC5 (20). Furthermore, nuc lear extracts depleted of NIPP1 reveal decreased premRNA splic ing activity in vitro compared to a control (150). Another hint that NIPP1 might be involved in pre-mRNA splicing stemmed from the finding that the Forkhead-associated (FHA) protein interaction domain interacts with the hPrp19/CDC5 complex component CDC5 (20), and only if CDC5 was phosphorylated, and with a TP dipeptide-rich, phosphorylated fragment of U2 SF3b 155 kDa (21). More specifically, both U2 SF3b 155 kDa and CDC5 compete for the same binding site (21). In addition, NIPP1 interacts with the protein Ser/Thr kinase MELK (matemal embryonic leuc ine zipper kinase), a potent inhibitor

PKA phosphorylation site $\quad$ P CK2 phosphorylation site

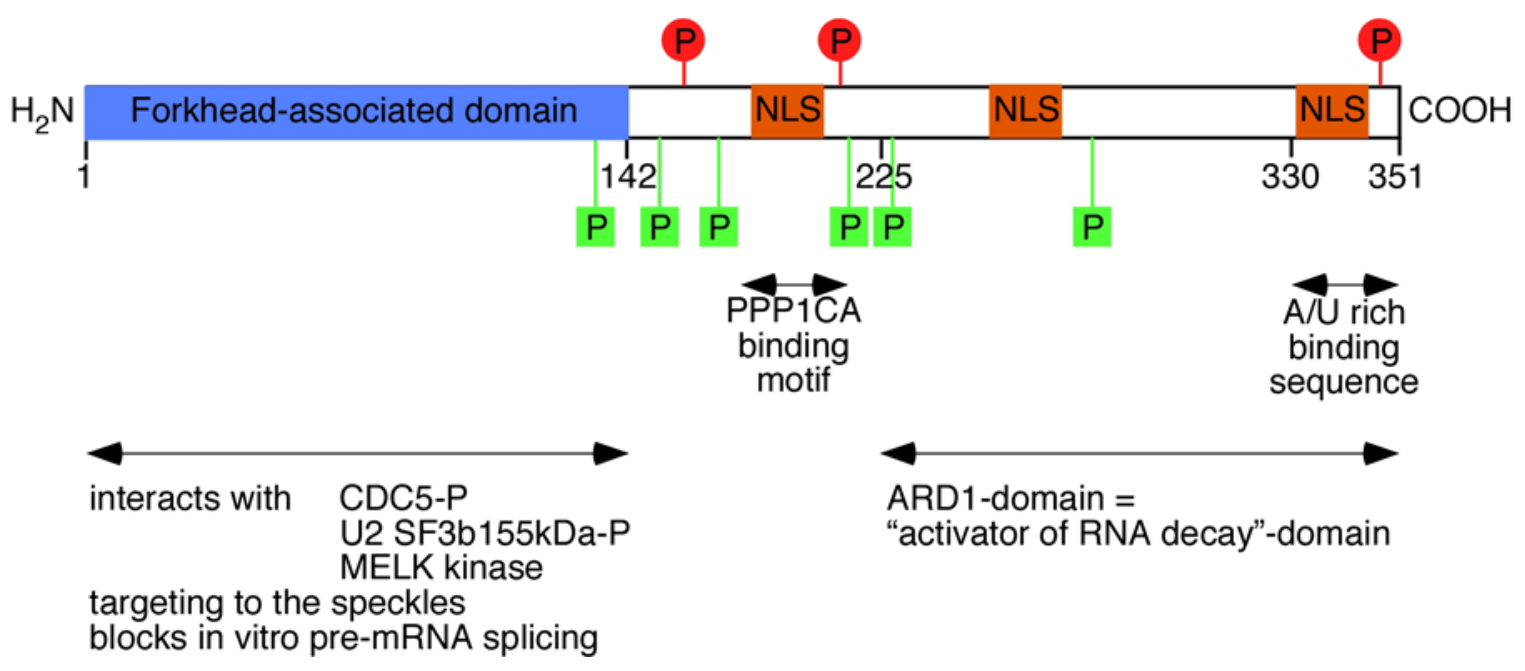

Fig. 26. Schematic representation of the domains of NIPP1. The domain structure of the $39 \mathrm{kDa}$ NIPP1 (negative inhibitor of protein phosphatase 1 ) is shown from the N-terminus $\left(\mathrm{H}_{2} \mathrm{~N}\right)$ to the $\mathrm{C}$-terminus $(\mathrm{COOH})$. Phosphorylation sites of Protein kinase $\mathrm{A}$ are shown in red, phosphorylation sites of Cyclin dependent kinase 2 are depicted in green. The $\mathrm{N}$ terminus comprises a FHA (Forkhead-associated) domain within aa 1 - 142, which interacts with phosphorylated CDC5 and U2 SF3b $155 \mathrm{kDa}$, as well as MELK kinase. In addition, targeting to the speckles depends on this domain, which was also shown to block pre-mRNA splicing in vitro. The acidic central third of the protein contains the binding motif for protein phosphatase 1 (PPP1CA). Amino acids 225 to 351 comprise the ARD1 (activator of RNA decay) domain and a lysine-rich A/U rich binding sequence from aa 330 - 351. Nuclear localization signals (NLSs) are indicated by orange boxes. Please note that the drawing is not to scale.

of an early step of spliceosome assembly in nuclear extracts (156). Interestingly, the FHA domain of NIPP1 blocks pre-mRNA splicing, indic ating that NIPP1 either targets CDC 5 or 
another associated protein for dephosphorylation by PPP1CA or serves as an anchor for both PPPICA and CDC5 (20). In addition, NIPP1 displays RNA-binding properties via a lysine-rich motif in the C-terminus, it binds preferentially U-rich sequences $(64,68)$. RNA binding is blocked by antibodies directed against the $\mathrm{COOH}$ teminus of NIPP1, but is not affected by phosphorylation. Data indicate that NIPP1 might function in targeting PPPICA to RNA since binding of NIPP1 to RNA and PPP1CA are not mutually exclusive (64). In fact, binding of NIPP1 to RNA reveals protein phosphatase activity of PPP1CA as does phosphorylation of NIPP1 itself. Finally it was demonstrated that NIPP1 is a pre-mRNA splicing factor involved in a late step of spliceosome assembly (10). This function of NIPP1 is unrelated to its ability to bind PPP1CA or RNA, indicating that NIPP1 can act independently as a splicing factor and as a protein phosphatase regulator. Dominant negative mutants of NIPP1 such as the FHA domain, NIPP1 [1 - 224] or NIPP1 [1 - 311] block spliceosome assembly at the transition from the $B$ to the $C$ complex (10). In collaboration with Prof. Dr. M. Bollen from the University of Leuven in Belgium we tested the feasibility of trapping/stalling spliceosomes in intermediate assembly stages using NIPP1 and tried to characterize them on the level of protein composition and structure.

\subsubsection{MS2 affinity selection of NIPP1 stalled splic eosomal B complex}

We now assayed whether the domina nt negative NIPP1 mutant has any effect on splicing in our system. To this end, we preincubated HeLa cell nuclear extract with increasing amounts of recombinant dominant negative NIPP1 [1 - 311] mutant as indicated above each lane in Figure 27 before addition of MS2-tagged MINX pre-mRNA (preincubated with a 20-fold molar excess of recombinant MS2-MBP fusion protein). The mix was incubated from 0 to 90 minutes under splicing conditions. RNA was recovered and resulting splic ing intermediates/products were separated by denaturing PAGE (Figure 27). Controls with either $\mathrm{H}_{2} \mathrm{O}$ (lanes 1 - 7) or protein storage buffer (buffer) (lanes 30 - 36) showed no detectable effect on pre-mRNA splicing. In contrast, addition of increasing amounts of NIPP1 [1 - 311] dominant negative mutant protein ranging in final concentrations from $2.5 \mu \mathrm{M}$ to $10 \mu \mathrm{M}$ inhibited splicing activity in a dose dependent manner. No remaining splicing activity could be detected in the presence of $10 \mu \mathrm{M}$ of NIPP1 [1 - 311] (lanes 22 - 28).

In parallel, we assayed the effect of NIPP1 [1 - 311] on spliceosomal complex formation on MS2-tagged MINX pre-mRNA in HeLa cell nuclear extract incubated under splicing conditions in the presence or absence of $10 \mu \mathrm{M}$ of NIPP1 [1 - 311] dominant negative mutant protein (Figure 28). A and B complexes appeared in both cases first after 5 minutes. In the absence of NIPP1, spliceosomal A complexes were quantitatively converted to $\mathrm{B}$ complexes, which themselves efficiently were tumed into $\mathrm{C}$ complexes, as 

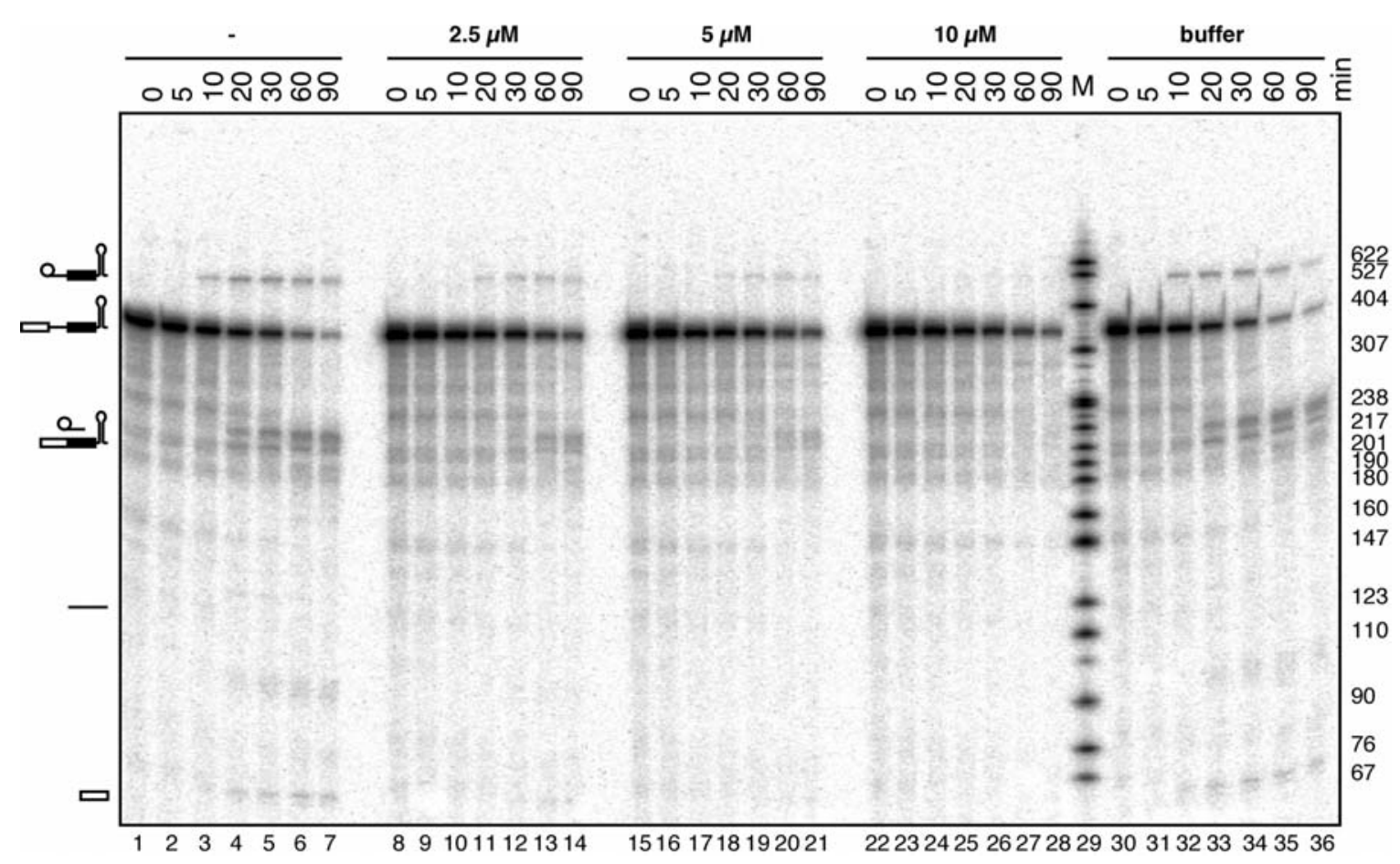

Fig. 27. In vitro splicing kinetics of 32P-labeled MS2-tagged MINX pre-mRNA in the presence of increasing concentrations of NIPP1 [1 - 311] protein. HeLa nuclear extract was preincubated for $10 \mathrm{~min}$ at $30^{\circ} \mathrm{C}$ in the presence of no (lanes $1-7$ ), $2.5 \mu \mathrm{M}$ (lanes 8 - 14), 5 $\mu \mathrm{M}$ (lanes 15 - 21), $10 \mu \mathrm{M}$ (lanes 22 - 28) or respective buffer (lanes 30 - 36) prior to adding 32P-labeled MS2-tagged MINX pre-mRNA. Splicing was performed in HeLa nuclear extract for 0 to 90 minutes as indicated above each lane. RNA was recovered and separated on an $8.3 \mathrm{M}$ urea-9.6 \% polyacrylamide gel. The ${ }^{32} \mathrm{P}$-labeled pre-mRNA and splicing intermediates or products were detected by autoradiography, and their positions are indicated on the left. The lengths (in base pairs) of a size marker ( 3 ' end-labeled Mspl cleaved pBR322) (NEB) (lane 29) are indic ated on the right. The NIPP1 [1 - 311] mutant was kindly provided by Dr. Monique Beullens and Prof. Mathieu Bollen, Katholieke Universiteit Leuven, Belgium.

evidenced by disappearing B complexes (lanes 11 - 19). In contrast, in the presence of 10 $\mu M$ of NIPP1 [1 - 311] dominant negative mutant, both A and B complexes did not form with the same efficiency as in the absence of NIPP1 (lanes 2 - 10). Furthemore, B complexes remained stable over a prolonged period of time and were not converted into later splic eosomal complexes, indic ating that NIPP1 functions at a step later than B complex formation.

Thus, NIPP1 [1 - 311] could be used to obtain stalled B complexes. Therefore, the large scale purification of NIPP1 B complexes was performed in order to leam about its protein content. This, in tum should allow us to place the NIPP1 B complex in the spliceosome assembly pathway by comparison to the other B complex proteome.

NIPP1 stalled B complexes were purified exactly as described for the purification of precatalytic $B$ complexes at $150 \mathrm{mM}$ salt, except that the splicing mix was preincubated with $10 \mu \mathrm{M}$ of NIPP1 [1 - 311] prior to addition of MINX pre-mRNA substrate. Splic eosomal complexes were allowed to form for 8 minutes and immediately separated by size on a 
linear $10-30 \%$ glycerol gradient. B complexes in the 405 region of the gradient were further purified by MS2 selection.

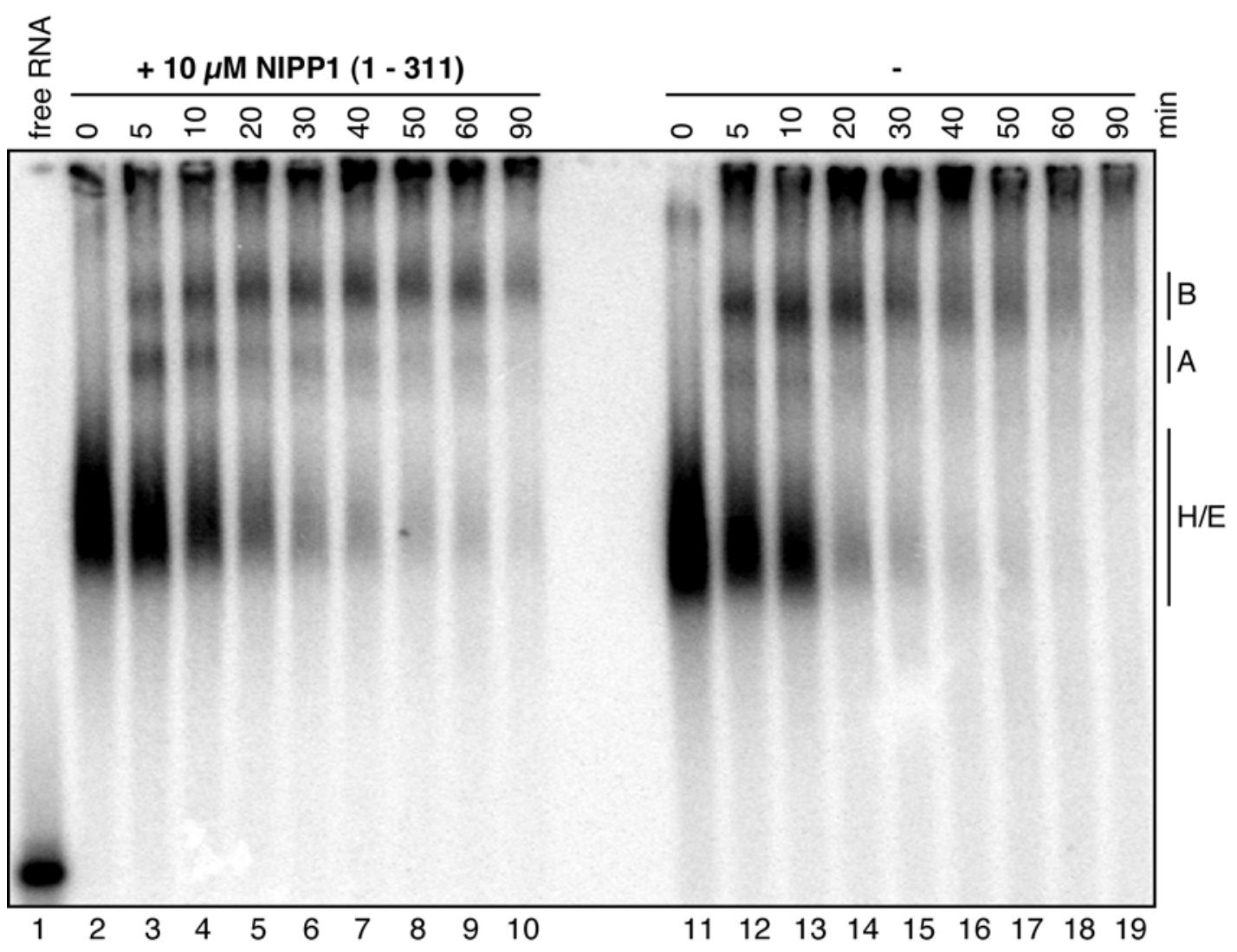

Fig. 28. In vitro spliceosomal complex assembly on 32P-labeled MS2-tagged MINX premRNA in the presence and absence of NIPP1 $(1$ - 311) dominant negative mutant protein. The time course of splicing reactions was monitored by a nalysing spliceosome assembly by native gel electrophoresis. Splicing was performed in HeLa cell nuclear extract preincubated in the presence (lanes 2 - 10) or absence (lanes 11 - 19) of $10 \mu \mathrm{M}$ of NIPP1 ( 1 - 311) dominant negative mutant protein for 0 to 90 minutes as indic ated above each lane. Complexes were separated on a native $2 \%$ low melting point agarose (Invitrogen) gel. The bands corresponding to the $\mathrm{H} / \mathrm{E}, \mathrm{A}$ and $\mathrm{B}$ complexes are indicated on the right. Lane 1: free 32P-labeled MS2-tagged MINX pre-mRNA.

The eluate contained exclusively unspliced MS2-tagged pre-mRNA and no splicing intermediates or products (Figure 29, panel B, lane 24). Complexes in the eluate contained the full set of snRNAs, however, U1 snRNA is underrepresented (panel A, lane 24). This finding indicates that a portion of purified complexes started activation and are therefore not in a precatalytic state any more. 
A

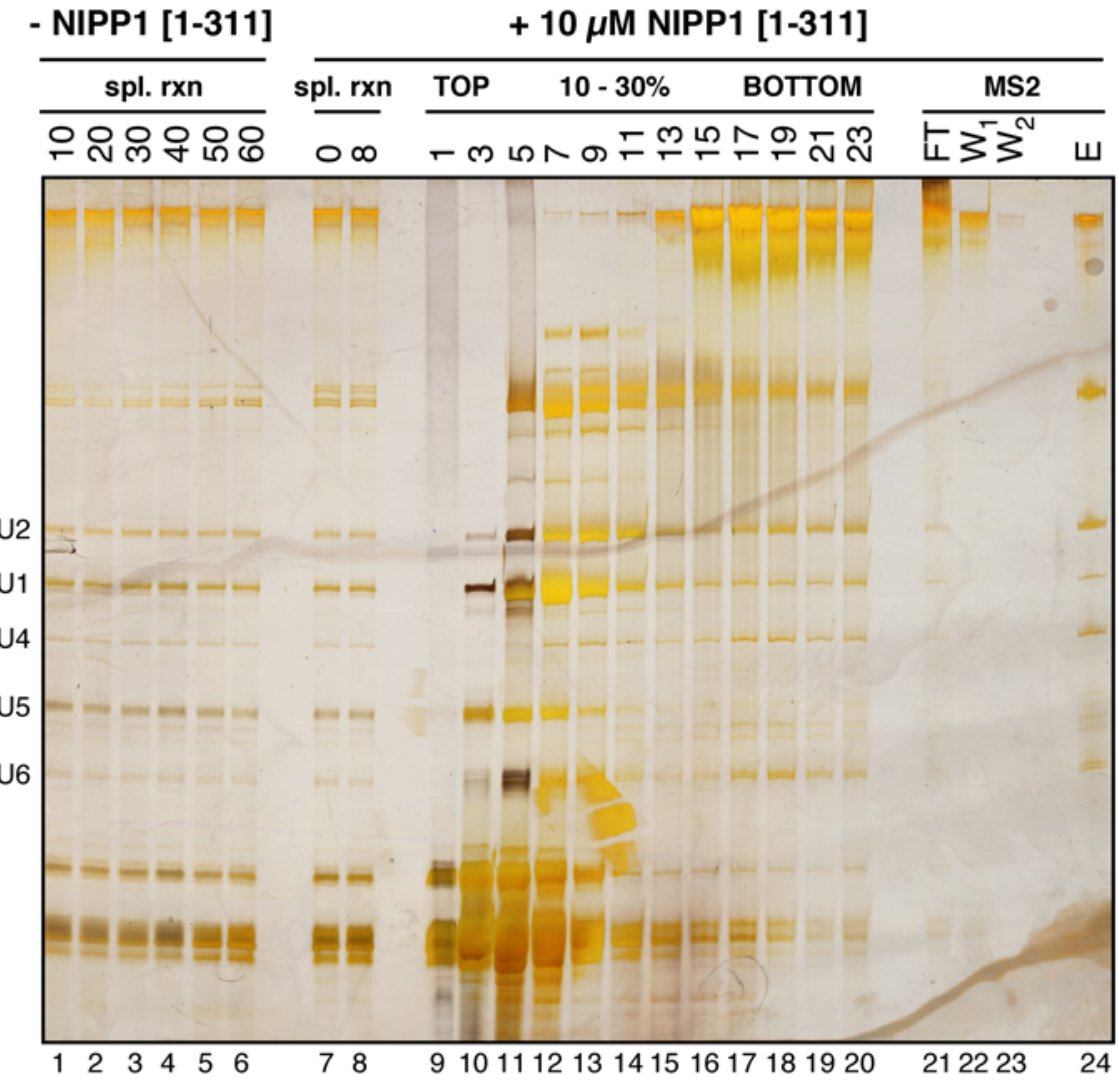

B

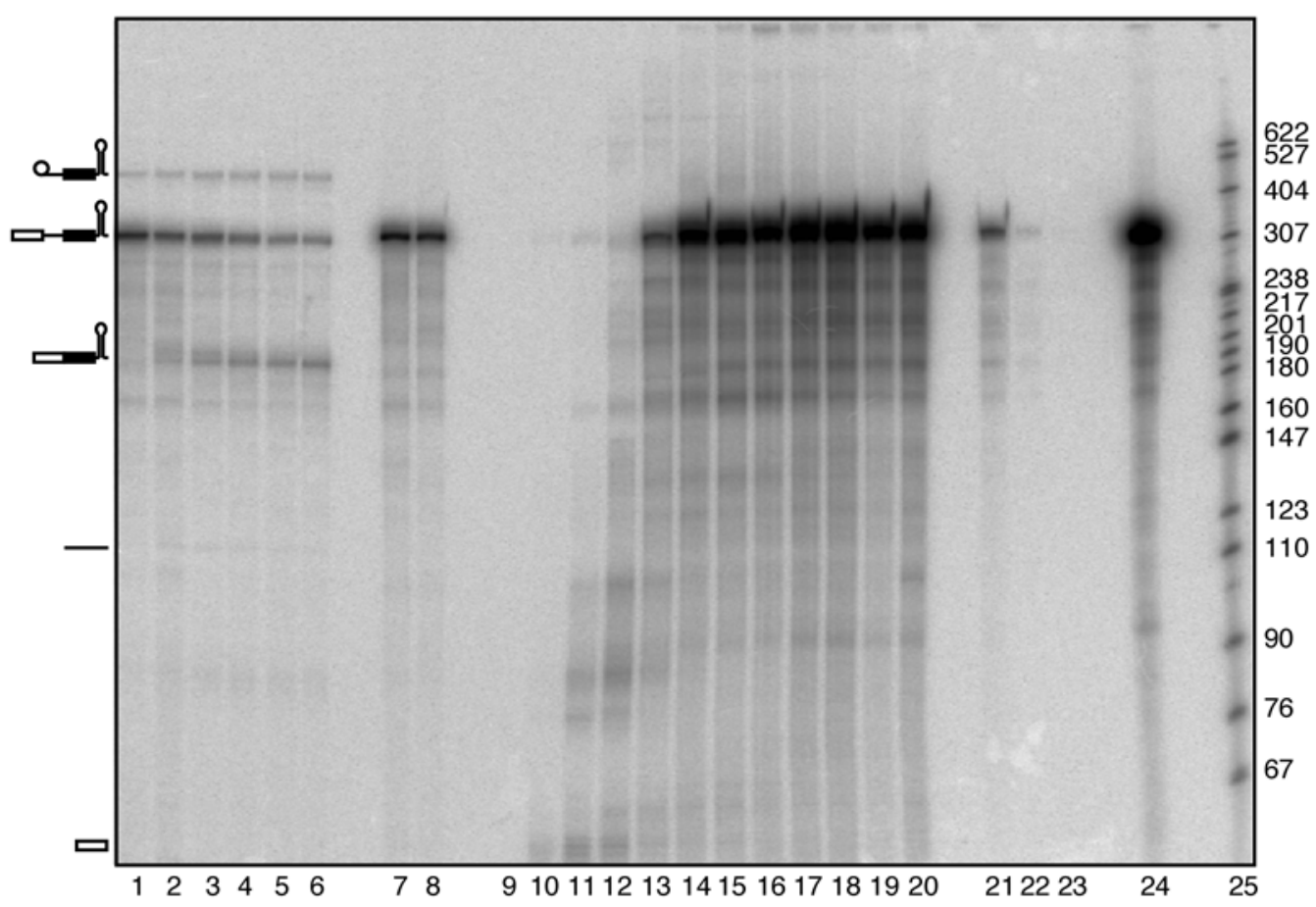

Fig. 29. Punification of MS2 affinity-selected NIPP1 (1 - 311) stalled B complexes at $150 \mathrm{mM}$ salt (A) RNA was recovered from distinct steps duning the purification procedure, separated on an $8.3 \mathrm{M}$ urea-9.6 \% polyacrylamide gel and visualized by staining with silver. As control reactions, splic ing was performed in HeLa cell nuclear extract for 0 to 60 min as indicated above each lane (lanes $1-6)$ in the absence of NIPP1 (1 - 311). Lanes 7 - 8: $1 / 720$ vol. of the splicing reaction mix incubated for 0 and 8 minutes in the presence of $10 \mu \mathrm{M}$ of NIPP1 (1 - 311); lanes $9-20$ : $1 / 30$ vol. of odd $10-30 \%$ linear glycerol gradient fractions after centrifugation for $16 \mathrm{~h}$ at $80000 \times \mathrm{g}$ in a Sorvall TST41.14 rotor and subsequent fractionation from TOP to BOTTOM; lane 21: 1/120 vol. flowthrough after 
binding of pooled NIPP1 stalled B complex peak gradient fractions to amylose beads (NEB); lanes 22 - 23: 1/5 vol. washes at the beginning and at the end of 25 column volumes of washing buffer; lane 24: RNA recovered from the last elution fraction after adding maltose to the amylose beads. The position of the snRNAs is indicated on the left. (B) The 32P-labeled pre-mRNA and splicing intermediates or products were detected by autoradiography. The positions of pre-mRNA, splicing intermediates or products are indicated on the left. The lengths (in base pairs) of a size marker ( 3 'end-labeled Mspl cleaved pBR322) (NEB) (lane 38) a re indic ated on the right.

\subsubsection{MS of MS2 affinity punified spliceosomal complexes stalled with NIPP1 (1 - 311)}

To get an idea which proteins are present or absent compared to $B$ complexes purified after 8 min of incubation in the absence of NIPP1 [1 - 311], we subsequently determined the protein composition of B complexes trapped with NIPP1 [1 - 311].

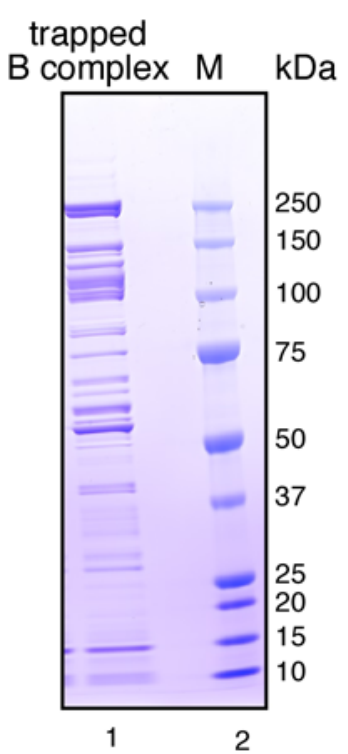

Fig. 30. Protein content of MS2 selected, NIPP1 [1 - 311] trapped spliceosomal complexes isolated under $150 \mathrm{mM}$ salt conditions. $4.5 \mathrm{pmol}$ (as judged by the activity of nucleic acid in the sample) of MS2 affinity purified, NIPP1 [1 - 311] trapped spliceosomal complexes (lane 1) were loaded onto a $1.5 \mathrm{~mm}$ thick precasted 4-12 \% NuPAGE Bis-Tris gel (Invitrogen) and subsequently stained with Coomassie. The molecular weights of protein standards from BIORAD (lane 2) are indic ated on the right in $\mathrm{kDa}$.

Proteins were fractionated by denaturing PAGE on 4 - $12 \%$ Bis-Tris gels (Invitrogen). Figure 30 shows the proteins as visualized by Coomassie staining. Proteins were again identified by liquid chromatography-tandem mass spectrometry (LC-MS/MS), and their presence (indicated by the absolute number of peptides sequenced in each preparation) is summarized in Tables 4 and 5 (column denoted 8' NIPP1).

Compared to B complexes isolated under standard conditions in the absence of a dominant negative protein variant such as NIPP1 [1 - 311], we identified a lmost the same protein composition but with some signific ant differences.

As corroborated by the underrepresented U1 snRNA in the purified complex, both U1 snRNP specific (U1-C and U1-A) and U1 snRNP associated proteins (FBP11, S164) were 
missing, the exception being U1-70kDa protein. Furthemore, we identified signific antly less of the hPrp19/CDC5 related proteins, despite the strong presence of proteins of the $14 \mathrm{~S}$ hPrp19/CDC5 complex (red boxed proteins in Tables 4 and 5). No RES complex components and only a minor fraction of non-snRNP proteins specific ally associated with B-like complexes.

It remains to be detemined whether the absence of these proteins is a direct or an ind irect effect of the presence of NIPP1 [1 - 311]. B $\Delta \mathrm{U} 1$ complexes purified under stringent conditions in the presence of Heparin also lacked most hPrp19/CDC5 related proteins, but in addition also almost all hPp19/CDC5 core components (91). In this study it was demonstrated that upon depletion of CDC5/AD002 and its associated proteins, B complex formation is not affected. Instead, the majority of spliceosomes had not undergone activation and pre-mRNA splicing is blocked prior to step I (91). We speculate that full length NIPP1 either is necessary to regulate the activity and/or the substrate specific ity of phosphatases. Altematively it may be acting as a platform to recruit and/or stabilize the association of other splic eosomal factors.

We conclude that stable association of full length NIPP1 is necessary at some stage between formation of precatalytic spliceosomal B complexes and activation of the spliceosome.

Surprisingly, we did not detect more C complex specific or 1st step splic ing factors when compared to standard B complexes purified after 8 min of incubation in HeLa cell nuclear extract. It therefore would be interesting whether over time we can drive more activity into NIPP1 [1 - 311] trapped spliceosomes. However, this is difficult, since the B complex stability/concentration is compromised after prolonged incubation times. In partic ular we are interested in the potential recruitment of later spliceosomal factors. These experiments are currently in progress. 


\subsection{Electron mic rosc opy of splic eosomal complexes}

\subsubsection{Structure analysis of splic eosomal complexes by electron mic rosc opy}

Up to now, no high resolution structure for any snRNP or spliceosomal complex is available. Single-particle cryo-electron mic roscopy is highly suited to get insight into the three-dimensional (3D) structure of large ribonucleopartic les at low resolution. Indeed, several snRNPs were studied by EM (138), in particular the U1 snRNP particle (137), a subcomplex of $17 S$ U2 snRNP, namely the multip rotein subunit SF3b (48), the U11/U12 disnRNP (47), the U5 snRNP, U4/U6 di-snRNP and the U4/U6.U5 tri-snRNP particle (120). In addition, splic eosomal complexes were the object of intense studies as well, such as the spliceosomal C complex $(71,72)$ and a B like complex (B $\Delta \mathrm{U} 1)(19)$, both punfied under stringent conditions in the presence of heparin. In unrelated studies, large 2005 tetrameric particles temed suprasplic eosomes were isolated from HeLa cell nuclear extract and studied by cryo-EM (5). However, the exact protein composition of supraspliceosomes is still unknown.

Here, for the first time we investigated the EM structure of a splic eosomal particle, the precatalytic B complex, isolated under very gentle conditions excluding the use of heparin. In the course of these studies we succeeded in dramatically increasing the image quality of these particles to an unprecedented level.

The specimen preparation procedure itself for EM analysis is very critical and has to be optimized for each individual partic le. We prepared our samples essentially as described (36). It is worth noting that particles were gently fixed during glycerol gradient centrifugation with buffer solution containing Glutaraldehyde. Electron mic roscopic raw images were recorded, followed by extracting individual particle images by applying semi-automated software. Subsequently, images were processed with Imagic-5. Further processing included an alignment procedure, multivariate statistical analysis and classific ation (see Materials and Methods). Two-dimensional (2D) class averages were based on 15 - 20 individual molecular images to improve the signal to noise ratio.

\subsubsection{Eectron mic rosc opy of purified native B complex}

EM analysis was performed by Daniel Boehninger, Monika Golas and Bjöm Sander in Holger Stark's group essentially as described in Deckert et al., 2006 (36). Briefly, we negatively stained our purified, Glutaraldehyde fixed complexes with uranyl formate and analyzed the particles by electron microscopy (EM). A typical EM raw image of the $B$ complex shows monodisperse partic les of similar sizes (Figure 31, panel B). The particles appear rhombic with a maximum dimension of $420 \AA$ (see Figure). In comparison to images obtained with the heparin-treated $B \Delta U 1$ complex $(19,91)$ (figure 31 , panel A), 
several significant improvements can already be detected at the level of the raw electron microsc opic image. Smaller partic les that may represent dissociation products of the $B$ complex cannot be detected, ensuring thus that subsequent image analysis is indeed only performed with an intact splic eosome, rather than one or more breakdown products. Additionally, the concentration of particles was more than doubled, and the staining appears homogeneous, which facilitated automatized image analysis. A total of 7,500 molecular images were subjected to image processing. Characteristic twodimensional averages of the splic eosomal B complex were obtained by averaging 20 individual images after "reference-free" image alignment, multiva riate statistical a nalysis (MSA), and classific ation (Figure 31, panelC). The most frequent class averages (the first

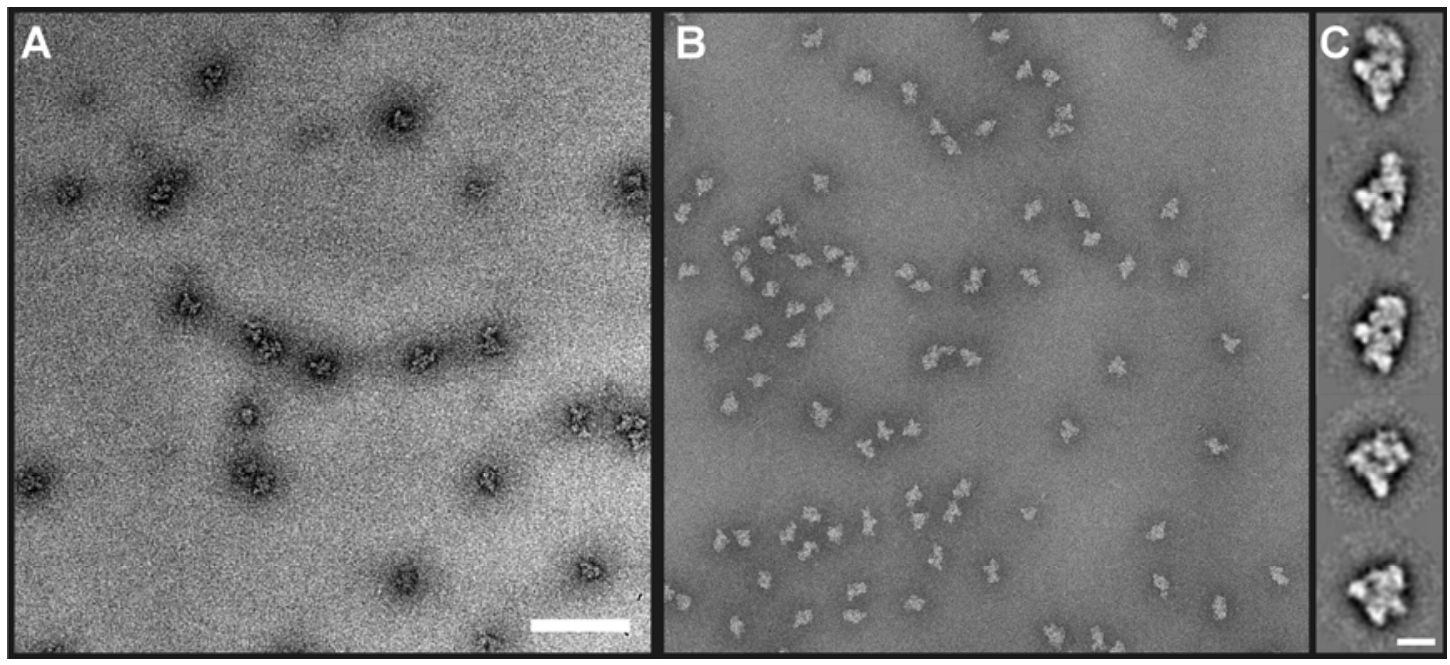

Fig. 31. EM of the native spliceosomal B complex. (A) CCD image of negatively sta ined complex BAU1. Particles were purified as previously described (19), adsorbed onto a carbon film, and sandwiched beneath another carbon film in $2 \%(w / v)$ uranyl formate. The images were taken at a magnific ation of $\times 27500$ under low-dose conditions. Bar, 1500 $\AA$. (B) CCD image of negatively stained complex B. Particles were adsorbed onto a carbon film and sandwiched beneath another carbon film in $2 \%(w / v)$ uranyl formate. The images were taken at a magnification of $\times 122000$ under low-dose conditions. (C) A gallery of individual class averages of the native B complex obtained by averaging around 20 individual raw images. Bar, $200 \AA$. The figure is published in Deckert et al., 2006 (36).

three from the top in Figure 31, panel C) show a central density surrounded by four peripheral density elements. The central density and the three peripheral density elements in the lower part of the image are arranged in a triangular shape of similar size in these class averages. The shape and position of the fourth density in the upper part of the images is different. The size and shape of the lower part of the image are reminiscent of the projection of the triangular body of the B $\Delta \mathrm{Ul}$ complex, which was isolated under stringent conditions. The density in the upper part of the image corresponds to the head density of the previously described BAU1 complex. Despite being structurally still better defined than the BAU1 complex, the head region of the MS2 affinity-purified B complexes displays conformational heterogeneity. However, due to improved structural definition of 
the entire complex, the head density of the native complex clearly reveals more fine structural details in the class averages compared to the $\mathrm{B} \Delta \mathrm{U} 1$ complex and appears to be larger. On the whole, this is consistent with the fact that the B complex contains signific antly more proteins than the BAU1 complex.

EM analysis of the NIPP1 [1- 311] stalled B complexes (see above) did not reveal any signific ant difference on a struc tural level at this low resolution (see Figure 32).

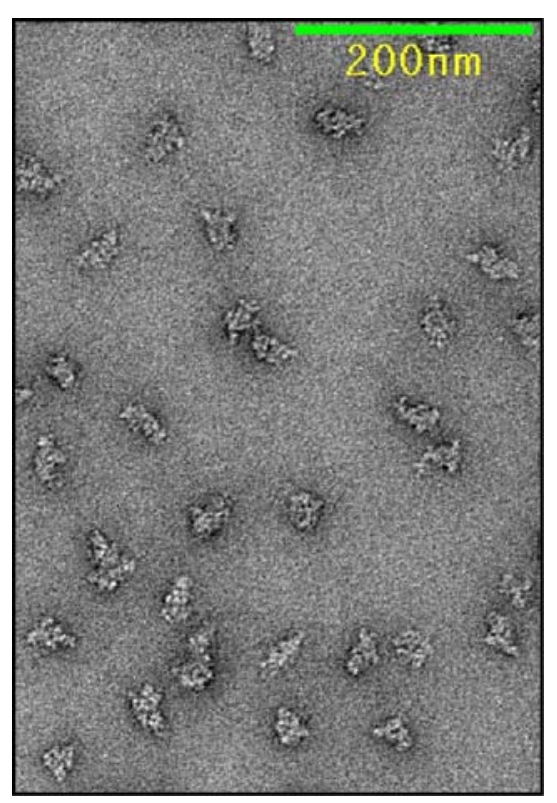

Fig. 32. EM of native spliceosomal complexes after 8 minutes of incubation in Hela nuclear extract in the presence of $10 \mu \mathrm{M}$ of NIPP1 (1 - 311). CCD image of negatively stained complexes of splic eosomes assembled for 8 minutes under splicing conditions in HeLa nuclear extract in the presence of $10 \mu \mathrm{M}$ of NIPP1 (1 - 311). Partic les were adsorbed onto a carbon film, and sandwiched beneath another carbon film in $2 \%$ (wt/vol) uranyl formate (48). The images were taken at a microscope magnific ation of $\times 88000$ at room temperature. Bar, $2000 \AA$.

It was not possible to assign a certain doma in in native B complexes to U1 snRNP due to the lack of this subdomain in NIPP1 [1 - 311] trapped complexes. The resolution of preliminary $3 \mathrm{D}$ structures is too low to allow such conclusions. One challenge in the future will be to define purification strategies to get $B$ complex preparations from which the protein content and structure can be detemined. However, this is presently diffic ult since the Glutaraldehyde fixation, which is essential for EM analysis is incompatible with present day proteomic analysis. 



\section{Disc ussion}

\subsection{Purification of precatalytic B complexes using two independent approaches}

The major a im of this study was to establish strategies for the purification of precatalytic spliceosomal B complex under native conditions. The methods should allow for largescale preparation of B complexes suitable for proteomic, functional and structural studies. To this end I extensively modified and extended existing purification methods and finally established two independent affinity selection methods.

One approach uses glycerol gradient centrifugation followed by MS2-based affinity selection (Figure 5), whereas the other one makes use of the tobramyc in affinity selection coupled with immunoaffinity purification (Figure 19). Common to both methods is the principle of kinetic control of B complex formation to minimize the assembly of later spliceosomes and tagging the pre-mRNA substrate with RNA aptamers for specific affinity selection steps.

Complexes isolated by both methods contained nearly stoichiometric amounts of unspliced pre-mRNA, U1, U2, U4, U5, and U6 snRNA, consistent with their designation as precatalytic spliceosomal B complexes (Figures 11 and 24). MS2 affinity-purified B complexes were shown to be functional, catalyzing splicing in nuclear extract depleted of one or more of the splic eosomal snRNPs (Figure 13). Subsequent cha racterization of the protein composition of both B complex preparations (Tables 4 and 5) and EM studies of the MS2 affinity purified complexes (Figure 31) revealed new insights into the structural rearrangements and the dynamics of protein recruitment and release during spliceosome assembly.

Detemining the protein composition of precatalytic B complexes purified by the two independent approaches several times allowed us to statistically evaluate the presence of protein factors in purified B complexes. Factors, which were detected either with both purific ation strategies or multiple times with one strategy were considered as bona fide $B$ complex components (Table 4). In contrast, proteins which were identified only once were considered as non-B complex components, and therefore, rather as conta minants (Table 5).

\subsection{Determining the stoichiometry of certain proteins within different spliceosomal complexes is a major task in the future}

Mass spectrometry is principally suited to both determine the full set of proteins within a complex mixture and also to quantify the relative and absolute abundance of certa in proteins present in one mixture compared with a nother. However, numerous experimental 
details might contribute to the loss of proteins in the course of the purification procedure and preparation of the samples for mass spectrometry a nalysis itself.

Several parameters influence the degree of protein coverage in MS analysis. These are the efficient fractionation of the peptide mixture by liquid chromatography, the complexity of the protein mixture per se, the abundance of the protein of lowest detectability and the ratio of the most versus the least abundant proteins (34). The last parameter touches on the problem of mass spectrometers to detect a very low abundance signal if a very high abundance signal is also present. In addition, another fundamental issue in proteomics is the problem posed by the enzymatic digestion with a single protease (as performed in this study), which is likely to miss proteins regardless of other aspects of the experiment. In principle, the sensitivity of the MS a nalysis can be increased by extensive fractionation, however, both more measurement time and increased sample consumption are the costs of this approach.

Assuming that we detected and identified the complete inventory of factors associated with B complexes in this study, how is the relative stoichiometry of certain proteins compared with other splic eosomal complexes?

In our analysis of the protein inventory of precatalytic spliceosomal B complexes we filtered both the absolute number of peptides sequenced for a particular protein (Tables 4 and 5) as well as the number of unique peptides (data not shown). These numbers might help to get a rough idea about the abundance of a factor in one complex with respect to the other. However, since there is no clear correlation between the molecular weight of a protein and the number of peptides identified, this information does not allow to determine the relative stoichiometry of the proteins in question. Only with respect to factors present in both complexes revealing the same number of peptides, a relative estimation might be eligible.

Thus, a major task that lies ahead will be to determine the relative and/or absolute quantities of the proteins or only subsets thereof within the different spliceosomal complexes. To gain knowledge about this important aspect of the composition of splic eosomal complexes, different a pproaches seem feasible, for example (i) quantita tive Westem Blotting, (ii) two-dimensional (2D) fluorescence difference gel electrophoresis (37), or (iii) stable isotope labeling by a mino acids in cell culture (SILAC) followed by nanoLC MS/MS analysis $(34,108)$.

\subsection{A number of proteins were detected only once in our purific ations}

Directly related to the question of sto ic hiometry is the fact that we detected a number of proteins only once in all our B complex preparations. These a re all listed in Table 5 . The peptide coverage of most of these proteins was very low. An in depth survey of the 
literature revealed that most of these proteins have not been associated with splicing before. Table 5 includes all proteins which were found more than once but with a very low peptide number and whose main function is known to be in other processes such as nonsense-mediated mRNA decay or mRNA degradation in general.

Among others, we detected RNA binding proteins (RBMXL1, RBM14, MG C 10433, IG F2BP3 or CIRP), peptidyl-prolyl isomerases (PPIG), factors involved in transcription regulation (PROX1 or BCLAF1), kinases (SRPK1, Nm23 or CRKRS), DEAD-H box proteins (DDX21 or DDX20) and factors conta ining SR-ric $h$ regions such as RBBP6.

It remains to be determined whether these factors are bona fide B complex proteins or unspecific contaminants. Are they highly underrepresented in HeLa cell nuclear extract or present in high amounts but associated with spliceosomes only transiently with low affinity and therefore lost upon complex purific ation? Are they necessary for splic ing activation and/or catalysis per se or involved in kinetic control of the two transesterification reactions? Altematively these proteins may be binding platforms for subsequent recruitment of other factors needed at later stages. We also cannot exclude that these proteins only appear to be substoichiometric, because they are diffic ult to be detected by MS. It also might be possible that these are factors needed at later spliceosome assembly stages, which could be present as contaminants in our B complex preparations. It remains to be investigated whether these will become more abundant in activated splic eosomes or $C$ complexes purified under comparable native conditions.

A number of unrelated experimental approaches could be used to investigate the function of these proteins. RNAi mediated knockdown experiments or in vivo localization studies by immunofluorescence of individual factors could reveal potential roles of these low abundance factors in pre-mRNA splicing. Furthemore, pull-down experiments using mono- or polyc lonal a ntibodies might a lso demonstrate their involvement in splicing.

\subsection{MS2 and tobramyc in affinity-purified B complexes are highly pure}

A number of observations attest to the high purity of the B complexes that we have isolated: (a) Our purified B complexes were not contaminated with post-second step spliceosomal/mRNP complexes as no spliced mRNA was detected (Figures 11 and 24). (b) Only faint amounts of splic ing intermediates (less than $2 \%$ of total pre-mRNA) were detected in our purified complexes, indicating that greater than $98 \%$ of the B complexes are precatalytic. (c) The presence of stoichiometric amounts of both the U4 and U1 snRNAs further suggests that these complexes had not undergone catalytic activation (Figures 11 and 24). (d) Most second-step factors were essentially not detected or at least highly underrepresented compared to other splicing factors, suggesting that these proteins are recruited at a later stage (Table 4). These would include Prp16, Prp17, Prp18, 
Prp22, Slu7 and Prp8. Based on different protein and ATP requirements, the second step of splicing can be divided into several stages. Available data demonstrate that following the first transesterification reaction, the RNA helicase Prp16 catalyzes an ATP-dependent rearrangement of the spliceosome $(123,124)$. Also Prp17 appears to act during the second step of splicing before or concomitant with an ATP-dependent reaction (70), its exact function, however, rema ins to be determined. Splic ing factors Slu7, Prp18 and Prp22 can only associate with splic eosomes following these rearrangements (65). Prp22 finally catalyzes an ATP-dependent conformational change which results in relea se of the mRNA (31). (e) Purified MS2 affinity-selected complexes appeared structurally highly homogeneous after examination in the electron microscope and subsequent image reconstruction, consistent with the idea that they consist predominantly of spliceosomes at a single assembly stage (Figure 31). (f) A factor required for activation, namely hPrp2, was detected in purified precatalytic spliceosomal B complexes. In yeast, this protein was shown to be an RNA-dependent ATPase (78) that activates the spliceosome before the first step of catalysis (131) and directly binds to the pre-mRNA substrate (148). In addition, Prp2 was the first DEAD/H box splicing factor whose interaction partner, namely Spp2p (=suppressor of Prp2), was identified. Consistent with the requirement of Prp2 prior to catalysis, Spp $2 p$ is required after spliceosome assembly but prior to the first transesterification reaction (115). Assuming a conserved role of the human homologue of Prp2p, the presence of this protein in precatalytic B complexes is in agreement with these data. (g) Structure a nalysis by electron mic rosc opy further revea ls a signific ant difference of purified precatalytic B complexes compared to earlier A complex (N. Behzadnia, M.M. Golas, K. Hartmuth, B. Sander, B. Kastner, J. Deckert, P. Dube, C.L. Will, H. Urla ub, H. Stark, R. Lühmann, ma nusc ript submitted) and la ter sta ges of splic eosome a ssembly $(19,72)$.

\subsection{Members of the exon junction complex are recruited after B complex formation}

During pre-mRNA splic ing, a complex of proteins (designated the exon junction complex, EJ C) is deposited ca. 20 nucleotides upstream of exon-exon junctions (reviewed in 142). This complex consists of a tetrameric core containing elF4AIII, Magoh, Y14, and MLN51 and at least 12 additional proteins that include, among others, Pinin and SRm160 (143). At present the assembly pathway of the EJ C during splicing is poorly understood. Most EJCassociated proteins were not found in our a ffinity-purified B complexes, consistent with the idea that they interact with the pre-mRNA at later stages of splicing. Exceptions included Y14, UAP56, Pinin, Acinus, SRm160, and elF4AIll. However, only a relatively low number of peptides was identified for these proteins (Table 4). Thus, these proteins are highly underrepresented in our purified complexes. SRm160 and Pinin have been shown 
additionally to function in pre-mRNA splicing per se $(44,159)$. Thus, these proteins might associate with the spliceosome at a much earlier stage, independent of other components of the EJ C complex. Previous studies indic ated that the heparin-resistant (i.e. stable) association of most EJC factors occurs first at the time of catalytic activation or C complex formation $(71,88)$. The further isolation of native $B^{*}$ and $C$ spliceosomal complexes in the absence of heparin should reveal the precise stage at which individual EJ C and step II factors associate with the pre-mRNA duning splicing. Indeed, preliminary experiments in our department indicate that members of the EJC complex are stably associated at the stage of $\mathrm{C}$ complex formation (S. Bessonov, personal communic ation). Native C complexes isolated under gentle conditions contained high amounts of EJC components compared to our precatalytic B complex as judged by the absolute number of peptides sequenced for this subcomplex.

\subsection{A large number of B complex proteins are lost upon treatment with heparin}

The complex set of proteins found associated with the spliceosomal B complex may not only be required for splicing on its own. Splicing is known to be highly coupled to transcription, pre-mRNA modific ation, export, translation and stability (93) and some of the $B$ complex proteins found may be involved in any of these processes. Compared to $B$ complexes previously isolated by immunoaffinity purific ation followed by glycerol gradient centrifugation under stringent conditions (i.e., in the presence of heparin; designated $B \Delta U 1)(91)$, the purified $B$ complexes a nalyzed here conta in considerably more proteins (Tables 4 and 5). This indic ates that a large number of proteins that associate with the $B$ complex are not stably bound; that is, their association does not withstand heparin trea tment. These include, a mong others, most of the SR and hnRNP proteins and nearly all components of the core complex and of the hPrp19/CDC5 related proteins.

RNA-binding proteins and hnRNP proteins are known to be involved in pre-mRNA processing, transcriptional regulation, splicing, transport, subcellular localization, nuclear export, translation and stability of mRNAs (40), and they mark exon-exon junctions. Generally they package RNA into compact RNP particles via their RRM (RNA recognition motif) motifs. It is unclear why we observed heterogeneity among hnRNP factors detected in our B complex preparations compared to bona fide snRNP proteins. However, association of hnRNP proteins to pre-mRNA and/or mRNA is probably highly dynamic by itself.

In contrast, those proteins that are present in both complexes - such as all 175 U2 SnRNP core proteins, nearly all tri-snRNP proteins (excluding U5 100kDa, LSm2/LSm6, and the trisnRNP specific $65 \mathrm{kDa}$ protein), and some 25 non-snRNP proteins - represent more stably 
integrated B complex components. As less stringent conditions were used in this study, proteins that were detected in BAU1 but not in the MS2 or tobramyc in affinity-selected B complexes likely represent either nonspliceosomal contaminants (e.g., Ncorl, Npat, or TBLR1 which have not been detected in any other MS study of spliceosome-associated proteins) or are potentially components of $B^{*} / C$ spliceosomal complexes that may be present in low amounts in the $\mathrm{B} \Delta \mathrm{U} 1$ preparations. Thus, a comparison of the proteomes of $B$ complexes isolated at $150 \mathrm{mM}$ either in the presence or absence of heparin provides useful information about the strength of association of B complex components identified in this study.

\subsection{The vast majority of A complex proteins are also present in the B complex}

As both complexes, A and B, respectively, were isolated under very similar conditions, a meaningful comparison of the proteome of the $B$ complexes isolated here using the Tobramycin affinity selection procedure coupled with immunoaffinity selection, with that of the previously described A complex can be made (56). Like the spliceosomal A complex, the human B complex conta ins the U1 snRNP specific proteins, U1 70kDa, U1 A, and U1 C, and all core 17S U2 snRNP proteins (SF3a, SF3b, U2 A' and U2 B' ') (Table 4). Several U2-associated proteins that copurified with human 175 U2 snRNPs (e.g. hPrp43, SPF45, and SPF30) (164) were present in both the A and B complexes. In contrast, the U2and A complex-a ssociated, DEAD-box protein hPrp5 was notably absent in all B complex preparations. Thus, it appears to be only transiently associated with the pre-mRNA prior to B complex formation. Prp5 plays an important role in bridging the U1 and U2 snRNPs within the A complex, and its absence in the B complex is consistent with the idea that its ac tivity or presence is only required for early splic eosome a ssembly events (167).

Interestingly, the early splicing factors U2AF35 and U2AF65 were also present in the B complex, indicating that they rema in associated at least until this stage of spliceosome assembly; previous studies with purified spliceosomes had suggested that both U2AF subunits are largely lost already during the transition from the $E$ to $A$ complex (9). A very similar, but not identical, set of SR and hnRNP proteins was found in both the $A$ and $B$ complexes. Likewise, most of the other non-snRNP factors found in the A complex were also present in our B complexes, with the exception of BUB3, MGC2803, FL 10839, SF1, tat SF1, E1B-APS, SMC1/2, and FL 21007. The apparent loss of the latter proteins is a first indic ation that they associate solely with early splic eosomal complexes and function prior to B complexformation. 


\subsection{A large number of proteins, including the hPp19/CDC5 complex, are recruited during $B$ complex formation}

A comparison of the proteomes of the A and B complexes isolated under low-stringency conditions indicates that a large number of proteins a re recruited to the pre-mRNA during B complex formation. As expected, essentia lly all proteins of the U4/U6.U5 tri-snRNP, which is recruited during B complex fomation, were detected in the MS2 and tobramycin affinity-selected B complexes. Exceptions include only those proteins that are typically difficult to detect by MS (i.e., the LSm5 protein). Unexpectedly, U5 52kDa, which was previously reported to be lost upon formation of the U4/U6.U5 tri-snRNP (82), was also found. Particularly, we detected U5 $100 \mathrm{kDa}$, whose yeast homologues protein, the DEADbox protein Prp28p, is involved in the dissociation of U1 snRNP from the 5 ' splice site during activation (136). Its presence in precata lytic splic eosomal B complexes is consistent with a role in activation of the splic eosome in a subsequent step.

Interestingly, human homologues of the yeast tri-snRNP proteins Snu23 and Prp38, as well as the human homologue of Spp382 (designated TFIP11), which is a genetic suppressor of yeast Prp38 (Shatakshi Pandit and Brian Rymond, personal communication), were also identified. None of these proteins is detected by MS in purified human U4/U6.U5 tri-snRNPS (Dr. H. Urlaub, personal communication). Like most of the human tri-snRNP proteins, hSnu23, hPrp38, and TFIP11 are recruited during B complex formation, and hSnu23 and TFIP11 are also stably integrated at this stage, as evidenced by their presence in heparintreated $\mathrm{B} \Delta \mathrm{U} 1$ complexes (91). Thus, one or more of these proteins may contribute to trisnRNP integration duning $B$ complex formation and/or may be involved in subsequent spliceosome activation or catalysis. Indeed, yeast Prp38p is an essential splicing factor that is required for conformational changes leading to catalytic activation of the spliceosome, i.e., unwinding of the U4/U6 snRNA intermolecular helix and U4 snRNP release $(13,166)$. Consistent with these results, the association of the human Prp38 protein with the spliceosome is destabilized concomitantly with the U4 SnRNA and U4/U6associated proteins, namely, during spliceosome activation (88). Genetic depletion of yeast Snu23p leads to a block in pre-mRNA splicing in vivo, but its precise function remains unknown (49). Finally, human TFIP11, which remains stably associated with the splic eosome at least until step I (i.e., it is found in purified $B^{*}$ and $C$ complexes) $(71,88)$, was also recently shown to function in pre-mRNA splicing, although its precise role also remains to be determined (162).

Unexpectedly, all recently identified subunits of the human 14S Prp 19/CDC 5 c omplex (i.e., hPrp19, CDC5L, SPF27, PRL1, CCAP1/hsp73, CCAP2/AD002, and $\beta$-like Catenin 1) were found in both B complex isolates, along with Npw38BP and Npw38, which also appear to copurify with the hPrp19/CDC5 complex (91). Likewise, 10 additional proteins, which we 
have designated Prp19/CDC5-related proteins, based on evidence that they (or their yeast homologues) physic ally or genetic ally associate with Prp19/CDC5, were also found. Most of these proteins are components of the $35 \mathrm{~S}$ U5 SnRNP, a form of U5 that is generated by RNP remodeling events within the spliceosome during its catalytic activation (88). Prp19/CDC5 and associated proteins were absent or highly underrepresented in the previous $\mathrm{B} \Delta \mathrm{U} 1$ complex (91), indicating that they are recruited during B complex formation but stably integrated at a later stage. Indeed, previous studies confimed that they are stable components of the $B^{*}$ complex (88). Thus, this large group of proteins interacts with the pre-mRNA prior to catalytic activation, but during subsequent RNP remodeling events accompanying catalytic activation, they become stably associated. Although the heptameric Prp19/CDC5 complex is recruited prior to activation, functional studies in humans indic ate that components of this complex a re not required for tri-snRNP addition $(2,91)$, but rather act at a subsequent step. However, several of the hPrp19/CDC5-related proteins could potentia lly act at this stage.

Immunoprecipitation studies initially suggested that Prp19p first interacts with the yeast spliceosome concomitant with or just after catalytic activation (144). However, these studies did not rule out that Prp19 might interact at an earlier stage; its presence in early complexes may have escaped detection due to the limitations of the experimental methods employed. Indeed, the function of components of the yeast Prp 19 complex prior to activation (and thus also associate ea rlier) has been suggested by recent experiments. In yeast, Prp19p is associated with at least eight proteins, forming the NTC, which is involved in the catalytic activation of the spliceosome (25). Three NTC components, Prp19, Cef1/CDC5, and Snt309 (human SPF27), are also found in the human Prp19/CDC5 complex, whereas the remaining NTC components are among those human proteins that we have designated Prp19/CDC5-related (Table 1).

Consistent with an early recruitment, recent data from yeast suggest that at least one component of the NTC complex - CIf1p (the yeast homologue of the human protein hSyf3 - functions during tri-snRNP integration at the transition from complex $A$ to $B$ and thus may be recruited at an earlier stage of spliceosome assembly and associate prior to its activation $(29,160)$. Thus, the recruitment of at least one Prp19/CDC5-related protein prior to the activation step appears to be conserved between yeast and man.

We also identified human homologues of the yeast RES (for retention and splicing) complex subunits, namely MGC13125, Snip1, and CGI-79, whose function in humans presently is unknown. The yeast trimeric complex which contains Bud13p, Pml1p and Snu17p (43) was shown to be required for effic ient splicing and the retention of pre-mRNA in the yeast nucleus. Furthemore, pull-down experiments indic ated that the RES complex associates with the yeast spliceosome prior to step I. The detection of the respective human counterparts of these proteins provides the first indication that like in yeast, 
components of the RES complex are involved in splicing and might act prior to the first catalytic step of splic ing.

\subsection{Analysis of the factor requirements for catalytic activation and step I of splic ing using MS2 affinity-selected B complexes}

MS2 affinity-purified B complexes catalyzed splicing in nuclear extract depleted of one or more of the spliceosomal snRNPs, indicating that they are not dead-end assembly intermediates (Figure 13). However, they were not capable of catalyzing splic ing in the absence of nuclear extract when incubated under splic ing conditions. This suggests that one or more factors required for catalytic activation and/or the catalytic steps of splicing is/are missing. Indeed, these complexes did not contain essential step II factors, such as hPrp16, hPrp18 or hPrp22. Thus, it is not unexpected that splicing products could not be formed. However, all currently known factors required for catalytic activation, as well as the first step of splicing (e.g., hPrp2), were detected in these complexes. As catalytic activation was not assayed per se, it is not clear whether our purified B complexes alone can undergo the conformational rearrangements that accompany this functionally decisive step. Nonetheless, splic ing intemediates were not detected, suggesting that one or more factors required for subsequent spliceosome activation and/or catalysis are lacking. Potential candidates include those proteins previously identified by MS in purified $B^{*}$ and/or C complexes that were not found in our MS2 affinity-purified B complexes. Excluding step II factors and EJ C components, this includes only a handful of proteins ( 71 , 88).

Altematively, MS2 affinity-purified B complexes could potentially contain a full protein complement required for at least the first step of splicing, but the incorrect posttranslational modification status of one or more spliceosomal proteins may block catalysis.

Posttranslational modific ations - especially de-/phosphorylation - play an important role in splicing. Spliceosome assembly is dependent on the phosphorylation of splic eosomal proteins such as members of the SR protein family, and SF3b 155kDa is hyperphosphorylated just prior to or during the first catalytic step of splicing (158). It was also shown that phosphorylation of splicing factor 1 (SF1) enhances the interaction with the U2AF 65kDa protein and promoted the formation of a temary complex with a model 3 ' intronic sequence (92). Furthemore, the phosphoprotein $9 \mathrm{G} 8$ is a specific target of the kinase CDC2L2, also called CDK11p110 (59) both in vivo and in vitro. Both of these proteins are present in our purified $B$ complexes.

In contrast, the catalytic steps of splicing require protein dephosphorylation that is mediated by members of the PP1 and PP2 phosphatase families $(98,102)$. Significantly, 
only PP1 was detected in our MS2 affinity-selected B complexes. However, whether it alone is sufficient to catalyze the dephosphorylation events required for catalysis is currently not known. It might be that these proteins are dephosphorylated by $\mathrm{PP} 2 \mathrm{C} \gamma$ which is required for formation of the spliceosomal A complex and associates with the splic eosome at an early stage (102). In addition, two proteins, namely U2 SF3b 155kDa and U5 $116 \mathrm{kDa}$, are dephosphorylated before or concomitant with the second step of splicing. Most likely, these factors are the key substrates of phosphatases PPP1CA and PP2A (127). It was also demonstrated that ASF/SF2 and U1 $70 \mathrm{kDa}$ must be dephosphorylated in order for the first step to occur $(24,147)$. Possibly, dephosphorylated ASF/SF2 and U1 70kDa facilitate the release of U1 snRNP from the spliceosome during catalytic activation.

Previously it was shown that the interaction of U2 SF3b $155 \mathrm{kDa}$ and CDC5 with the phosphatase inhibitor NIPP1 is phosphorylation dependent. In light of these observations it is not surprising that we could not detect NIPP1 in all our purifications, since no precautions were taken to prevent dephosphorylation reactions during our independent purification procedures. It is currently not known whether certain factors cannot be detected by MS due to their low abundance, transient interaction with the spliceosome or unfavourable posttranslational states of interaction partners.

Taken together, since covalently attached post-translational modifications a re usually present in substoichiometric levels and since we did not ensure the maintenance of any post-translational modific ation pattem in the course of our purific ation procedure, it is very likely that some protein factors specifically associated with precatalytic spliceosomal B complexes were not detected in our studies. Future experiments under slightly modified purific ation conditions could help to ga in some knowledge in this respect.

\subsection{Spliceosome assembly can be stalled with dominant negative protein variants}

In this work, conditions were established to punify precatalytic splic eosomal B complex in highly concentrated form in solution using two independent approaches. Kinetic control of B complex formation was used to specific ally enrich for that splic eosome and minimize the copurific ation of conta minating, later stage splic eosomes.

Finally I investigated the feasibility of trapping spliceosomes in intermediate stages by adding a dominant negative protein variant. The ideal target was NIPP1 ( 1 - 311), which was shown to inhibit C complex formation. The N-terminus of NIPP1 comprises a FHA domain, which interacts with phosphorylated CDC5 and U2 SF3b 155kDa. In addition, the MELK kinase was also shown to bind to this region. The central third of NIPP1 is very acidic 
and contains the binding region for PPP1CA. The C-terminal end comprises the ARD1domain and an A/U rich binding sequence from a a 330 - 351, respectively.

We first titrated NIPP1 (1 - 311) into standard splicing reactions and assaying in vitro splicing by denaturing PAGE and complex formation analysis on native gels (Figures 27 and 28). This dominant negative protein variant indeed inhibited splicing in a dose dependent manner by preventing $C$ complex formation. Large scale purfic ations of B-like complexes in the presence of NIPP1 $(1-311)$ revealed that spliceosome assembly was trapped after B complex formation and maybe subsequent release of U1 snRNP in the course of activation (Figure 29). However, I cannot formally exclude the possibility that NIPP1 (1 - 311) is incapable of stabilizing the presence of U1 snRNP in spliceosomal B complexes per se, since after 8 minutes of incubation, a lmost no splic eosomal activation is usually detected. That this spliceosomal complex is indeed trapped revealed an experiment where I incubated substrate pre-mRNA for 30 minutes in HeLa nuclear extract under standard splicing conditions but in the presence of NIPP1 (1 - 311). No splic eosomal intermediates or products could be observed, only unspliced pre-mRNA was present, clearly indicating that no first or sec ond step of splicing occured.

MS a na lysis of NIPP1 (1 - 311) stalled B-like complexes revealed that a number of proteins are not present any more compared to standard B complexes (Tables 4 and 5). Among others, I did not detect U1 snRNP specific and associated proteins and I identified signific antly less hPrp19/CDC5 related proteins, no RES complex components and only a minor fraction of non-snRNP proteins specific a lly associated with B complexes.

The NIPP1 ( 1 - 311) protein variant lacks part of the ARD1 domain including the lysine rich $A / U$ rich binding domain shown to be involved in RNA binding. This indicates that lack of this domain is somehow - whether direct or indirect - involved in recruitment and/or stabilization of certain proteins such as the hPrp19/CDC5 related proteins and components of the RES complex.

In conclusion, the experiments showed that association of full length NIPP1 is nec essary at some stage between formation of precatalytic splic eosomal B complexes and activation of the spliceosome. However, the exact role of NIPP1 remains to be determined in future experiments. Nevertheless, these preliminary experiments indicate the potential of dominant negative protein variants in dissecting the assembly pathway of spliceosomes.

\subsection{Electron mic rosc opy of MS2 affinity-purified B complexes}

Negatively stained images of MS2 affinity-purified, Glutaraldehyde fixed B complexes could be obtained with much improved image quality compared to previous spliceosome preparations (19) (Figure 31). Visual inspection of the EM raw images already revealed greatly enhanced and uniform image contrast, low background stain and a 
significantly higher amount of particles per specimen area, which greatly facilitates computerized image analysis of these complexes. The most significant difference to previous EM work on spliceosomal complexes is the high level of structural preservation and homogeneity, which is evidenced by the fact that practically no dissociation products could be detected.

In principle, one would assume that a stripped complex should give a homogeneous sample since the stripping agent - heparin in this case - should destabilize all loosely bound factors. This is not observed, because the mild conditions used for the purification of MS2 a ffinity-purified B complexes a llows for the isola tion of spliceosomal complexes that are more structurally homogenous than those isolated under more stringent purification conditions. In summary, images of MS2 affinity-purified B complexes are at an unprecedented quality level, and thus they should be well suited for three-dimensional struc ture analyses, based on criteria such as their structural integrity and homogeneity.

However, in the initial image processing analysis we could still detect potential movements of the two major structural domains, the triangular body and the head doma in, relative to each other. The level of conformational heterogeneity present in the data set appears to be reduced compared to the BAU1 complex. Notwithstanding, a significant a mount of conformational heterogeneity could still be detected which makes high-resolution structure determination difficult. To what extent this conformational heterogeneity reflects dynamic movements required for function is presently not clear. There are many indications based on other macromolecular complexes such as ribosomes (38) or the a naphase promoting complex (41) that such flexibilities indeed play important roles in tems of function. Data in yeast indic ated that GTP hydrolysis leads to rearrangement between Prp8 and the C-teminus of the GTPase Snu114 (the yeast counterpart of U5 $116 \mathrm{kDa}$ ) thereby destabilizing U1 and U4 snRNPs, thereby activating splic ing catalysis (22).

Thus, the observed conformational heterogeneity may well be correlated with different states of the splic eosome. It may, for example, be waiting for an additional component to bind in order to finally lock it into the next structurally stable state that can perform the subsequent step of the reaction cycle. Clearly, additional studies a re required to clarify the significance of this structural flexibility.

The availability of spliceosomal B complexes made possible through this work laid the foundation for these future studies. 


\section{References}

1. Abovich, N., and M. Rosbash. 1997. Cross-intron bridging interactions in the yeast commitment complexare conserved in ma mmals. Cell 89:403-12.

2. Ajuh, P., B. Kuster, K. Panov, J. C. Zomerdijk, M. Mann, and A. I. Lamond. 2000. Functional analysis of the human CDC5L complex and identification of its components by mass spectrometry. EMBO I 19:6569-81.

3. Ajuh, P., and A. I. Lamond. 2003. Identification of peptide inhibitors of pre-mRNA splicing derived from the essential interaction domains of CDC5L and PLRG1. Nuc leic Acids Res 31:6104-16.

4. Anderson, G. J., M. Bach, R. Lühmann, and J. D. Beggs. 1989. Conservation between yeast and man of a protein associated with U5 small nuclear ribonucleoprotein. Nature 342:819-21.

5. Azubel, M., S. G. Wolf, J. Sperling, and R. Sperling. 2004. Three-dimensional structure of the native splic eosome by cryo-electron mic rosc opy. Mol Cell 15:833-9.

6. Bach, M., G. Winkelmann, and R. Lühmmann. 1989. $20 \mathrm{~S}$ small nuclear ribonucleoprotein U5 shows a surprisingly complex protein composition. Proc Natl Acad SciU SA 86:6038-42.

7. Behrens, S. E., and R. Lühmann. 1991. Immunoaffinity purific ation of a [U4/U6.U5] tri-snRNP from human cells. Genes Dev 5:1439-52.

8. Behzadnia, N., K. Hartmuth, C. L Will, and R Lühmann. 2006. Functional spliceosomal A complexes can be assembled in vitro in the absence of a pentasnRNP. RNA 12:1738-46.

9. Bennett, M., S. Michaud, J. Kingston, and R. Reed. 1992. Protein components specifically associated with prespliceosome and spliceosome complexes. Genes Dev 6:1986-2000.

10. Beullens, M., and M. Bollen. 2002. The protein phosphatase-1 regulator NIPP1 is also a splicing factor involved in a late step of spliceosome assembly. J Biol Chem 277:19855-60.

11. Beullens, M., A. Van Eynde, M. Bollen, and W. Stalmans. 1993. Inactivation of nuclear inhibitory polypeptides of protein phosphata se-1 (NIPP-1) by protein kina se A. J Biol Chem 268:13172-7.

12. Black, D. L 2003. Mechanisms of altemative pre-messenger RNA splic ing. Annu Rev Biochem 72:291-336.

13. Blanton, S., A. Sinivasan, and B. C. Rymond. 1992. PRP38 encodes a yeast protein required for pre-mRNA splicing and maintenance of stable U6 small nuclear RNA levels. Mol Cell Biol 12:3939-47.

14. Blenc owe, B. J. 2006. Altemative splic ing: new insights from global analyses. Cell 126:37-47.

15. Blenc owe, B. J., R. Issner, J. A. Nickerson, and P. A. Sharp. 1998. A coa ctivator of pre-mRNA splic ing. Genes Dev 12:996-1009.

16. Blencowe, B. J., B. S. Sproat, U. Ryder, S. Barabino, and A. I. Lamond. 1989. Antisense probing of the human U4/U6. Cell 59:531-9.

17. Blum, H., Beier, H., Gross, H.J. 1987. Improved silver staining of plant proteins, RNA and DNA polyacryla mide gels. Electrophoresis 8:93-99.

18. Bochnig, P., R. Reuter, P. Bringmann, and R. Lühmann. 1987. A monoclonal antibody against 2,2,7-trimethylguanosine that reacts with intact, class $U$, small nuclear ribonucleoproteins as well as with 7-methylguanosine-capped RNAs. Eur J Biochem 168:461-7.

19. Boehringer, D., E. M. Makarov, B. Sander, O. V. Makarova, B. Kastner, R. Lühmann, and H. Stark. 2004. Three-dimensional structure of a pre-catalytic human splic eosomal complex B. Nat Struct Mol Biol 11:463-8.

20. Boudrez, A., M. Beullens, P. Groenen, A. Van Eynde, V. Vulsteke, I. Jagiello, M. Muray, A. R. Krainer, W. Stalmans, and M. Bollen. 2000. NIPP1-mediated interaction of protein phosphatase-1 with $C D C 5 \mathrm{~L}$, a regulator of pre-mRNA splicing and mitotic entry. J Biol Chem 275:25411-7. 
21. Boudrez, A., M. Beullens, E. Waelkens, W. Stalmans, and M. Bollen. 2002. Phosphorylation-dependent interaction between the splic ing factors SAP155 and NIPP1. J Biol Chem 277:31834-41.

22. Brenner, T. J., and C. Guthrie. 2005. Genetic analysis reveals a role for the C teminus of the Saccharomyces cerevisiae GTPase Snul14 during spliceosome activation. Genetics 170:1063-80.

23. Bringmann, P., B. Appel, J. Rinke, R. Reuter, H. Theissen, and R. Lühmann. 1984. Evidence for the existence of snRNAs U4 and $\mathrm{U} 6$ in a single ribonucleoprotein complex and for their association by intermolecular base paing. EMBO J 3:135763.

24. Cao, W., S. F. Jamison, and M. A. Garcia-Blanco. 1997. Both phosphorylation and dephosphorylation of ASF/SF2 are required for pre-mRNA splicing in vitro. RNA 3:1456-67.

25. Chan, S. P., D. I. Kao, W. Y. Tsai, and S. C. Cheng. 2003. The Prp19p-associated complex in spliceosome activation. Sc ience 302:279-82.

26. Chen, C. H., W. C. Yu, T. Y. Tsao, L Y. Wang, H. R. Chen, J. Y. Lin, W. Y. Tsai, and S. C. Cheng. 2002. Functional and physical interactions between components of the Prp19p-associated complex. Nucleic Acids Res 30:1029-37.

27. Cheng, C., and P. A. Sham. 2006. Regulation of CD44 altemative splic ing by SRm160 and its potential role in tumor cell invasion. Mol Cell Biol 26:362-70.

28. Chiara, M. D., L Palandjian, R. Feld Kramer, and R. Reed. 1997. Evidence that U5 snRNP recognizes the 3' splice site for catalytic step II in mammals. EMBO J 16:474659.

29. Chung, S., M. R. Mc Lean, and B. C. Rymond. 1999. Yeast ortholog of the Drosophila crooked neck protein promotes spliceosome assembly through stable U4/U6.U5 snRNP addition. RNA 5:1042-54.

30. Chusainow, J., P. M. Ajuh, L Thinkle-Mulcahy, J. E. Sleeman, J. Elenberg, and A. I. Lamond. 2005. FRET a nalyses of the U2AF complex localize the U2AF35/U2AF65 interaction in vivo and reveal a novel self-interaction of U2AF35. RNA 11:1201-14.

31. Company, M., J. Arenas, and J. Abelson. 1991. Requirement of the RNA helicaselike protein PRP22 for release of messenger RNA from spliceosomes. Nature 349:487-93.

32. Das, $\mathbf{R}, \mathbf{Z}$ Zhou, and $\mathbf{R}$. Reed. 2000. Functional association of U2 snRNP with the ATP-independent splic eosomal complex E. Mol C ell 5:779-87.

33. Datta, B., and A. M. Weiner. 1991. Genetic evidence for base paing between U2 and $U 6$ snRNA in mammalian mRNA splic ing. Nature 352:821-4.

34. de Godoy, L M., J. V. Olsen, G. A. de Souza, G. Li, P. Mortensen, and M. Mann. 2006. Status of complete proteome analysis by mass spectrometry: SILAC labeled yeast as a model system. Genome Biol 7:R50.

35. de la Mata, M., and A. R. Komblihtt 2006. RNA polymerase II C-terminal domain mediates regulation of a ltemative splic ing by SRp20. Nat Struct Mol Biol.

36. Deckert, J., K. Hartmuth, D. Boehringer, N. Behzadnia, C. L Will, B. Kastner, H. Stark, H. Ulaub, and R. Lühmann. 2006. Protein composition and electron microscopy structure of affinity-purified human spliceosomal B complexes isolated under physiologic al conditions. Mol Cell Biol 26:5528-43.

37. Delom, F., and E. Chevet 2006. Phosphoprotein analysis: from proteins to proteomes. Proteome Sci 4:15.

38. Diaconu, M., U. Kothe, F. Schlunzen, N. Fischer, J. M. Hams, A. G. Tonevitsky, H. Stark, M. V. Rodnina, and M. C. Wahl. 2005. Structural basis for the function of the ribosomal L7/ 12 sta lk in factor binding and G TPa se activation. Cell 121:991-1004.

39. Dignam, J. D., R. M. Lebovitz, and R. G. Roeder. 1983. Accurate transcription initiation by RNA polymerase II in a soluble extract from isolated mammalian nuclei. Nucleic Acids Res 11:1475-89.

40. Dreyfuss, G., V. N. Kim, and N. Kataoka. 2002. Messenger-RNA-binding proteins and the messa ges they camy. Nat Rev Mol Cell Biol 3:195-205. 
41. Dube, P., F. Herzog, C. Gieffers, B. Sander, D. Riedel, S. A. Muller, A. Engel, J. M. Peters, and H. Stark. 2005. Localization of the coactivator Cdh1 and the cullin subunit Apc 2 in a cryo-electron mic rosc opy model of vertebrate APC/C. Mol Cell 20:867-79.

42. Dube, P., P. Tavares, R. Lurz, and M. van Heel. 1993. The portal protein of bacteriophage SPP1: a DNA pump with 13-fold symmetry. EMBO J 12:1303-9.

43. Dziembowski, A., A. P. Ventura, B. Rutz, F. Caspary, C. Faux, F. Halgand, 0. Laprevote, and B. Seraphin. 2004. Proteomic analysis identifies a new complex required for nuclear pre-mRNA retention and splicing. EMBO J 23:4847-56.

44. Edridge, A. G., Y. Li, P. A. Sham, and B. J. Blencowe. 1999. The SRm160/300 splic ing coactivator is required for exon-enhancer function. Proc Natl Acad Sci U S A 96:6125-30.

45. Fenn, J. B., M. Mann, C. K. Meng, S. F. Wong, and C. M. Whitehouse. 1989. Electrospray ionization for mass spectrometry of large biomolecules. Science 246:64-71.

46. Fetzer, S., J. Lauber, C. L Will, and $\mathbf{R}$ Lühmmann. 1997. The [U4/U6.U5] tri-snRNPspecific $27 \mathrm{~K}$ protein is a novel SR protein that can be phosphorylated by the snRNP-associated protein kinase. RNA 3:344-55.

47. Golas, M. M., B. Sander, C. L Will, R. Lühmann, and H. Stark. 2005. Major conformational change in the complex SF3b upon integration into the spliceosomal U11/U12 di-snRNP as revealed by electron cryomic rosc opy. Mol Cell 17:869-83.

48. Golas, M. M., B. Sander, C. L Will, R. Lühmann, and H. Stark. 2003. Molecular architecture of the multip rotein splic ing factor SF3b. Sc ience 300:980-4.

49. Gottsc halk, A., G. Neubauer, J. Banroques, M. Mann, R. Lühmann, and P. Fabrizio. 1999. Identification by mass spectrometry and functional a nalysis of novel proteins of the yeast [U4/U6.U5] tri-snRNP. EMBO J 18:4535-48.

50. Gozani, O., J. G. Patton, and R. Reed. 1994. A novel set of splic eosome-associa ted proteins and the essential splicing factor PSF bind stably to pre-mRNA prior to catalytic step II of the splic ing reaction. EMBO J 13:3356-67.

51. Graveley, B. R. 2001. Altemative splicing: increasing diversity in the proteomic world. Trends Genet 17:100-7.

52. Graveley, B. R 2005. Mutually exclusive splicing of the insect Dscam pre-mRNA directed by competing intronic RNA secondary structures. Cell 123:65-73.

53. Graveley, B. R. 2005. Small molecule control of pre-mRNA splicing. RNA 11:355-8.

54. Griffith, B. N., C. M. Walsh, W. Szeszel-Fedorowicz, A. T. Timperman, and L M. Salati. 2006. Identification of hnRNPs K, Land A2/B1 as candidate proteins involved in the nutritional regulation of mRNA splic ing. Biochim Biophys Acta.

55. Grillari, J., P. Ajuh, G. Stadler, M. Losc her, R. Voglauer, W. Emst, J. Chusainow, F. Eisenhaber, M. Pokar, K. Fortschegger, M. Grey, A. I. Lamond, and H. Katinger. 2005. SNEV is an evolutiona rily conserved splic ing factor whose oligomerization is necessary for splic eosome assembly. Nuc leic Acids Res 33:6868-83.

56. Hartmuth, K., H. UHlaub, H. P. Vomlocher, C. L Will, M. Gentzel, M. Wilm, and R. Lühmann. 2002. Protein composition of human prespliceosomes isolated by a tobramyc in affinity-selection method. Proc Natl Acad Sci U SA 99:16719-24.

57. Hazbun, T. R, L Malmstrom, S. Anderson, B. J. Graczyk, B. Fox, M. Riffle, B. A. Sundin, J. D. Aranda, W. H. Mc Donald, C. H. Chiu, B. E. Snydsman, P. Bradley, E. G. Muller, S. Fields, D. Baker, J. R. Yates, 3rd, and T. N. Davis. 2003. Assigning function to yeast proteins by integration of technologies. Mol Cell 12:1353-65.

58. Horowitz, D. S., R. Kobayashi, and A. R. Krainer. 1997. A new cyclophilin and the human homologues of yeast Prp3 and Prp4 form a complex associated with U4/U6 snRNPs. RNA 3:1374-87.

59. Hu, D., A. Mayeda, J. H. Trembley, J. M. Lahti, and V. J. Kidd. 2003. CDK11 complexes promote pre-mRNA splic ing. J Biol Chem 278:8623-9.

60. Huang, Y., and J. A. Steitz. 2005. SRprises along a messenger's joumey. Mol Cell 17:613-5. 
61. Ibrahim el, C., T. D. Schaal, K. J. Hertel, R. Reed, and T. Maniatis. 2005. Serine/arginine-rich protein-dependent suppression of exon skipping by exonic splicing enhancers. Proc Natl Acad Sc i U SA 102:5002-7.

62. Ismaili, N., M. Sha, E. H. Gustafson, and M. M. Konarska. 2001. The 100-kda U5 snRNP protein (hPrp28p) contacts the $5^{\prime}$ splice site through its ATPase site. RNA 7:182-93.

63. Izaunalde, E., J. Lewis, C. McGuigan, M. Jankowska, E. Darzynkiewicz, and I. W. Mattaj. 1994. A nuclear cap binding protein complex involved in pre-mRNA splicing. Cell 78:657-68.

64. Jagiello, I., M. Beullens, V. Vulsteke, S. Wera, B. Sohlberg, W. Stalmans, A. von Gabain, and M. Bollen. 1997. NIPP-1, a nuclear inhibitory subunit of protein phosphatase-1, has RNA-binding properties. J Biol Chem 272:22067-71.

65. James, S. A., W. Tumer, and B. Schwer. 2002. How Slu7 and Prp18 cooperate in the second step of yeast pre-mRNA splicing. RNA 8:1068-77.

66. Jankowsky, E., M. E. Faiman, and Q. Yang. 2005. RNA helicases: versatile ATPdriven nanomotors. J Nanosc i Nanotec hnol 5:1983-9.

67. Jankowsky, E., C. H. Gross, S. Shuman, and A. M. Pyle. 2001. Active disnuption of an RNA-protein interaction by a DExH/D RNA helic ase. Sc ience 291:121-5.

68. Jin, Q., M. Beullens, I. Jagiello, A. Van Eynde, V. Vulsteke, W. Stalmans, and M. Bollen. 1999. Mapping of the RNA-binding and endoribonuclease domains of NIPP1, a nuclear targeting subunit of protein phosphatase 1. Biochem J 342 ( Pt 1):13-9.

69. Johnson, J. M., J. Castle, P. GamettEngele, Z Kan, P. M. Loerch, C. D. Amour, R. Santos, E. E. Schadt, R. Stoughton, and D. D. Shoemaker. 2003. Genome-wide survey of human altemative pre-mRNA splicing with exon junction mic roarrays. Science 302:2141-4.

70. Jones, M. H., D. N. Frank, and C. Guthrie. 1995. Characterization and functional ordering of Slu7p and Prp17p during the second step of pre-mRNA splicing in yeast. Proc Natl Acad Sci U S A 92:9687-91.

71. Jurica, M. S., L J. Licklider, S. R. Gygi, N. Grigorieff, and M. J. Moore. 2002. Purification and characterization of native spliceosomes suitable for threedimensional structural a nalysis. RNA 8:426-39.

72. Jurica, M. S., D. Sousa, M. J. Moore, and N. Grigonieff. 2004. Three-dimensional structure of C complex splic eosomes by electron mic rosc opy. Nat Struct Mol Biol 11:265-9.

73. Karas, M., and F. Hillenkamp. 1988. Laser desorption ionization of proteins with molecular masses exceeding 10,000 daltons. Anal Chem 60:2299-301.

74. Kastner, B. 1998. Purific ation and Electron Microscopy of Splic eosomal snRNPs, p. 95 - 140. In J. Schenkel (ed.), RNP Particles, Splicing and Autoimmune Diseases. Springer Lab Manual, Heidelberg.

75. Kastner, B., and R. Lühmann. 1989. Electron microscopy of U1 small nuclear ribonucleoprotein particles: shape of the particle and position of the $5^{\prime}$ RNA terminus. EMBO J 8:277-86.

76. Kent, O. A., and A. M. MacMillan. 2002. Early organization of pre-mRNA during splic eosome assembly. Nat Struct Biol 9:576-81.

77. Kent, O. A., D. B. Ritchie, and A. M. Macmillan. 2005. Characterization of a U2AFindependent commitment complex (E') in the mammalian spliceosome assembly pathway. Mol Cell Biol 25:233-40.

78. Kim, S. H., J. Smith, A. Claude, and R. J. Lin. 1992. The purified yeast pre-mRNA splic ing factor PRP2 is a n RNA-dependent NTPa se. EMBO J 11:2319-26.

79. Konarska, M. M., and P. A. Sham. 1986. Electrophoretic separation of complexes involved in the splicing of precursors to mRNAs. Cell 46:845-55.

80. Kuhn, A. N., Z Li, and D. A. Brow. 1999. Splicing factor Prp8 govems U4/U6 RNA unwind ing during activation of the spliceosome. Mol Cell 3:65-75.

81. Laemmli, U. K. 1970. Cleavage of structural proteins during the assembly of the head of bacteriophage T4. Nature 227:680-5. 
82. Laggerbauer, B., S. Liu, E. Makarov, H. P. Vomlocher, O. Makarova, D. Ingelfinger, T. Achsel, and $\mathbf{R}$ Lühmann. 2005. The human U5 snRNP 52K protein (CD2BP2) interacts with U5-102K (hPrp6), a U4/U6.U5 tri-snRNP bridging protein, but dissoc iates upon tri-snRNP formation. RNA 11:598-608.

83. Lamond, A. I., M. M. Konarska, and P. A. Sham. 1987. A mutational a nalysis of spliceosome assembly: evidence for splice site collaboration during splic eosome formation. Genes Dev 1:532-43.

84. Lauber, J., G. Plessel, S. Prehn, C. L Will, P. Fabrizio, K. Groning, W. S. Lane, and R. Lühmann. 1997. The human U4/U6 snRNP conta ins 60 and 90kD proteins that are structurally homologous to the yeast splicing factors Prp4p and Prp3p. RNA 3:92641.

85. LeCuyer, K A., L S. Behlen, and O. C. Uhlenbeck. 1995. Mutants of the bacteriophage MS2 coat protein that alter its cooperative binding to RNA. Bioc hemistry 34:10600-6.

86. Li, J., I. C. Hawkins, C. D. Harvey, J. L Jennings, A. J. Link, and J. G. Patton. 2003. Regulation of altemative splicing by SRrp86 and its interacting proteins. Mol Cell Biol 23:7437-47.

87. Lybarger, S., K. Beic kman, V. Brown, N. Dembla-Rajpal, K. Morey, R. Seipelt, and B. C. Rymond. 1999. Elevated levels of a U4/U6.U5 snRNP-associated protein, Spp381p, rescue a mutant defective in spliceosome maturation. Mol Cell Biol 19:577-84.

88. Makarov, E. M., O. V. Makarova, H. Urlaub, M. Gentzel, C. L Will, M. Wilm, and R. Lühmann. 2002. Small nuclear ribonucleoprotein remodeling during catalytic activation of the splic eosome. Science 298:2205-8.

89. Makarova, O. V., E. M. Makarov, S. Lu, H. P. Vomlocher, and R. Lühmann. 2002. Protein $61 \mathrm{~K}$, encoded by a gene (PRPF31) linked to autosomal dominant retinitis pigmentosa, is required for U4/U6*U5 tri-snRNP formation and pre-mRNA splicing. EMBO J 21:1148-57.

90. Makarova, O. V., E. M. Makarov, and R. Lühmann. 2001. The 65 and 110 kDa SRrelated proteins of the U4/U6.U5 tri-snRNP are essential for the assembly of mature spliceosomes. EMBO J 20:2553-63.

91. Makarova, O. V., E. M. Makarov, H. Urlaub, C. L Will, M. Gentzel, M. Wilm, and R. Lühmann. 2004. A subset of human 35S U5 proteins, including Prp19, function prior to catalytic step 1 of splic ing. EMBO J 23:2381-91.

92. Manceau, V., M. Swenson, J. P. Le Caer, A. Sobel, C. L Kelkopf, and A. Mauc uer. 2006. Major phosphorylation of SF1 on adjacent Ser-Pro motifs enhances interaction with U2AF65. FebsJ 273:577-87.

93. Maniatis, T., and R. Reed. 2002. An extensive network of coupling among gene expression machines. Nature 416:499-506.

94. Mann, M., R. C. Hendrickson, and A. Pandey. 2001. Analysis of proteins and proteomes by mass spectrometry. Annu Rev Biochem 70:437-73.

95. Masuda, S., R. Das, H. Cheng, E. Hurt, N. Dorman, and R. Reed. 2005. Rec ruitment of the human TREX complex to mRNA during splicing. Genes Dev 19:1512-7.

96. Matlin, A. J., F. Clark, and C. W. Smith. 2005. Understanding altemative splicing: towards a cellular code. Nat Rev Mol Cell Biol 6:386-98.

97. Matter, N., and H. Konig. 2005. Targeted 'knockdown' of spliceosome function in mammalian cells. Nucleic Acids Res 33:e41.

98. Memoud, J. E., P. Cohen, and A. I. Lamond. 1992. Ser/Thr-specific protein phosphatases a re required for both catalytic steps of pre-mRNA splic ing. Nucleic Acids Res 20:5263-9.

99. Modrek, B., and C. Lee. 2002. A genomic view of altemative splicing. Nat Genet 30:13-9.

100. Moore, M. J., and P. A. Sham. 1993. Evidence for two active sites in the spliceosome provided by stereochemistry of pre-mRNA splicing. Nature 365:364-8.

101. Muraki, M., B. Ohkawara, T. Hosoya, H. Onogi, J. Koizumi, T. Koizumi, K. Sumi, J. Yomoda, M. V. Muray, H. Kimura, K. Funuic hi, H. Shibuya, A. R. Krainer, M. Suzuki, 
and M. Hagiwara. 2004. Ma nipulation of a ltemative splicing by a newly developed inhibitor of Clks. J Biol Chem 279:24246-54.

102. Muray, M. V., R. Kobayashi, and A. R Krainer. 1999. The type 2C Ser/Thr phosphatase PP2C gamma is a pre-mRNA splicing factor. Genes Dev 13:87-97.

103. Neubauer, G., A. King, J. Rappsilber, C. Calvio, M. Watson, P. Ajuh, J. Sleeman, A. Lamond, and M. Mann. 1998. Mass spectrometry and EST-database searching allows characterization of the multi-protein spliceosome complex. Nat Genet 20:46-50.

104. Newman, A. J. 1997. The role of U5 snRNP in pre-mRNA splicing. EMBO J 16:5797800.

105. Nilsen, T. W. 1998. RNA-RNA interactions in nuclear pre-mRNA splic ing, p. 279-307. In R. W. Simons and a. M. Grunberg-Manago (ed.), RNA structure and function. Cold Spring Harbor Laboratory Press, Cold Spring Harbor, New York.

106. Nottrott, S., K. Hartmuth, P. Fabrizio, H. UHlaub, I. Vidovic, R. Ficner, and R. Lühmann. 1999. Functional interaction of a novel 15.5kD [U4/U6.U5] tri-snRNP protein with the 5 ' stem-loop of U4 snRNA. EMBO J 18:6119-33.

107. Ohi, M. D., and K. L Gould. 2002. Characterization of interactions among the Cef1p-Prp19p-associated splic ing complex. RNA 8:798-815.

108. Ong, S. E, L J. Foster, and M. Mann. 2003. Mass spectrometric-based a pproaches in quantitative proteomic s. Methods 29:124-30.

109. Rappsilber, J., U. Ryder, A. I. Lamond, and M. Mann. 2002. Large-scale proteomic analysis of the human splice osome. Genome Res 12:1231-45.

110. Reed, R. 2000. Mechanisms of fidelity in pre-mRNA splicing. Cur Opin Cell Biol 12:340-5.

111. Reed, R., and H. Cheng. 2005. TREX, SR proteins and export of mRNA. Curr O pin Cell Biol 17:269-73.

112. Reed, $\mathbf{R}$, and T. Maniatis. 1988. The role of the mammalian branchpoint sequence in pre-mRNA splic ing. Genes Dev 2:1268-76.

113. Reuter, K., S. Nottrott, P. Fabrizio, R. lühmann, and R. Fic ner. 1999. Identific ation, characterization and crystal structure analysis of the human spliceosomal U5 snRNP-specific $15 \mathrm{kD}$ protein. J Mol Biol 294:515-25.

114. Rothrock, C. R. A. E. House, and K. W. Lynch. 2005. HnRNP L represses exon splic ing via a regulated exonic splicing silencer. EMBO J 24:2792-802.

115. Roy, J., K. Kim, J. R. Maddock, J. G. Anthony, and J. L Woolford, J r. 1995. The final stages of splic eosome maturation require Spp2p that can interact with the DEAH box protein Prp2p and promote step 1 of splic ing. RNA 1:375-90.

116. Ruby, S. W., S. E. Goelz, Z Hostomsky, and J. N. Abelson. 1990. Affinity chromatogra phy with biotinylated RNAs. Methods Enzymol 181:97-121.

117. Ruskin, B., and M. R. Green. 1985. An RNA processing a ctivity that debranches RNA lariats. Sc ience 229:135-40.

118. Ryder, U., B. S. Sproat, and A. I. Lamond. 1990. Sequence-specific a ffinity selection of mammalian splic ing complexes. Nucleic Acids Res 18:7373-9.

119. Sambrook, J., Fritsch, E.F., and Maniatis, T. 1989. Molecular Cloning. A Laboratory Manual, 2nd ed. Cold Spring Harbor Laboratory Press, Cold Spring Harbor, NY.

120. Sander, B., M. M. Golas, E. M. Makarov, H. Brahms, B. Kastner, R. Lühmann, and H. Stark. 2006. Organization of core spliceosomal components U5 snRNA loop I and U4/U6 Di-snRNP within U4/U6.U5 Tri-snRNP as revealed by electron cryomic rosc opy. Mol Cell 24:267-78.

121. Schemer, F. W., J r., and M. Spingola. 2006. A subset of Merlp-dependent introns requires Bud 13p for splic ing activation and nuclear retention. RNA 12:1361-72.

122. Schmittgen, T. D., J. F. J U, K. D. Danenberg, and P. V. Danenberg. 2003. Inhibition of pre-mRNA splic ing by cisplatin and platinum a nalogs. Int J Oncol 23:785-9.

123. Schwer, B., and C. Guthrie. 1992. A conformational rearrangement in the splic eosome is dependent on PRP16 and ATP hydrolysis. EMBO J 11:5033-9.

124. Schwer, B., and C. Guthrie. 1991. PRP16 is an RNA-dependent ATPa se that interacts transiently with the splic eosome. Nature 349:494-9. 
125. Segault, V., C. L Will, B. S. Sproat, and R. Lühmann. 1995. In vitro rec onstitution of mammalian U2 and U5 snRNPs active in splicing: Sm proteins are functionally interchangeable and are essential for the formation of functional U2 and U5 snRNPs. EMBO J 14:4010-21.

126. Shevchenko, A., M. Wilm, O. Vorm, and M. Mann. 1996. Mass spectrometric sequencing of proteins silver-sta ined polya cryla mide gels. Anal Chem 68:850-8.

127. Shi, Y., B. Reddy, and J. L Manley. 2006. PP1/PP2A Phosphatases Are Required for the Sec ond Step of Pre-mRNA Splic ing and Target Spec ific snRNP Proteins. Mol Cell 23:819-29.

128. Shin, C., and J. L Manley. 2002. The SR protein SRp 38 represses splic ing in M phase cells. Cell 111:407-17.

129. Shomron, N., and G. Ast 2003. Boric ac id reversibly inhibits the second step of premRNA splic ing. FEBS Lett 552:219-24.

130. Shomron, N., H. Malca, I. Vig, and G. Ast 2002. Reversible inhibition of the sec ond step of splicing suggests a possible role of zinc in the second step of splicing. Nucleic Acids Res 30:4127-37.

131. Silverman, E. J., A. Maeda, J. Wei, P. Smith, J. D. Beggs, and R. J. Lin. 2004. Interaction between a G-patch protein and a spliceosomal DEXD/H-box ATPase that is critic al for splic ing. Mol Cell Biol 24:10101-10.

132. Smith, C. W. 2005. Altemative splic ing--when two's a crowd. Cell 123:1-3.

133. Smith, C. W., and J. Valcarcel. 2000. Altemative pre-mRNA splicing: the logic of combina torial control. Trends Bioc hem Sci 25:381-8.

134. Smith, P. K., R. I. Krohn, G. T. Hemanson, A. K. Mallia, F. H. Gartner, M. D. Provenzano, E. K. Fujimoto, N. M. Goeke, B. J. Olson, and D. C. Kenk. 1985. Mea surement of protein using bic inchoninic acid. Anal Biochem 150:76-85.

135. Soret, J., N. Bakkour, S. Maire, S. Durand, L Zekni, M. Gabut, W. Fic, G. Divita, C. Rivalle, D. Dauzonne, C. H. Nguyen, P. Jeanteur, and J. Tazi. 2005. Selective modification of altemative splicing by indole derivatives that target serinearginine-rich protein splic ing factors. Proc Natl Acad Sci U SA 102:8764-9.

136. Staley, J. P., and C. Guthrie. 1999. An RNA switch at the 5 'splice site requires ATP and the DEAD boxprotein Prp28p. Mol Cell 3:55-64.

137. Stark, H., P. Dube, R. Lühmann, and B. Kastner. 2001. Arrangement of RNA and proteins in the spliceosomal U1 small nuclear ribonucleoprotein particle. Nature 409:539-42.

138. Stark, H., and R. Lühmann. 2006. Cryo-electron microscopy of spliceosomal components. Annu Rev Biophys Biomol Struct 35:435-57.

139. Stevens, S. W., and J. Abelson. 1999. Purific ation of the yeast U4/U6.U5 small nuclear ribonucleoprotein particle and identification of its proteins. Proc Natl Acad SciU SA 96:7226-31.

140. Strasser, K, S. Masuda, P. Mason, J. Pfannstiel, M. Oppizzi, S. Rodriguez-Navamo, A. G. Rondon, A. Aguilera, K. Struhl, R. Reed, and E. Hurt 2002. TREX is a conserved complex coupling transc ription with messenger RNA export. Nature 417:304-8.

141. Sun, J. S., and J. L Manley. 1995. A novel U2-U6 snRNA structure is necessary for mammalian mRNA splicing. Genes Dev 9:843-54.

142. Tange, T. O., A. Nott, and M. J. Moore. 2004. The ever-increasing complexities of the exon junction complex. Curr O pin Cell Biol 16:279-84.

143. Tange, T. O., T. Shibuya, M. S. J urica, and M. J. Moore. 2005. Biochemic al a na lysis of the EJC reveals two new factors and a stable tetrameric protein core. RNA 11:1869-83.

144. Tam, W. Y., K. R. Lee, and S. C. Cheng. 1993. Yeast precursor mRNA processing protein PRP19 associates with the spliceosome concomitant with or just after dissociation of U4 small nuc lear RNA. Proc Natl Acad Sci U SA 90:10821-5.

145. Tam, W. Y., K. R. Lee, and S. C. Cheng. 1993. The yeast PRP19 protein is not tightly associated with small nuclear RNAs, but appears to associate with the spliceosome after binding of U2 to the pre-mRNA and prior to formation of the functional splic eosome. Mol Cell Biol 13:1883-91. 
146. Tazi, J., N. Bakkour, J. Soret, L Zekni, B. Hazra, W. Laine, B. Baldeyrou, A. Lansiaux, and C. Bailly. 2005. Selective inhibition of topoisomerase I and various steps of splic eosome a ssembly by diospyrin derivatives. Mol Pha ma col 67:1186-94.

147. Tazi, J., U. Komstadt, F. Rossi, P. Jeanteur, G. Cathala, C. Brunel, and R. Lühmann. 1993. Thiophosphorylation of U1-70K protein inhibits pre-mRNA splicing. Nature 363:283-6.

148. Teigelkamp, S., M. McGaney, M. Plumpton, and J. D. Beggs. 1994. The splicing factor PRP2, a putative RNA helic ase, interacts directly with pre-mRNA. EMBO J 13:888-97.

149. Teigelkamp, S., A. J. Newman, and J. D. Beggs. 1995. Extensive interac tions of PRP8 protein with the $5^{\prime}$ and $3^{\prime}$ splice sites during splicing suggest a role in stabilization of exon alignment by U5 snRNA. EMBO J 14:2602-12.

150. Thinkle-Mulc ahy, L, P. Ajuh, A. Prescott, F. Claverie-Martin, S. Cohen, A. I. Lamond, and P. Cohen. 1999. Nuclear organisation of NIPP1, a regulatory subunit of protein phosphatase 1 that associates with pre-mRNA splicing factors. J Cell Sci 112 ( Pt 2):157-68.

151. Van Eynde, A., S. Wera, M. Beullens, S. Tomekens, F. Van Leuven, W. Stalmans, and M. Bollen. 1995. Molecular cloning of NIPP-1, a nuclear inhibitor of protein phosphatase-1, reveals homology with polypeptides involved in RNA processing. J Biol Chem 270:28068-74.

152. van Heel, M. 1989. Classification of very large electron mic rosc opical image data sets. Optik 82:114-126.

153. van Heel, M., and J. Frank. 1981. Use of multivariate statistics in analysing the ima ges of biologic al mac romolecules. Ultra mic rosc opy 6:187-94.

154. van Heel, M., G. Harauz, E V. Orlova, R. Schmidt, and M. Schatz. 1996. A new generation of the IMAGIC image processing system. J Struct Biol 116:17-24.

155. Venter, J. C., M. D. Adams, E. W. Myers, P. W. Li, R. J. Mural, G. G. Sutton, H. 0. Smith, M. Yandell, C. A. Evans, R. A. Holt, J. D. Gocayne, P. Amanatides, R. M. Ballew, D. H. Huson, J. R. Wortman, Q. Zhang, C. D. Kodira, X. H. Zheng, L Chen, M. Skupski, G. Subramanian, P. D. Thomas, J. Zhang, G. L Gabor Miklos, C. Nelson, S. Broder, A. G. Clark, J. Nadeau, V. A. McKusick, N. Znder, A. J. Levine, R. J. Roberts, M. Simon, C. Slayman, M. Hunkapiller, R. Bolanos, A. Delcher, I. Dew, D. Fasulo, M. Fanigan, L Forea, A. Halpem, S. Hannenhalli, S. Kravitz, S. Levy, C. Mobary, K. Reinert, K. Remington, J. Abu-Threideh, E. Beasley, K. Biddick, V. Bonazz, R. Brandon, M. Cargill, I. Chandramouliswaran, R. Charlab, K. Chaturvedi, Z Deng, V. Di Francesco, P. Dunn, K. Elbeck, C. Evangelista, A. E. Gabrielian, W. Gan, W. Ge, F. Gong, Z Gu, P. Guan, T. J. Heiman, M. E. Higgins, R. R. Ji, Z Ke, K. A. Ketchum, Z Lai, Y. Lei, Z Li, J. Li, Y. Liang, X. Lin, F. Lu, G. V. Merkulov, N. Milshina, H. M. Moore, A. K. Naik, V. A. Narayan, B. Neelam, D. Nusskem, D. B. Rusch, S. Salzberg, W. Shao, B. Shue, J. Sun, Z Wang, A. Wang, X. Wang, J. Wang, M. Wei, R. Wides, C. Xiao, C. Yan, et al. 2001. The sequence of the human genome. Science 291:130451.

156. Vulsteke, V., M. Beullens, A. Boudrez, S. Keppens, A. Van Eynde, M. H. Rider, W. Stalmans, and M. Bollen. 2004. Inhibition of spliceosome assembly by the cell cycle-regulated protein kinase MELK and involvement of splicing factor NIPP1. J Biol Chem 279:8642-7.

157. Vulsteke, V., M. Beullens, E. Waelkens, W. Stalmans, and M. Bollen. 1997. Properties and phosphorylation sites of baculovinus-expressed nuclear inhibitor of protein phosphata se-1 (NIPP-1). J Biol Chem 272:32972-8.

158. Wang, C., K. Chua, W. Seghezz, E. Lees, O. Gozani, and R. Reed. 1998. Phosphorylation of spliceosomal protein SAP 155 coupled with splicing catalysis. Genes Dev 12:1409-14.

159. Wang, P., P. J. Lou, S. Leu, and P. Ouyang. 2002. Modulation of altemative premRNA splic ing in vivo by pinin. Biochem Biophys Res Commun 294:448-55. 
160. Wang, Q., K. Hobbs, B. Lynn, and B. C. Rymond. 2003. The CIf1p splic ing factor promotes spliceosome assembly through $\mathrm{N}$-teminal tetratricopeptide repeat contacts. J Biol Chem 278:7875-83.

161. Wang, Y., and R. R. Rando. 1995. Spec ific binding of aminoglyc oside a ntibiotics to RNA. Chem Biol 2:281-90.

162. Wen, X., Y. P. Lei, Y. L Zhou, C. T. Okamoto, M. L Snead, and M. L Paine. 2005. Structural organization and cellular localization of tuftelin-interacting protein 11 (TFIP11). Cell Mol Life Sci 62:1038-46.

163. Will, C. L, and R. Lühmann. 2006. Splic eosome structure and function, p. 369-400. In R. F. Gesteland, T. R. Cech, and a. J. F. Atkins (ed.), The RNA world, 3rd ed. Cold Spring Harbor Laboratory Press, Cold Spring Harbor, New York.

164. Will, C. L, H. Urlaub, T. Achsel, M. Gentzel, M. Wilm, and R. Lühmann. 2002. Characterization of novel SF3b and 17S U2 snRNP proteins, including a human Prp5p homologue and an SF3b DEAD-box protein. EMBO J 21:4978-88.

165. Wu, J. Y., A. Kar, D. Kuo, B. Yu, and N. Havlioglu. 2006. SRp54 (SFRS11), a regulator for tau exon 10 altemative splicing identified by an expression cloning strategy. Mol Cell Biol 26:6739-47.

166. Xie, J., K. Beickman, E. Otte, and B. C. Rymond. 1998. Progression through the spliceosome cycle requires Prp38p function for U4/U6 snRNA dissociation. EMBO J 17:2938-46.

167. Xu, Y. Z, C. M. Newnham, S. Kameoka, T. Huang, M. M. Konarska, and C. C. Query. 2004. Prp5 bridges U1 and U2 snRNPs and enables stable U2 snRNP association with intron RNA. EMBO J 23:376-85.

168. Yang, Q., and E. Jankowsky. 2005. ATP- and ADP-dependent modulation of RNA unwinding and strand annealing activities by the DEAD-box protein DED1. Bioc hemistry 44:13591-601.

169. Zhang, W. J., and J. Y. Wu. 1996. Functional properties of p54, a novel SR protein active in constitutive and a ltemative splic ing. Mol Cell Biol 16:5400-8.

170. Zhou, Z, L J. Licklider, S. P. Gygi, and R. Reed. 2002. Comprehensive proteomic analysis of the human splic eosome. Nature 419:182-5.

171. Zhou, Z, J. Sim, J. Griffith, and R. Reed. 2002. Purific ation and electron mic rosc opic visualization of functional human spliceosomes. Proc Natl Acad Sci U S A 99:122037.

172. Zllmann, M., M. L Zapp, and S. M. Berget 1988. Gel electrophoretic isolation of splicing complexes containing U1 small nuclear ribonucleoprotein particles. Mol Cell Biol 8:814-21. 



\section{Appendix}

\subsection{Abbreviations}

\begin{tabular}{|c|c|}
\hline & anti \\
\hline A & Adenosine \\
\hline AA & Acrylamide \\
\hline Ac & Acetate \\
\hline Amp. & Ampicillin \\
\hline APS & Ammoniumperoxodisulfate \\
\hline ATP & Adenosintriphosphate \\
\hline $\mathrm{BCA}$ & bic inchoninic acid \\
\hline bp & base pair \\
\hline BP & branchpoint \\
\hline BSA & Bovine serum a lbumin \\
\hline C & Cytosine \\
\hline${ }^{\circ} \mathrm{C}$ & degree Centigrade \\
\hline ca. & circa \\
\hline CCD & charged-coupled device \\
\hline CDNA & complementary DNA \\
\hline C. elegans & Caenorhabditis elegans \\
\hline $\mathrm{Ci}-\mathrm{r}$ & Curie \\
\hline $\mathrm{cm}$ & Centimeter \\
\hline cpm & counts per minute \\
\hline d & desoxy \\
\hline $\mathrm{Da}$ & Dalton \\
\hline dd & double distilled \\
\hline $\mathrm{DExD} / \mathrm{H}$ & consensus sequence of helic ases \\
\hline D. melanogaster & Drosophila melanogaster \\
\hline DMSO & Dimethylsulfoxide \\
\hline DNA & Desoxyribonucleic acid \\
\hline ds & double stranded \\
\hline DTE & 1,4-Dithioerythrol \\
\hline DTT & Dithiothreitol \\
\hline $\mathrm{ECL}$ & enhanced chemiluminiscence \\
\hline E. coli & Escherichia coli \\
\hline EDTA & Ethylendia mintetra ac eta te \\
\hline EM & Electron Microsc opy \\
\hline engl. & english \\
\hline $\mathrm{EtOH}$ & Ethanol \\
\hline et al. & et alii \\
\hline f & femto \\
\hline Fig. & figure \\
\hline G & Gua nosine \\
\hline g & Gram/centrifugal force \\
\hline h & hour/human \\
\hline $\mathrm{HCl}$ & Hydrochlorid \\
\hline HEPES & $\mathrm{N}-2$-Hydroxyethylpiperazin-N-2-etha nsulfonic a cid \\
\hline $\mathrm{hn}$ & heterogenous nuclear \\
\hline k & kilo \\
\hline $\mathrm{kb}$ & kilo bases \\
\hline $\mathrm{kDa}$ & Kilodalton \\
\hline I & Liter \\
\hline BB-Medium & Luria-Berta ni-Medium \\
\hline
\end{tabular}




\begin{tabular}{|c|c|}
\hline $\mathrm{m}$ & milli \\
\hline$\mu$ & micro \\
\hline MW & molecularweight \\
\hline$m^{3} \mathrm{G}$ & $\mathrm{N}^{2}, \mathrm{~N}^{2}, \mathrm{~N}^{7}$-Trimethylgua nosine \\
\hline$m^{7} G$ & N7-Monomethylgua nosine \\
\hline $\min$ & Minutes \\
\hline $\mathrm{mM}$ & millimolar \\
\hline mRNA & messenger RNA \\
\hline $\mathrm{n}$ & nano \\
\hline $\mathrm{NCBI}$ & National Center of Biotec hnology Information \\
\hline NIS & Non-Immunserum \\
\hline NTA & Nitrilo-tria cetic acid \\
\hline nts & Nucleotide \\
\hline NTPs & Nuc leosid-5'-Triphosphate \\
\hline OAC & Acetate \\
\hline OD & Optic al density \\
\hline Oligo & Oligonucleotide \\
\hline $\mathrm{O} / \mathrm{N}$ & ovemight \\
\hline ORF & open reading frame \\
\hline $\mathrm{P}$ & Phosphate \\
\hline $\mathrm{p}$ & pico \\
\hline PAA & Polya cryla mide \\
\hline PAGE & polya c ryla mide gel-elec trophoresis \\
\hline PBS & Phosphate Buffered Saline \\
\hline PCA & Phenol, Chloroform, Isoa myla lkohol \\
\hline PCR & polymerase chain reaction \\
\hline PFA & Parafomaldehyde \\
\hline $\mathrm{pH}$ & preponderance of hydrogen ions \\
\hline PMSF & Phenylmethylsulfonylfluoride \\
\hline Pre-mRNA & precursor-mRNA \\
\hline $\operatorname{Prp}$ & pre-mRNA processing \\
\hline$\%$ & percent \\
\hline Py & Pyrimid ine base \\
\hline $\mathrm{R}$ & Purine base \\
\hline RBD & RNA-binding doma in \\
\hline RNA & Ribonuc leic acid \\
\hline RNAi & RNA-Interference \\
\hline RNa se & Ribonuclease \\
\hline RNasin & Ribonuc lea se-Inhibitor \\
\hline RNP & Ribonucleoprotein \\
\hline pm & revolutions per minute \\
\hline RRM & RNA recognition motif \\
\hline rRNA & ribosomal RNA \\
\hline RT & Room temperature \\
\hline$S$ & Sved bert-unit (10-13s) \\
\hline $\mathrm{S}$ & Second \\
\hline S. cerevisiae & Saccharomyces cerevisiae \\
\hline SDS & Sodium-Dodecyl-Sulfate \\
\hline siRNA & small interfering RNA \\
\hline sn & small nuclear \\
\hline sno & small nuc leolar \\
\hline S. pombe & Sc hizosa ccha romyces pombe \\
\hline SR & Serine Arginine rich \\
\hline SS & single stranded \\
\hline SS & Splice site \\
\hline $\mathrm{T}$ & Thymid ine \\
\hline
\end{tabular}




$\begin{array}{ll}\text { Tab. } & \text { Table } \\ \text { TBE } & \text { Tris-Borat-EDTA-solution } \\ \text { TE } & \text { Tris-EDTA } \\ \text { TEMED } & \text { N, N, N', N'-Tetra methylethylendia mine } \\ \text { Tm } & \text { melting temperature } \\ \text { Tris/HCI } & \text { Tris-(hydroxymethyl)-a minomethyn-Hydrochloride } \\ \text { tRNA } & \text { transfer RNA } \\ \text { U } & \text { Uracil/Unit } \\ \text { U snRNA } & \text { uridine-rich sma Il nuclear RNA } \\ \text { U snRNP } & \text { uridine-rich small nuclear ribonucleoprotein } \\ \text { UTP } & \text { Uridintriphosphate } \\ \text { UTR } & \text { untranslated region } \\ \text { UV } & \text { Ultraviolet } \\ \text { V } & \text { Volt } \\ \text { Vol. } & \text { Volume } \\ \text { V/V } & \text { volume per volume } \\ \text { W } & \text { Watts } \\ \text { WB } & \text { Westem Blot } \\ \text { W/V } & \text { weight per volume } \\ \text { WT } & \text { Wild type } \\ \text { Y } & \text { Pyrimidine base }\end{array}$





\subsection{Acknowledgements}

This work would have been impossible or at least not as enjoyable without the support and contribution of many people. I wish to express my sinc ere gratitude to:

Reinhard for his assistance and support, encouragement and advice. I highly appreciate that I could present my studies with a poster at a Jacques-Monod conference in Ausso is (France) and with a talk at the a nnual meeting of the RNA soc iety in Seattle (USA).

I also would like to thank Prof. Dr. H.-J . Fritz and Prof. Dr. T. Pieler for their supervision of this extemal Ph.D. thesis. In addition, many thanks to Prof. Dr. G. Braus, Prof. Dr. C. Gatz, Prof. Dr. R. Fic ner and Prof. Dr. E. Wimmer for being members of my extended thesis committee.

My special thanks go to Klaus and Henning for the enomous support duning this work and their fruitful discussions and encouraging remarks. I am partic ula rly grateful to Kla us who introduced me to the challenging aspects of the RNA world in the course of a lab rotation followed by a Master and Doctoral Thesis.

I would like to thank all the other members of the department of cellular biochemistry, of the bioanalytic al mass spectrometry group and the 3D electron cryomic roscopy group at our institute for the friendly working atmosphere, all their technical help, scientific discussions and profound advices. Without your help, this work would not have been possible.

At last, I would like to thank my family and friends, especially Nadja for her continuous support in numerous scientific ups and downs, her commitment to our private life and all her love. 



\subsection{Publications}

Dybkov, O., Will, C.L., Deckert, J., Behza dnia, N., Hartmuth, K., Lühmann, R. (2006) U2 snRNA-protein contacts in purified human $17 \mathrm{~S}$ U2 snRNPs and in spliceosomal A and B complexes. MCB, Vol. 26, No. 7, $2803-2816$

Deckert, J., Hartmuth, K., Boehninger, D., Behzadnia, N., Will, C.L. Kastner, B., Stark, H., Urlaub, H., Lühmann, R. (2006) Protein composition and electron microscopy structure of affinity-purified human splic eosomal B complexes isolated under physiolog ic al conditions. MCB, Vol. 26, No. 14, $5528-5543$

Behza dnia, N., G olas, M.M., Hartmuth, K., Sander, B., Kastner, B., Deckert, J., Dube, P., Will, C.L., Urla ub, H., Stark, H., Lühmmann, R. Composition and three-dimensional EM structure of double affinity-purified, human presplic eosomal A complexes. Manuscript under revision 



\subsection{Ekklänung/Affidavit}

Hiemit erkläre ich an Eides Statt, dass die Dissertation mit dem Titel "Isolation and Characterization of Human Precatalytic Spliceosomal B Complexes" selbständig und ohne unerlaubte Hilfe angefertigt wurde.

I declare that my Doctoral Thesis "Isolation and Characterization of Human Precatalytic Splic eosomal B Complexes" has been written independently and with no other sources and aids then quoted.

Jochen Deckert

Göttingen, December 2006

Parts of this thesis were published in:

Deckert, J., Hartmuth, K., Boehringer, D., Behzadnia, N., Will, C.L, Kastner, B., Stark, H., Urlaub, H., Lühmann, R. (2006) Protein composition and electron mic roscopy structure of affinity-purified human spliceosomal B complexes isolated under physiological conditions. MCB, Vol. 26, No. 14, 5528 - 5543 



\subsection{Curric ulum Vitae}

\section{Personal data}

Name

Date of birth

Place of birth

\section{Education}

09/1986 - 06/1995

$06 / 1995$

10/1996 - 08/2001

$08 / 2001$

09/2001 - 04/2003

$04 / 2003$

since $04 / 2003$

\section{Practical Education}

03/1998 - 07/ 1998

09/1999 - 01/2000

09/2000 - 04/2001

$10 / 2002-03 / 2003$

since $04 / 2003$
J ochen Deckert

O ctober $18^{\text {th }} 1975$

Neumarkt i. d. Opf., Gemany

Williba Id-G luck-Gymnasium, Neumarkt i. d. Opf.

Abitur

Study: Biochemical Eng ineering at the University of Applied Sciences Weihenstephan, Freising, Germany

Degree: Biochemic al Engineer (FH)

Study: Molecular Biology at the Intemational Max-

Planck-Research School, Göttingen, Gemany

Degree: Master of Science

Doctoral Studies at the Max-Planck-Institute of

Biophysic al Chemistry, Department of Cellular Biochemistry of Prof. Dr. R. Lühmann, Göttingen, Germany

First practical semester at the Max-Planck-Institute for Immunobiology, Department of Cellular Immunology, Freiburg, Gemany

Second practical semester at The Scrippps Research Institute, Department of Molecular Biology, San Diego, Califomia, USA

Diploma work for the Degree as Biochemical Engineer at the University of Massa c husetts Medic al School, Department of Biochemistry and Molecular Biology, Worcester, Massa c husetts, USA

Master Thesis at the Max-Planck-Institute of Biophysical Chemistry, Department of Cellular Biochemistry, Göttingen, Gemany

Doctoral Studies at the Max-Planck-Institute of Biophysical Chemistry, Department of Cellular Bioc hemistry, Göttingen, Gemany

\section{Public ations:}

2006 Dybkov, O., Will, C.L, Deckert, J., Behzadnia, N., Hartmuth, K., Lühmann, R. U2 snRNA-protein contacts in purified human 175 U2 snRNPs and in spliceosomal A and B complexes. MCB, Vol. 26, No. 7, $2803-2816$

2006 Deckert, J., Hartmuth, K., Boehninger, D., Behza dnia, N., Will, C.L., Ka stner, B., Stark, H., Urlaub, H., Lühmmann, R. Protein composition and electron mic roscopy structure of affinity-purified human spliceosomal B complexes isolated under physiological conditions. MCB, Vol. 26, No. 14, 5528 - 5543 